\title{
Analysis and Development of Draw Strategies for a Multi-Tank Thermal Storage System for Solar Heating Applications
}

\author{
by \\ Ryan M. Dickinson, B.Eng., Mechanical Engineering \\ Carleton University
}

\begin{abstract}
A thesis submitted to the
Faculty of Graduate and Postdoctoral Affairs

in partial fulfillment of the requirements for the degree of

Master of Applied Science

in

Mechanical Engineering

Department of Mechanical and Aerospace Engineering

Carleton University

Ottawa, Ontario, Canada

December, 2012
\end{abstract}

(C)Copyright

Ryan M. Dickinson, 2012 
Library and Archives

Canada

Published Heritage

Branch

395 Wellington Street

Ottawa ON K1A ON4

Canada
Bibliothèque et

Archives Canada

Direction du

Patrimoine de l'édition

395 , rue Wellington

Ottawa ON K1A ON4

Canada
Your file Votre référence

ISBN: $978-0-494-94253-6$

Our file Notre référence

ISBN: $978-0-494-94253-6$
NOTICE:

The author has granted a nonexclusive license allowing Library and Archives Canada to reproduce, publish, archive, preserve, conserve, communicate to the public by telecommunication or on the Internet, loan, distrbute and sell theses worldwide, for commercial or noncommercial purposes, in microform, paper, electronic and/or any other formats.

The author retains copyright ownership and moral rights in this thesis. Neither the thesis nor substantial extracts from it may be printed or otherwise reproduced without the author's permission.
AVIS:

L'auteur a accordé une licence non exclusive permettant à la Bibliothèque et Archives Canada de reproduire, publier, archiver, sauvegarder, conserver, transmettre au public par télécommunication ou par l'Internet, prêter, distribuer et vendre des thèses partout dans le monde, à des fins commerciales ou autres, sur support microforme, papier, électronique et/ou autres formats.

L'auteur conserve la propriété du droit d'auteur et des droits moraux qui protege cette thèse. $\mathrm{Ni}$ la thèse ni des extraits substantiels de celle-ci ne doivent être imprimés ou autrement reproduits sans son autorisation.
In compliance with the Canadian Privacy Act some supporting forms may have been removed from this thesis.

While these forms may be included in the document page count, their removal does not represent any loss of content from the thesis.
Conformément à la loi canadienne sur la protection de la vie privée, quelques formulaires secondaires ont été enlevés de cette thèse.

Bien que ces formulaires aient inclus dans la pagination, il n'y aura aucun contenu manquant. 
The undersigned hereby recommends to the

Faculty of Graduate and Postdoctoral Affairs acceptance of the thesis

\title{
Analysis and Development of Draw Strategies for a Multi-Tank Thermal Storage System for Solar Heating Applications
}

\author{
submitted by Ryan M. Dickinson, B.Eng., Mechanical Engineering \\ Carleton University
}

in partial fulfillment of the requirements for the degree of

Master of Applied Science in Mechanical Engineering 
Dr. Cynthia Cruickshank, Supervisor

Internal Examiner

Internal Examiner

External Examiner

Dr. Metin Yaras, Chair,

Department of Mechanical and Aerospace Engineering

Department of Mechanical and Aerospace Engineering

Carleton University

December, 2012 


\section{Abstract}

An experimental and numerical study was conducted on a multi-tank thermal energy storage (TES) for solar hot water heating applications. The setup consisted of three commercially available $270 \mathrm{~L}$ domestic hot water tanks and three side-arm, natural convection heat exchangers (NCHE). The tanks were connected in both series and parallel charging and discharging configurations, and the system configurations were evaluated under: (i) constant temperature charging and constant volume discharging, and (ii) variable input power charging and variable volume discharging.

Numerical modelling was implemented using the TRNSYS simulation environment, and the model was found to be in good agreement with the experimental results. Discrepancies between data were found mainly in the regions of high temperature gradients as a result of the limitations in the modelling components.

The three test configurations which were studied include: (i) series charge and series discharge, (ii) parallel charge and parallel discharge, and (iii) series charge and parallel discharge. To quantify the performance of these configurations, delivered energy values and stored exergy values were compared, and annual simulations were conducted for Ottawa, Ontario. Results indicated, both experimentally and numerically, that the parallel charge and parallel discharge configuration achieved the highest delivered energy, highest stored exergy, as well as the highest solar fraction and system efficiency compared to the other configurations. 
To my wife, Jasmine Rose Helane Dickinson. 


\section{Acknowledgments}

I would first like to acknowledge my supervisor. Dr. Cynthia Cruickshank. Her support, guidance, and motivation over the past two years has been invaluable, and I'm extremely grateful for being given this opportunity to pursue my Master's under her supervision.

I would like to acknowledge the funding and support of the Natural Sciences and Engineering Research Council of Canada (NSERC), as well as the NSERC Smart Net-zero Energy Buildings strategic Research Network (SNEBRN). Without it, this work would not have been possible. I would also like to acknowledge Dr. Stephen Harrison, Gary Johnson, Herbert Lam, and Wilkie Choi at the Queen's University Solar Calorimetry Lab. Their assistance during my many visits was greatly appreciated, and it was a pleasure to work with all of them.

A special thank you to all my friends who have been by my side over the past two years. Also, another special thank you to David Ouellette, Chris Baldwin, and Jenny Chu, who took the time to review sections of this thesis, and were always nearby if I had questions.

Finally, thank you to my family for their endless encouragement, love and support. 


\section{Table of Contents}

Abstract iv

Acknowledgments $\quad$ vi

Table of Contents vii

List of Tables $\quad$ xi

List of Figures $\quad$ xiii

Nomenclature $\quad$ xvii

1 Introduction 1

1.1 Energy Use in Canada . . . . . . . . . . . . . . . . . . . . 1

1.2 Background on Solar Domestic Hot Water Systems . . . . . . . . . . 2

1.2.1 Solar Collectors and Canada's Solar Market . . . . . . . . . . 3

1.2.2 Thermal Energy Storage . . . . . . . . . . . . . . . 5

1.2.3 Thermal Stratification . . . . . . . . . . . . 7

1.2.4 Multi-Tank Thermal Energy Storage Systems . . . . . . . 8

1.3 Problem Definition . . . . . . . . . . . . . 10

1.4 Contribution of Research . . . . . . . . . . . . . . . . . . 11

1.5 Organization of Research . . . . . . . . . . . . . . . . . 12 
2 Literature Review 14

2.1 Introduction . . . . . . . . . . . . . . . . . . . . 14

2.2 Stratification in Storage Tanks . . . . . . . . . . . . 15

2.3 Development of Draw Profiles . . . . . . . . . . . . . . . . . . . 19

2.4 Discharging of Thermal Energy Storage . . . . . . . . . . . . 23

3 Modelling Approach $\quad 26$

3.1 Introduction . . . . . . . . . . . . . . . . . 26

3.2 Multi-Tank Model . . . . . . . . . . . . . . . 27

3.3 Modelling of the Thermal Energy Storage . . . . . . . . . . . . 27

3.4 Modelling of the Natural Convection Heat Exchanger . . . . . . . . . 32

3.5 Modelling of Discharge Strategies . . . . . . . . . . . . . 36

4 Experimental Approach $\quad 38$

4.1 Introduction . . . . . . . . . . . . . . . . . . 38

4.2 System Components . . . . . . . . . . . . . . . . 39

4.3 Instrumentation and Data Measurement . . . . . . . . . . 42

4.4 System Additions . . . . . . . . . . . . . . . . . . 44

4.5 Test Method . . . . . . . . . . . . . . . . . . 47

4.5.1 Constant Temperature Charge and Constant Volume Discharge Tests ...................... 47

4.5.2 Variable Input Power Charge and Variable Volume Discharge Tests .......................... 49

5 Experimental and Simulation Results $\quad \mathbf{5 3}$

5.1 Introduction . . . . . . . . . . . . . . . . 53

5.2 Preliminary Charge Tests . . . . . . . . . . . . 54 
5.3 Constant Temperature Charge and Constant Volume Discharge Tests 58

5.3 .1 Series Charge and Series Discharge . . . . . . . . . . 59

5.3.2 Parallel Charge and Parallel Discharge . . . . . . . . . 63

5.3.3 Series Charge and Parallel Discharge . . . . . . . . . 65

5.4 Variable Input Power Charge and Variable Volume Discharge Tests . 67

5.4.1 Series Charge and Series Discharge . . . . . . . . . 68

5.4.2 Parallel Charge and Parallel Discharge . . . . . . . . . . 69

5.4 .3 Series Charge and Parallel Discharge . . . . . . . . . . . 69

6 Discussion of Results $\quad 74$

6.1 Introduction . . . . . . . . . . . . . . . 74

6.2 Energy Delivered to Load . . . . . . . . . . . . . 75

6.2.1 Constant Temperature Charge and Constant Volume Discharge Tests ........................ 76

6.2.2 Variable Input Power Charge and Variable Volume Discharge Tests ........................ 77

6.3 Exergy Analysis . . . . . . . . . . . . . . . . . . 78

6.3.1 Constant Temperature Charge and Constant Volume Hourly Discharge Tests . . . . . . . . . . . . . . 80

6.3.2 Variable Input Power Charge and Variable Volume Discharge Tests ......................... 84

6.4 Annual Performance Simulation of a SDHW System . . . . . . . . . 87

7 Conclusions and Recommendations for Future Work 94

7.1 Conclusions . . . . . . . . . . . . . . . . . . 94

7.2 Recommendations for Future Work . . . . . . . . . . . . 96 
Appendix A Previous Work on Solar Combisystems 106

A.1 Solar Combisystems . . . . . . . . . . . . . . . . . . . . . . 108

A.1.1 The International Energy Agency . . . . . . . . . . . . . . 109

A.1.2 IEA-SHC Task 26 . . . . . . . . . . . . . 110

A.1.3 Altener Project . . . . . . . . . . . . . . . 115

A.1.4 IEA-SHC Task $32 \ldots \ldots . \ldots . \ldots . . \ldots . . \ldots 115$

A.1.5 Canadian Combisystems . . . . . . . . . . . 118

Appendix B Empirical Correlation of Natural Convection Heat

Exchanger Performance Characteristics

Appendix C Instrumentation Calibration and Uncertainty Analysis 125

C.1 Discharge Flow Rate and Draw Volume Uncertainty . . . . . . . . . . 126

C.2 Collector Loop Flow Rate Uncertainty . . . . . . . . . . . . . . . 130

C.3 Thermocouple Uncertainty . . . . . . . . . . . . . . . . . . . . . 130

C.4 Error Propagation in Delivered Energy Calculations . . . . . . . . . . 133

Appendix D Inter-Tank Fluid Circulation in the Series Charge and Parallel Discharge Configuration $\quad 136$

Appendix E Supplemental Figures and Results 139

Appendix F Error Analysis of Experimental and Simulation Results 146

$\begin{array}{ll}\text { Appendix G Annual Simulation Model } & 148\end{array}$

$\begin{array}{ll}\text { Appendix H Sample TRNSYS Deck File } & 149\end{array}$ 


\section{List of Tables}

2.1 SRCC draw specifications. . . . . . . . . . . . . . . . . 22

2.2 CSA draw profiles. . . . . . . . . . . . . . . 23

4.1 Specifications for storage tanks. . . . . . . . . . . . . . 41

4.2 Specifications for heat exchangers. . . . . . . . . . . . . 41

4.3 Parameters for constant temperature charge and constant volume discharge tests. . . . . . . . . . . . . . . . . . 48

4.4 Parameters for variable input power charge and variable volume discharge tests. . . . . . . . . . . . . . . . . . . 49 49

4.5 Modified CSA-F379.1 draw profile considered for the variable input power charge and variable volume discharge tests. . . . . . . . . . 51

6.1 Delivered energy values for the constant temperature charge and constant volune discharge tests. . . . . . . . . . . 76

6.2 Delivered energy values for the variable input power charge and variable volume discharge tests. . . . . . . . . . . . . . 77

6.3 Specific exergy values at the end of the testing period for constant temperature charge and constant volume discharge tests. . . . . . . . 82

6.4 Specific exergy values at the end of the testing period for variable input power charge and variable volume discharge tests. . . . . . . 84

6.5 Anmual Performance Simulation Test Parameters. . . . . . . . . . . . 89 
6.6 Annual performance simulation results. . . . . . . . . . . . . 92

C.1 Uncertainty values used in the error propagation for delivered energy. 134

C.2 Delivered energy uncertainty for a range of tested draw volumes. . . . 135

F.1 Temperature error between experimental and simulation results for constant temperature charge and constant volume discharge tests. . . 147

F.2 Temperature error between experimental and simulation results for variable input power charge and variable volume discharge tests. . . . 147 


\section{List of Figures}

1.1 Schematic of a typical indirect "pumped" SDHW system and an indirect SDHW system utilizing natural convection. . . . . . . . . . 3

1.2 Differing levels of stratification within a storage tank. . . . . . . 7

1.3 Schematics of two different plumbing configurations for a multi-tank thermal energy storage system. . . . . . . . . . . . . . . . . 9 9

1.4 Flowchart of the approach taken to complete this study. . . . . . . . 13

3.1 TRNSYS models of the investigated multi-tank system configurations for constant temperature charge and constant volume discharge tests. 28

3.2 Destratification between adjacent nodes due to wall conduction. . . . 29

3.3 Energy balance for Node i. . . . . . . . . . . . . . . . . . 30

3.4 Schematic showing the heights, temperatures and flow rates used for modelling the heat exchanger. . . . . . . . . . . . . 33

4.1 Multi-tank apparatus. ................. 40

4.2 Solar simulator. . . . . . . . . . . . . . . . . 42

4.3 Schematic of temperature probe and thermocouple placement for each

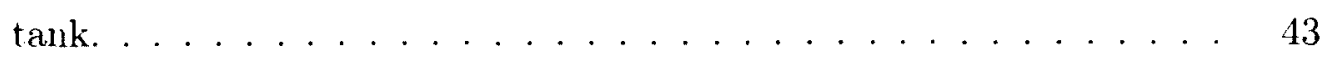

4.4 Screenshot from LabVIEW of a series charge test after 4 hours, with a charge loop flow rate of $3 \mathrm{~L} / \mathrm{min}$ and temperature set-point of $55^{\circ} \mathrm{C}$. . 43

4.5 Photographs of the added system components. . . . . . . . . . 45 
4.6 Screenshot of the added LabVIEW draw routine for a constant volume hourly discharge test with $60 \mathrm{~L}$ draws. . . . . . . . . . . . . . . 46

4.7 Solar radiation profile and draw schedule considered for the variable power charge and variable volume discharge tests. . . . . . . . . 50

5.1 Experimental temperature profile of the series charge configuration with a collector loop flow rate of $3 \mathrm{~L} / \mathrm{min}$, initial tank temperature of $16.5^{\circ} \mathrm{C}$, and collector outlet temperature (charge temperature) set-

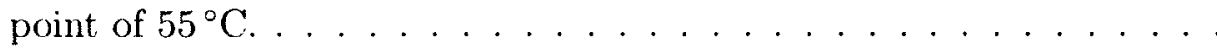

5.2 Comparison of experimental and simulation temperature profiles for Tank 1 of the series charge configuration. . . . . . . . . . 56

5.3 Comparison between experimental thermocouple positions and TRNSYS node positions. . . . . . . . . . . . . . . . 56

5.4 Experimental and simulation results for Test 4, series charge and series discharge, $135 \mathrm{~L}$ draws. . . . . . . . . . . . . . . . 60

5.5 Comparison between every second thermocouple and node for Test 4, series charge and series discharge, 135 L draws. . . . . . . . . . . 6

5.6 Experimental and simulation results for Test 5, parallel charge and parallel discharge, $135 \mathrm{~L}$ draws. . . . . . . . . . . . . . . .

5.7 Experimental and simulation results for Test 6, series charge and parallel discharge, $135 \mathrm{~L}$ draws. . . . . . . . . . . . . . . . . 66

5.8 Experimental and simulation results for Test 7, variable input power charge and CSA draw profile discharge test, series charge and series discharge configuration. . . . . . . . . . . . 70

5.9 Experimental and simulation results for Test 8, variable input power charge and CSA draw profile discharge test, parallel charge and parallel discharge configuration. . . . . . . . . . . . . 
5.10 Experimental and simulation results for Test 9, variable input power charge and CSA draw profile discharge test. series charge and parallel discharge configuration. . . . . . . . . . . . . .

6.1 Specific exergy values for the three system configurations with constant temperature charging and $135 \mathrm{~L}$ draws. . . . . . . . . . . . 81

6.2 Test 2 exergy values for Tanks 1-3 of the parallel charge and parallel discharge configuration with $60 \mathrm{~L}$ draws.

6.3 Specific exergy comparison of experimental and simulation results for Test 8 , parallel charge and parallel discharge configuration with variable input power charge profile and variable volume draws. . . . . . .

6.4 Specific exergy comparison of experimental results for the three test configurations with variable input power charge profile and variable volume draws. . . . . . . . . . . . . . . . . . .

6.5 Monthly solar energy delivered to load by each of the three multi-tank configurations compared to a single tank configurations. . . . . . . . . 93

B.1 Plot of empirical correlations for charging in either series or parallel. .

C.1 LabVIEW draw volumes and gravimetric volumes before and after cal-

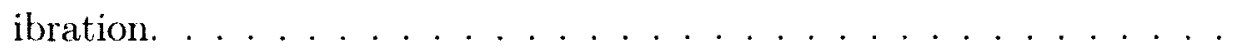

C.2 Delivery and mains thermocouple measurements before and after cali-

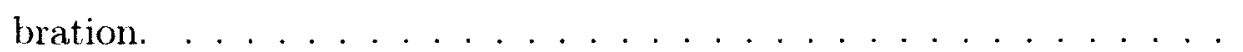

D.1 Temperature profiles for Tank 1 (initially at $50^{\circ} \mathrm{C}$ ) and Tank 2 (initially at $16^{\circ} \mathrm{C}$ ) as they equalize in temperature and pressure. . . . . . 137

D.2 Hydrostatic pressure difference between Tank 1 (initially at $50^{\circ} \mathrm{C}$ ) and Tank 2 (initially at $16^{\circ} \mathrm{C}$ ). . . . . . . . . . . . 138

E.1 Experimental and simulation results for Test 1, series charge and series discharge, $60 \mathrm{~L}$ draws. 
E.2 Experimental and simulation results for Test 2, parallel charge and parallel discharge, $60 \mathrm{~L}$ draws. . . . . . . . . . . . . . . . . . 141

E.3 Experimental and simulation results for Test 3, series charge and parallel discharge, $60 \mathrm{~L}$ draws. . . . . . . . . . . . . . . . . . . 142

E.1 Specific exergy values for the three systern configurations with constant temperature charging and $60 \mathrm{~L}$ draws. . . . . . . . . . . . 143

E.5 Specific exergy comparison of experimental and simulation results for T'est 7 , series charge and series discharge configuration with variable input power charge profile and variable volume draws. . . . . . . . . . 144

E.6 Specific exergy comparison of experimental and simulation results for Test 9 , series charge and parallel discharge configuration with variable input power charge profile and variable volume draws. . . . . . . . . 145

G.1 Annual simulation model of the parallel charge and parallel discharge configuration in TRNSYS. . . . . . . . . . . . . . 148 


\section{Nomenclature}

\begin{tabular}{lll}
\hline Symbols & Definition & Units \\
\hline \hline$A$ & Coefficient for heat exchanger correlation & - \\
$A_{c}$ & Collector area & $\mathrm{m}^{2}$ \\
$A_{\mathrm{c}, \text { wall }}$ & Cross-sectional area of tank fluid & $\mathrm{m}^{2}$ \\
$b$ & Cross-sectional area of tank wall & $\mathrm{m}^{2}$ \\
$b_{0}$ & Coefficient for heat exchanger correlation & - \\
$C_{r}$ & 1st-order coefficient in the incidence angle & - \\
$c_{1}$ & modifier equation & $\mathrm{kJ} / \mathrm{kgK}^{2}$ \\
& 2nd-order coefficient in the incidence angle & - \\
& Modifier equation &
\end{tabular}




\begin{tabular}{|c|c|c|}
\hline$e$ & Cocfficient for heat exchanger correlation & - \\
\hline$E x$ & Specific exergy & $\mathrm{kJ} / \mathrm{kg}$ \\
\hline$F_{R}$ & Collector heat removal factor & - \\
\hline$F_{s}$ & Solar fraction & - \\
\hline 9 & Gravitational constant & $\mathrm{m} / \mathrm{s}^{2}$ \\
\hline$G_{T}$ & Incident solar radiation on a tilted surface & $\mathrm{kJ} / \mathrm{h} \cdot \mathrm{m}^{2}$ \\
\hline$h$ & Specific enthalpy & $\mathrm{kJ} / \mathrm{kg}$ \\
\hline$H$ & Height & $\mathrm{m}$ \\
\hline$k$ & Fluid conductivity & $\mathrm{kJ} / \mathrm{h} \cdot \mathrm{mK}$ \\
\hline$k_{\text {wall }}$ & Tank wall conductivity & $\mathrm{kJ} / \mathrm{h} \cdot \mathrm{mK}$ \\
\hline$K_{\tau \alpha}$ & Incidence angle modifier & - \\
\hline$\Delta k$ & Destratification conductivity & $\mathrm{kJ} / \mathrm{h} \cdot \mathrm{mK}$ \\
\hline$\Delta P$ & Pressure head & $\mathrm{Pa}$ \\
\hline$m$ & Mass & $\mathrm{kg}$ \\
\hline$\dot{m}$ & Mass flow rate & $\mathrm{kg} / \mathrm{h}$ \\
\hline$N$ & Number of nodes & - \\
\hline$\dot{q}$ & Rate of heat transfer per unit mass & $\mathrm{kJ} / \mathrm{kg}$ \\
\hline$Q$ & Energy & $\mathrm{kJ}$ \\
\hline
\end{tabular}

xviii 


$\begin{array}{llc}\dot{Q} & \text { Rate of heat transfer } & \mathrm{W} ; \mathrm{kJ} / \mathrm{h} \\ s & \text { Specific entropy } & \mathrm{kJ} / \mathrm{kgK} \\ t & \text { Time } & \mathrm{min} \\ T & \text { Temperature } & { }^{\circ} \mathrm{C} \\ \Delta T & \text { Temperature difference } & { }^{\circ} \mathrm{C} \\ \Delta x & \text { Distance between nodes } & \mathrm{m} \\ U & \text { Overall heat transfer coefficient } & \mathrm{kJ} / \mathrm{h} \cdot \mathrm{m}^{2}{ }^{\circ} \mathrm{C} \\ U_{L} & \text { Collector overall heat loss coefficient } & \mathrm{kJ} / \mathrm{h} \cdot \mathrm{m}^{2}{ }^{\circ} \mathrm{C} \\ U A & \text { Overall heat transfer coefficient-area product } & \mathrm{kJ} / \mathrm{h}{ }^{\circ} \mathrm{C} ; \mathrm{W} /{ }^{\circ} \mathrm{C} \\ \forall & \text { Volume } & \mathrm{L} ; \mathrm{m}^{3} \\ \dot{\forall} & \text { Volume flow rate } & \mathrm{L} / \mathrm{min}\end{array}$

Greek Symbols

Symbols Definition Units

\begin{tabular}{lll}
\hline$\epsilon$ & Heat exchanger effectiveness & - \\
$\epsilon^{\prime}$ & Nodified heat exchanger effectiveness & - \\
$\eta$ & System efficiency & - \\
$\theta$ & Angle between surface normal and incident & - \\
& radiation
\end{tabular}




\begin{tabular}{|c|c|c|}
\hline$\rho$ & Density & $\mathrm{kg} / \mathrm{m}^{3}$ \\
\hline$(r \alpha)_{n}$ & $\begin{array}{l}\text { Product of the cover transmittance and the } \\
\text { absorber absorptance at normal incidence }\end{array}$ & - \\
\hline \multicolumn{3}{|c|}{ Uncertainty Variables } \\
\hline Symbols & Definition & Units \\
\hline$i$ & Iteration index & - \\
\hline$L$ & Sample size & - \\
\hline$R$ & Calculated result based on $x_{i}$ & - \\
\hline $\bar{R}$ & Mean value of the result & - \\
\hline$R^{\prime}$ & True mean value of the result & - \\
\hline$S_{r}$ & Sample standard deviation & - \\
\hline$t_{L-1,95}$ & T-estimator for a probability of $95 \%$ & - \\
\hline$u$ & Uncertainty of $x_{i}$ & - \\
\hline$x_{i}$ & Independent variable & - \\
\hline $\bar{x}$ & Sample mean of $x_{i}$ & - \\
\hline$\theta_{i}$ & Partial derivative of $\mathrm{R}$ with respect to $x_{i}$ & - \\
\hline
\end{tabular}




\section{Subscripts}

\begin{tabular}{|c|c|c|}
\hline Symbols & Definition & Units \\
\hline 1 & Heat exchanger inlet, collector side flow & - \\
\hline 2 & Heat exchanger outlet, storage side flow & - \\
\hline 3 & Heat exchanger inlet, storage side flow & - \\
\hline 4 & Heat exchanger outlet, collector side flow & - \\
\hline$a m b)$ & Ambient air temperature & - \\
\hline aux & Auxiliary heat input & - \\
\hline c & Collector side & - \\
\hline del & Delivery water; delivered energy & - \\
\hline env & Environment & - \\
\hline $\mathrm{HX}$ & Heat exchanger & - \\
\hline $\mathrm{i}$ & Node number & - \\
\hline in & Inlet flow & - \\
\hline losses & Thermal losses & - \\
\hline mains & Mains water & - \\
\hline o & Dead state & - \\
\hline out & Outlet flow & - \\
\hline
\end{tabular}




\begin{tabular}{lll} 
par & Parasitic energy; pump energy consumption & - \\
ref & Reference system & - \\
set & Set-point & - \\
s & Storage side & - \\
u & Useful solar energy gain \\
w & Water & - \\
\hline
\end{tabular}




\section{Chapter 1}

\section{Introduction}

\subsection{Energy Use in Canada}

According to Natural Resources Canada, building energy use in the residential sector currently accounts for $17 \%$ of Canada's secondary energy consumption, where secondary energy is defined as the total amount of energy consumed by an end-use, and excludes the energy consumed to convert the energy into a useable form from it's primary resource. [1]. The breakdown by end-use within the residential sector shows that water heating accounts for $17 \%$ of the secondary energy consumption, while space heating accounts for $63 \%$. For these two end-uses in Canada, heating is typically provided by either electricity or natural gas. Comparing data from 1990 to 2009 , electricity and natural gas consumption in the residential sector has grown by $23.4 \%$ and $25.0 \%$, respectively.

As an alternative method for heating potable water, solar domestic hot water (SDHW) systems can make use of solar radiation to heat water directly and on-site, without the need for purchasing energy in the form of electricity or natural gas. Solar radiation is also an abundant and renewable form of energy, and by implementing solar thermal technology, the consumption of non-renewable energy sources can be 
significantly reduced. Furthermore, by displacing the energy produced by fossil fuels with clean, renewable energies, greenhouse gas (GHG) emissions can be mitigated. According to Natural Resources Canada, residential GHG emissions from space heating and water heating alone amounted to $54.4 \mathrm{Mt}$ of $\mathrm{CO}_{2}$ in 2009 , which is comparable to the $43.3 \mathrm{Mt}$ of $\mathrm{CO}_{2}$ produced by passenger cars in Canada that same year [1].

\subsection{Background on Solar Domestic Hot Water Systems}

The main components of a SDHW system include solar thermal collectors, a heat exchanger and a storage tank to store hot water. Solar thermal collectors may heat either potable water directly, which is referred to as an open-loop or direct system, or they may heat a separate circulating fluid, referred to as a closed-loop or indirect system. 'The use of a freeze-resistant circulating fluid such as a $50 / 50 \%$ by volume propylene glycol and water mixture, is particularly important for cold climates where outdoor temperatures often fall below the freezing point of water during winter months.

Solar domestic hot water systems can also be designed as either active or passive systems. Active systems utilize forced-circulation by means of a pump and differential controller to circulate the fluid through the collector, while passive systems have no moving parts and utilize natural convection as the circulation method [2]. Two typical SDHW systems are shown in Fig. 1.1. Both configurations consist of a scparate collector loop to circulate an anti-freeze solution through the collector, but they differ in that one configuration uses a pump on the storage side to circulate potable water through the heat exchanger, while the other uses natural convection. Natural convection is achicved by a net hydrostatic pressure difference between the storage tank and heat exchanger, causing a buoyancy force-driven flow [4]. This is further 


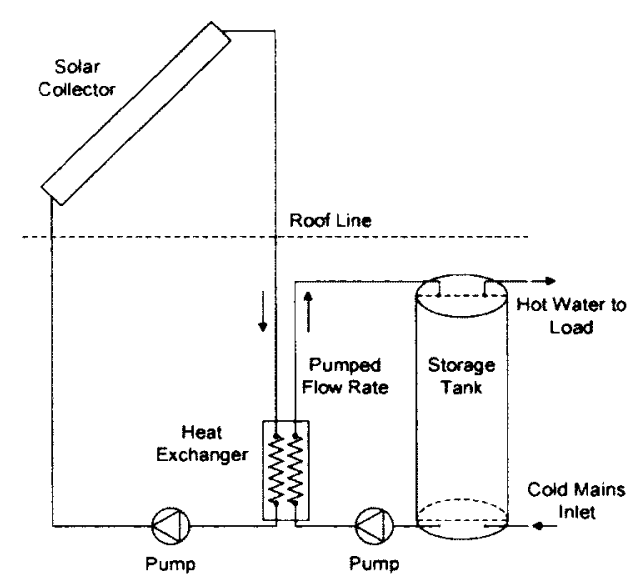

(a)

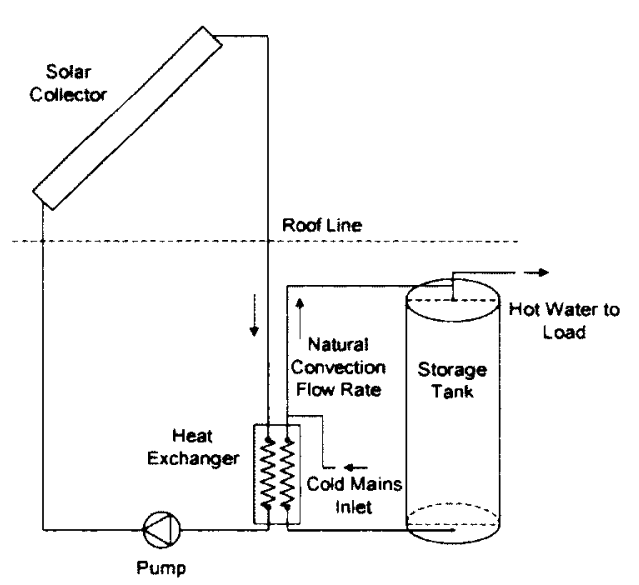

(b)

Figure 1.1: Schematic of (a) a typical indirect "pumped" SDHW system and (b) an indirect SDHW system utilizing natural convection, adapted from [3].

discussed in Chapter 3.

As previously mentioned, one of the main components of a SDHW system is the solar collector. Several types of solar collectors are currently available for heating applications, and a brief overview of the collector types are presented below.

\subsubsection{Solar Collectors and Canada's Solar Market}

There are three main types of solar water collectors worldwide: unglazed collectors, glazed flat plate collectors, and evacuated tube collectors $[2,5]$. Unglazed collectors are common in North America for pool heating applications, and consist of an absorber sheet which is used to transfer heat to a fluid. These collectors are typically not used for SDHW heating applications, unlike glazed flat plate collectors and evacuated tube collectors.

Glazed flat plate collectors use an absorber sheet similar to that of the unglazed collector, but differ in that they have a glass cover and a series of copper pipes. The copper pipe is placed in contact with the absorber sheet, and is typically arranged 
in either a serpentine arrangement or in parallel branches. Heat is transferred to the copper pipes, which allows the collector fluid to flow through the collector. Flat-plate collectors are most commonly designed for applications requiring moderate delivery temperatures (up to $100^{\circ} \mathrm{C}$ ) [2].

In contrast, evacuated tube collectors are designed for higher delivery temperature applications, and possess higher efficiencies than flat plate collectors at higher temperature differences with the surrounding. This is one reason why evacuated tube collectors are ideal for cold climates, as they have minimal conductive and convective heat losses since the absorber sheet is placed within a vacuum insulated glass tube.

Evacuated tube collectors are arranged with numerous glass tubes placed in parallel, which feed into a manifold containing the flowing collector fluid. Each glass tube consists of an absorber plate and a fluid channel. As the fluid vaporizes inside the channel, vapor travels up to the manifold where heat is transferred to the circulating collector fluid. The vapor inside the channel then condenses back to a liquid and falls back to the bottom of the tube.

In a report produced annually by the International Energy Agency entitled Solar Heat Worldwide [5], Canada and the United States were shown to have the third largest installed solar capacity in operation in 2010 of $16.0 \mathrm{GW}_{\mathrm{th}}$, equivalent to $8.2 \%$ of the solar market after China (60.1\%) and Europe (18.4\%). In Canada, there were $459.5 \mathrm{MW}_{\mathrm{th}}$ of installed unglazed water collectors, $33.4 \mathrm{MW}_{\mathrm{th}}$ of installed flat plate collectors, and $12.9 \mathrm{MW}_{\text {th }}$ of installed evacuated tube collectors. This data shows that for Canada, the market is primarily dominated by unglazed solar collectors at $90.8 \%$ of the total capacity, followed by flat plate collectors $(6.6 \%)$ and evacuated tube collectors $(2.6 \%)$. The equivalent total installed collector area for Canada is $722,699 \mathrm{~m}^{2}$, while the United States had a total installed collector area of $21,807,440 \mathrm{~m}^{2}$ (with the majority of this belonging to unglazed water collectors as well). On the global scale, 
Canada accounted for only $0.3 \%$ of the total installed collector area worldwide, while the United States accounted for approximately $7.8 \%$.

\subsubsection{Thermal Energy Storage}

The themnal energy storage, commonly abbreviated as "TES", is another main component in a SDHW system. Designing an effective TES for a SDHW system is essential for meeting the heating demands when solar energy is not readily available. Solar energy varies daily and is highly unpredictable, where consecutive days of inadequate sunshine could have a significant impact on the systems ability to provide heat. The mismatch between supply and demand of energy is even more severe during the winter months, when solar availability is at its lowest [6]. For this reason, TES has been an important area of research for enhancing the performance of SHDW systems.

There are a number of energy storage methods available, including sensible heat storage, latent heat storage, and thermochemical storage, all of which are applicable to SDHW systems. Sensible heat storage is defined as a material which rises or lowers in temperature when energy is added or removed. The effectiveness of the storage depends on the specific heat capacity and density of the storage material [6]. This is expressed by the following equation:

$$
Q=m c_{p} \Delta T
$$

where $Q$ is the energy required to heat (or the energy released by) a material of mass $m$ and specific heat capacity $c_{p}$ as it undergoes a temperature change from State 1 to State 2. Water is a commonly selected medium for sensible heat storage due to its high specific heat capacity at ambient temperature and widespread availability.

Latent heat storage describes a system in which the storage medium undergoes 
a phase change as it is being charged or discharged (for example, solid to liquid or liquid to gas). These types of systems can reduce the volume of the storage device by as much as one hundred times when compared to a sensible heat storage, due to the energy released when the material undergoes the phase change process (referred to as the heat of fusion at the melting point and the heat of vaporization at the boiling point) [6]. Some examples of phase change materials include ice melting to water, water evaporating to steam, and the molting of paraffin wax.

Lastly, thermochemical thermal storage consists of a process in which a reversible chemical reaction absorbs and releases energy. Energy is stored in the chemical bonds of a material (e.g., zeolite and water), and the material is charged and discharged according to endothermic and exothermic reactions. While thermochemical systems present the possibility of storing a large amount of energy, they are not a financially viable solution for low temperature applications [6].

Another consideration for selecting an effective TES is in sizing the system for the desired storage period. Thermal energy storage systems are classified as either diurnal ("short-term") or seasonal ("long-term"). Diurnal storage systems are effective at storing energy over a period of a few hours or days, while seasonal storage systems are more effective at storing energy over longer periods. An application of seasonal storage would be through the use of a borehole thermal energy storage system, which could be used to store hot water in order to provide heating during the winter season. Seasonal storage systems differ compared to diurnal systems in that they typically comprise a very large capacity (in the order of a hundred times the capacity of diurnal storage), and as a result, require more care in minimizing thermal losses [6]. These systems are also high in cost, and have thus been considered less economical then their more cost-effective counterpart for residential applications. 


\subsubsection{Thermal Stratification}

Another important consideration of a TES is promoting thermal stratification. Thermal stratification occurs within a TES as a result of temperature gradients and buoyancy effects during charging (as the temperature of water increases, the density of the fluid decreases, causing hot water to rise to the top of a TES while cold water falls to the bottom). This effect produces regions of hot and cold water (i.e., thermal layers), separated by a temperature gradient commonly referred to as a thermocline. Three storage tanks are illustrated in Fig. 1.2 which show differing levels of stratification. Figure 1.2(a) is representative of a highly stratified storage tank, due to its large temperature gradient $(d T / d x)$ and small thermocline. Figure $1.2(\mathrm{~b})$ is representative of a moderately stratified storage tank, due to its smaller temperature gradient and larger thermocline. Finally, Fig. 1.2(c) illustrates a fully mixed tank with uniform temperature, and experiences no stratification.
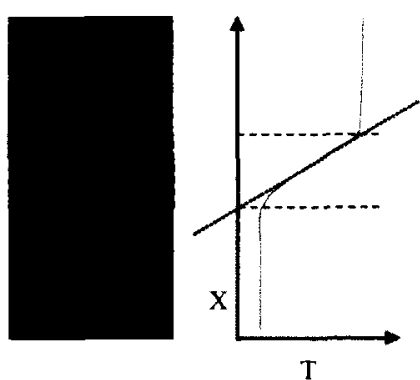

(a)

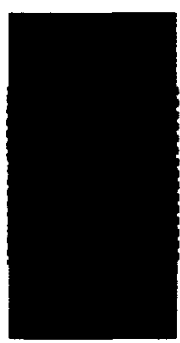

(b)

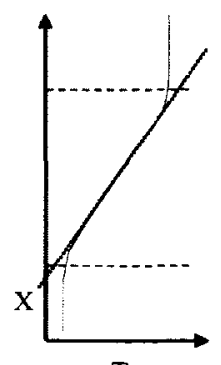

$\mathrm{T}$

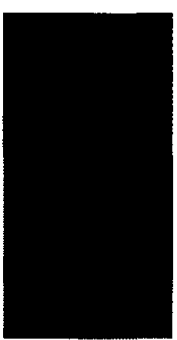

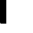

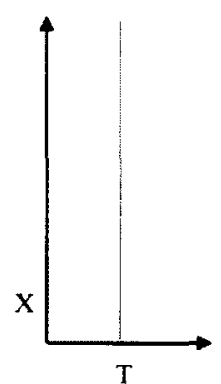

(c)

Figure 1.2: Differing levels of stratification within a storage tank for cases of (a) highly stratified storage; (b) moderately stratified storage; and (c) fully mixed, unstratified storage [3].

A number of parameters affect the degree of stratification in a storage tank. These include the volume and configuration of the tank, the size, location and design of the inlets and outlets, the flow rates of the entering and exiting streams, and the duration of the charging, storing and discharging periods [6]. In addition, there are four 
primary factors contributing to destratification, including: heat losses to the surroundings, heat conduction between hot and cold regions of stored fluid, conduction along the tank wall, and mixing during charging and discharging periods [6].

As previously mentioned for SDHW systems, charging can be achieved in either a direct or indirect configuration. Indirect systems are preferable to direct systems in colder climates as they make use of a freeze-resistant circulating fluid. There are two common methods for indirectly charging a TES, i.e., through an internal (inmmersed) heat exchanger or an external (side-arm) heat exchanger. Immersed coil heat exchangers are typically placed near the bottom of the storage tank so that energy is transferred to water at the lowest temperature. This causes the water to heat up and rise from the bottom of the tank to the top. As the water travels upwards, mixing occurs producing near uniform tank temperatures during charging. In contrast, a side-arm heat exchanger draws cold water from the bottom of the tank and deposits hot water on top by means of a circulating pump or natural convection. This promotes stratification within the system since the coldest fluid would always be drawn from the bottom of the tank for charging, while hot water would be available at the top of the tank for distribution during discharge. Furthermore, maintaining cold water at the bottom of the storage tank also results in improved collector efficiency, due to a large temperature difference across the collector [2].

\subsubsection{Multi-Tank Thermal Energy Storage Systems}

Sensible, water-based, diurnal TES was previously introduced in Section 1.2.2. Sizes of TES vary from standard, cylindrical $270 \mathrm{~L}$ tanks which are produced in large quantities in North America, to various larger sizes (in excess of 10,000 L) and geometries. Larger storage tanks are typically used in seasonal storage applications or for large multi-unit residential buildings where large storage capacities are required to meet 
the heating demands of several occupants. However, these systems are typically high in cost, and are incorporated into the design of a building and installed early in construction. As a cost-effective alternative, several smaller tanks can be interconnected in order to achieve the same storage capacity. This approach is ideal for retrofit applications, in instances where the system capacity is desired to be increased, yet it would be too difficult to replace a pre-existing system with a larger one. The concept of coupling small tanks would solve this problem and at low cost, as the installation would be less invasive to the structure of the building.

This concept formed the basis of this study. The system studied is shown in Fig. 1.3, and consists of three standard $270 \mathrm{~L}$ domestic hot water tanks, each equipped with a side-arm natural convection heat exchanger. The system is plumbed such that the system can be charged or discharged in either series or in parallel, or any combination thereof. Further details on the experimental apparatus are provided in Chapter 4 .

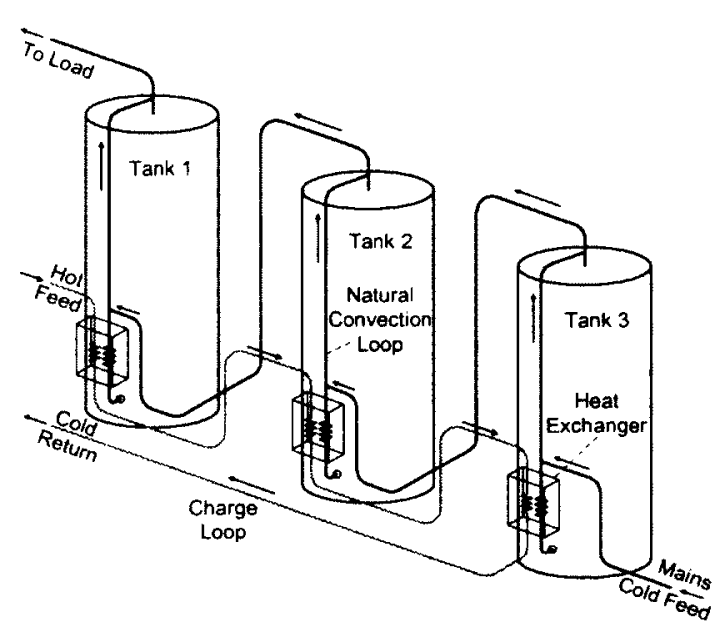

(a) Series charge and series discharge.

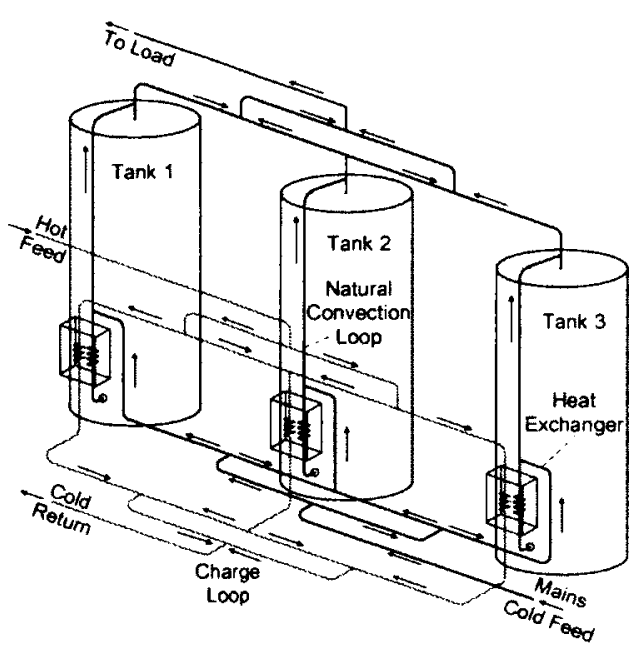

(b) Parallel charge and parallel discharge.

Figure 1.3: Schematics of two different plumbing configurations for a multi-tank thermal energy storage system, adapted from [3]. 
Another application of multi-tank systems is in solar combined space and domestic hot water heating systems (also referred to as solar "combisystems"), which are designed to meet the demands of space and hot water heating loads. Due to the larger storage capacity provided by multi-tank arrangements, these systems would be ideal for providing space heating in addition to domestic hot water. A review of these systems was conducted [7], and is presented in Appendix A.

\subsection{Problem Definition}

A multi-tank TES system was designed, constructed, instrumented, and commissioned at Queen's University in Kingston, Ontario, Canada, as part of a previous study by Cruickshank [3]. Experimental testing of the apparatus consisted of constant temperature charge tests and variable input power charge tests. Discharge of the TES was not a focus of the previous work, but was partially examined in order to verify the operation of the system. Discharge tests were performed at fully charged and uniformly mixed states, and the tanks were discharged at a constant flow rate until all three tanks were at mains temperature (i.e., fully-discharged). In the closing remarks of the study, it was recommended that future work explore additional charge and discharge scenarios, as well as nighttime standby losses and their effect on the operation and stratification levels of the TES.

As a continuation of the previous work, the current study investigated the performance of the multi-tank system under realistic draw profiles when subjected to a variable input power charge representative of the power output of a fixed-orientation solar collector. Initial tests consisted of constant temperature charging and constant volume draws $[8,9]$ in order to refine the numerical model, followed by an investigation of two-day (48-hour) realistic charge and draw profile scenarios [10]. As an 
additional aspect to the study, the effects of nighttime standby losses were examined for a period of 14 hours following the 10-hour daily charging period. Finally, the study examined the annual performance of the system using computer simulation. For all test cases. three plumbing configurations were studied, including: (i) series charge and series discharge, (ii) parallel charge and parallel discharge, and (iii) series charge and parallel discharge. The fourth possible system configuration consisting of a parallel charge and series discharge was not investigated, as a series charge would achieve higher temperatures in the first tank compared to a parallel charge. Furthermore, hot water is only drawn from the first tank when discharging in series, so lower temperatures would be drawn from the first tank compared to a series charge, and the additional energy added to downstream tanks when charging in parallel would not be used as effectively.

\subsection{Contribution of Research}

This work has:

1. proposed and implemented modifications to the multi-tank apparatus to facilitate discharging;

2. developed a computer model for the multi-tank system in the TRNSYS simulation environment; and

3. investigated the performance of the system under realistic charge and discharge profiles for various system configurations. 


\subsection{Organization of Research}

The information presented in this thesis documents research conducted over a span of two years. Over this period, three papers have been published in conference proceedings, and one journal paper has been accepted for publication. This thesis represents a compilation of results presented in these papers, and are referenced throughout the document. This thesis is divided into the following chapters:

Chapter 1 presents an introduction to solar domestic how water systems, thermal energy storage, and thermal stratification, as well as discusses the scope of this study;

Chapter 2 presents a review of current literature on thermal stratification, hot water use patterns and draw profiles, and discharge analyses;

Chapter 3 presents the theory and mathematical expressions used to model the multi-tank system in the TRNSYS simulation environment;

Chapter 4 presents a description of the experimental setup and an outline of the experimental test procedure;

Chapter 5 presents and compares the results of the experimental and simulation study based on temperature profiles and stratification levels;

Chapter 6 presents an analysis of the delivered energy and stored exergy levels of the system, as well as the results of an annual simulation study conducted for Ottawa, Ontario; and

Chapter 7 presents some concluding remarks of the study and recommendations for future work.

Appendices $\mathrm{A}$ through $\mathrm{H}$ present additional material that supports this research. A flowchart summarizing the approach of this study is shown in Fig. 1.4. 


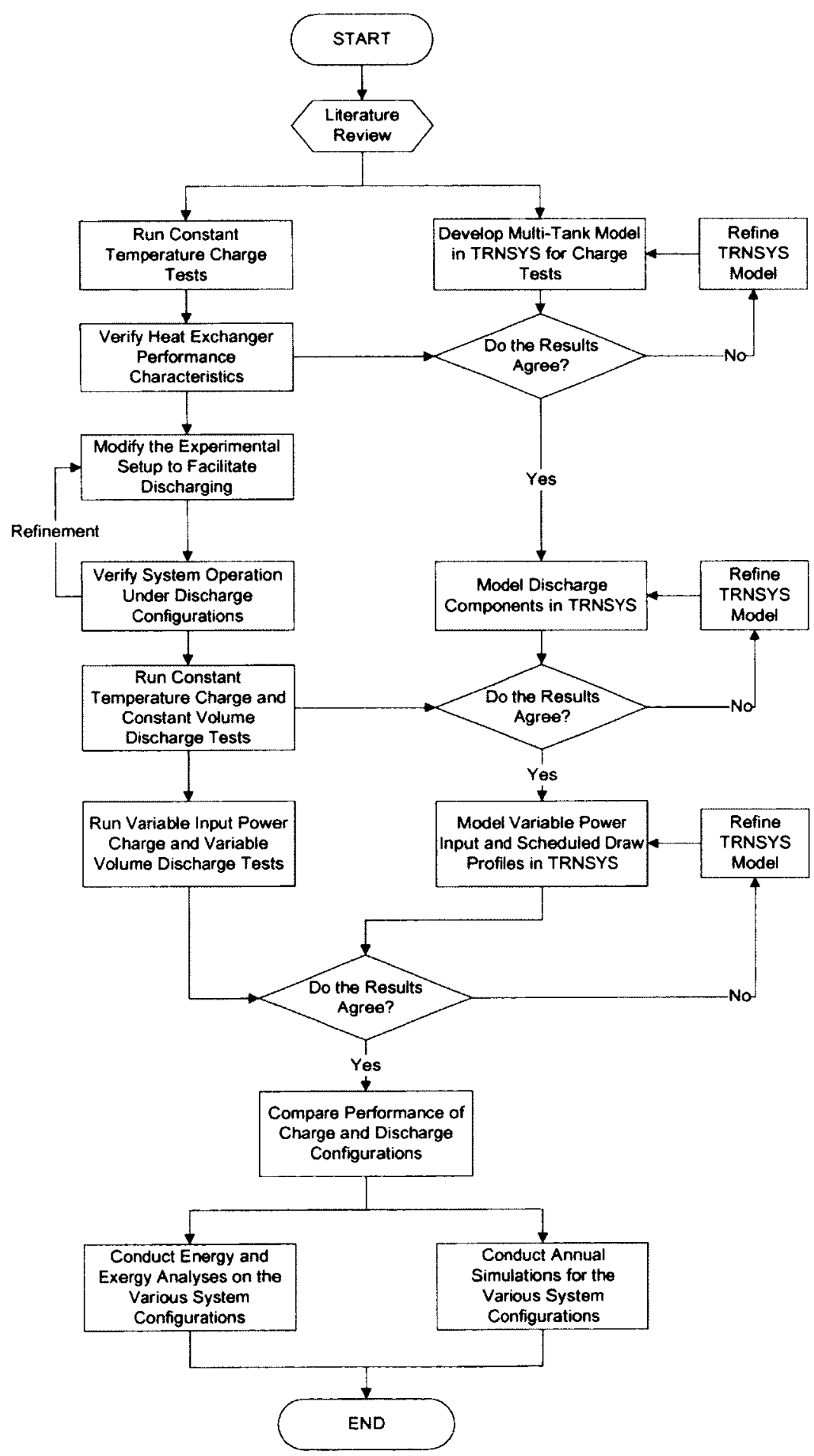

Figure 1.4: Flowchart of the approach taken to complete this study. 


\section{Chapter 2}

\section{Literature Review}

\section{$2.1 \quad$ Introduction}

In recent years, solar thermal systems have received a lot of attention due to the rising concern over energy demand and the need for efficient thermal energy storage. As such, these systems have been an important area of research. Most notably, the texts published by Duffie and Beckman [2] and Dinçer and Rosen [6] have become the standard in presenting the theory and design principles of solar technology and thermal energy storage systems, respectively. In the text by Dinçer and Rosen, the authors discuss several topics on thermal energy storage including: energy storage methods, environmental impacts, energy savings, performance measures, modelling methods, and energy and exergy analyses.

Literature relevant to thermal energy storage was reviewed as part of this study, and focused on the following topics: thermal stratification in hot water storage tanks; developments in defining domestic hot water draw profiles; and past studies on discharging of thermal energy storages. 


\subsection{Stratification in Storage Tanks}

Stratification was briefly introduced in Chapter 1, and occurs within a thermal energy storage as a result of tempcrature gradients and buoyancy effects during charging. Stratification is desirable in a TES as it ensures that hot water is available to be drawn off the top of the tank carly in the day, compared to a TES that is uniform in temperature. As such, methods for enhancing stratification in TES has been extensively researched in single tank and multi-tank systems.

Design elements such as baffles and diffusers (typically referred to as "stratifiers") may be added to the interior of the storage tank to promote stratification, but these items further increase the complexity and cost of the overall system. Altuntop et al. [11] discussed the effects of six different baffle designs on the thermal stratification in hot water storage tanks. The results demonstrated that baffles provided better stratification compared to the no baffle case, and more specifically, that baffles with a gap in the center produced better stratification compared to those having gaps at the tank wall.

In addition, studies have shown that for direct and indirect systems, destratification can oceur due to high flow velocities. Hollands and Lightstone [12] found that a $17 \%$ improvement in delivered energy is possible using low-flow systems due to the improved stratification achieved. Furthermore, the authors state that a perfectly stratified tank can produce as much as $38 \%$ more heat than a fully mixed tank. In a similar study, Shah and Furbo [13] examined the effects of three different inlet designs and various inlet flow velocities on the thermal stratification of a storage tank. The authors concluded that the energy quality is reduced with a poor inlet design (i.e., a raw pipe compared to pipes with baffle plates), and that higher entropy and exergy efficiencies were achieved at lower flow rates. 
Han et al. [14] presented an extensive review of methods for enhancing and destroying thermal stratification. modelling thermal stratification, influencing factors, and performance indiees to quantify stratification levels. The authors concluded that thermal stratification within water tanks can effectively improve the exergy and the utilization efficiency of entire solar thermal systems. Han et al. also recommend exergy analyses for quantifying stratification as it accounts not only for energy stored but also for the temperature at which the energy is stored. This is also confirmed by Dinçer and Rosen in their text, which states that exergy performance measures are more meaningful than energy performance measures, as exergy describes the quality or usefulness of the energy stored [6].

When referring to performance measures or indices, Han et al. also discussed the stratification number, energy efficiency, exergy efficiency, flow factor, Richardson number, Peclet number, Archimedean number, inlet Reynolds number, and Froude number. A further investigation on the suitability of using stratification efficiencies for characterizing stratification was presented by Haller et al. [15] for hypothetical charge and discharge processes, however, none of the applied methods were able to distinguish between the rate of entropy production caused by mixing and the entropy changes due to heat losses. Finally, when attempting to compare various types of thermal energy storage systems based on performance indices, Dinçer and Rosen concluded that "no generally valid basis for comparing the achieved performance of one storage with that of another operating under different conditions has found broad acceptance" $[6]$.

Stratification has also been extensively studied within multi-tank storage systems. Mather et al. [16] proposed a multi-tank system with a number of $200 \mathrm{~L}$ hot water storage tanks connected in series. Immersed coil heat exchangers were placed at the bottom of the tanks and connected to the solar loop in order to charge the system, 
while immersed heat exchangers were placed at the top of the tanks and connected to the load loop, which was used to discharge the system. Mather also discussed the "thermal diode" effect of the series charge configuration. When hot fluid enters the heat exchanger at the bottom of the first tank, a buoyant plume forms, causing the first tank to increase in temperature as the plume moves upwards and mixes the tank fluid. In the case of cooler water entering the heat exchanger at the bottom of the first tank, only the region surrounding the heat exchanger is cooled, while the top tank temperature is maintained at a hotter temperature. Therefore, as the collector loop temperature falls, the fluid will pass through the first heat exchanger without causing a significant temperature difference, until a tank at a lower temperature than the collector loop is encountered. The experimental test consisted of an 8-hour constant temperature charge, with initial tank temperatures of $20^{\circ} \mathrm{C}$ and a charge loop temperature of $60^{\circ} \mathrm{C}$. Following this, the tanks were discharged by producing a $25^{\circ} \mathrm{C}$ flow through the load loop (passing through the heat exchangers at the top of the tanks). In the second study, Mather considered four different charge temperatures $\left(40^{\circ} \mathrm{C}, 60^{\circ} \mathrm{C}, 35^{\circ} \mathrm{C}\right.$, and $\left.25^{\circ} \mathrm{C}\right)$, each 2 hours in duration. The results of the study showed that a high degree of effective stratification was observed, and that the thermal diode effect was present when the charge temperature fell.

A study conducted by Cruickshank [3] was based on a similar concept and considered a multi-tank system with three standard $270 \mathrm{~L}$ hot water storage tanks, each equipped with an external, side-arm natural convection heat exchanger. The system could be charged or discharged in either a series or parallel configuration. Constant temperature charge tests were conducted for a number of charge temperatures ranging from $20^{\circ} \mathrm{C}$ to $80^{\circ} \mathrm{C}$, and charge flow rates ranging from $0.9 \mathrm{~L} / \mathrm{min}$ to $1.5 \mathrm{~L} / \mathrm{min}$. The results showed that sequential stratification was achieved in the series charge 
configuration. while the tanks charged simultaneously in the parallel charge configuration.

Another study on variable input power charge conditions was conducted by Cruickshank $[3,17]$, where the effects of charging with two consecutive clear days or combinations of a clear and overcast day was examined. Nighttime periods and discharging was not considered as part of the study. Each day consisted of a 10-hour charge profile approximated by a sine function, where clear days provided a maximum input of $3 \mathrm{~kW}$ to the system, and overcast days provided a maximum input of $1.5 \mathrm{~kW}$ to the system. Tests were conducted at flow rates ranging from $1.2 \mathrm{~L} / \mathrm{min}$ to $4.5 \mathrm{~L} / \mathrm{min}$. Results showed that the series-connected charge configuration reached high levels of temperature stratification during periods of rising charge temperatures, and limited destratification during periods of falling charge temperatures. This was in agreement with the thermal diode effect observed by Mather. where sequential stratification was achieved and energy was distributed according to temperature level. Additionally, the study found that at high charge flow rates $(4.5 \mathrm{~L} / \mathrm{min})$, the temperature distribution in the series configuration was similar to that of the parallel configuration. Furthermore. at high flow rates in the series configuration and in the parallel configuration, falling charge-loop temperatures resulted in more mixing and destratification compared to the series configuration at low flow rates.

Finally, Cruickshank [3] examined the stored exergy of the constant temperature charge and variable input power charge tests to measure the performance of the system. Under constant temperature charge conditions, the parallel charge configuration was found to exhibit higher exergy levels compared to the series charge configuration. Under variable input power charge conditions, it was observed that at low charge flow rates, the series charge configuration experienced a higher stored exergy value at the 
end of the test period, while at high flow rates, the parallel charge configuration experienced a higher stored exergy value at the end of the test period. Furthermore, as the collector loop flow rate increased, the rate at which exergy was stored decreased in both series and parallel configurations.

\subsection{Development of Draw Profiles}

An extensive amount of work has been published over the past several decades in developing standard domestic hot water load profiles which represent various uses and applications. These draw profiles have been based on numerous studies which have measured and examined the hot water use patterns of occupants.

Between 1981 and 1984, Perlman and Mills [18] conducted a study of 58 residences in Ontario, producing a data base of over two million hot water use measurements. The authors identified three main categories of patterns: high morning (32 of 58 families), high evening (19 of 58 families), and low user ( 7 of 58 families) patterns, and defined a "typical" household as consisting of two adults and two children, with a clothes washer and dishwasher present. The average daily hot water use per household for the whole group was $236 \mathrm{~L}$, and $239 \mathrm{~L}$ for the "typical" group. The average daily hot water use per person was $62.1 \mathrm{~L}$ and $60.5 \mathrm{~L}$ for each group, respectively. Perlman and Wills concluded that the greatest influencing factors were time-of-use, including hour of day, day of week, month, and season of year, along with the size of the family, presence and age of clildren, and presence of people home during the day.

Between 1982 and 1984, Merrigan [19] monitored the performance of 74 domestic hot water systems in Florida, and in 1985, monitored the performance of 24 additional solar hot water systems in North Carolina. Hot water use patterns were recorded at 15-minute intervals, and were compared between winter and summer months, as well 
as weekday and weekend use. Thermostat temperatures on the 74 water heaters in Florida varied between $43^{\circ} \mathrm{C}$ and $68^{\circ} \mathrm{C}$, and demonstrated that thermostat settings lad a strong influence on the daily hot water use. Based on the collected data, Merrigan stated that the average hot water consumption per day for a family of two was $167 \mathrm{~L}$. with an additional $45 \mathrm{~L}$ per person per day for each additional family member. In addition, average daily hot water usage increased $21 \%$ in the winter season when compared to the summer months. Finally, weekend data showed that hot water use began later in the mornings compared to weekday morning use.

In 1986, Perlman and Milligan [20] conducted a one-year study in Toronto which monitored the hot water consumption from gas-fired domestic hot water systems in five multi-unit residential buildings. In addition, all five central hot water systems were set at an operating temperature of $60^{\circ} \mathrm{C}$. The study looked at the differences in consumption between senior citizens, condominiums and rental properties. The average hot water use per suite was found to be $242 \mathrm{~L}$, with an average daily consumption per person of $79 \mathrm{~L}$. Overall, seniors had a daily hot water consumption of $67.8 \mathrm{~L} /$ suite, condos with $256.9 \mathrm{~L} /$ suite, and rental units with $396.2 \mathrm{~L} /$ suite. Winter daily consumption was shown to be $20 \%$ higher than during the summer, which was consistent with the study by Merrigan.

In 1990, Becker and Stogsdill [21] conducted a study that analyzed over 30 million data points on hot water use from the three previously discussed studies [18-20], as well as studies by Gilbert Associates Inc. [22] and Hirst et al. [23]. Becker and Stogsdill compared average hourly use, monthly use, seasonal use, and weekday versus weekend use, and presented a comprehensive cumulation of existing data on hot water consumption. 
In 2004. Fairey and Parker [24] conducted a review of hot water draw profiles. The author compared daily draw profiles obtained from previous studies, including Perlman and Mills [18], ASHRAE Standard 90.2 [25], Becker and Stogsdill [21], Bouchelle et al. [26], as well as the Solar Rating and Certification Corporation (SRCC) which had adapted the data obtained by Perlman and Mills, and Becker and Stogsdill. The authors concluded that the data presented by Becker and Stogsdill, and ASHRAE Standard 90.2 were in general agreement and should be used for performance analysis of hot water systems in the US in place of the other profiles. Their argument against the other profiles were that the draw profiles by Perlman and Mills were based solely on Canadian data, and the SRCC data was not consistent with the other draw profiles presented.

In recent years, a new study has been conducted on hot water use patterns in Canada by Thomas et al. [27]. The study monitored 38 households in Ottawa between October 2007 and July 2008, and 36 households in Hamilton, London and Sudbury between July 2009 and October 2009. Draw volume flow rates were recorded in the first study at 2-second intervals, while the second study recorded the data at 4-second intervals. The study found that since the studies conducted by Perlman and Mills [18], average draw volumes have decreased, average draw volume flow rates have decreased, and the average number of draws per day has increased compared to the current water heater performance test standards. Of the monitored test sites, $83 \%$ of households used less than the current testing standard of $243 \mathrm{~L} /$ day, with an average of $185.6 \mathrm{~L} /$ day. Furthermore, the study found that the average number of daily water draws per household ranged from 5 to 179 per day, with a study average of 79 per day. This far exceeds the assumption of 6 draws per day at $40.6 \mathrm{~L}$ per draw, used in the current water heater performance test standards [28-30]. Hot water draws ranged from $0.7 \mathrm{~L}$ to $7.5 \mathrm{~L}$ with an average of $2.7 \mathrm{~L}$, and maximum draw volumes per 
houschold ranged from $24 \mathrm{~L}$ to $299 \mathrm{~L}$. Finally, hot water draw flow rates ranged from $0.8 \mathrm{~L} / \mathrm{min}$ to $23.3 \mathrm{~L} / \mathrm{min}$ across all test sites, with average flow rates at each test site ranging from $1.3 \mathrm{~L} / \mathrm{min}$ to $5.0 \mathrm{~L} / \mathrm{min}$, and a mean flow rate of $2.8 \mathrm{~L} / \mathrm{min}$.

Apart from the previous studies which have been conducted based on monitored data, draw profiles used in the testing of SDHW systems in the United States and Canada are based on standards developed by the SRCC [31] and the Canadian Standards Association (CSA) [32]. Hot water draws from the SRCC's OG-300 Operating Guidelines for Certifying Solar Water Heating Systems are based on draw energy rather than draw volumes, and involve a total of 6 draws with one conducted at the beginning of each hour. The draw specifications are summarized in 'Table 2.1, and were adapted for use in the constant temperature charge and constant volume discharge tests presented in Chapter 4.

Table 2.1: SRCC draw specifications.

\begin{tabular}{lc}
\hline Parameter & Value \\
\hline Environmental Temperature & $19.7^{\circ} \mathrm{C}$ \\
Set-Point Temperature & $57.2^{\circ} \mathrm{C}$ \\
Mains Temperature & $14.4^{\circ} \mathrm{C}$ \\
Total Energy Draw & $43.302 \mathrm{MJ}$ \\
Approximate Volume Draw & $243 \mathrm{~L}$ \\
Draw Rate & $11.4 \mathrm{~L} / \mathrm{min}$ \\
\hline
\end{tabular}

Finally, the Canadian Standard Association's (CSA) F379.1-88 Standard for Solar Domestic Hot Water Systems includes three typical draw profiles for occupancies of $1-2$ persons $(150 \mathrm{~L}), 3-4$ persons $(225 \mathrm{~L})$, and 5 or more persons $(300 \mathrm{~L})$. The corresponding hourly draw volumes are listed in Table 2.2, and were adapted for both the variable input power charge tests and the amnual simulations presented in Chapter 4 and 6 , respectively. 
Table 2.2: CSA draw profiles.

\begin{tabular}{cccc}
\hline \multicolumn{4}{c}{ Draw Volume (L) } \\
Time & Schedule A & Schedule B & Schedule C \\
\hline 07:00 & 5 & 10 & 10 \\
$08: 00$ & 25 & 25 & 25 \\
09:00 & 0 & 5 & 25 \\
$10: 00$ & 45 & 45 & 45 \\
$11: 00$ & 0 & 5 & 25 \\
$12: 00$ & 5 & 10 & 10 \\
$13: 00$ & 0 & 5 & 5 \\
$14: 00$ & 0 & 0 & 0 \\
$15: 00$ & 0 & 0 & 0 \\
$16: 00$ & 0 & 10 & 15 \\
$17: 00$ & 5 & 25 & 25 \\
$18: 00$ & 10 & 45 & 45 \\
$19: 00$ & 30 & 25 & 25 \\
$20: 00$ & 20 & 10 & 30 \\
$21: 00$ & 0 & 5 & 10 \\
$22: 00$ & 0 & 0 & 5 \\
\hline TOTAL & 150 & 225 & 300 \\
\hline
\end{tabular}

\subsection{Discharging of Thermal Energy Storage}

In addition to charging of the TES, discharging also represents an important area of study. For single tank systems, hot water is typically drawn from the top of the tank where water is at its highest temperature, but when dealing with multiple storage tanks, the question arises as to whether one should draw off from one tank or all of them simultaneous. Another challenge lies in how to choose a draw profile that's representative of the type of application. In the previous section, a number of studies 
have been reviewed which looked exclusively at hot water use patterns and draw profiles. but there is no universally accepted standard. This section looks at some of the recent work which has been conducted on the discharging of storage tanks, the types of draws which were performed, and the analysis methods presented.

As previously mentioned in Section 2.2, destratification can occur due to high flow velocities. Consequently, discharging of TES has been found to cause a significant decrease in the thermal performance of SDHW systems due to mixing during draw-offs [33-36]. One such study by Jordan and Vajen [37] studied the influence of domestic hot water (DHW) load profiles with a constant total yearly heat demand for a solar combisystem through TRNSYS simulation. The storage tank consisted of an internal thermosyphonally driven discharge unit, and draws were conducted based on a $200 \mathrm{~L}$ per day volume with a load temperature of $45^{\circ} \mathrm{C}$, at flow rates varying between $4 \mathrm{~L} / \mathrm{min}$ and $20 \mathrm{~L} / \mathrm{min}$. Various DHW load profiles were considered, with simplified profiles consisting of either one or three draws per day (at 07:00, 12:00, and 19:00), and a more realistic profile based on hourly draws. The results of annual simulations were compared based on the fractional energy savings of the system, and the authors concluded that the load profile had a significant impact on the fractional energy savings, especially if the duration and flow rates of the DHW draw-offs have an influence on the temperature stratification in the storage tank.

Dehghan and Barzegar [38] investigated the performance of a storage tank in a SDHW system through numerical modelling. During discharge, mains water was fed into the bottom of the tank while hot water was extracted from the top of the tank. Charging of the tank by the collector loop occurred through a mantle heat exchanger, and continued during discharge. Discharge flow rates were varied according to a range of Reynolds numbers between 100 and 1000, and the thermal stratification of the tank was investigated by comparing values of Grashof number and inlet Reynolds number. 
The results indicated that for low values of Grashof and Richardson numbers, stratification was destroved by the entering mains water, while higher numbers preserved thermal stratification during discharge. For low values of the inlet Reynolds number (below 200), thermal stratification was preserved at the top of the tank, while higher numbers intensified mixing in the top region.

Finally, Haltiwanger and Davidson [39] performed an experimental study on a 350 L storage tank with a cylindrical baffle and an immorsed coil heat exchanger placed in the gap between the baffle and the tank wall. The tank was continually discharged through the heat exchanger by starting the flow of mains water at the heat exchanger inlet at a mass flow rate of $0.1 \mathrm{~kg} / \mathrm{s}$ (i.e., $6 \mathrm{~L} / \mathrm{min}$ ). The tank was studied from both uniformly mixed and stratified initial conditions, with and without the baffle. The results of the study indicated that the baffle increased the storage side convective heat transfer to the heat exchanger by $20 \%$, producing higher delivery water temperatures and higher fractional energy values.

Based on the reviewed literature, it can be concluded that the volume, frequency and flow rates of draws have a significant impact on the thermal stratification and annual performance of a SDHW system. In addition, the method of discharging the tank, either through an immersed coil heat exchanger or by extracting hot water from the top directly, has an impact on the performance as well. In the following chapter, an overview of the modelling approach for the multi-tank system will be presented, as well as the mathematical relations necessary to model the thermal energy storage and natural convection heat exchanger components in the TRNSYS simulation environment. 


\section{Chapter 3}

\section{Modelling Approach}

\subsection{Introduction}

Computer modelling for this study was conducted in the TRNSYS simulation environment [40] and was used to investigate the performance of the multi-tank system under varying operating conditions prior to testing. TRNSYS Version 17 was selected as the simulation tool for its ability to accurately model the performance of transient processes. Simulation models are constructed in the "Simulation Studio" and written to an input file referred to as the "deck" file. The Simulation Studio employs a graphical interface to link components to one another as they would be in a real physical system. TRNSYS contains a library of components (also referred to as "Types") whose outputs can be represented as a mathematical function of inputs (time-dependent values) and parameters (time-independent values). As each time step progresses during a simulation, the output of one component is used as the input to the next component, and the values at the end of the time step are solved iteratively until convergence is attained. These values are then used as initial values for the following time step. 


\subsection{Multi-Tank Model}

The multi-tank system was designed with modularity in mind, maintaining the ability to charge or discharge the system in either series or parallel, or any combination thereof. The three configurations selected for this study were a series charge and scries discharge configuration, a parallel charge and parallel discharge configuration, and a series charge and parallel discharge configuration. As a result, three distinct TRNSYS models were constructed to model each configuration. Screenshots from the TRNSYS Simulation Studio for two of the three modelled configurations are given in Fig. 3.1. The blue lines represent the flow of cold water entering the tanks from the mains supply, or exiting the bottom of the tanks and feeding the heat exchangers. The red lines represent the flow of hot water leaving the heat exchangers, as well as hot water flowing out of the top of the tanks. The green lines represent the flow of the propylene glycol and water mixture in the charge loop. Finally, the dotted black lines represent any other interactions between components. The multi-tank model consisted of standard library components, with the exception of two custom components developed by Lin et al. [4] which were necessary to model the natural convection heat exchanger and flow rate in the thermosyphon loop.

\subsection{Modelling of the Thermal Energy Storage}

The standard TRNSYS component selected to model the thermal energy storage within the system was Type 60 . The Type 60 component was developed by Brian Newton at the University of Wisconsin-Madison [41] in order to replace the previous standard tank model, Type 4 . The Type 4 component modelled a stratified fluid storage tank with up to 100 fully-mixed, equal segment nodes, and accommodated two 


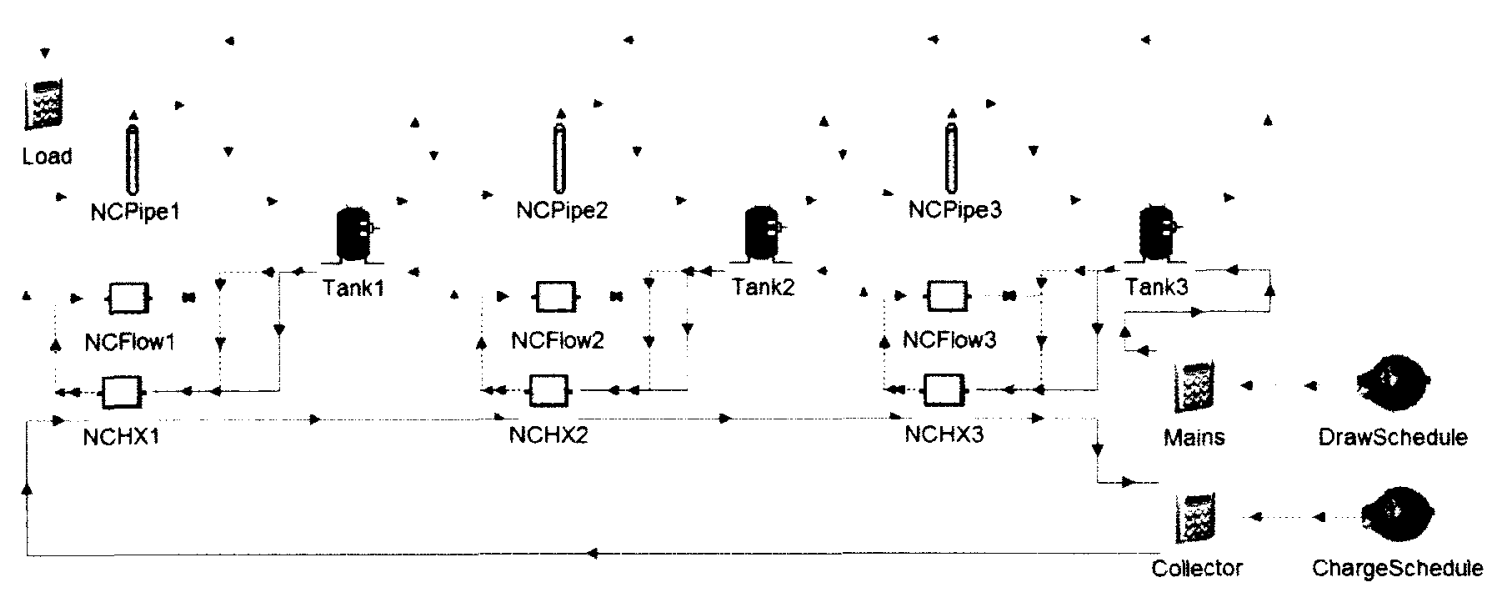

(a) Series charge and series discharge configuration.

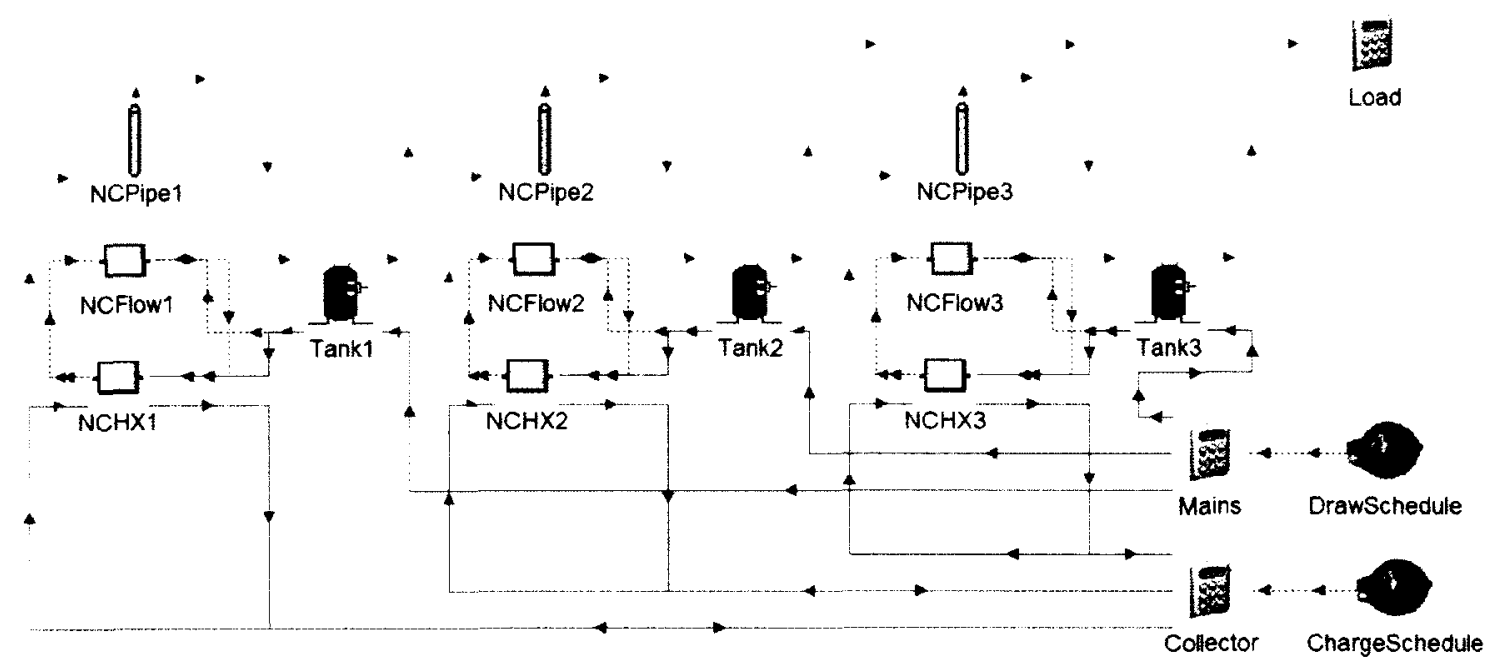

(b) Parallel charge and parallel discharge configuration.

Figure 3.1: TRNSYS models of the investigated multi-tank system configurations for constant temperature charge and constant volume discharge tests. 
inlets and two outlets per tank; however, the Type 60 component has been demonstrated by Newton to model temperature profiles and stratification more accurately by taking into consideration destratification due to conductivity at the tank wall and node surfaces (one of the four primary factors in contributing to destratification as mentioned in Section 1.2.3). Newton also stated that it was observed that stratification decayed more rapidly than at a rate calculated theoretically using the conductivity of water, and implemented an additional factor into Type 60 to account for wall conduction [41]. Conduction along the tank wall is shown in Fig. 3.2.

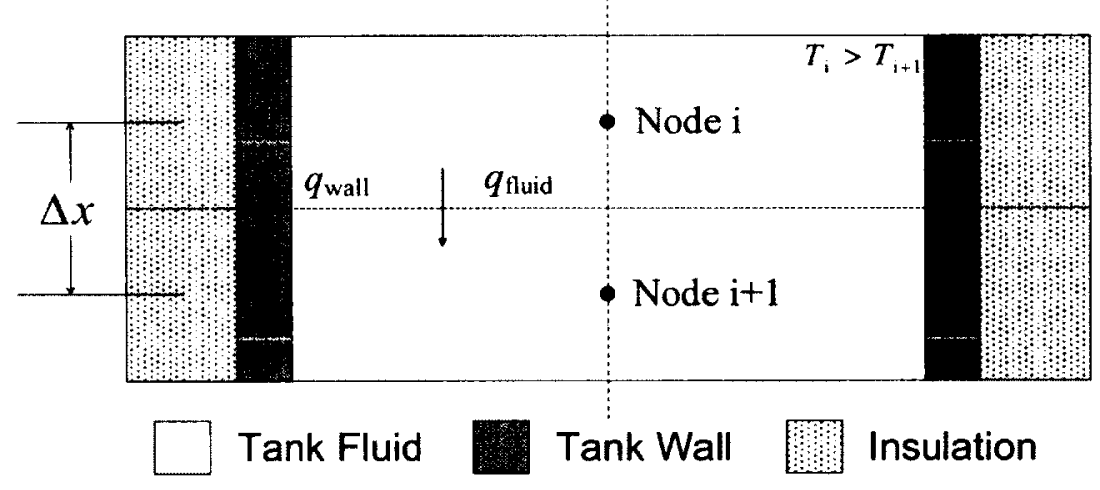

Figure 3.2: Destratification between adjacent nodes duc to wall conduction, adapted from [41].

The heat transfer rate $\dot{q}$ from Node i to Node $i+1$ is given by Eq. (3.1),

$$
\dot{q}=\frac{(k+\Delta k) A_{\mathrm{c}}}{\Delta x}\left(T_{\mathrm{i}}-T_{\mathrm{i}+1}\right)
$$

where $k$ is the fluid conductivity, $\Delta k$ is an additional conductivity term due to the interactions at the wall and node surfaces, $A_{c}$ is the cross-sectional area of the tank fluid, $\Delta x$ is the distance between nodes (for equal segment nodes, this is the same as the node height), and $T$ is the temperature at Node $\mathrm{i}$ and Node $\mathrm{i}+1$. The additional conductivity term can be approximated using Eq. (3.2), 


$$
\Delta k=k_{\text {wall }} \frac{A_{\mathrm{c}, \text { wall }}}{A_{\mathrm{c}}}
$$

where $k_{\text {wall }}$ is the thermal conductivity of the tank wall material, and $A_{c, \text { wall }}$ is the cross-sectional area of the wall.

Figure 3.3 shows a simplified energy flow diagram for one node using the Type 60 algorithm, assuming no auxiliary heat input from the internal electric resistance heaters $\left(Q_{\mathrm{aux}}=0\right)$, no heat input from the immersed heat exchanger $\left(U A_{\mathrm{HX}}=0\right)$, and uniform tank insulation $(\Delta U=0)$. The model applies a 1-D finite-volume approach, assuming that temperature gradients exist in the vertical direction but are negligible in the horizontal direction. 'The 1-D assumption has been verified in literature [6], as well as on the current multi-tank apparatus through the use of a horizontal temperature probe [3]. The investigation demonstrated that virtually no horizontal temperature gradients were present during charging. The energy balance equation applied at each node is given in Eq. (3.3).

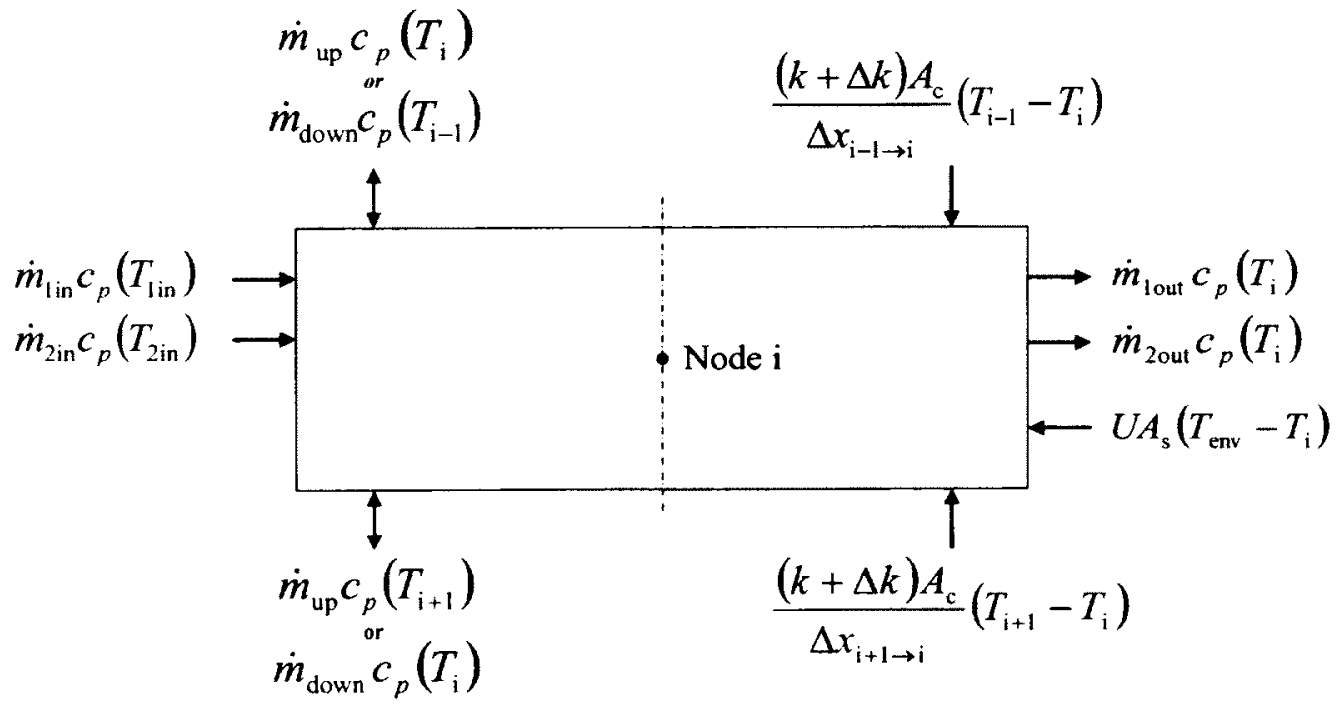

Figure 3.3: Energy balance for Node i, adapted from [41]. 


$$
\begin{aligned}
m_{\mathrm{i}} c_{p}\left(\frac{d T_{\mathrm{i}}}{d t}\right) & =\frac{(k+\Delta k) A_{\mathrm{c}}}{\Delta x_{\mathrm{i}+1 \rightarrow \mathrm{i}}}\left(T_{\mathrm{i}+1}-T_{\mathrm{i}}\right)+\frac{(k+\Delta k) A_{\mathrm{c}}}{\Delta x_{\mathrm{i}-1 \rightarrow \mathrm{i}}}\left(T_{\mathrm{i}-1}-T_{\mathrm{i}}\right) \\
& +U A_{\mathrm{s}}\left(T_{\mathrm{env}}-T_{\mathrm{i}}\right)+\dot{m}_{\mathrm{down}} c_{p}\left(T_{\mathrm{i}-1}\right)-\dot{m}_{\mathrm{up}} c_{p}\left(T_{\mathrm{i}}\right) \\
& -\dot{m}_{\text {down }} c_{p}\left(T_{\mathrm{i}}\right)+\dot{m}_{\mathrm{up}} c_{p}\left(T_{\mathrm{i}+1}\right)+\dot{m}_{\text {lin }} c_{p}\left(T_{1 \mathrm{in}}\right) \\
& -\dot{m}_{1 \text { out }} c_{p}\left(T_{\mathrm{i}}\right)+\dot{m}_{2 \mathrm{in}} c_{p}\left(T_{2 \mathrm{in}}\right)-\dot{m}_{2 \mathrm{out}} c_{p}\left(T_{\mathrm{i}}\right)
\end{aligned}
$$

The Type 60 component assembles $\mathrm{N}$ equations based on the number of nodes, and builds a two-dimensional array consisting of constant coefficients grouped with their corresponding node temperatures. TRNSYS then solves the array for every node in the tank. Newton investigated several different solutions for solving the energy balance equation, but selected the Crank-Nicolson solution as it produced the most accurate values with the fewest number of iterations [41]. The program then iteratively solves each node temperature until they converge within $0.001^{\circ} \mathrm{C}$. Instead of using the time steps specified in TRNSYS to solve for the temperatures (which in some cases may be quite large), Type 60 employs an internal time step to improve accuracy.

For the multi-tank model, each domestic hot water tank was modelled using a single Type 60 component. The height of the tank in the TRNSYS model was selected as $1.35 \mathrm{~m}$ based on the experimental setup (which will be further discussed in Chapter 4), and the volume of each tank was selected as $0.27 \mathrm{~m}^{3}$. The maximum number of nodes allowed per simulation was limited by the Type 60 component to 100 nodes. As a result, each tank consisted of 33 equal volume nodes, with a corresponding node height of approximately $0.0409 \mathrm{~m}$. From these node heights, 10 nodes were selected for comparison with experimental values based on the $0.15 \mathrm{~m}$ spacing used for the thermocouples attached to the experimental temperature probe. A comparison between the experimental thermocouple locations and the Type 60 node locations is presented in Section 5.2 . 
An alternative, non-standard TRNSYS component for modelling thermal energy storage, Type 534, was also available from the TESS component library. In a study by Allard et al. [42], five different TRNSYS tank models were compared based on a number of criteria. While Type 534 was capable of simulating up to 500 nodes compared to the 100 node limit of Type 60 , the results of the study concluded that both components produced vertical temperature profiles that differed to some extent when compared to experimental measurements, especially in the mixing zone. Since Type 534 did not significantly improve the modelling performance of the vertical temperature profile compared to Type 60, it was not considered any further in this study.

\subsection{Modelling of the Natural Convection Heat Exchanger}

The standard TRNSYS component library contains a number of heat exchanger models for various configurations, such as constant effectiveness, counter flow, cross flow, parallel flow, and shell and tube configurations: however, the models are limited to forced flow conditions for both fluids. For the considered multi-tank system, each storage tank is equipped with a side-arm, natural convection heat exchanger, connected in a counter flow arrangement (Fig. 3.4).

For a typical counter flow heat exchanger with forced flow on both sides, the effectiveness is calculated using Eq. (3.4),

$$
\epsilon=\frac{\dot{Q}}{\dot{Q}_{\max }}
$$

where $\epsilon$ is the heat exchanger effectiveness, $\dot{Q}$ is the actual rate of heat transfer between fluids, and $\dot{Q}_{\max }$ is the maximum possible rate of heat transfer between fluids. 


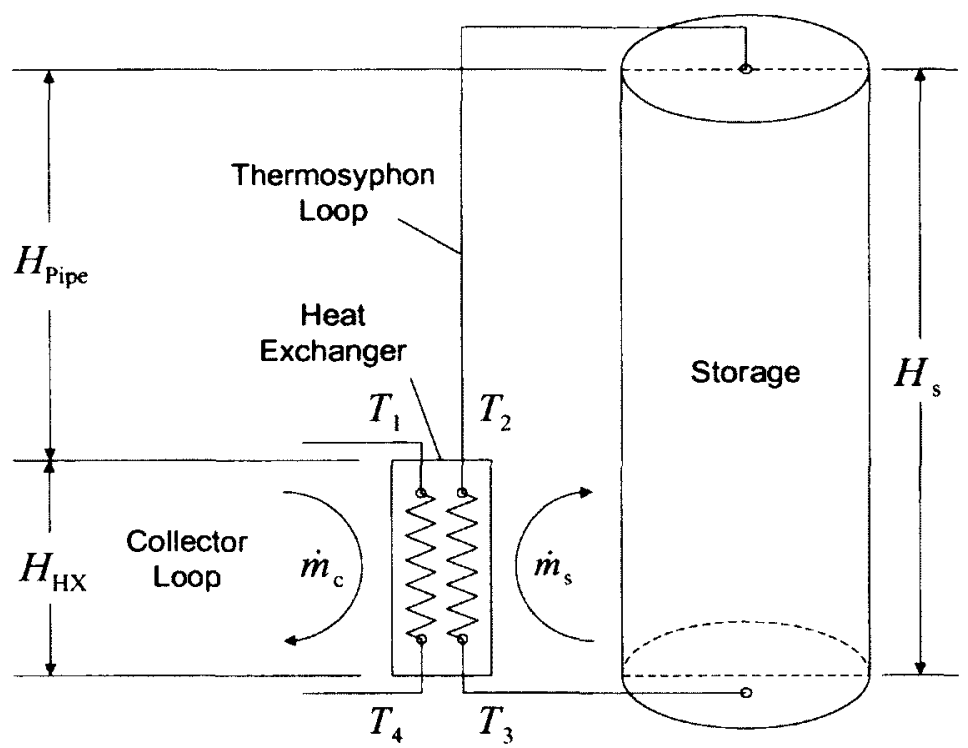

Figure 3.4: Schematic showing the heights, temperatures and flow rates used for modelling the heat exchanger.

The actual rate of heat transfer can be calculated according to Eq. (3.5) using either the energy lost by the hot fluid or the energy gained by the cold fluid,

$$
\dot{Q}=\dot{m}_{\mathrm{c}} c_{p_{\mathrm{c}}}\left(T_{1}-T_{4}\right)=\dot{m}_{\mathrm{s}} c_{p_{\mathrm{s}}}\left(T_{2}-T_{3}\right)
$$

where $\dot{m}_{\mathrm{c}}$ corresponds to the collector flow rate, $\dot{m}_{\mathrm{s}}$ corresponds to the storage side flow rate (which will be considered as a forced flow for now), and $c_{p_{\mathrm{c}}}$ and $c_{p_{\mathrm{s}}}$ are the specific heats of the collector fluid (propylene glycol and water mixture) and storage fluid (water), respectively. Temperatures $T_{1}$ and $T_{4}$ correspond to the inlet and outlet temperatures of the heat exchanger on the collector side, and temperatures $T_{3}$ and $T_{2}$ correspond to the inlet and outlet temperatures of the heat exchanger on the storage side, respectively.

The maximum possible rate of heat transfer is specified by the fluid which would receive the maximum temperature difference across the heat exchanger, and this would only occur for the fluid having the minimum value of $\dot{m} c_{p}$, which is referred to 
as the fluid capacitance. In the case where the minimum capacitance value applies to the storage fluid, the resulting calculation for the maximum rate of heat transfer is given in Eq. (3.6),

$$
\dot{Q}_{\max }=\dot{m}_{\mathrm{s}} c_{p_{\mathrm{s}}}\left(T_{1}-T_{3}\right)
$$

where $\left(T_{1}-T_{3}\right)$ represents the temperature difference between the inlet temperatures of the hot and cold fluids. Substituting in the heat transfer for the collector side from Eq. (3.5), the resulting effectiveness is then given by Eq. (3.7).

$$
\epsilon=\frac{\dot{m}_{\mathrm{c}} c_{p_{\mathrm{c}}}\left(T_{1}-T_{4}\right)}{\dot{m}_{\mathrm{s}} c_{p_{\mathrm{s}}}\left(T_{1}-T_{3}\right)}
$$

The problem with applying these equations to a natural convection heat exchanger lies in the minimum capacitance value, $\dot{m}_{\mathrm{s}} c_{p_{\mathrm{s}}}$. As the storage tank heats up during charging, the natural convection flow rate decreases, causing the capacitance value to approach zero. As this occurs, the denominator approaches zero, and the effectiveness approaches infinity. This is contrary to what is expected, as the effectiveness should decrease as charging occurs, not increase. Additionally, the effectiveness cannot exceed a value of 1 , otherwise, that would suggest that the actual heat being transferred is greater than the maximum heat which could be transferred.

An alternative method to modelling the performance of a natural convection heat exchanger was proposed by Fraser et al. [43], Purdy et al. [44] and Lin et al. [4], which considered a modified effectiveness valuc, $\epsilon^{\prime}$, which could be calculated by Eq. (3.8). This equation is based on the previous effectiveness calculation method, but the minimum capacitance value in the denominator is replaced by the forced flow (collector) capacitance value.

$$
\epsilon^{\prime}=\frac{\dot{Q}}{\dot{Q}_{\max }}=\frac{\dot{m}_{\mathrm{s}} c_{p_{\mathrm{s}}}\left(T_{2}-T_{3}\right)}{\dot{m}_{\mathrm{c}} c_{p_{\mathrm{c}}}\left(T_{1}-T_{3}\right)}
$$


To implement this in TRNSYS, custom components were written and compiled in $\mathrm{C}++$ based on models that were previously developed at Queen's Lniversity in 2000 by Lin et al. [4]. Type 206 was created to model the natural convection flow rate through the compact heat exchanger based on a pressure drop characteristic determined by experimental tests, and Type 207 was created to calculate the effectiveness, heat transfer rate, and outlet temperatures of the natural convection heat exchanger.

The process for solving the natural convection flow rate in Type 206 begins by solving for the net hrdrostatic pressure difference in the heat exchanger, which is caused by the temperature-dependent buoyancy forces within the storage tank and heat exchanger. The expression for the pressure difference can be determined from Fig. 3.4, and is given in Eq. (3.9) [3].

$$
\Delta P_{\text {nyd }}{ }_{\text {hydrostatic }}=\rho_{\mathrm{s}} \cdot g \cdot H_{\mathrm{s}}-\rho_{\text {Pipe }} \cdot g \cdot H_{\text {Pipe }}-\rho_{\mathrm{HX}} \cdot g \cdot H_{\mathrm{HX}}
$$

where $\rho_{\mathrm{s}}$ is the mean density of water in the storage tank, $\rho_{\text {Pipe }}$ is the mean density of water in the pipe, $\rho_{\mathrm{HX}}$ is the mean density of water in the heat exchanger on the storage side, $g$ is the acceleration due to gravity, $H_{\mathrm{s}}$ is the height of the storage tank, $H_{\text {Pipe }}$ is the height of the pipe, and $H_{\mathrm{Hx}}$ is the height of the heat exchanger between the inlet and outlet. The height values for the storage tank, pipe and heat exchanger were measured as $1.35 \mathrm{~m}, 1.06 \mathrm{~m}$ and $0.29 \mathrm{~m}$, respectively.

The net hydrostatic pressure head can then be used to determine the natural convection flow rate, $\dot{m}_{\mathrm{s}}$, based on the following empirical correlation,

$$
\dot{m}_{\mathrm{s}}=a \cdot(\Delta P)^{b}
$$

where the cocfficients $a$ and $b$ were determined to be $2.388 \mathrm{~kg} / \mathrm{h}$ and 0.6505 , respectively [3]. As the system had not been used since the end of the previous study, the cmpirical coefficients were verified by performing numerous charge tests and applying 
a curve fit to the data. The results of this analysis demonstrated that the coefficients were representative of the data, and are presented in greater detail in Appendix B.

Once the natural convection flow rate is calculated by Type 206 according to Eq. (3.10), the flow rate is received as an input to Type 207 which calculates the modified capacitance ratio, $C_{r}^{\prime}$. and the modified cffectiveness, $\epsilon^{\prime}$, using another empirical correlation as shown in Eqs. (3.11) and (3.12),

$$
\begin{gathered}
C_{r}^{\prime}=\frac{\dot{m}_{\mathrm{s}} c_{p_{\mathrm{s}}}}{\dot{m}_{\mathrm{c}} c_{p_{\mathrm{c}}}} \\
c^{\prime}=c \cdot C_{r}^{\prime 2}+d \cdot C_{r}^{\prime}+e
\end{gathered}
$$

where the coefficients $c, d$ and $e$ were verified in Appendix B to be $-0.3488,1.1402$ and 0, respectively [3]. Rearranging Eq. (3.8), the actual rate of heat transfer for the natural convection heat exchanger is calculated according to Eq. (3.13).

$$
\dot{Q}=\epsilon^{\prime} \dot{m}_{\mathrm{c}} c_{p_{\mathrm{c}}}\left(T_{1}-T_{3}\right)
$$

Finally, the outlet temperatures of the heat exchanger on the collector side and storage side $\left(T_{4}\right.$ and $\left.T_{2}\right)$ can be found from Eq. (3.5).

\subsection{Modelling of Discharge Strategies}

Apart from the thermal energy storage component and the two natural convection heat exchanger components, the remainder of the TRNSYS model was created using standard forcing functions and equation blocks (which calculate output values based on simple mathematical expressions consisting of input values). Draw profiles were implemented using the forcing function, Type 14b. and an equation block specified a discharge flow rate of $11.4 \mathrm{~L} / \mathrm{min}$ as well as a constant mains water temperature based on the initial tank temperatures of the experimental tests. For constant temperature 
charging, an equation block was used to specify a constant temperature, $T_{c}$, equal to $55^{\circ} \mathrm{C}$. For the variable input power charge tests. the output power of a fixed orientation solar collector was simulated with a data reader, Type 9a, which read one column (collector output power) from an excel input file. The collector output power was calculated based on a sinusoidal curve with an amplitude of $6 \mathrm{~kW}$ and a period of 20 hours. The charge profile consisted of the first 10 hours of the sinusoidal curve (corresponding to the positive values) at 0.05 -hour (3-minute) intervals. The collector outlet temperature could then be obtained using the specified power output and the inlet temperature, which was the return temperature from the heat exchangers calculated in the previous time step. This is given in Eq. (3.14).

$$
T_{c, \text { out }}=T_{c, \text { in }}+\frac{\dot{Q}}{\dot{m}_{c} c_{p_{c}}}
$$

Lastly, Type $14 \mathrm{~h}$ was used as a forcing function to represent the collector loop flow rate, where a flow rate of $3 \mathrm{~L} / \mathrm{min}$ was output when the system was charging, and a flow rate of $0 \mathrm{~L} / \mathrm{min}$ was output during draws as well as during night-time periods (indicating that the pump and heaters had been shut off). Simulations were conducted at 0.01-hour (36-second) time steps, and a Type 25 printer was used to output the results to an excel file.

For the ammual simulations, the model was adapted by including additional components to simulate the performance of a solar collector and the charge loop. For a list of components which were added, refer to Section 6.4 .

In the following chapter, an overview of the experimental setup and test procedure will be presented. 


\section{Chapter 4}

\section{Experimental Approach}

\subsection{Introduction}

The focus of this study was to investigate different discharge strategies for a multitank thermal storage system developed at Queen's University in Kingston, Ontario, Canada. The setup was initially constructed, instrumented and commissioned at the Solar Calorimetry Lab for the purpose of evaluating the performance of a multi-tank system under a range of operating conditions. A previous study placed an emphasis on charging the system under two plumbing configurations, series and parallel, and consisted of both constant temperature and variable input power charge tests [3]. The previous study, however, did not consider realistic hourly draws from either fully charged or partially charged states. More importantly, simultaneous charging and discharging of the setup was not explored. Lastly, the study did not investigate the losses associated with nighttime standby periods.

As a continuation of the previous work, the current study investigated the performance of the multi-tank system under realistic draw profiles when subjected to a variable input power charge representative of the power output of a fixed-orientation solar collector. Initial tests consisted of constant temperature charging and constant 
volume draws in order to refine the numerical model, followed by an investigation of two-day (48-hour) realistic charge and draw profile scenarios. As an additional aspect to the study, the effects of nighttinne standby losses were examined for a period of 14 hours following the charging period of each day. For all test cases, three plumbing configurations were studied, including: (i) series charge and series discharge, (ii) parallel charge and parallel discharge, and (iii) series charge and parallel discharge.

\subsection{System Components}

The experimental setup consisted of a three-tank thermal storage system, with each storage tank equipped with a side-arm, natural convection heat exchanger ( $\mathrm{NCHE}$ ) to allow for individual charging. The system was plumbed such that the tanks could be charged or discharged in either a series or parallel configuration. Charging occurred in series beginning with Tank 1. During series draws, mains water entered the bottom of Tank 3, while the water in Tank 3 flowed from the top of the tank to the bottom of Tank 2, and from the top of Tank 2 to the bottom of Tank 1. In the parallel configuration. all three tanks were charged and discharged simultaneously (i.e., equal charge and draw rates across all three tanks). The experimental setup of the multitank apparatus is shown in Fig. 4.1.

The storage tanks were standard, commercially available electric hot water tanks with a volume of $270 \mathrm{~L}$ each, resulting in a total system capacity of $810 \mathrm{~L}$. The heating elements inside each tank were disabled, as the use of internal auxiliary heaters was not considered as part of this study. The heat exchangers were commercially available compact, brazed-plate units and were connected to the tanks via a thermosyphon loop. The loop permitted water to circulate by means of natural convection during charging, eliminating the need for an additional pump. Furthermore, the mains supply 


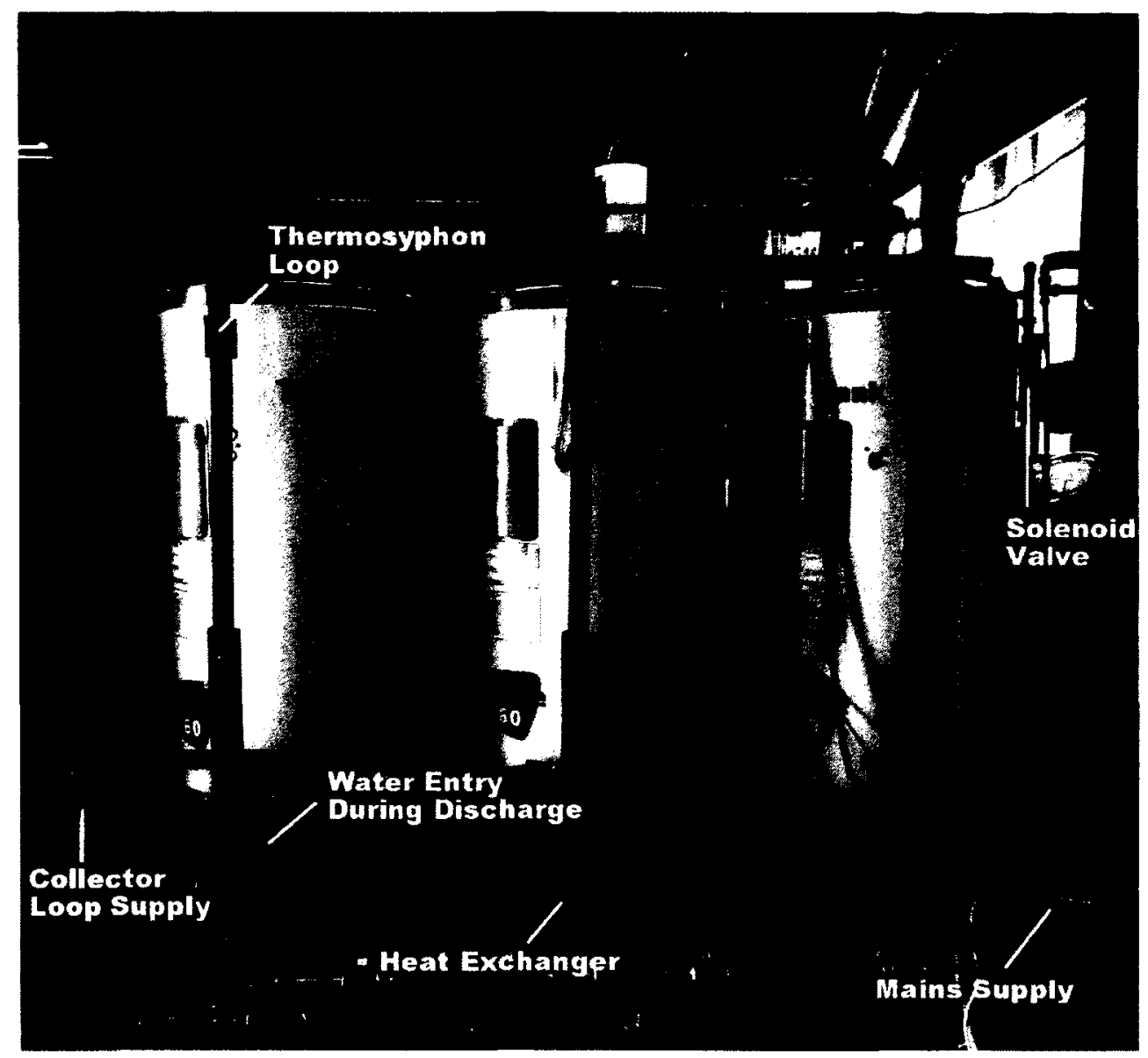

Figure 4.1: Multi-tank apparatus.

was connected to the thermosyphon loop above the heat exchanger as an anti-fouling measure. During draws, this would cause the mains water to flush through the heat exchanger before entering the bottom of the tank. This had the effect of removing any build-up in the water-side channels of the heat exchanger [45]. Specifications for the tanks and heat exchangers are given in Tables 4.1 and 4.2 , respectively.

Solar input was simulated through the use of two $3 \mathrm{~kW}$ electric heaters that maintained a constant temperature charge. The electric heaters were also capable of simulating a variable input power charge by means of a controller, which would vary the power output of the heater by relaying a voltage from the data acquisition (DA) 
Table 4.1: Specifications for storage tanks.

\begin{tabular}{ll}
\hline Parameter & Value \\
\hline Shape & Cylindrical \\
Volume & $270 \mathrm{~L}$ \\
Temperature Probe Height & $1.35 \mathrm{~m}$ \\
Outer Diameter & $0.55 \mathrm{~m}$ \\
Wall Material & Steel (glass lined) \\
Insulation Material & Fibreglass \\
Insulation Thickness & $0.05 \mathrm{~m}$ \\
Overall Tank Loss Coefficient & $5 \mathrm{~kJ} / \mathrm{h} \cdot \mathrm{m}^{2}{ }^{\circ} \mathrm{C}$ \\
\hline
\end{tabular}

Table 4.2: Specifications for heat exchangers.

\begin{tabular}{ll}
\hline Parameter & Value \\
\hline Type & Brazed-Plate \\
& $20(10$ channels on cold side, \\
Number of Plates & $0.29 \mathrm{~m}$ \\
Height & $0.396 \mathrm{~m}^{2}$ \\
Effective Heat Transfer Area & $160-220 \mathrm{~W} /{ }^{\circ} \mathrm{C}$ \\
Overall Heat Transfer & \\
Coefficient-Area Product & \\
\hline
\end{tabular}




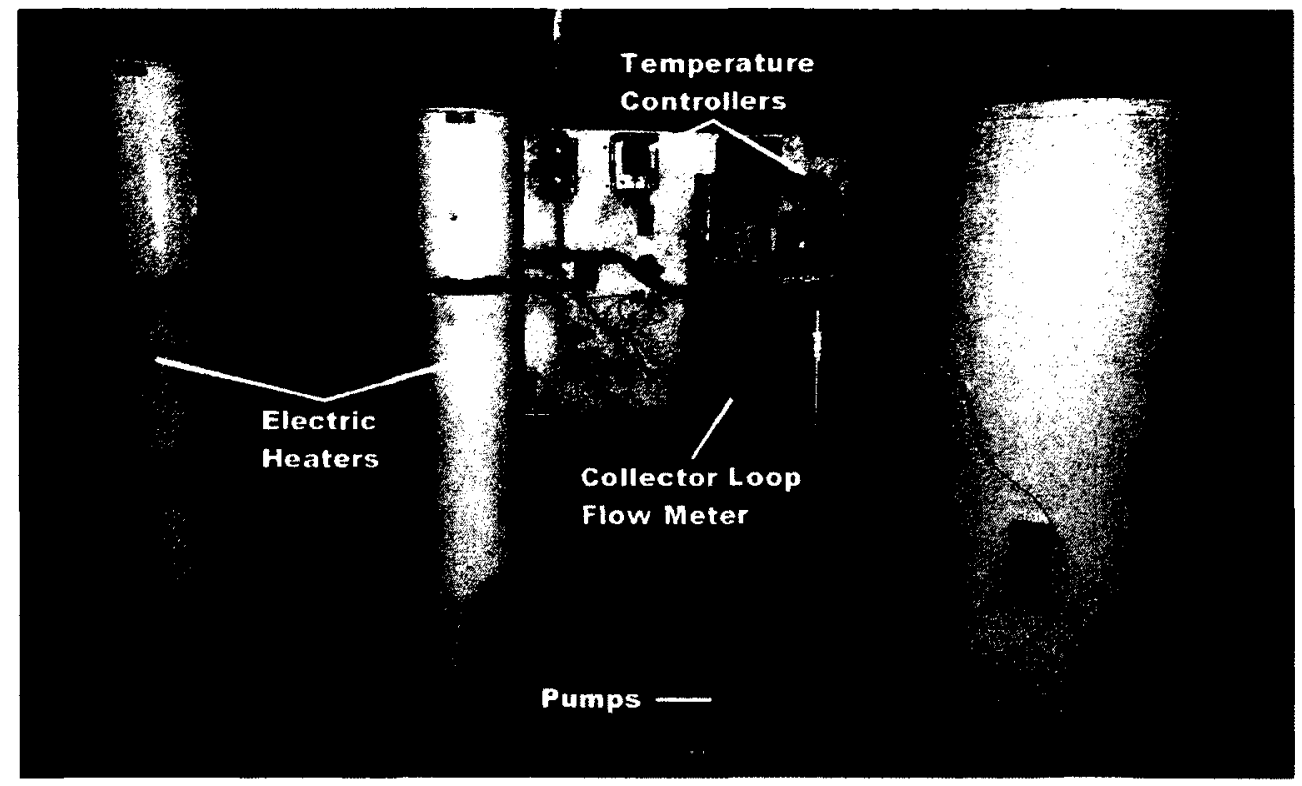

Figure 4.2: Solar simulator.

system between $0 \mathrm{~V}$ and $5 \mathrm{~V}$ (where a $5 \mathrm{~V}$ signal would cause one heater to output the maximum power of $3 \mathrm{~kW}$ ). The solar simulator is shown in Fig. 4.2.

\subsection{Instrumentation and Data Measurement}

A temperature probe consisting of 10 Type " $\mathrm{T}$ " thermocouples was inserted in each tank to record the temperature profile at $0.15 \mathrm{~m}$ intervals and to allow stratification levels to be determined. In addition, temperature measurements at the inlets and outlets of each heat exchanger were recorded. Thermocouple data was recorded by a computer based DA system and a custom National Instruments LabVIEW [46] program. which displayed the storage temperature profiles and heat exchanger temperatures in real-time. A schematic illustrating the placement of thermocouples is shown in Fig. 4.3, and a screenshot of the LabVIEW front panel is shown in Fig. 4.4. 


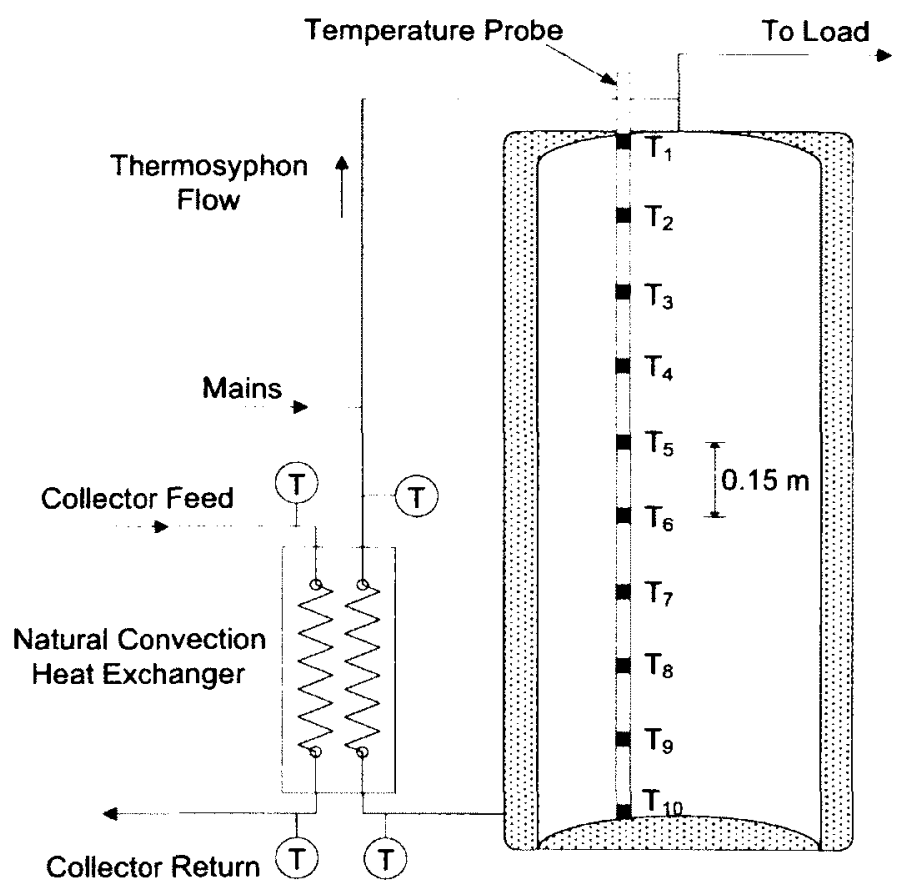

Figure 4.3: Schematic of temperature probe and thermocouple placement for each tank, adapted from [3].

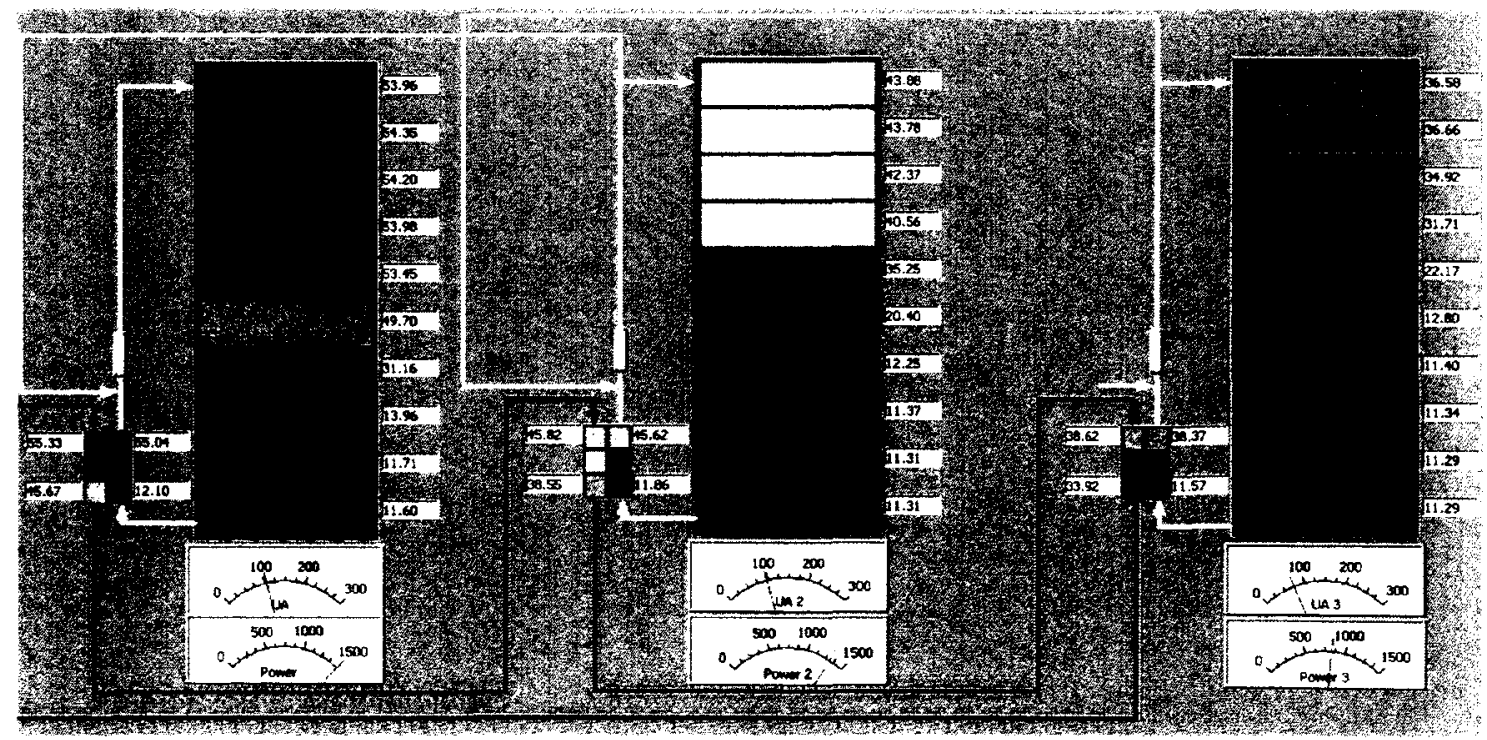

Figure 4.4: Screenshot from LabVIEW of a series charge test after 4 hours, with a charge loop flow rate of $3 \mathrm{~L} / \mathrm{min}$ and temperature set-point of $55^{\circ} \mathrm{C}$. 


\subsection{System Additions}

In order to automate scheduled draws, modifications to both the experimental setup and the LabVIEW program were made. The modifications included the addition of:

- one pressure regulating valve placed upstream from the flow meter in order to regulate the mains pressure passing through the flow meter (and subsequently entering the tanks);

- one plunger-type solenoid valve installed downstream from the storage tanks along the discharge line;

- one positive displacement flow meter installed along the mains line to record the flow rate of water entering (and thereby leaving) the system during draws;

- one circuit balancing valve installed upstream from the solenoid valve in order to maintain a constant draw flow rate of $11.4 \mathrm{~L} / \mathrm{min}$ :

- one check valve installed at the top of each tank to prevent water from circulating between storages;

- two Type $\mathrm{T}$ thermocouples to measure the mains and delivery water temperatures; and

- various LabVIEW routines to facilitate the draws.

Photographs of the added components are shown in Fig 4.5.

At the start of each scheduled draw, the DA system would transmit a $5 \mathrm{~V}$ signal to the solenoid to open the valve and allow hot water to flow from the tanks. During the draw, the DA system recorded the number of pulses received from the flow meter (with each pulse representing $0.0381644 \mathrm{~L}$ ), while LabVIEW calculated the cumulative volume of water which has entered the system. When the calculated volume reached the scheduled draw amount, the DA system would stop transmitting the $5 \mathrm{~V}$ signal 


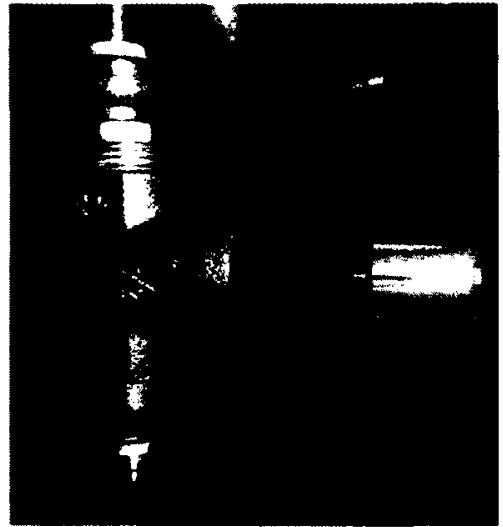

(a)

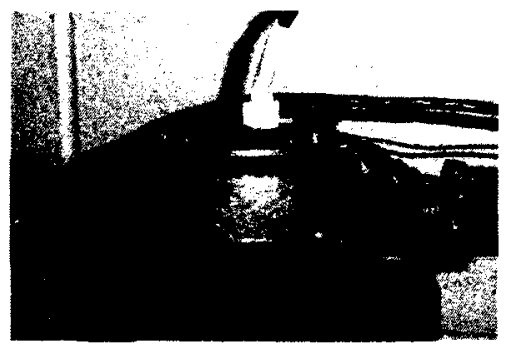

(c)

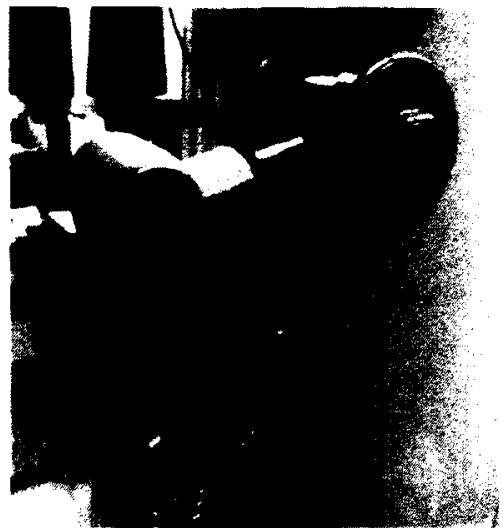

(b)

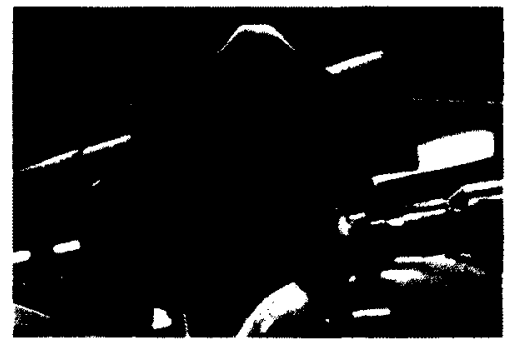

(d)

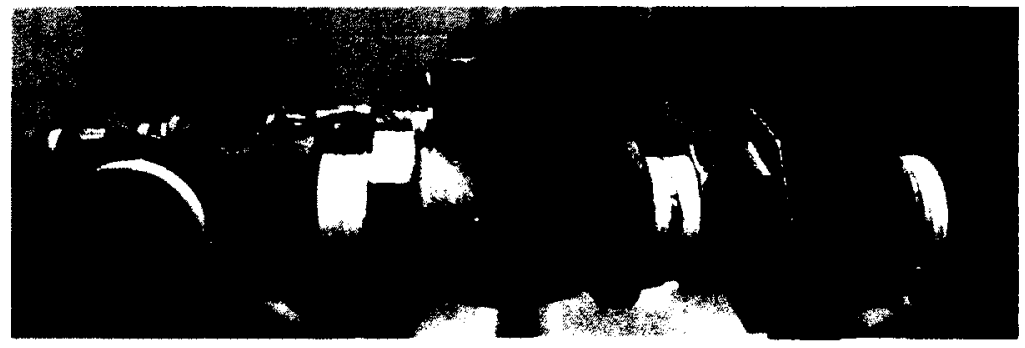

(e)

Figure 4.5: Photographs of the added system components: (a) one pressure regulating valve; (b) one solenoid valve; (c) one positive displacement flow meter: (d) one circuit balancing valve; and (e) three check valves. 
to the solenoid and the valve would close, terminating the draw. Calibration of the discharge flow rate and draw volumes are given in Appendix C.

The addition of check valves at the top of each tank was not necessary for performing draws, but was found to reduce mixing and exergy losses in the series charge and parallel discharge configuration. After preliminary testing of the system, it was observed that the three tanks would try to equalize their temperatures and pressures. This was a result of the first tank always having a higher degree of charge in the series charge configuration compared to the remaining two tanks. This is further discussed in Appendix D.

Apart from the experimental additions, a new LabVIEW routine was added to the program to enable computer controlled draws and display real-time temperature measurements for the incoming mains water and delivery water. The LabVIEW routine was programmed with draw profiles from the CSA-F379.1 Standard [32], but also allowed users to input a custom draw profile if desired. A screenshot of the draw routine is shown in Fig. 4.6.

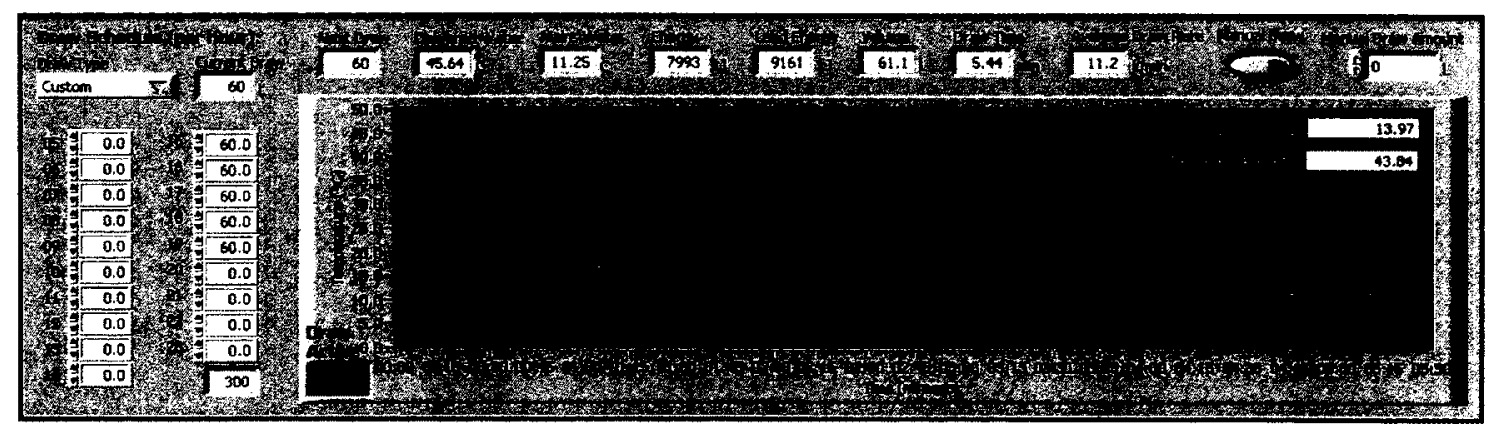

Figure 4.6: Screenshot of the added LabVIEW draw routine for a constant volume hourly discharge test with $60 \mathrm{~L}$ draws. 


\subsection{Test Method}

Constant temperature charge tests were performed to gain familiarity with the system and verify the empirical correlation for the natural convection heat exchanger model in TRNSYS. Tests were conducted for a charge flow rate of $3 \mathrm{~L} / \mathrm{min}$ and a temperature set-point of $55^{\circ} \mathrm{C}$. The temperature profile for a 24-hour charge test is presented in Chapter 5, and a comparison between the empirical correlation and experimental data is given in Appendix B.

Subsequent tests of the multi-tank system included constant temperature charging and constant volume discharging $[8,9]$, followed by variable input power charging and variable volume discharging [10]. Prior to starting each test, the three tanks were fully discharged for 1 hour, then mixed using a circulating pump for 30 minutes. This was done to ensure that the tanks were uniform in temperature with the mains supply.

\subsubsection{Constant Temperature Charge and Constant Volume Discharge Tests}

Following the constant temperature charge tests, constant volume hourly draws were incorporated to ensure that the added system components and draw routines performed as expected, and also to begin refining the numerical model. It was also necessary to perform these idealized test cases to establish a basis for comparing and understanding more complex test cases later on.

Six experimental tests were performed which looked at the thermal stratification in the tanks during the charge and draw sequences. For this analysis, three plumbing configurations were considered. The configurations studied were: series charge and series discharge; parallel charge and parallel discharge; and series charge and parallel discharge. 
The test parameters which were varied are given in Table 4.3. For each test, all three tanks were initially mixed to a uniform temperature of $11^{\circ} \mathrm{C}$, and were charged with a constant collector loop flow rate of $3 \mathrm{~L} / \mathrm{min}$ and a set-point temperature of $55^{\circ} \mathrm{C}$ for a total of 8 hours. The charge fluid consisted of a $50 \%$ propylene glycol and $50 \%$ water (by volume) mixture. Five draws were conducted at a flow rate of 11.4 L/min and were initiated at the beginning of each hour after the fourth hour inclusive (i.e., draws occurred at the start of Hours 4, 5, 6, 7 and 8). As each draw commenced, the collector flow was diverted around the heat exchangers and returned to the heaters. This procedure limited preheating of the mains supply as water flowed through the NCHE in a parallel flow direction with the charging fluid, before entering the bottom of the storage tank. Draws were terminated once the specified volume had been reached (either $60 \mathrm{~L}$ or $135 \mathrm{~L}$ ).

Table 4.3: Parameters for constant temperature charge and constant volume discharge tests.

\begin{tabular}{|c|c|c|c|c|c|c|}
\hline \multirow{2}{*}{ Test } & \multicolumn{2}{|c|}{ Charge Configuration $^{a}$} & \multicolumn{2}{|c|}{ Draw Configuration $^{b}$} & \multicolumn{2}{|c|}{ Draw Volume $^{b}(\mathrm{~L})$} \\
\hline & Series & Parallel & Series & Parallel & 60 & 135 \\
\hline 1 & $\bullet$ & & $\bullet$ & & $\bullet$ & \\
\hline 2 & & $\bullet$ & & $\bullet$ & - & \\
\hline 3 & $\bullet$ & & & - & $\bullet$ & \\
\hline 4 & - & & $\bullet$ & & & $\bullet$ \\
\hline 5 & & $\bullet$ & & $\bullet$ & & $\bullet$ \\
\hline 6 & - & & & $\bullet$ & & $\bullet$ \\
\hline
\end{tabular}




\subsubsection{Variable Input Power Charge and Variable Volume Discharge Tests}

In an effort to produce more realistic test scenarios, a study was conducted that considered variable input power charging and variable volume discharging. Three experimental tests were performed such that the thermal stratification within the tanks during the charge and draw sequences could be observed. The test parameters which were varied are given in Table 4.4 .

Table 4.4: Parameters for variable input power charge and variable volume discharge tests.

\begin{tabular}{|c|c|c|c|c|}
\hline \multirow{2}{*}{ Test } & \multicolumn{2}{|c|}{ Charge Configuration $^{a}$} & \multicolumn{2}{|c|}{ Draw Configuration $^{b}$} \\
\hline & Series & Parallel & Series & Parallel \\
\hline 7 & $\bullet$ & & $\bullet$ & \\
\hline 8 & & $\bullet$ & & - \\
\hline 9 & $\bullet$ & & & $\bullet$ \\
\hline
\end{tabular}

A similar methodology was used in conducting the tests as Section 4.5.1, with the exception that realistic charge and discharge profiles were used. In addition, the tanks were initially mixed to a uniform temperature of $12^{\circ} \mathrm{C}$ due to slightly higher mains temperature at the time of testing. Collector loop flow rates and discharge flow rates were unchanged.

The power input charge profile was based on a sinusoidal function, representative of a fixed solar collector oriented with an azimuth of zero. The profile assumed that the highest collector output occurred after 5 hours of charging, i.e., halfway through a 10-hour daily charge cycle, and the maximum output power was selected as $6 \mathrm{~kW}$ 
based on the available power from the two $3 \mathrm{~kW}$ electric heaters. After the 10-hour daily charge cycle, the circulating pumps for the collector loop were shut off overnight and standby losses within the tanks were observed for the duration of the day. At the start of the second day, identical charge and discharge profiles were re-initiated. The charge and draw schedules are illustrated in Fig. 4.7.

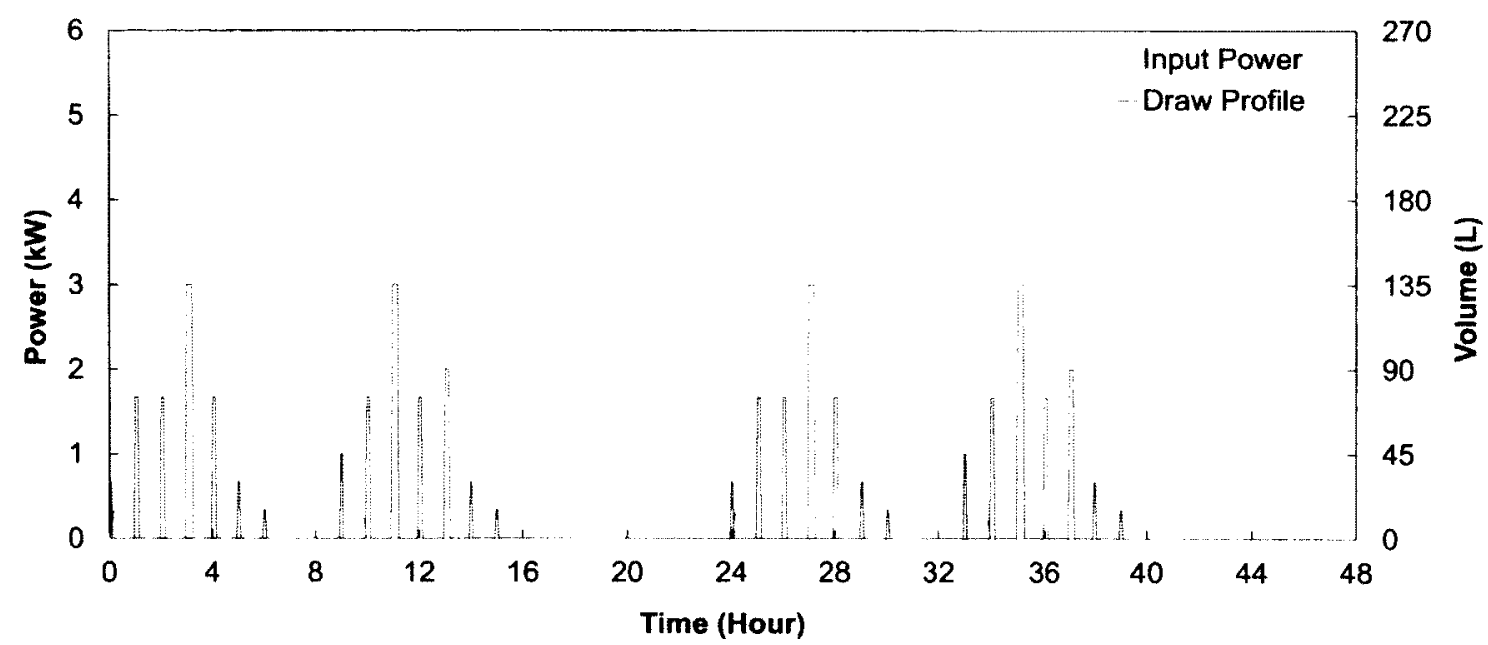

Figure 4.7: Solar radiation profile and draw schedule considered for the variable power charge and variable volume discharge tests.

Through preliminary TRNSYS simulations, it was found that after 2 days, the system had achieved steady state. In other words, the thermal behaviour of the tanks on the second day (between 24 and 48 hours) represented the daily temperature profile within the tanks which would be observed in subsequent days of testing assuming that the radiation profile and draw schedule were maintained. As a result, the length of experimental testing required in order to sufficiently predict the thermal behaviour of the system was selected as 2 days (48 hours), including nighttime standby periods.

Realistic draws were conducted through the charge sequence according to a modified CSA-F379.1 draw schedule [32]. Schedule C of the CSA Standard (300 L per day for 5 or more persons) was scaled to $900 \mathrm{~L}$ per day, since the multi-tank system consists of three individual $270 \mathrm{~L}$ storage tank. Furthermore, this type of draw 
profile may be representative of a multi-unit residential building with 15 or more occupants. Draws were initiated at the start of each hour according to Table 4.5, where the "Hour" column corresponds to the experimental and simulation time, and the "Time" column corresponds to the time of day. Both time scales are referred to interchangeably when discussing the test results in Chapters 5 and 6 .

Table 4.5: Modified CSA-F379.1 draw profile considered for the variable input power charge and variable volume discharge tests.

\begin{tabular}{ccc|ccc}
\hline & \multicolumn{2}{c|}{ Day 1 } & \multicolumn{3}{c}{ Day 2 } \\
Hour & Time & Draw Volume (L) & Hour & Time & Draw Volume (L) \\
\hline 0 & $07: 00$ & 30 & 24 & $07: 00$ & 30 \\
1 & $08: 00$ & 75 & 25 & $08: 00$ & 75 \\
2 & $09: 00$ & 75 & 26 & $09: 00$ & 75 \\
3 & $10: 00$ & 135 & 27 & $10: 00$ & 135 \\
4 & $11: 00$ & 75 & 28 & $11: 00$ & 75 \\
5 & $12: 00$ & 30 & 29 & $12: 00$ & 30 \\
6 & $13: 00$ & 15 & 30 & $13: 00$ & 15 \\
7 & $14: 00$ & 0 & 31 & $14: 00$ & 0 \\
8 & $15: 00$ & 0 & 32 & $15: 00$ & 0 \\
9 & $16: 00$ & 45 & 33 & $16: 00$ & 45 \\
10 & $17: 00$ & 75 & 34 & $17: 00$ & 75 \\
11 & $18: 00$ & 135 & 35 & $18: 00$ & 135 \\
12 & $19: 00$ & 75 & 36 & $19: 00$ & 75 \\
13 & $20: 00$ & 90 & 37 & $20: 00$ & 90 \\
14 & $21: 00$ & 30 & 38 & $21: 00$ & 30 \\
15 & $22: 00$ & 15 & 39 & $22: 00$ & 15 \\
\hline & TOTAL & 900 & & TOTAL & 900 \\
\hline
\end{tabular}


Experimental tests began at 07:00 (corresponding to Hour 0) and ended at 07:00 (Hour 48) two days later. Draws were conducted from Hours 0 to 15 on Day 1 (with the first draw of $30 \mathrm{~L}$ occurring at the start of the test. i.e., Hour 0). while charging occurred during Hours 0 to 10 (following the 10-hour daily charge profile, which began at 07:00 and ended at 17:00, with the peak solar output occurring at 12:00). In a similar fashion, draws were conducted from Hours 24 to 39 on Day 2, while charging occurred during Hours 24 to 34, using the same charge and discharge profiles as Day 1.

Chapter 5 will examine the results of both studies with respect to the thermal behaviour and stratification levels of the storage tanks. Following this, Chapter 6 will further discuss the results with respect to delivered energy, stored exergy values, as well as through annual simulation. 


\section{Chapter 5}

\section{Experimental and Simulation Results}

\subsection{Introduction}

In Chapter 3, the mathematical models used by TRNSYS to predict the performance of the thermal energy storage and natural convection heat exchangers were discussed, and the simulation models were presented. Following this, Chapter 4 discussed the experimental setup and the test method for two test scenarios, constant temperature charging with constant volume draws, and variable input power charging with variable volume draws. Within these tests, three different combinations of charge and discharge plumbing configurations were explored: charging in series and discharging in series, charging in parallel and discharging in parallel. and finally, charging in series and discharging in parallel. The results of the experimental and simulation analysis are presented in this chapter. 


\subsection{Preliminary Charge Tests}

Constant temperature charge tests were initially performed in order to characterize the performance of the natural convection heat exchanger and to verify the accuracy of the numerical model under charging conditions. Tests were conducted in both serics and parallel configurations for collector-loop flow rates of $3 \mathrm{~L} / \mathrm{min}$ and a charge temperature of $55^{\circ} \mathrm{C}$. A sample temperature profile is shown in Fig. 5.1 for a series charge test with an initial tank temperature of $16.5^{\circ} \mathrm{C}$. Each black line in the figure corresponds to a set of temperature data recorded by one of the ten equally spaced thermocouples (instrumentation of the system is discussed in greater detail in Section 4.3). The uncertainty associated with the tank thermocouple measurements was $\pm 1.0^{\circ} \mathrm{C}$ according to the ASME PTC 19.3-1974 Standard for Type T thermocouples [47]. Additional uncertainty and calibration information is presented in Appendix C.

The temperature profile shown in Fig. 5.1 illustrates that in the initial moments of charging, hot water was deposited at the top of the tank from the thermosyphon loop, resulting in a temperature increase at the top thermocouple. As charging continued, the remaining thermocouples began showing an increase in temperature as the temperature layers (i.e., thermoclines) moved downward.

Experimental and simulation results for Tank 1 of the series charge test are compared in Fig. 5.2. An identical model to the one presented in Fig. 3.1 was used with the discharge components removed. The black lines in Fig. 5.2 correspond to the thermocouple measurements as before, while the red lines correspond to the output data from the TRNSYS model. Figure 5.3 shows the size and location of each node in the TRNSYS tank model relative to the placement of thermocouples in the experimental setup, and the nodes highlighted in blue correspond to the plotted data. 

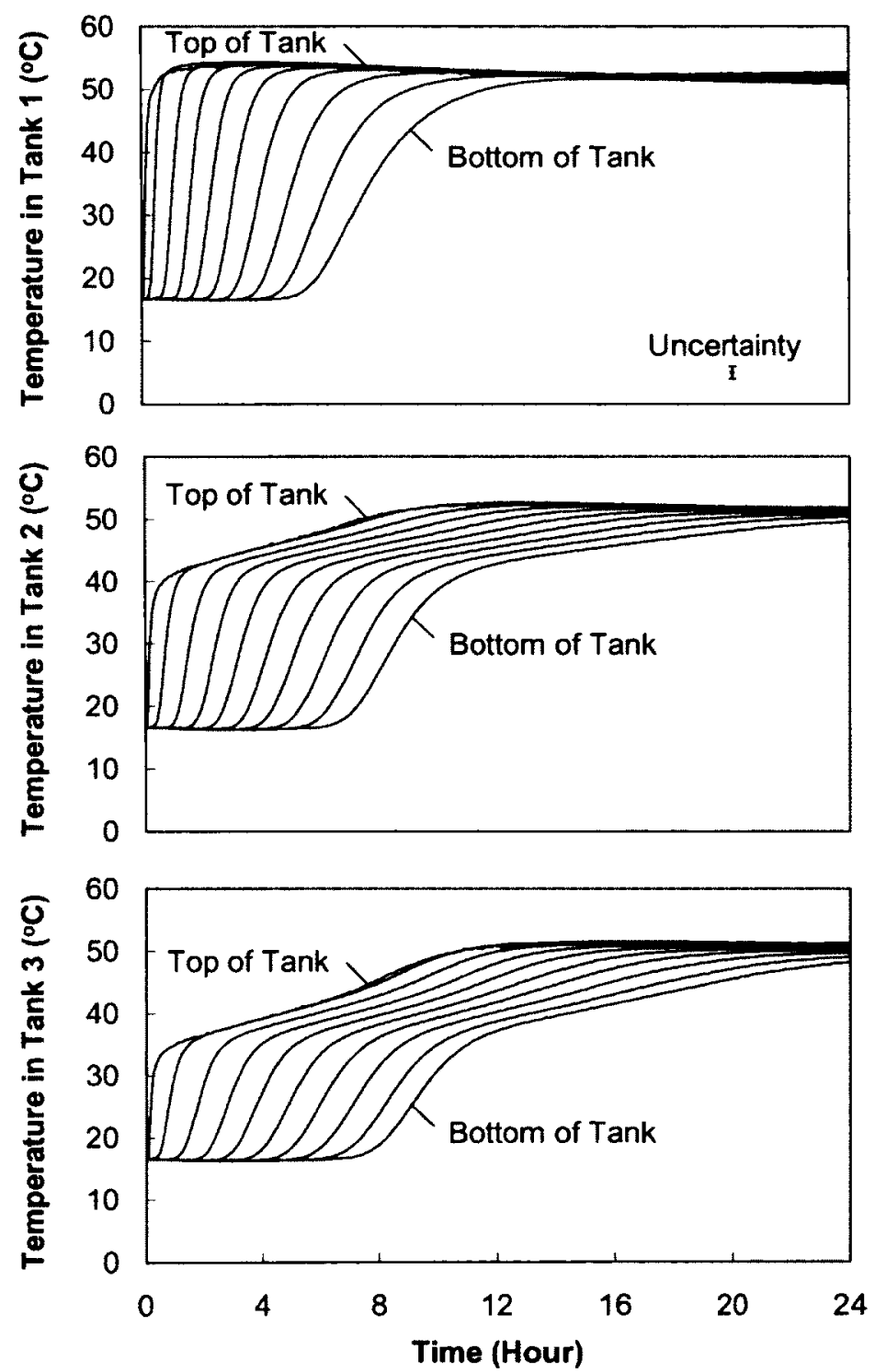

Figure 5.1: Experimental temperature profile of the series charge configuration with a collector loop flow rate of $3 \mathrm{~L} / \mathrm{min}$, initial tank temperature of $16.5^{\circ} \mathrm{C}$, and collector outlet temperature (charge temperature) set-point of $55^{\circ} \mathrm{C}$. 


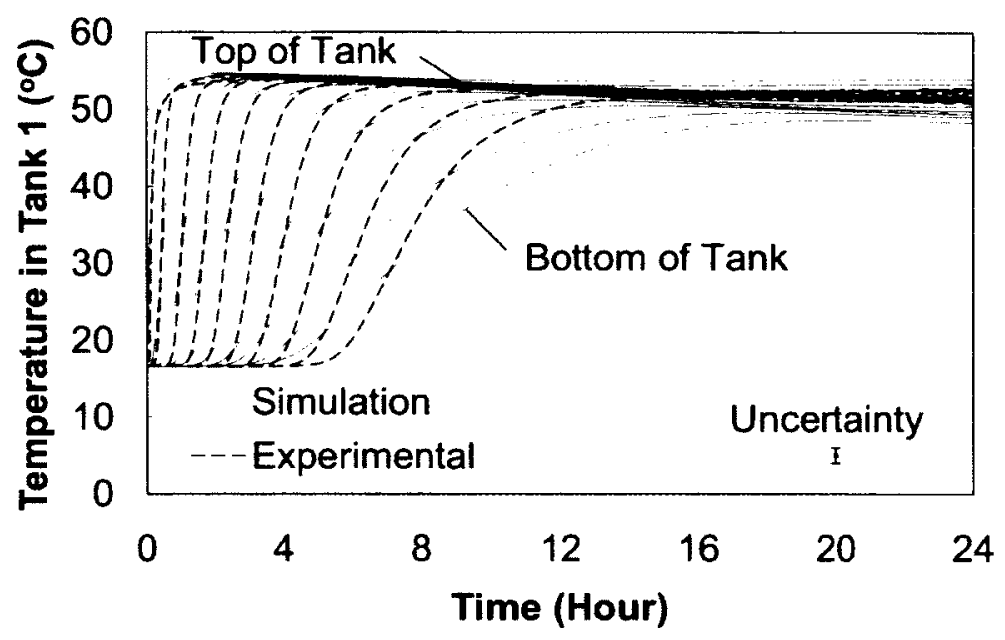

Figure 5.2: Comparison of experimental and simulation temperature profiles (shown in black and red, respectively) for Tank 1 of the series charge configuration.
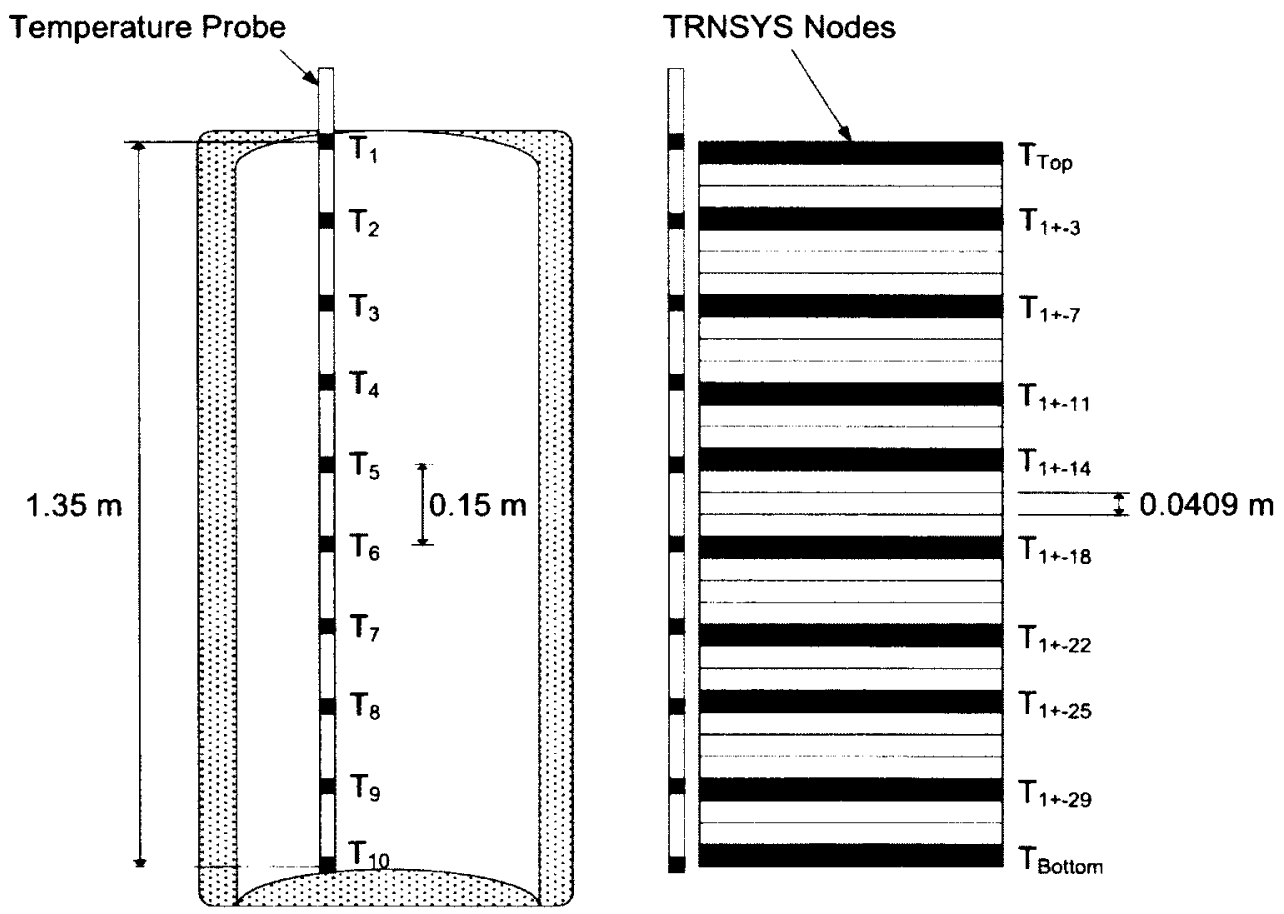

Figure 5.3: Comparison between experimental thermocouple positions and TRNSYS node positions. 
For the series charge test, it was observed that the model accurately predicted the temperature profile at the top of the tank, but deviated from the experimental data in regions of high temperature gradients and as the nodes moved closer towards the bottom of the tank. In a similar study, Newton [41] modelled a single tank being charged, with cold water being withdrawn from the bottom of the tank and hot water being deposited at the top. Experimental results produced by Zurigat et al. [48] were compared against a 15 node model and a 50 node model using the Type 60 component. In both cases, a similar discrepancy as the one shown in Fig. 5.2 was observed. Newton concluded that choosing too few nodes can introduce a considerable amount of error when the tank is being charged (or discharged), and that the fewer the number of nodes used, the more mixing is assumed to occur in the tank. Based on the conclusions of Newton's study, the discrepancy between the experimental and simulation results of this study were similarly attributed to the number of nodes used in the TRNSYS model.

Cruickshank [3] also investigated the effects of varying node numbers in the Type 60 component on the temperature profile of a single tank. The sensitivity analysis consisted of a comparison of temperature profiles for 1 node, 3 nodes, 5 nodes, 15 nodes, 30 nodes and 60 nodes for a single tank being charged with an external natural convection heat exchanger. The results indicated that the accuracy of the temperature profile improved as the number of nodes increased, which agreed with the conclusions of Newton's study. Furthermore, an additional study by Cruickshank [49] examined the effects of varying node numbers on the energy storage values of a single tank in the parallel charge configuration. The results indicated that the predicted energy transfer to the tank depended on the number of nodes, and that the error was less than $1 \%$ relative to the 60 node case when more than 10 nodes were used. 
After verifying that the temperature profiles were modelled as accurately as possible using Type 60, a combination of constant temperature charging with scheduled, constant volume, hourly draws were investigated before looking at more complex. realistic scenarios.

\subsection{Constant Temperature Charge and Constant Volume Discharge Tests}

As a baseline case, six experimental tests (Tests $1-6$ ) were conducted which examined the effects of constant volume discharging on a partially charged system. For each test, all three tanks were initially mixed to a uniform temperature of $11^{\circ} \mathrm{C}$, and were charged with a constant collector flow rate of $3 \mathrm{~L} / \mathrm{min}$ and a set-point temperature of $55^{\circ} \mathrm{C}$ for 8 hours. Five draws were conducted at a flow rate of $11.4 \mathrm{~L} / \mathrm{min}$ and were initiated at the beginning of each hour after the fourth hour. For each of the three plumbing configurations investigated, two different hourly draw volumes were considered, $60 \mathrm{~L}$ draws and $135 \mathrm{~L}$ draws. These volumes were taken from the modified CSA draw profile given by Table 4.5, and represent roughly $25 \%$ and $50 \%$ of the storage volume of a single $270 \mathrm{~L}$ tank, respectively. In addition, draws were chosen to begin after 4 hours of charging to ensure that roughly half of the total storage volume had been charged (e.g., Fig. 4.4 shows a sample temperature distribution after 4 hours of charging in series). A summary of the parameters for Tests $1-6$ is given in Table 4.3.

The following sections will focus on the results of Tests $4-6$ which consisted of $135 \mathrm{~L}$ draws, as the $60 \mathrm{~L}$ draw tests experienced similar trends. Refer to Appendix E for the temperature profiles of Tests $1-3$. 


\subsubsection{Series Charge and Series Discharge}

Tests 1 and 4 corresponds to the series charge and series discharge configurations with $60 \mathrm{~L}$ and $135 \mathrm{~L}$ draws, respectively. During these tests, it was observed that charging in series resulted in sequentially stratified tanks (i.e., Tank 1 was charged first, followed by Tank 2, then Tank 3). As a result, Tank 1 received the largest amount of energy from the charge loop, and subsequently stored the hottest water compared to the other tanks. Tank 1 was also the source of hot water during discharging. When discharging in series, some mixing was observed at the bottom of 'Tanks 1 and 2 due to the temperature differences with Tanks 2 and 3, respectively. This was caused by hot water from the top of the downstream tanks flowing into the bottom of the upstream tanks during draws, resulting in some mixing at the bottom of the tanks (e.g., water from the top of Tank 2 flowed into the bottom of Tank 1). Experimental and simulated temperature profiles are compared in Fig. 5.4 for Test 4, with superimposed results presented in Fig. 5.5 for every second thermocouple and node.

Figures 5.4 and 5.5 demonstrate that the experimental and simulation results correspond well for both tests, and illustrate the thermal behaviour of the tanks (i.e., stratification) during the charging and discharging sequences. In addition to comparing the experimental and simulation results graphically, an error analysis was conducted to quantify the temperature difference between results and is presented in Appendix F. For Test 4, the error in experimental and simulation results was found to be $\pm 5.45^{\circ} \mathrm{C}$ for Tank $1, \pm 3.90^{\circ} \mathrm{C}$ for Tank 2 , and $\pm 3.65^{\circ} \mathrm{C}$ for Tank 3 , assuming a $95 \%$ confidence level. 

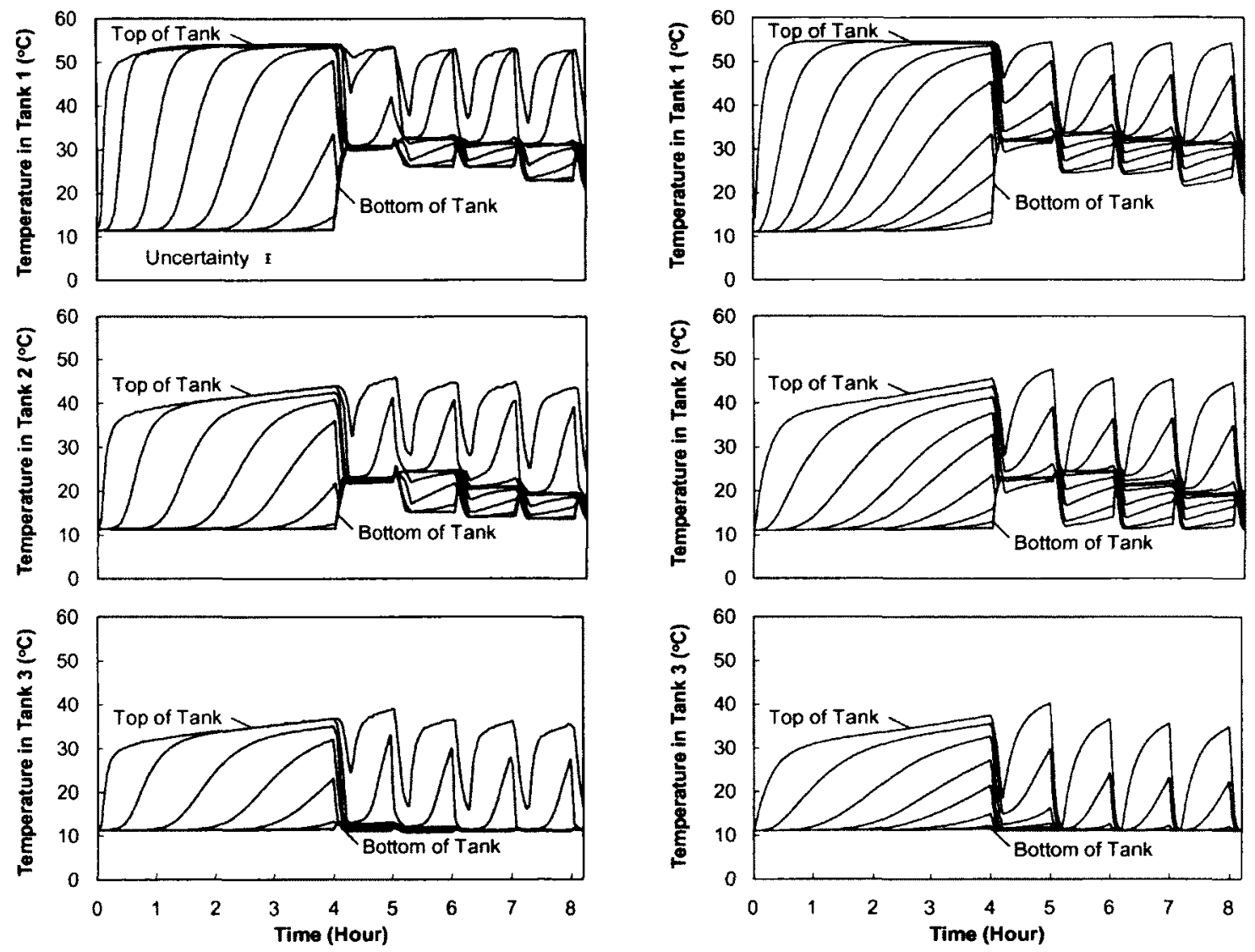

(a) Experimental Results.

(b) Simulation Results.

Figure 5.4: Experimental and simulation results for Test 4, series charge and series discharge, $135 \mathrm{~L}$ draws. 

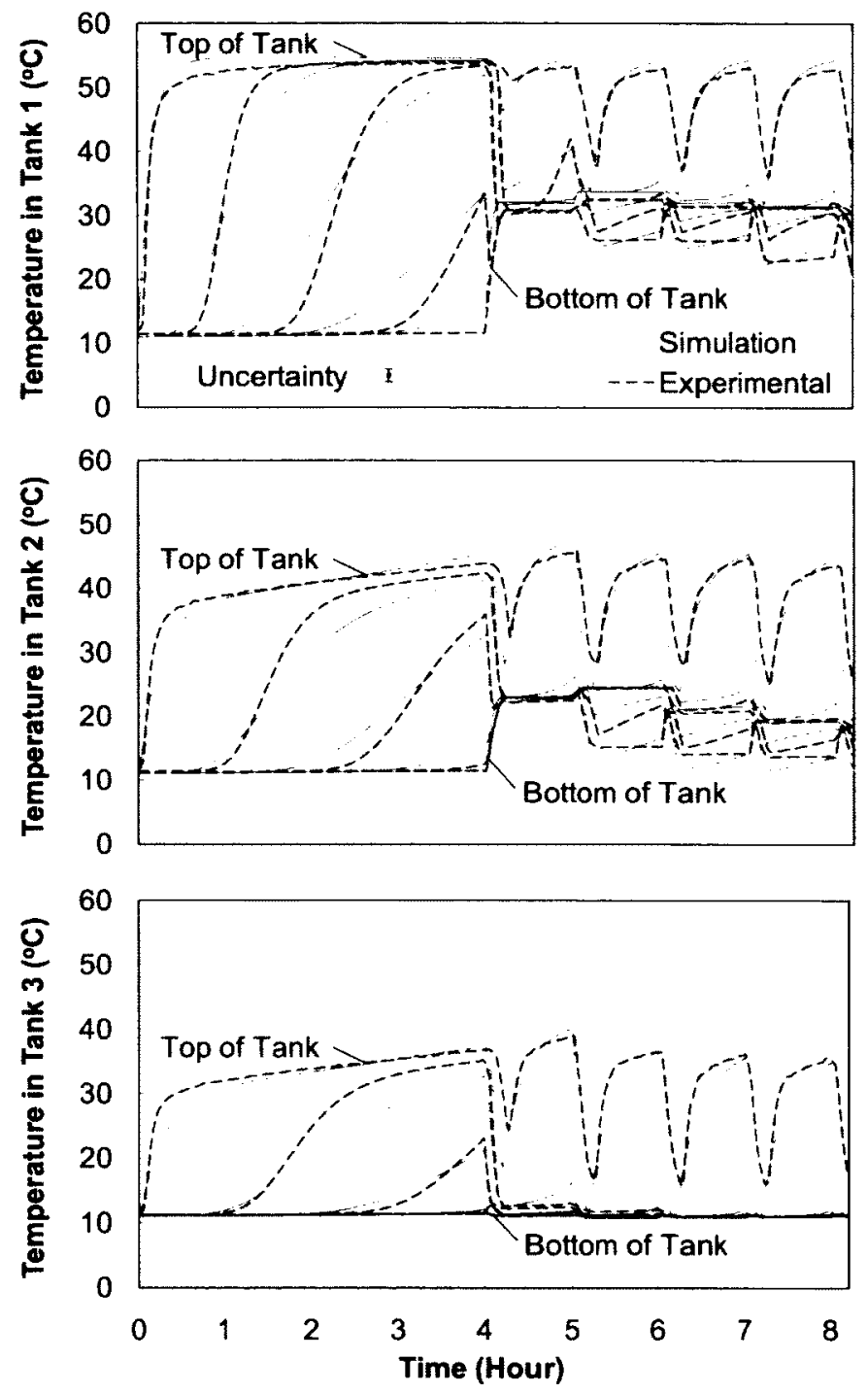

Figure 5.5: Comparison between every second thermocouple and node for Test 4 , series charge and series discharge, $135 \mathrm{~L}$ draws. 
When comparing the top tank temperature at the end of each draw (e.g., Hour 4 , 5, 6, 7 and 8), lower temperatures were predicted in the TRNSYS model compared to experimental results. This was a result of the limitation in the number of nodes allowed by Type 60. Since each tank was limited to 33 nodes, and the node volumes were uniform in temperature, the model assumed that more mixing occurred in the tank. Therefore, a higher predicted amount of mixing would correspond to lower predicted temperatures at the end of each draw.

Another discrepancy can be seen in the simulation results along the bottom tank temperatures for Tanks 1 and 2 after draws had commenced. As a result of the TRNSYS model overpredicting the amount of mixing at the top of the tanks, the temperature of water flowing into the bottom of Tanks 1 and 2 from the downstream tanks were slightly cooler than experimentally observed. Secondly, the mains supply, as well as the connections between Tanks 1 and 2, and Tanks 2 and 3, were introduced into the thermosyphon loop above the heat exchanger in the experimental setup. This configuration was not modelled in the TRNSYS simulation, which assumed the mains supply and the water exiting the top of the downstream tanks immediately entered the bottom of the upstream tanks. As a result, the model didn't account for any heat transfer that would have taken place across the heat exchanger during draws. This heat transfer was reduced experimentally by diverting the charge flow around the heat exchangers, however. the charge fluid trapped inside the heat exchanger was observed to fall in temperature during the draw, implying some preheating of the water entering the bottom of the tanks. This is shown in Fig. 5.5, where the simulation results predicted lower temperatures at the bottom of the tank immediately after a draw has commenced. Despite these modelling limitations, the charging and discharging trends were still well represented by the TRNSYS model. 
Comparing the experimental results for Tests 1 and 4 , it was observed that the volume of water being drawn each hour had a significant impact on the amount of mixing that occurred. For Test 4 , recurring draws at volumes of $135 \mathrm{~L}$ resulted in significantly lower tank temperatures and more mixing compared to Test 1 with $60 \mathrm{~L}$ draws. Additionally, neither test was able to maintain a constant delivery temperature for the duration of the test, as shown by the significant drop in temperature at the top of Tank 1 during each subsequent draw. Delivery temperature and delivered energy is discussed further in Chapter 6.

\subsubsection{Parallel Charge and Parallel Discharge}

For the parallel charge and parallel discharge tests, multiple attempts were made to achieve a balanced flow distribution through the heat exchangers during charging for the entire test period of Tests 2 and 5. The experimental and simulation results for Tests 5 are shown in Fig. 5.6, and demonstrate that the third tank charged at a slightly slower rate than the first two tanks in both cases. The unpredictable nature of achieving a balanced flow along the charge loop in this arrangement may lead to significant losses in performance over time if not corrected, and are further discussed in Chapter 6.

Comparing Tests 2 and 5 . similar temperature profiles in the three tanks were observed, and demonstrated that the three tanks charged nearly simultaneously. One difference between the tests was in the magnitude of temperature drops associated with each draw as expected (i.e., lower temperatures were present in Test 5 as larger volumes of water were drawn). In both cases, however, a high degree of stratification was maintained and, as shown in Fig. 5.6, there was a good agreement between the experimental and simulation results. The simulation results predicted that all three tanks would charge at an identical rate, but as discussed, this was not achieved. 

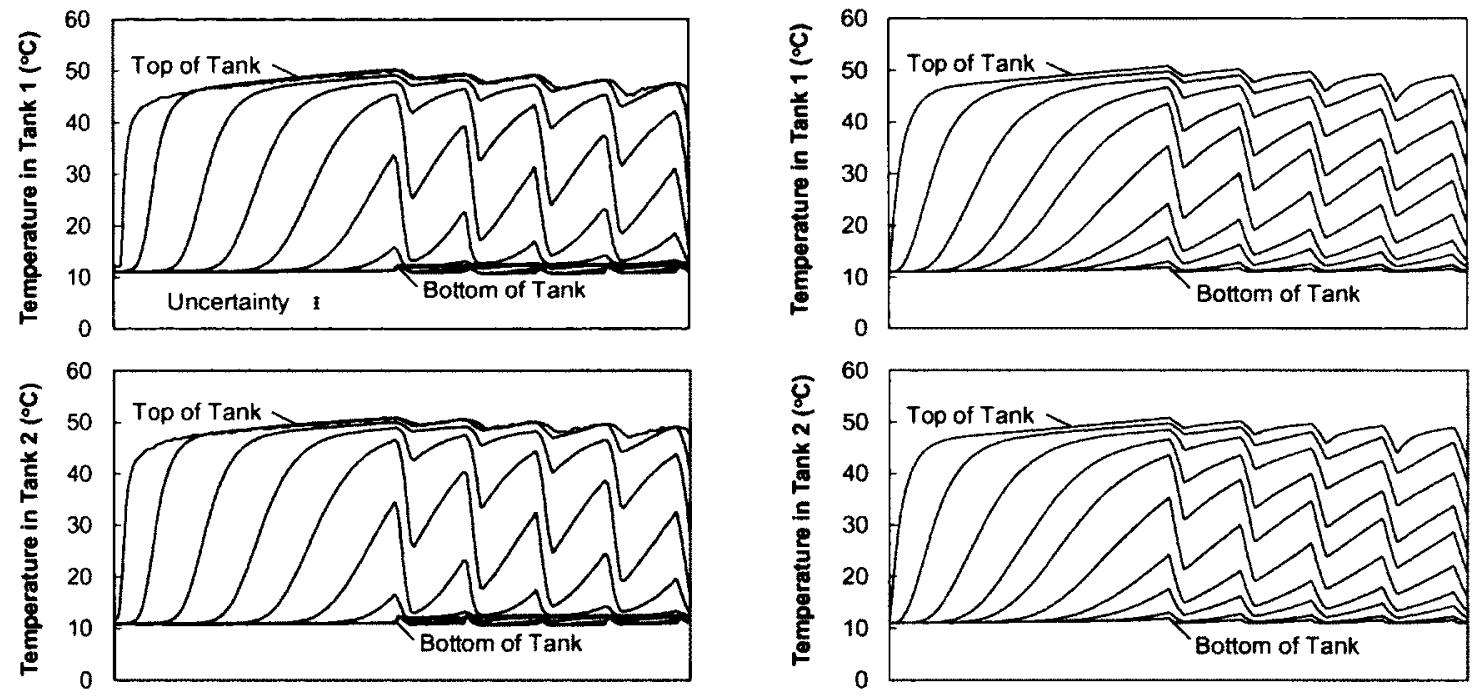

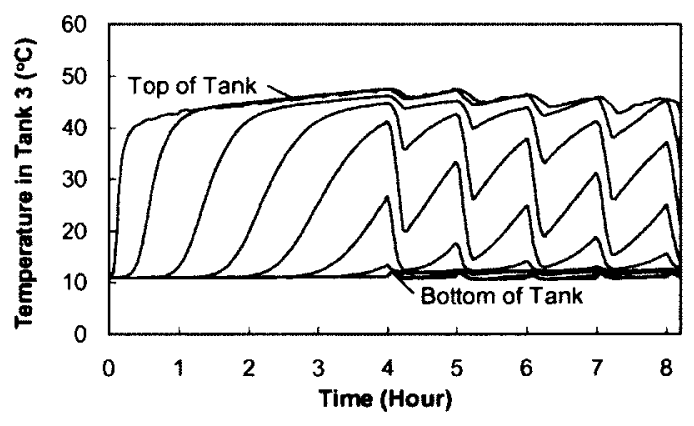

(a) Experimental Results.

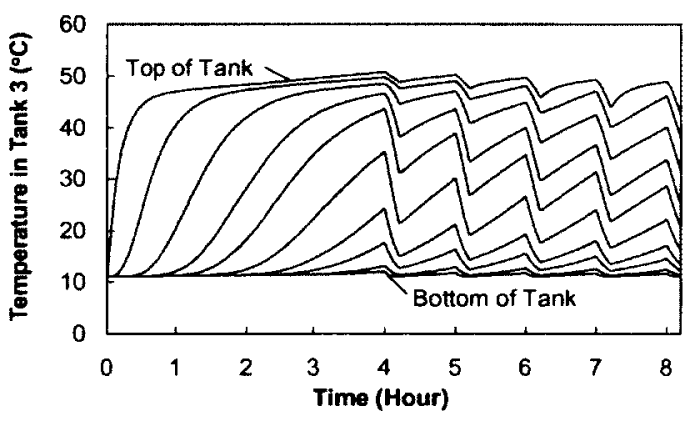

(b) Simulation Results.

Figure 5.6: Experimental and simulation results for Test 5, parallel charge and parallel discharge, $135 \mathrm{~L}$ draws. 
When comparing the experimental tank temperatures between Tests 4 and 5 for $135 \mathrm{~L}$ draws (Figs. 5.4 and 5.6), it was observed that the first tank in the series configuration (which was the source of delivery water) charged more quickly and reached slightly higher temperatures than those achieved in the tanks in the parallel charge configuration. This was a result of more heat transfer occurring across the first heat exchanger before sequentially charging the remaining two downstream tanks in the series configuration. The branched arrangement in the parallel configuration charged all three tanks simultaneously, but had the drawback of a lower charge flow rate passing through each heat exchanger (roughly equal to one third the value coming from the heaters). Comparisons between the experimental data and the empirical correlations are presented in Appendix B for Test 5, showing the first 4 hours of charge data for the parallel configuration.

\subsubsection{Series Charge and Parallel Discharge}

Combining the advantages of charging the system in series and discharging in parallel, the series charge and parallel discharge configuration was investigated in Tests 3 and 6. The purpose of this test was to determine whether the benefits of sequential stratification could be applied to discharging in parallel, while eliminating the mixing which occurred at the bottom of Tanks 1 and 2 in the series discharge configuration. The experimental and simulation results for Test 6 are shown in Fig. 5.7. Both sets of experimental and simulation results correspond well during the charge and discharge periods.

Similar to the previous results for Tests 1 and 4, charging in series demonstrated sequential stratification across the three tanks, while discharging in parallel maintained a high degree of stratification within each tank (as demonstrated by Tests 2 and 5). By charging in series, Tank 1 reached the set-point temperature more quickly 

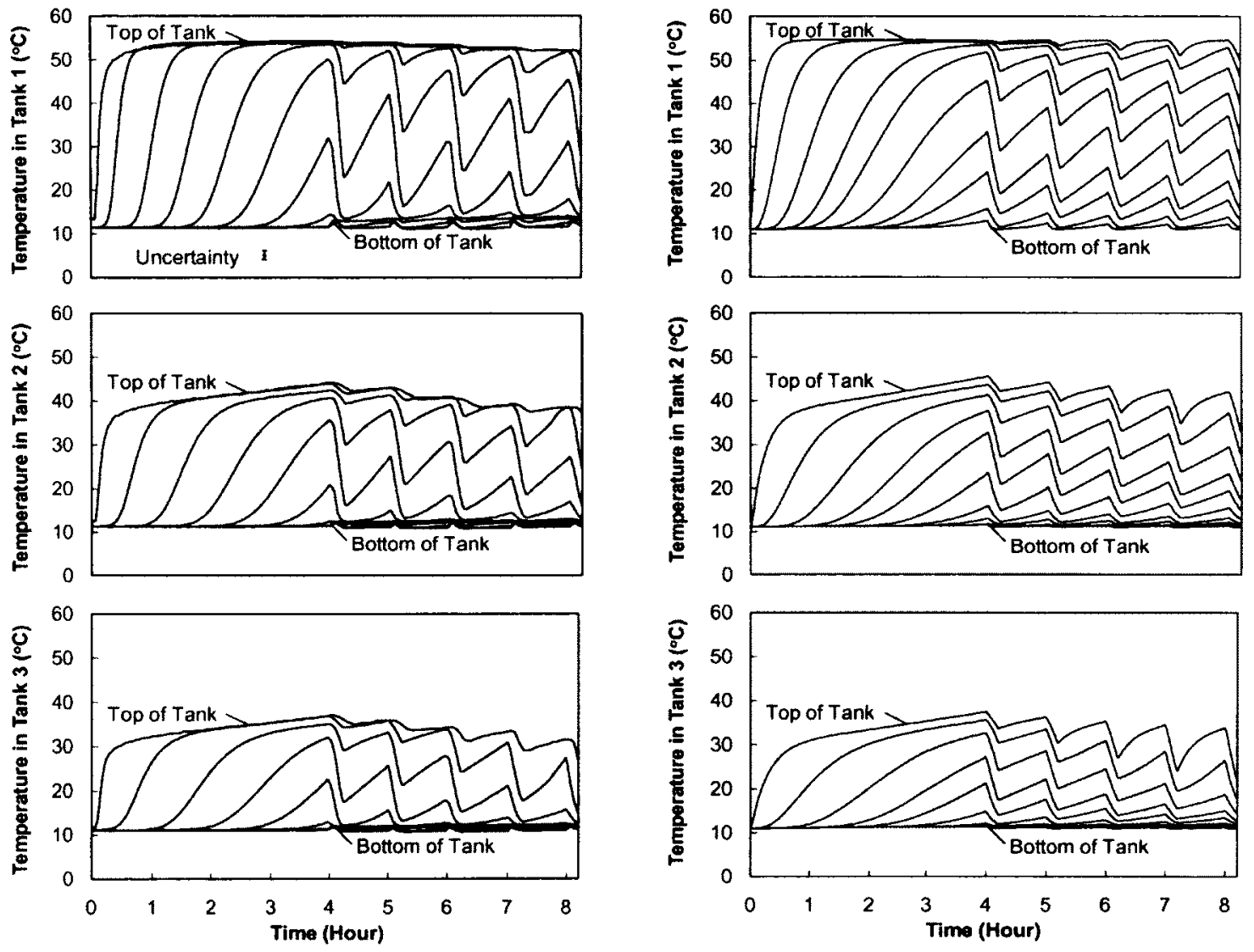

(a) Experimental Results.

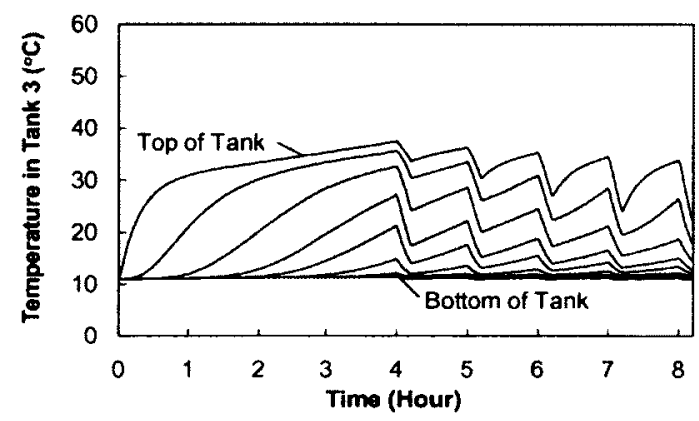

(b) Simulation Results.

Figure 5.7: Experimental and simulation results for Test 6, series charge and parallel discharge, $135 \mathrm{~L}$ draws. 
due to the higher charge flow rate compared to charging in parallel, and did not experience the high degree of mixing at the bottom of Tanks 1 and 2 as observed when discharging in series. One drawback for this arrangement, when compared to the parallel charge and parallel discharge configuration, were lower delivery temperatures during draws. Equal volumes of water were drawn from the top of each tank in the parallel discharge configuration. resulting in mixing between the hot water from Tank 1 and cool water from downstream tanks. This is further discussed in Section 6.2.

\subsection{Variable Input Power Charge and Variable Volume Discharge Tests}

In an effort to produce more realistic test scenarios, another study was conducted which considered variable input power charging and variable volume discharging. Three experimental tests (Tests 7 - 9) were performed such that the thermal stratification within the tanks during the charge and draw sequences could be observed. Tests were conducted over a period of 2 days, with all three tanks initially mixed to a uniform temperature of $12^{\circ} \mathrm{C}$. The charge sequence consisted of a constant collector flow rate of $3 \mathrm{~L} / \mathrm{min}$ and a power input charge profile based on a sinusoidal function. Realistic hot water draws were conducted through the charge sequence according to the $900 \mathrm{~L}$ per day draw profile given in Table 4.5. A summary of the parameters for Tests $7-9$ is given in Table 4.4 .

In addition to observing the thermal behaviour of the system as a result of charging and discharging, nighttime standby losses were also examined. After the 10-hour daily charge cycle for each day, the circulating pumps for the charge loop were shut off and the data acquisition system continued recording temperature measurements at 3-minute intervals. 


\subsubsection{Series Charge and Series Discharge}

The experimental and simulated results for the series charge and series discharge configuration (Test 7) are shown in Fig. 5.8. The experimental and simulation results correspond well, both showing the thermal behaviour of the tanks (i.e., stratification) during the charging and discharging sequences.

The results demonstrated that sequential stratification was achieved in the series charge configuration as before. During periods of falling charge loop temperatures, mixing occurred at the top of each tank as cooler water was deposited from the thermosyphon loop. This effect was reduced for the downstream tanks (Tanks 2 and 3), since they were charged to a lesser extent than the first tank and experienced less destratification due to their lower temperatures. Tank 1 experienced the most destratification at the top of the tank, as shown by the convergence of the thermocouple (and node) temperatures starting at Hour 6. During the same time periods, Tanks 2 and 3 continued to be charged by the collector loop up until Hour 9 .

As the charge loop temperature dropped below the average temperature of Tank 1 , water from the storage tank began transferring heat to the charge loop in the heat exchanger. This caused a negative net hydrostatic pressure difference, and resulted in a "reverse thermosyphon flow", where the flow on the storage side of the heat exchanger reversed direction. In the TRNSYS model, this wasn't properly represented since the natural convection heat exchanger assumed that the pressure drop was always positive (i.e., greater than zero). Under reverse flow conditions, the pressure drop becomes negative. As a result, the TRNSYS component treated the pressure drop as being zero. resulting in a natural convection flow rate of zero as well. Although energy was gained by the charge loop (from Tank 1) in the series charge configuration, the energy was later transferred to the next downstream storage tank that was at a lower temperature. In addition, discharging in series produced the same amount of 
mixing at the bottom of each tank as was observed in the constant volume discharge tests. The resulting warm temperatures at the bottom of Tank 1 were also a factor in causing the reverse thermosyphon flow.

\subsubsection{Parallel Charge and Parallel Discharge}

The experimental and simulation data for the parallel charge and parallel discharge configuration (Test 8) are plotted in Fig. 5.9. In the parallel charge configuration, all three tanks were charged simultaneously, as opposed to the sequential charge achieved in the series charge configuration. Consequently, falling collector outlet temperatures led to destratification at the top of all three tanks as cooler water was deposited from the thermosyphon loop (e.g., Hour 6). In addition, a high degree of stratification in each tank was maintained by discharging in parallel. One of the advantages to maintaining stratification in each tank (compared to having a sequentially stratified system), was that the bottom tank temperature was maintained at the mains temperature. When combined with variable input power charging, this ensured that cold water was withdrawn from the bottom of the tank for charging. As the charge temperature began to fall, the effects of reverse thermosyphon flows were reduced compared to Tank 1 of the series charge and series discharge configuration due to the lower overall tank temperatures.

\subsubsection{Series Charge and Parallel Discharge}

The experimental and simulation data plotted in Fig. 5.10 for the series charge and parallel discharge configuration (Test 9) demonstrate that there is a close agreement between the results. Charging the system in series resulted in the same sequential 

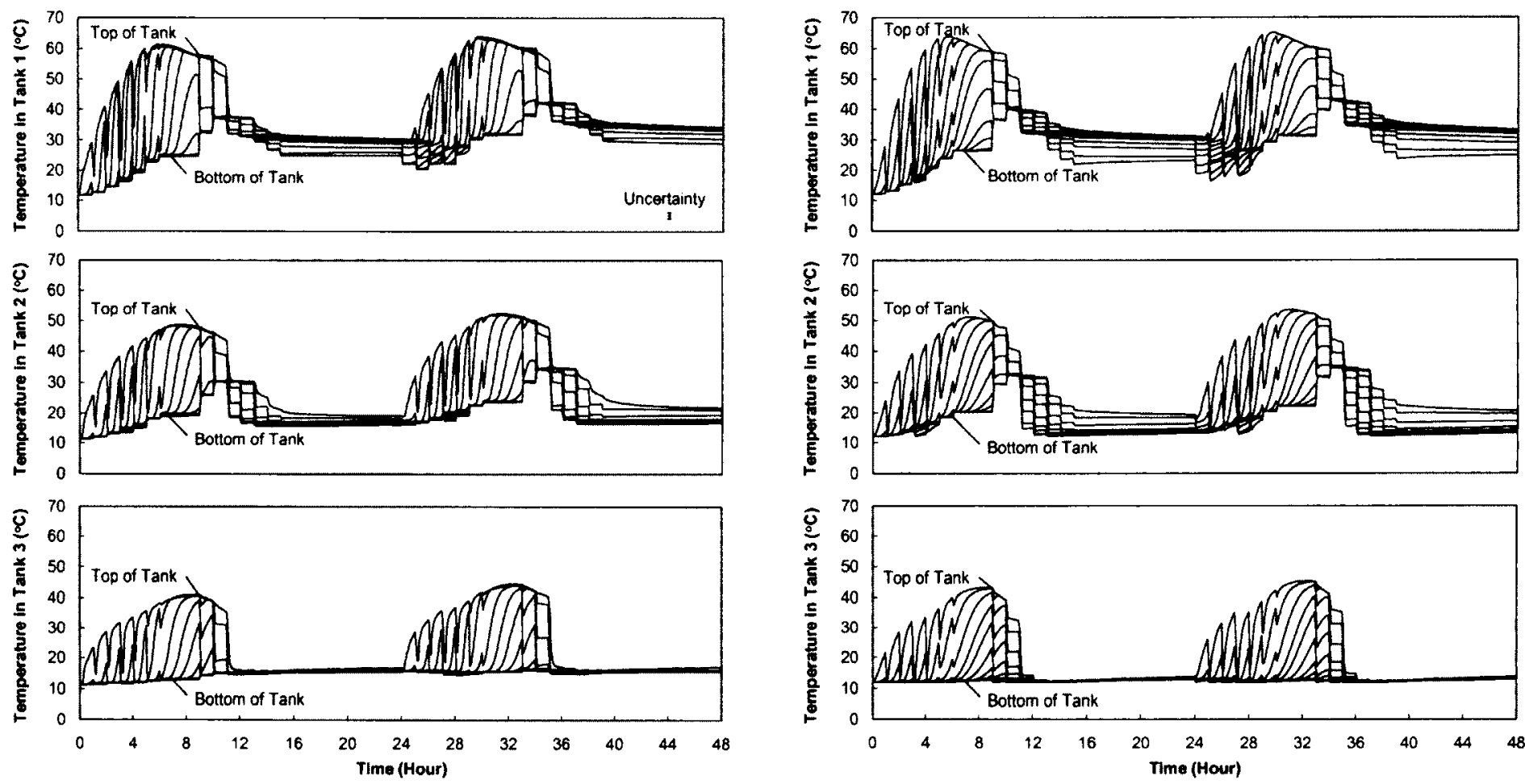

(a) Experimental Results.

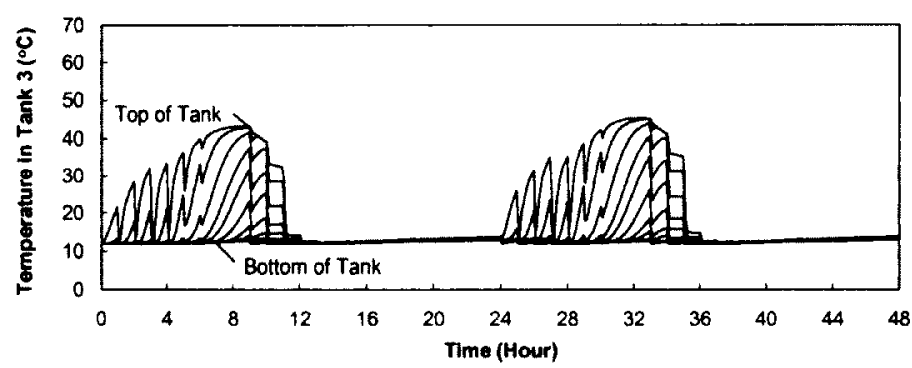

(b) Simulation Results.

Figure 5.8: Experimental and simulation results for Test 7, variable input power charge and CSA draw profile discharge test. series charge and series discharge configuration. 

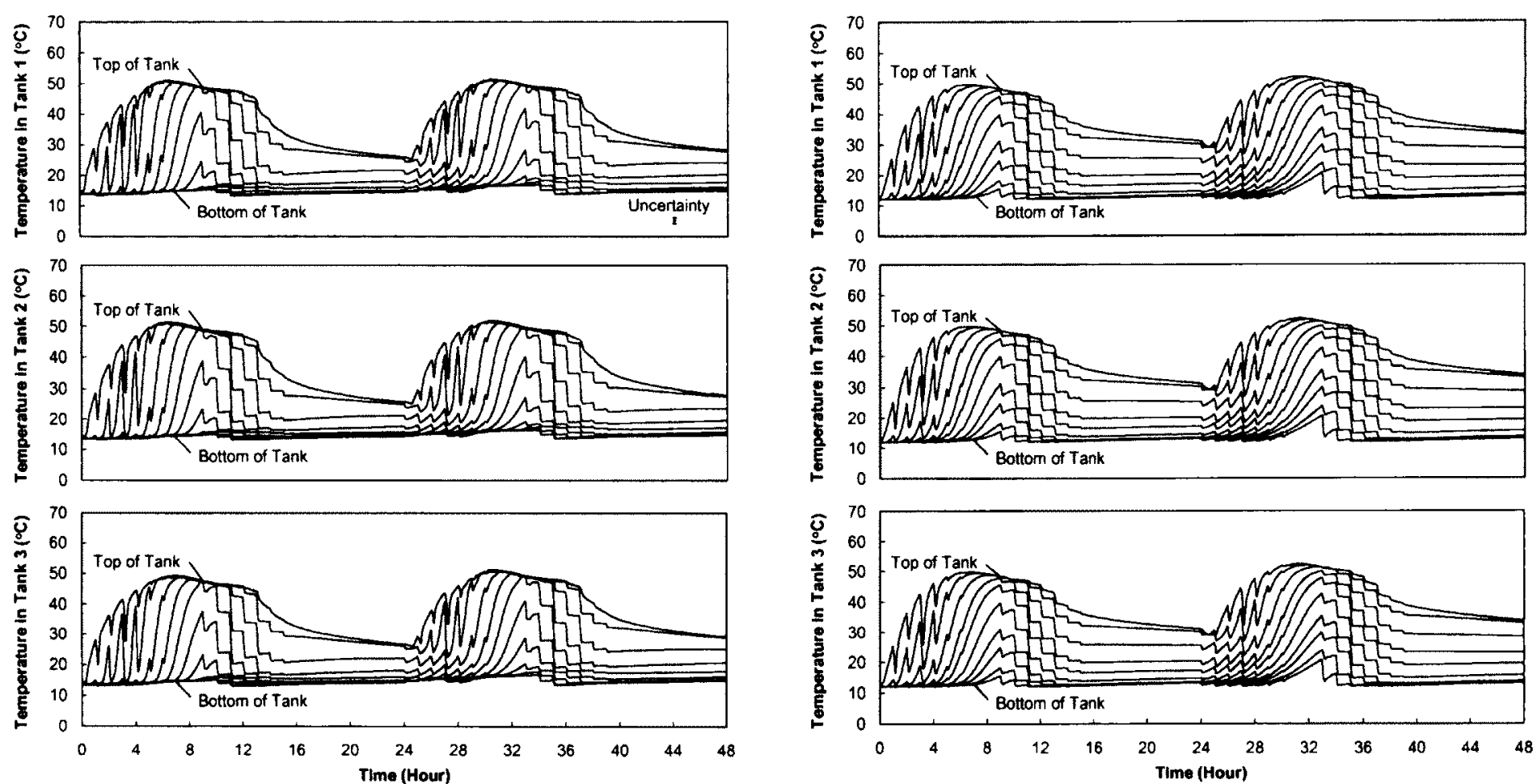

(a) Experimental Results.

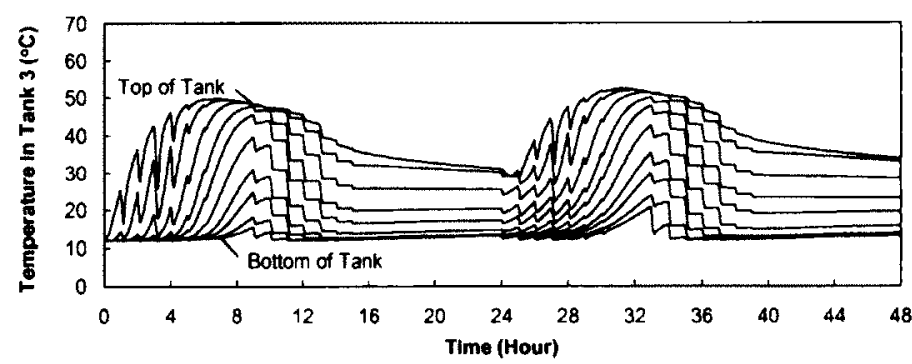

(b) Simulation Results.

Figure 5.9: Experimental and simulation results for Test 8, variable input power charge and CSA draw profile discharge test, parallel charge and parallel discharge configuration. 

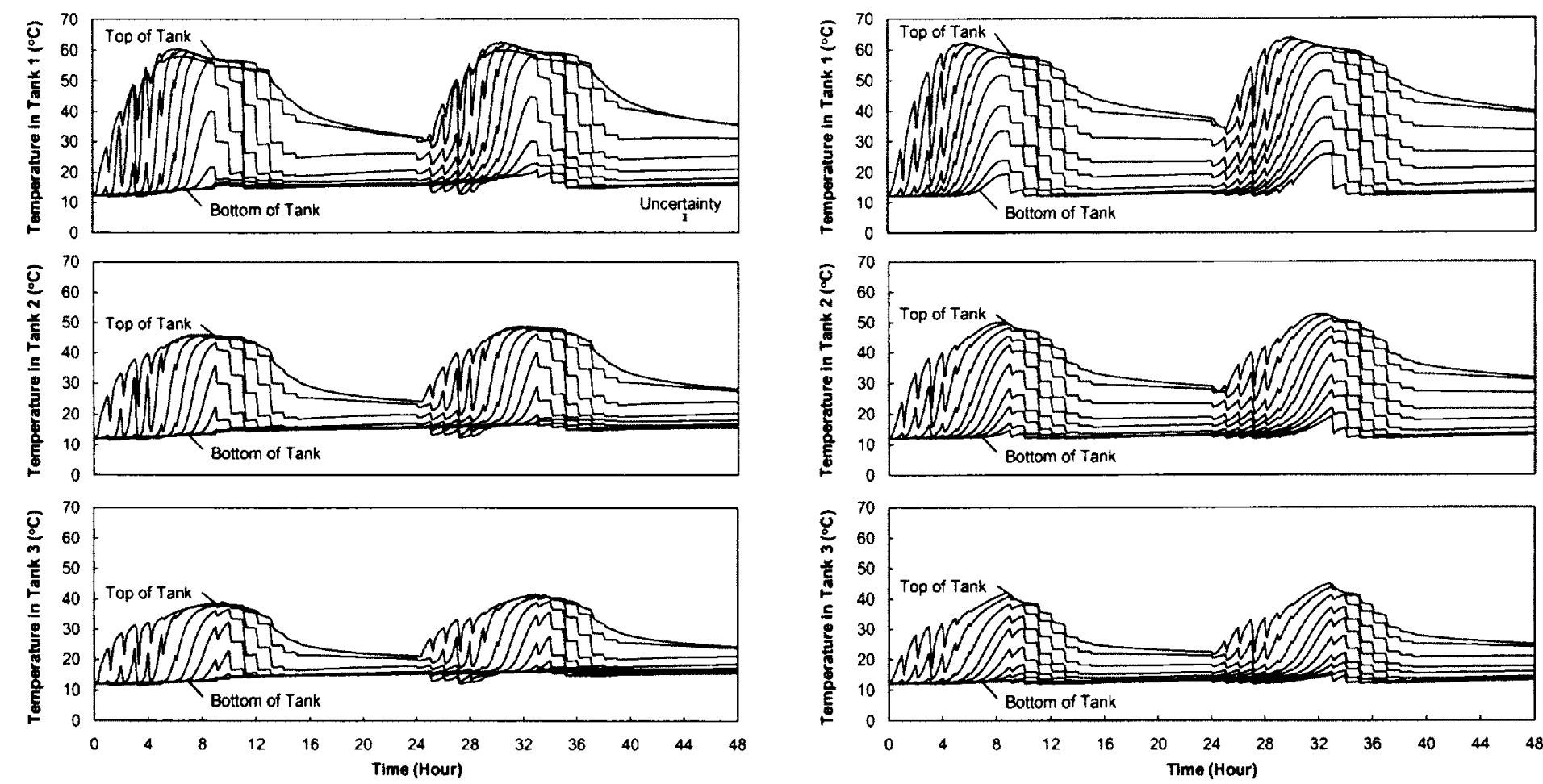

(a) Experimental Results.

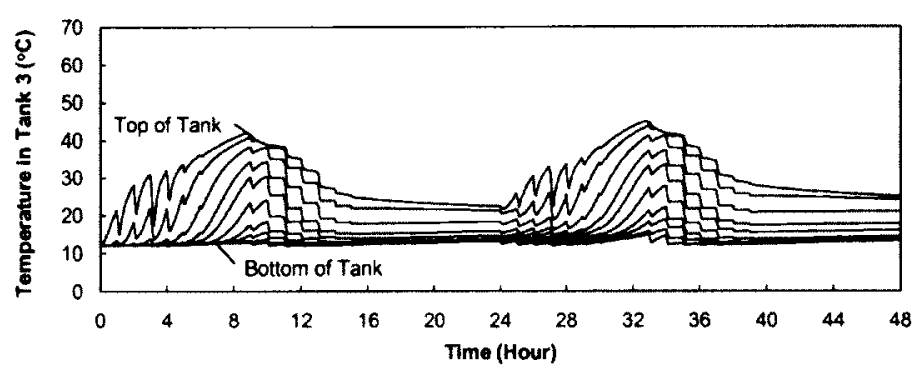

(b) Simulation Results.

Figure 5.10: Experimental and simulation results for Test 9. variable input power charge and CSA draw profile discharge test, series charge and parallel discharge configuration. 
stratification previously observed from Test 7 . The effect of falling collector temperatures was also reduced compared to Test 8 as the downstream tanks (Tanks 2 and 3) continued to charge after the charge temperature had begun falling. Each tank also maintained a good degree of stratification from being discharged in parallel, thereby reducing the occurrences of reverse thermosyphon flow by maintaining cold water at the bottom of the tanks. However, the series charge and parallel discharge configuration demonstrated lower delivery water temperatures, as a result of the mixing of hot water from Tank 1 with cool water from downstream tanks.

One final limitation of the TRNSYS model is most apparent in Fig. 5.10. The TRNSYS model assumed a constant mains temperature of $12{ }^{\circ} \mathrm{C}$ for Tests $7-9$, however, the mains temperature had increased during the afternoon of Day 1 to $15^{\circ} \mathrm{C}$ (resulting in warmer tank temperatures near the bottom), and had fallen back down to $12{ }^{\circ} \mathrm{C}$ on Day 2 between Hours 25 to 30 . The effects of varying mains temperatures was less apparent in Tests $1-6$ as the test period was limited to 8 hours.

In the following chapter, a comparison of the different system configurations will be examined based on the amount of energy delivered during draws, the stored exergy levels within the tanks, and the solar fraction and system efficiency obtained for an ammual simulation. 


\section{Chapter 6}

\section{Discussion of Results}

\subsection{Introduction}

The previous chapter presented experimental and simulation results for the multitank storage system for three different charge and discharge configurations, and addressed the modelling limitations which were observed. Temperature profiles were compared for two general cases: constant temperature charging with constant volune discharging, and variable input power charging with variable volume discharging. The comparison between experimental and simulation temperature profiles demonstrated that there was good agreement between results, and that the discrepancies mainly occurred in regions of high temperature gradients due to the limitations in the TRNSYS model (more specifically, modelling of the thermal storage). This chapter aims to compare the performance of the three system configurations in terms of delivered energy, stored exergy values, and by annual simulation. These performance characteristics will be discussed in the upcoming sections. 


\subsection{Energy Delivered to Load}

The first basis for comparing the three different system configurations was on delivered energy: The ideal system configuration would exhibit the largest amount of delivered energy, as this would reduce the amount of auxiliary energy input required to meet the set-point temperature.

During discharge periods, temperature and volume measurements were recorded at 5-second intervals, compared to the 3-minute intervals used to record tank temperatures. To determine the total amount of energy delivered during the test period, individual energy values were summed at each time step. The delivered energy, $Q_{\text {del }}$, was calculated according to Eq. (6.1),

$$
Q_{\mathrm{del}}=\forall \rho_{\mathrm{w}} c_{p_{\mathrm{w}}}\left(T_{\mathrm{del}}-T_{\text {mains }}\right)
$$

where $\forall$ is the volume of water drawn in $\mathrm{m}^{3}, \rho_{\mathrm{w}}$ is the density of water in $\mathrm{kg} / \mathrm{m}^{3}$ calculated at the mean temperature, $c_{p_{w}}$ is the specific heat capacity of water in $\mathrm{kJ} / \mathrm{kgK}$ calculated at the mean temperature, $T_{\text {del }}$ is the delivery water temperature, and $T_{\text {mains }}$ is the mains water temperature.

Temperature and volume measurements were calibrated according to the relationships presented in Appendix C, and the associated uncertainty values were calculated as $\pm 0.31 \mathrm{~L}$ for the volume measurements, $\pm 0.32 \%$ for the density, $\pm 0.15 \%$ for the specific heat capacity. and $\pm 0.07^{\circ} \mathrm{C}$ for the temperature measurements. The corresponding error for the delivered energy was found to be in the range of $0.49 \%$ and $2.1 \%$. 


\subsubsection{Constant Temperature Charge and Constant Volume Discharge Tests}

For Tests $1-6$, delivered energy values were calculated and are shown in Table 6.1. In each test, the TRNSYS model overpredicted the amount of delivered energy by a significant amount. The main factor contributing to this discrepancy was the assumption of a constant mains temperature of $11^{\circ} \mathrm{C}$. It was observed experimentally that the mains temperature varied by several degrees throughout the test periods, and this was not adequately represented in the numerical model. Comparing experimental to simulation values, the delivered energy varied between $9.7 \%$ and $23.1 \%$ for Tests $1-3$, and between $6.8 \%$ and $10.1 \%$ for Tests $4-6$. Test 2 was found to have a considerable amount of error, as it was obscrved that Tank 3 was significantly undercharged compared to the other two tanks in the parallel charge and parallel discharge configuration. As a result, lower temperatures were drawn from Tank 3, producing a lower experimental delivered energy value.

Table 6.1: Delivered energy values for the constant temperature charge and constant volume discharge tests.

\begin{tabular}{|c|c|c|c|c|}
\hline \multirow{2}{*}{ Test } & \multirow{2}{*}{ Configuration } & \multirow{2}{*}{ Draw Volume $(\mathrm{L})$} & \multicolumn{2}{|c|}{ Delivered Energy, $Q_{\text {del }}(\mathrm{MJ})$} \\
\hline & & & Experimental & Simulation \\
\hline 1 & Series Series & 60 & 46.73 & 51.76 \\
\hline 2 & Parallel Parallel & 60 & 39.54 & 51.42 \\
\hline 3 & Series Parallel & 60 & 36.35 & 44.98 \\
\hline 4 & Series Series & 135 & 79.15 & 88.06 \\
\hline 5 & Parallel Parallel & 135 & 97.71 & 105.54 \\
\hline 6 & Series Parallel & 135 & 82.04 & 88.03 \\
\hline
\end{tabular}


Based on delivered energy values for the constant temperature charge and constant volume discharge tests, the parallel charge and parallel discharge configuration with $135 \mathrm{~L}$ draws (Test 5) delivered the highest amount of energy. Compared to Tests 4 and 6 , the parallel configuration delivered $23.4 \%$ and $19.1 \%$ more energy, respectively. This demonstrates that the parallel charge and parallel discharge configuration had the best performance under these test conditions. At lower draw volumes (i.e., $60 \mathrm{~L}$ ), the series charge and series discharge configuration had higher delivery temperatures, however, these tests did not reflect the losses due to mixing at the bottom of the tanks as clearly as the $135 \mathrm{~L}$ tests. This is more apparent in Section 6.3 .1 when considering the stored exergy of the system.

\subsubsection{Variable Input Power Charge and Variable Volume Discharge Tests}

As a better comparison of system performance, delivered energy values were calculated for Tests $7-9$, and are presented in Table 6.2 .

Table 6.2: Delivered energy values for the variable input power charge and variable volume discharge tests.

\begin{tabular}{clcc}
\hline \multirow{2}{*}{ Test } & Configuration & \multicolumn{2}{c}{ Delivered Energy, $Q_{\text {del }}(\mathrm{MJ})$} \\
& & Experimental & Simulation \\
\hline 7 & Series Series & 160.56 & 211.38 \\
8 & Parallel Parallel & 174.77 & 217.36 \\
9 & Series Parallel & 168.11 & 210.05 \\
\hline
\end{tabular}


The discrepancy between experimental and simulation results was fairly significant, with errors between $19.6 \%$ to $24.0 \%$. As before, a large amount of error was introduced by the assumption of constant mains temperature in the TRNSYS model, since the temperature varied experimentally by several degrees over the 48-hour test period. Furthermore, the TRNSYS model consistently overpredicted the top tank temperature for the variable input power charge tests, resulting in higher predicted delivered energy values.

Based on the delivered energy values for the variable temperature charge and variable volume discharge tests, the parallel charge and parallel discharge configuration (Test 8) delivered the highest amount of energy. Compared to Tests 7 and 9, the parallel configuration delivered $8.9 \%$ and $4.0 \%$ more energy, respectively. Therefore, under variable input power charge and variable volume discharge conditions, the parallel charge and parallel discharge configuration had the best performance based on delivered energy.

\subsection{Exergy Analysis}

As a means of characterizing the "usefulness" of the energy stored in the multi-tank system, an exergy analysis was conducted for Tests 1 - 9. An example demonstrating the concept of exergy is a single hot water tank with two equal volume regions (i.e., nodes). In one configuration, the tank is fully-mixed. implying that both nodes are equal in temperature (e.g., $50^{\circ} \mathrm{C}$ ). while the sccond configuration has regions of hot and cold temperatures (e.g., $80^{\circ} \mathrm{C}$ for the top node, and $20^{\circ} \mathrm{C}$ for the bottom node). Both systems contain the same amount of internal energy, but from a discharge perspective, water would be supplied at a higher temperature by the tank containing

$80^{\circ} \mathrm{C}$ water at the top, compared to the fully-mixed tank which would supply $50^{\circ} \mathrm{C}$ 
water. In this case, the tank with regions of hot and cold water would have a higher exergy level due to it's stratification. The specific exergy. $E x$, can be quantified according to Eq. (6.2),

$$
E x=\left(h-h_{\mathrm{o}}\right)-T_{\mathrm{o}} \cdot\left(s-s_{\mathrm{o}}\right)
$$

where $h$ is the specific enthalpy of the fluid in $\mathrm{kJ} / \mathrm{kg}$ for a given temperature. $s$ is the specific entropy of the fluid in $\mathrm{kJ} / \mathrm{kgK}$ for a given temperature, and $h_{\mathrm{o}}, s_{\mathrm{o}}$ and $T_{0}$ are the specific enthalpy, specific entropy and temperature at the dead state. The thermophysical properties (enthalpy and entropy) of the fluid at the dead state are found when the system is in thermodynamic equilibrium with the environment it is in (i.e., at the dead state, the useful work potential of the system is zero) [6]. For the previous example, if the dead state is selected as $20^{\circ} \mathrm{C}$, then the corresponding specific exergy values calculated from Eq. (6.2) are $11.3 \mathrm{~kJ} / \mathrm{kg}$ and $6.0 \mathrm{~kJ} / \mathrm{kg}$ for the two-region tank and the fully-mixed tank, respectively.

The same method of comparing system configurations can be applied to the multitank system under study. A closed-system approach was used for the analysis which neglected the exergy contribution from fluid flow during draws. This assumption was found to be valid since the exergy value associated with the velocity of the fluid moving through the system during draws was negligible in comparison to the total exergy stored at any instantaneous moment.

For this analysis, the specific exergy values were calculated at each time step and for each thermocouple and node according to Eq. (6.2). The values for each of the ten thermocouples and nodes were summed to represent the specific exergy for each tank. and finally, the values for the three tanks were summed to represent the exergy stored in the system. The two corresponding expressions are shown in Eq. (6.3) and (6.4) 


$$
\begin{aligned}
E x_{\text {Tank }}(t) & =\sum_{\text {node }=1}^{10} E x_{\text {node }}(t) \\
E x_{\text {Stored }}(t) & =\sum_{\text {Tank }=1}^{3} E x_{\text {Tank }}(t)
\end{aligned}
$$

The dead state was selected as $11^{\circ} \mathrm{C}$ for Tests $1-6$, and $12{ }^{\circ} \mathrm{C}$ for Tests $7-9$, to correspond with the mains temperature and the initial tank temperatures of the system. Finally, the thermophysical properties of water were obtained from the Engineering Equation Solver (EES) [50] software, which was also used to perform the exergy calculations.

\subsubsection{Constant Temperature Charge and Constant Volume Hourly Discharge Tests}

For the six experimental tests performed with constant temperature charging and constant volume discharging, specific exergy values were determined at each time step for both experimental and simulation data. The values of specific exergy calculated at the end of the testing period for both experimental and simulation results are given in Table 6.3, with the corresponding plots of specific exergy versus time shown in Fig. 6.1 for Tests $4-6$ conditions. For the plotted results of Tests $1-3$, refer to Appendix E.

Comparing experimental and simulation specific exergy values at the end of the test period. it was found that the values differed between $4.5 \%$ and $16.1 \%$. The results of this analysis also demonstrated that the parallel charge and parallel discharge configuration for Tests 2 and 5 stored the largest amount of exergy for both draw volumes for both experimental and simulation results, and therefore, maintained the 


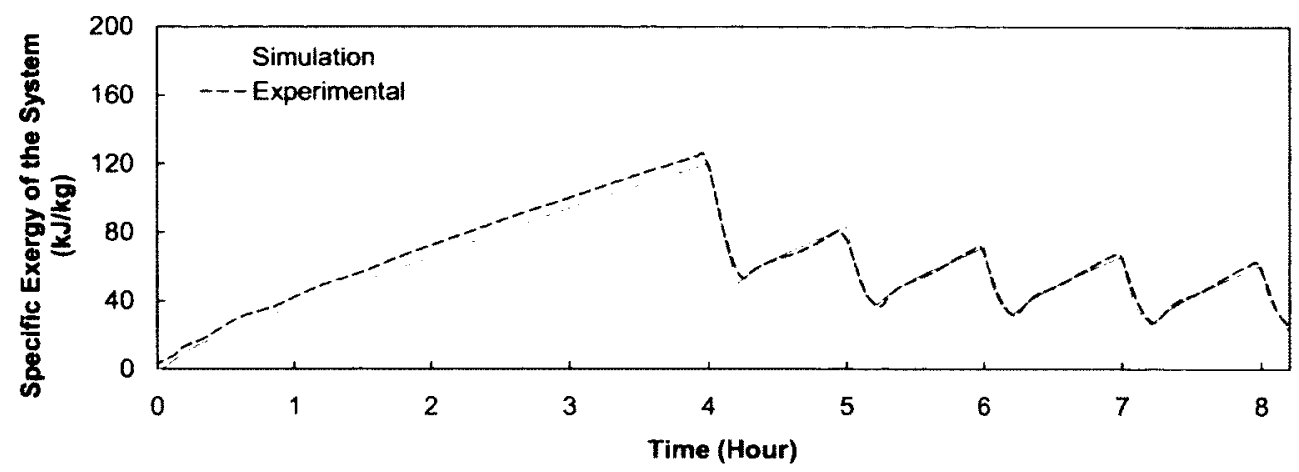

(a) Test 4 exergy values for the series charge and series discharge configuration.

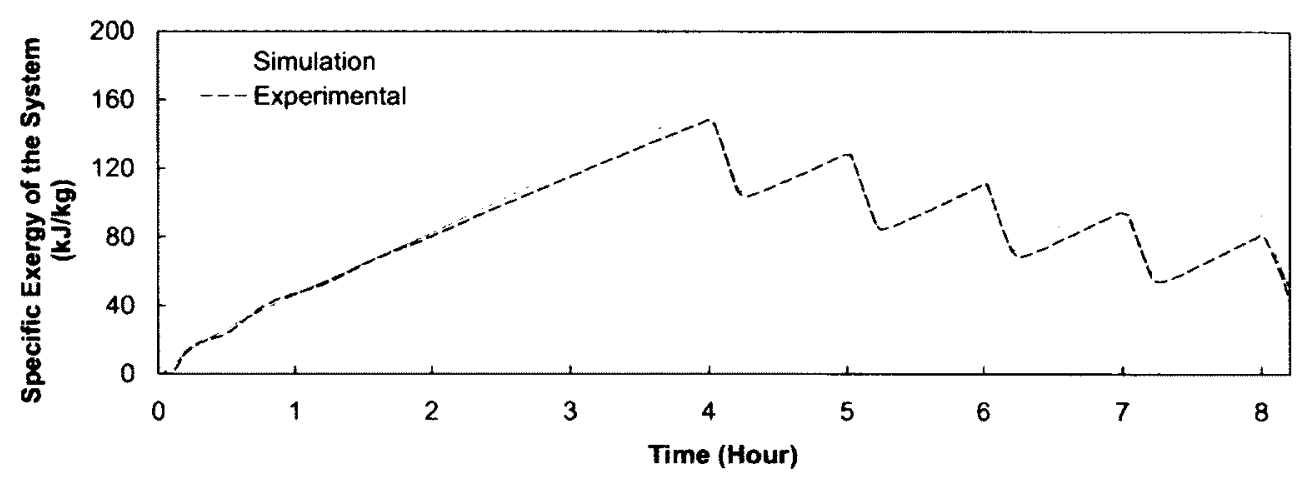

(b) Test 5 exergy values for the parallel charge and parallel discharge configuration.

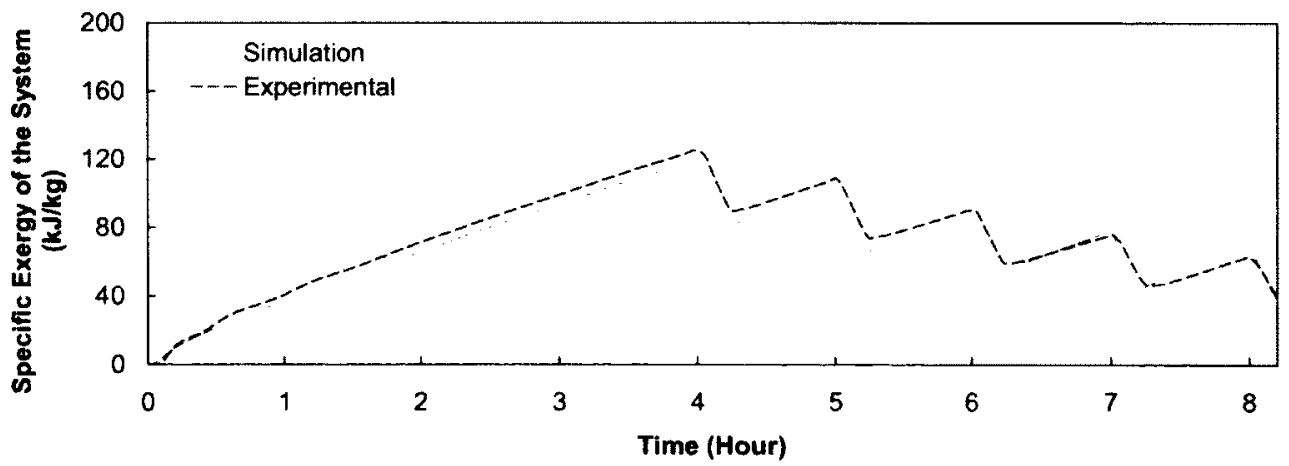

(c) Test 6 exergy values for the series charge and parallel discharge configuration.

Figure 6.1: Specific exergy values for the three system configurations with constant temperature charging and $135 \mathrm{~L}$ draws. 
Table 6.3: Specific exergy values at the end of the testing period for constant temperature charge and constant volume discharge tests.

\begin{tabular}{|c|c|c|c|c|}
\hline \multirow{2}{*}{ Test } & \multirow{2}{*}{ Configuration } & \multirow{2}{*}{ Draw Volume (L) } & \multicolumn{2}{|c|}{ Specific Exergy, $E x_{\text {Stored }}(\mathrm{kJ} / \mathrm{kg})$} \\
\hline & & & Experimental & Simulation \\
\hline 1 & Series Series & 60 & 83.6 & 87.5 \\
\hline 2 & Parallel Parallel & 60 & 141.7 & 159.0 \\
\hline 3 & Series Parallel & 60 & 129.5 & 117.9 \\
\hline 4 & Series Series & 135 & 24.9 & 22.3 \\
\hline 5 & Parallel Parallel & 135 & 42.3 & 50.4 \\
\hline 6 & Series Parallel & 135 & 39.6 & 37.6 \\
\hline
\end{tabular}

highest degree of stratification. Compared to Tests 1 and 3, Test 2 stored $69.5 \%$ and $9.4 \%$ more exergy, respectively, while Test 5 stored $69.9 \%$ and $6.8 \%$ more exergy compared to Tests 4 and 6 .

In Section 6.2.1, there was a large discrepancy between experimental and modelled delivered energy values for Test 2 , which was attributed to the significant undercharging of Tank 3. Apart from comparing temperature profiles, the specific exergy values between the three tanks can be compared to give an indication of the degree of charge. Specific exergy values for Tanks 1 - 3 of the parallel charge and parallel discharge configuration test with 60 draws were plotted with respect to time, and are shown in Fig. 6.2. The figure shows that there is good agreement between the TRNSYS model and experimental results for Tanks 1 and 2, while Tank 3 achieved significantly lower exergy values due to the lower charge it received. 

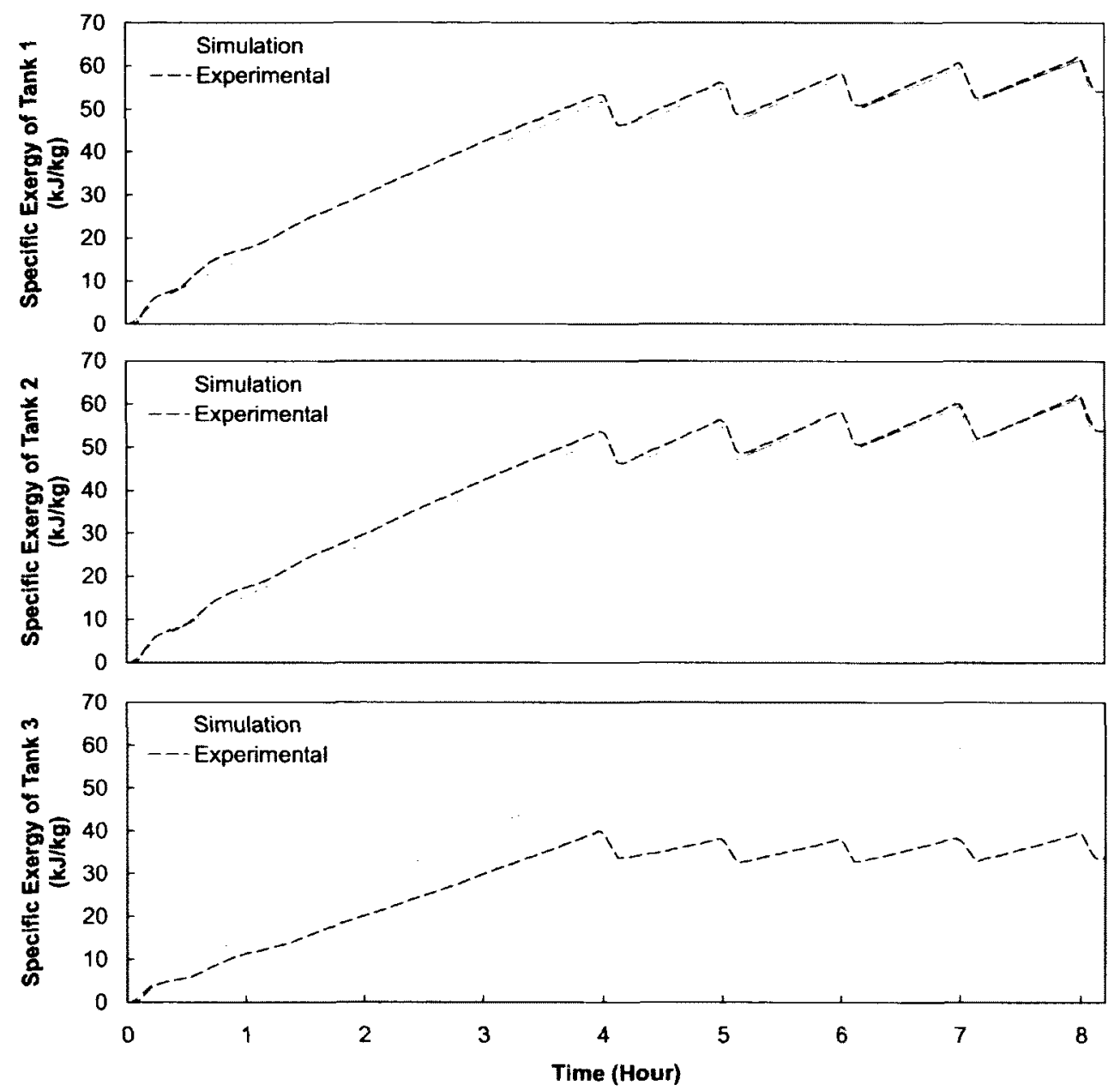

Figure 6.2: Test 2 exergy values for Tanks 1-3 of the parallel charge and parallel discharge configuration with $60 \mathrm{~L}$ draws. 


\subsubsection{Variable Input Power Charge and Variable Volume Discharge Tests}

As an indication of system performance, the specific exergy of the system was compared for the variable input power charge and variable volume discharge tests. The values of specific exergy at the end of the testing period for both experimental and simulation results are given in Table 6.4.

Table 6.4: Specific exergy values at the end of the testing period for variable input power charge and variable volume discharge tests.

\begin{tabular}{|c|c|c|c|}
\hline \multirow{2}{*}{ Test } & \multirow{2}{*}{ Configuration } & \multicolumn{2}{|c|}{ Specific Excrgy, Ex $x_{\text {Stored }}(\mathrm{kJ} / \mathrm{kg}$} \\
\hline & & Experimental & Simulation \\
\hline 7 & Series Series & 39.4 & 30.2 \\
\hline 8 & Parallel Parallel & 20.9 & 33.7 \\
\hline 9 & Series Parallel & 25.9 & 30.5 \\
\hline
\end{tabular}

The specific exergy values are plotted in Fig. 6.3 for the parallel charge and discharge configuration (Test 8), with the results of Tests 7 and 9 given in Appendix E. Contrary to the results of the delivered energy analysis and the exergy analysis for constant temperature charging and constant volume discharging, the parallel charge and parallel discharge configuration resulted in the lowest amount of stored exergy experimentally. The TRNSYS model, however, predicted that the parallel configuration would store the highest amount of exergy. From Fig. 6.3, it is apparent that Tank 3 was charged to a lesser extent than Tanks 1 and 2, since the first two tanks had similar exergy levels compared to the simulation results. In addition, the simulation model overpredicted the temperatures and exergy levels at Hour 13, when the charge loop would have fallen below the average tank temperatures, thereby extracting energy from the tanks through reverse thermosyphoning. This resulted in higher 

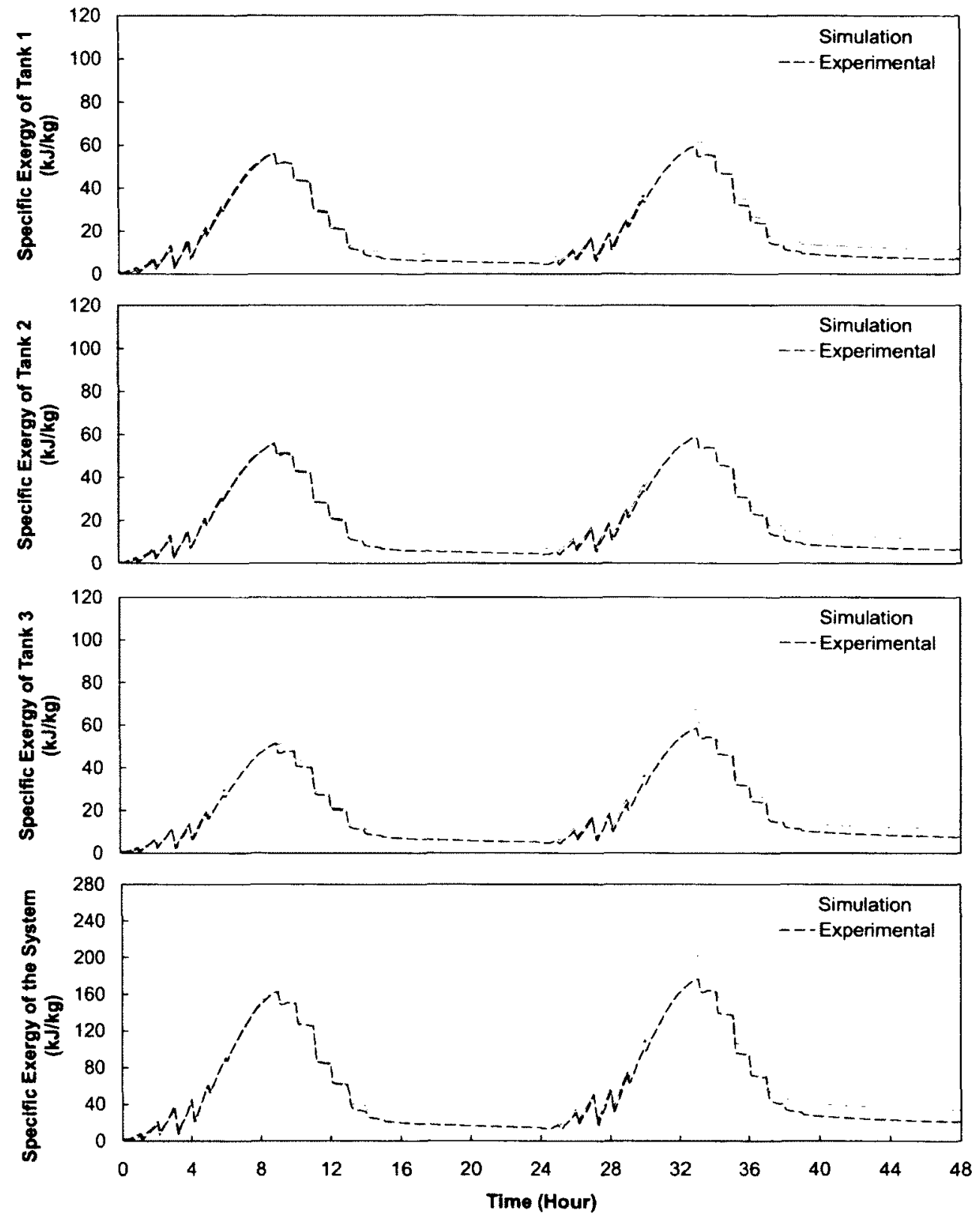

Figure 6.3: Specific exergy comparison of experimental and simulation results for Test 8, parallel charge and parallel discharge configuration with variable input power charge profile and variable volume draws. 

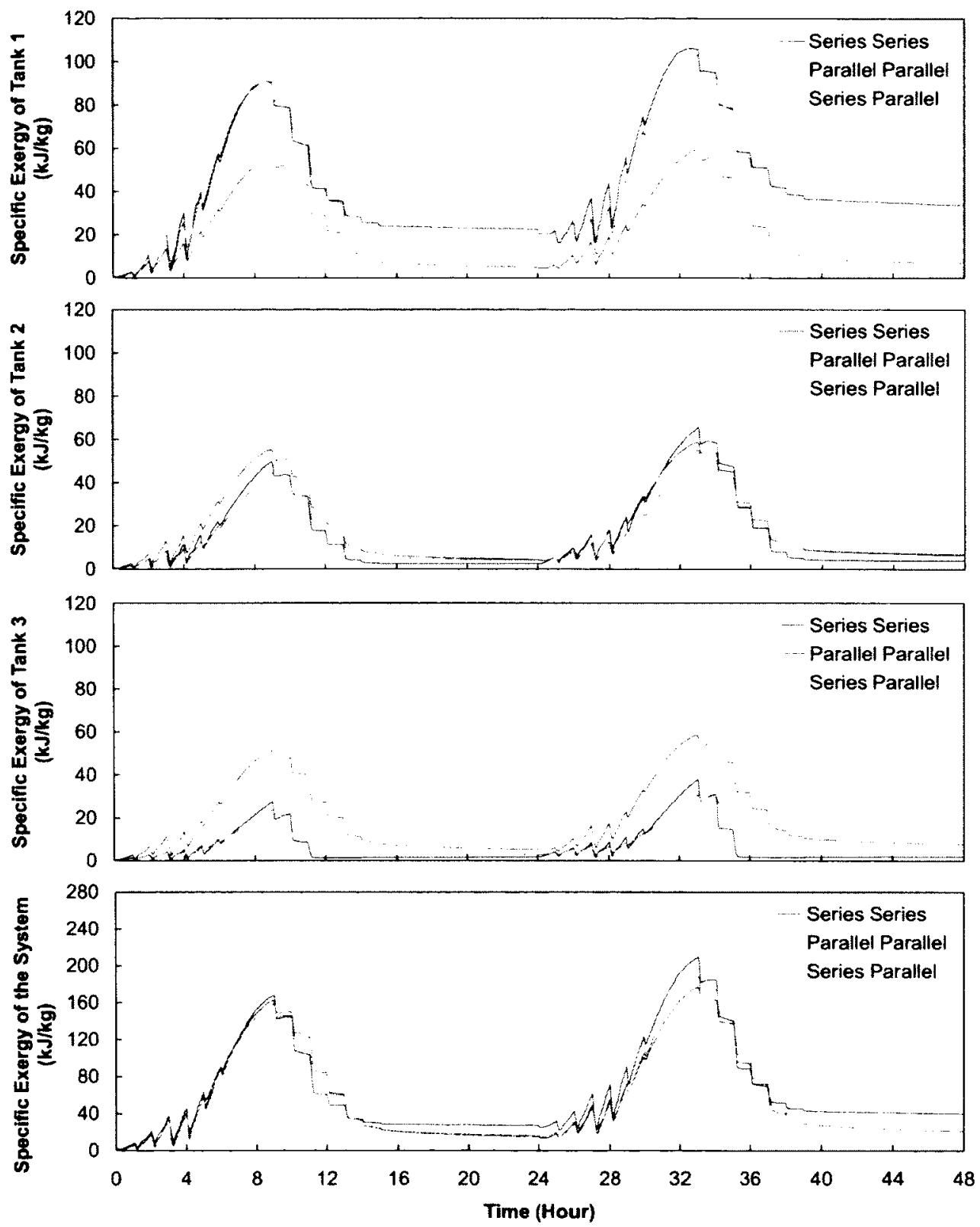

Figure 6.4: Specific exergy comparison of experimental results for the three test configurations with variable input power charge profile and variable volume draws. 
predicted tank temperatures in the simulation results, which carried over to Day 2. Finally, since the modelled tank temperatures were higher at the start of Day 2, the additional energy input caused further temperature discrepancies.

The series charge and series discharge test (Test 7) also strongly deviated from the simulation results, where the experimental amount of stored exergy was greater than predicted. By comparing the temperature profiles in Fig 5.8, the TRNSYS model underpredicted the bottom tank temperatures at the end of Day 1, resulting in a lower amount of stored exergy. This can be attributed to TRNSYS incorrectly modelling the mixing that occurred at the bottom of Tanks 1 and 2 during draws.

Finally, a comparison of the experimental specific exergy values for the three test configurations is shown in Fig. 6.4. Comparing all three configurations, it is evident that the series charge and series discharge configuration (shown in blue) had the best performance in terms of stored exergy. In terms of exergy, this indicates that the series charge and series discharge configuration had the most useful energy stored in Tank 1 at the end of the test period, which was mainly due to the high temperatures of stored water inside the tank. However, when considering the entire test period, Test 7 delivered the least amount of energy out of all three configurations. While exergy is a good indication of the stratification within a system, as well as an indication of the usefulness of the stored energy, it is not a sufficient parameter to compare system performance alone.

\subsection{Annual Performance Simulation of a SDHW System}

In the previous sections, the performance of three multi-tank configurations were compared based on experimental and simulation results for delivered energy and 
stored exergy. In a final analysis, the numerical model used in the variable input power charge and variable volume discharge test was adapted to include additional TRNSYS components to facilitate annual performance testing. A screenshot from the TRNSYS Simulation Studio for the parallel charge and parallel discharge configuration is given in Appendix G, with the corresponding deck file given in Appendix $\mathrm{H}$.

Solar input was simulated through the use of a flat-plate solar collector with 2nd-order incidence angle modifiers (Type 1b) and a weather data reader (Type 156). The weather file was selected from the expanded TRNSYS weather database, and consisted of a Meteonorm data file (TMY2 format) for Ottawa, Ontario, which provided weather data to the solar collector. In addition, the mains water temperature was calculated from the weather file based on the algorithm developed by Christensen and Burch at the US National Renewable Energy Laboratory, which consists of a sinusoidal approximation as a function of the ambient temperature [51].

A differential temperature controller (Type 2b), single speed pump (Type 3b), and pipe duct to and from the collector (Type 31), were used to complete the collector loop. The differential controller operated by turning on the pump when the temperature difference between the

Finally, a custom flow mixer was used to place an upper limit of $55^{\circ} \mathrm{C}$ on the delivery water temperature. If the delivery water temperature from the tanks was below $55^{\circ} \mathrm{C}$, the maximum hot water flow rate of $11.4 \mathrm{~L} / \mathrm{min}$ was drawn from the tanks, however, if the delivery temperature was above the set-point temperature, a lower hot water flow rate would be drawn from the tanks and mixed with mains water to achieve the desired set-point. Specifications for the added components are provided in Table 6.5 . 
Table 6.5: Annual Performance Sinulation Test Parameters.

\begin{tabular}{lc}
\hline Parameter & Value \\
\hline Collector Area & $17.148 \mathrm{~m}^{2}$ \\
Collector Slope & $45^{\circ}$ \\
Azimuth & $0^{\circ}$ \\
Intercept Efficiency, $F_{R}(\tau \alpha)_{n}$ & 0.650 \\
Efficiency Slope. $F_{R} U_{L}$ & 15.9912 \\
1st-Order Incidence Angle Modifier, $b_{0}$ & 0.202 \\
2nd-Order Incidence Angle Modifier, $b_{1}$ & 0 \\
Maximum Pump Power & $111.5 \mathrm{~kJ} / \mathrm{h}$ \\
\hline
\end{tabular}

Collector and pump parameters were selected from a similar study conducted by Cruickshank [3], where $F_{R}$ represents the collector heat removal factor, $(\tau \alpha)_{n}$ represents the product of the cover transmittance and the absorber absorptance at normal incidence, and $U_{L}$ represents the heat transfer resistance from the absorber plate to the ambient air [2]. Combined, these values define an efficiency curve for a solar collector, where the product $F_{R}(\tau \alpha)_{n}$ gives the intercept efficiency (i.e., the $y$-intercept of an efficiency versus temperature difference plot) and $F_{R} U_{L}$ gives the slope of the efficiency curve. The useful solar energy gain from the collector. $\dot{Q}_{\mathrm{u}}$, can then be expressed according to Eq. (6.5) [2],

$$
\dot{Q}_{\mathrm{u}}=A\left[G_{T} K_{\tau \alpha} F_{R}(\tau \alpha)_{n}-F_{R} U_{L}\left(T_{\mathrm{in}}-T_{\mathrm{amb}}\right)\right]
$$

where $A$ is the gross collector area in $\mathrm{m}^{2}, G_{T}$ is the incident solar radiation on the collector surface in $\mathrm{kJ} / \mathrm{h} \cdot \mathrm{m}^{2}, K_{\tau \alpha}$ is the incidence angle modificr for beam radiation, $T_{\text {in }}$ is the inlet fluid temperature to the collector and $T_{\text {anb }}$ is the ambient air temperature. The incidence angle modifier is calculated according to Eq. (6.6) [2], 


$$
K_{\tau \alpha}=1-b_{0}\left(\frac{1}{\cos \theta}-1\right)-b_{1}\left(\frac{1}{\cos \theta}-1\right)^{2}
$$

where the 1st-order coefficient of the incidence angle modifier equation, $b_{0}$, corrects for the angle $\theta$ at which solar radiation makes with the surface relative to the normal direction. This is necessary as the performance of the collector is measured perpendicular (i.e., normal) to the collector plane.

The collection efficiency, $\eta$, can then be defined by Eq. (6.7) [2].

$$
\eta=\frac{\int \dot{Q}_{\mathrm{u}} d t}{A \int G_{T} d t}
$$

The three multi-tank configurations were evaluated in terms of 6 parameters: useful solar energy gained by the collector $\left(Q_{\mathrm{u}}\right)$, solar energy delivered to the heating load $\left(Q_{\text {del }}\right)$, thermal storage losses $\left(Q_{\text {losses }}\right)$, parasitic energy (i.e., pump consumption, $\left.Q_{\text {par }}\right)$, solar fraction $\left(F_{s}\right)$, and collection efficiency $(\eta)$. The solar fraction represents the percentage of the heating load supplied by solar energy, and is defined in Eq. (6.8),

$$
F_{s}=\frac{Q_{\text {del }}}{Q_{\text {ref }}}
$$

where $Q_{\text {ref }}$, represents the energy required of a reference system to meet the heating load with no supply of solar energy (i.e., auxiliary energy heats the mains water to the delivery set-point temperature). This is calculated according to Eq. (6.9),

$$
Q_{\mathrm{ref}}=\int \dot{m}_{\mathrm{del}} c_{p_{\mathrm{w}}}\left(T_{\mathrm{set}}-T_{\text {mains }}\right) d t
$$

where the set-point temperature for the reference system, $T_{\text {set }}$, was selected to be $55^{\circ} \mathrm{C}$. Furthermore, the delivered energy for a solar thermal system can be related 
to the reference system (without solar) according to Eq. (6.10).

$$
Q_{\mathrm{del}}+Q_{\mathrm{aux}}=Q_{\mathrm{ref}}
$$

The three nulti-tank configurations were compared against a stratified single tank model and a fully-mixed single tank model. Both single tank configurations consisted of a single Type 60 tank component with a height of $1.35 \mathrm{~m}$ and a volume of $810 \mathrm{~L}$ (instead of the typical $270 \mathrm{~L}$ volume per tank used in the multi-tank models), and a single natural convection heat exchanger. The stratified single tank model consisted of 33 nodes with identical node positions as the multi-tank configurations, while the fully-mixed single tank model consisted of only one node.

To ensure that the same amount of energy was transferred across the single heat exchanger as in the multi-tank system with three heat exchangers, the " $a$ " coefficient in the natural convection flow rate calculation, Eq. (3.10), was increased until the delivered energy (i.e., solar fraction) of the single tank configuration was equivalent to the parallel charge and parallel discharge configuration with zero heat loss. Defining zero heat loss was necessary when equating the solar fraction of both models, as the parallel charge and parallel discharge configuration would experience more heat loss due to the larger surface area. The results of this study are summarized in Table 6.6.

Based on the results of the annual simulation, the parallel charge and parallel discharge configuration had the highest solar fraction and system efficiency of the multi-tank configurations. This is consistent with the results of the delivered energy analysis presented for the variable input power charge and variable volume discharge tests. The single stratified tank configuration had the highest solar fraction and system efficiency of the annual simulation results, since the model operated in a similar manner to the parallel charge and parallel discharge, but had less surface area and 
Table 6.6: Annual performance simulation results.

\begin{tabular}{cccccc}
\hline Parameter & $\begin{array}{c}\text { Series } \\
\text { Series }\end{array}$ & $\begin{array}{c}\text { Parallel } \\
\text { Parallel }\end{array}$ & $\begin{array}{c}\text { Series } \\
\text { Parallel }\end{array}$ & $\begin{array}{c}\text { Stratified } \\
\text { Single Tank }\end{array}$ & $\begin{array}{c}\text { Fully-Mixed } \\
\text { Single Tank }\end{array}$ \\
\hline$Q_{\text {ref }}(\mathrm{GJ})$ & 59.66 & 59.66 & 59.66 & 59.66 & 59.66 \\
$Q_{\text {u }}(\mathrm{GJ})$ & 37.74 & 39.84 & 39.44 & 39.51 & 30.29 \\
$Q_{\text {del }}(\mathrm{GJ})$ & 35.08 & 37.95 & 33.89 & 38.29 & 27.82 \\
$Q_{\text {losses }}(\mathrm{GJ})$ & 1.269 & 1.902 & 0.8381 & 1.253 & 2.567 \\
$Q_{\text {par }}(\mathrm{GJ})$ & 0.4495 & 0.3679 & 0.4055 & 0.3731 & 0.2851 \\
\hline$F_{s}$ & 58.81 & 63.61 & 56.81 & 64.18 & 46.63 \\
$\eta$ & 37.90 & 40.01 & 39.61 & 39.68 & 30.42 \\
\hline
\end{tabular}

less heat loss. Compared to the fully-mixed single tank model, the single stratified tank model demonstrated a significant increase in performance. In terms of storage losses, the results indicated that the series charge and parallel discharge configuration had the least amount of net losses, since the configuration had comparable storage losses to the single stratified tank configuration in the summer months, but significantly more thermal gains during the winter months. Finally, the parasitic energy consumption by the pumps was found to be lowest in the parallel charge and parallel discharge configuration. A monthly comparison of the delivered energy for each of the configurations is presented in Fig. 6.5.

Comparing the delivered energy on a monthly basis, it is evident that all of the multi-tank configurations are fairly similar in performance. Delivered cnergy was highest during the summer months due to the larger solar gains at that time of year, while the winter months experienced a significant reduction in delivered energy. The stratified single tank closely resembled the parallel charge and parallel discharge configuration. where the additional heat loss by the multi-tank system accounted for only a small loss in delivered energy (i.e., performance) each month. Furthermore, 


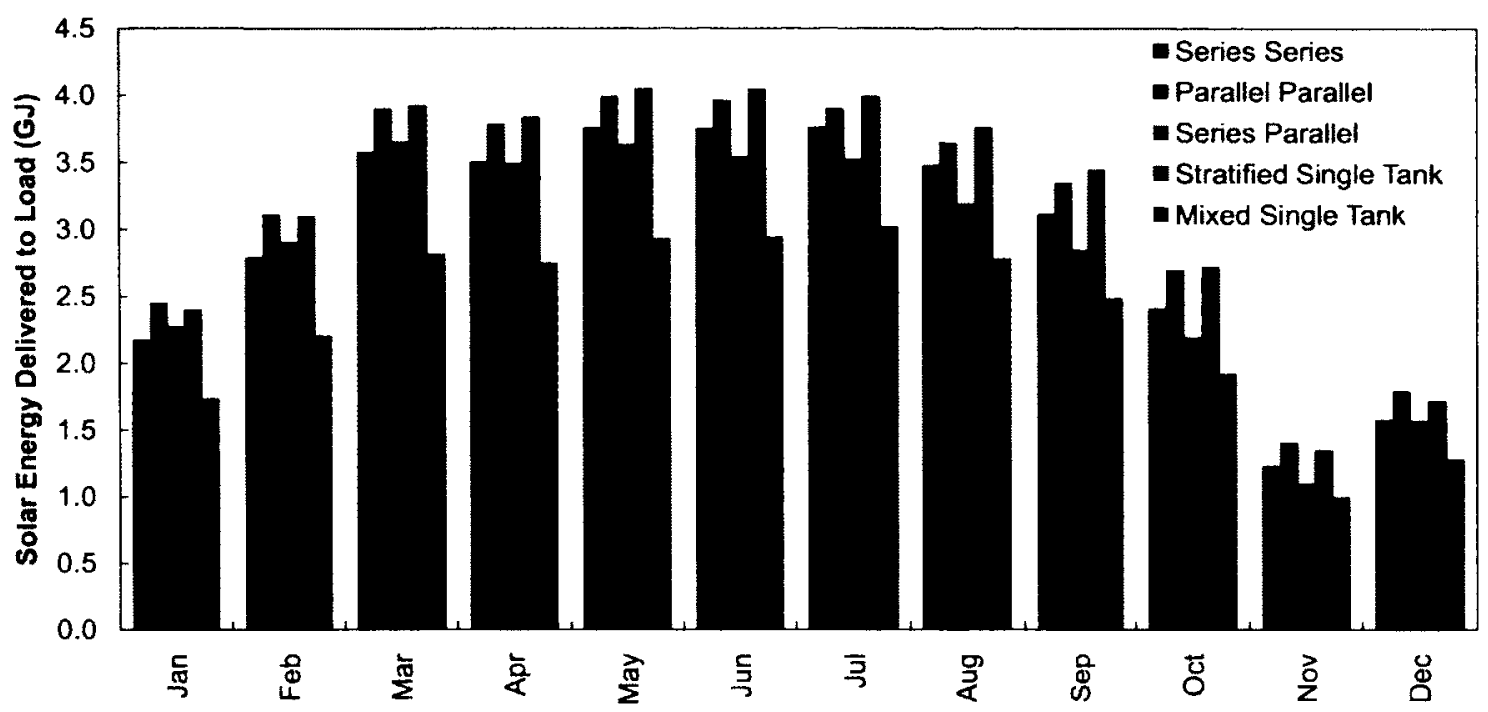

Figure 6.5: Monthly solar energy delivered to load by each of the three multi-tank configurations compared to a single tank configurations.

the parallel charge and parallel discharge configuration performed slightly better in the winter months compared to the single stratified tank, as a result of the additional heat gain from the surroundings caused by the larger surface area of the three tanks. Finally, the series charge and series discharge configuration, and the series charge and parallel discharge configuration had the lowest delivered energy each month, and therefore, had the lowest performance.

In the following chapter, some concluding remarks will be presented, followed by some recommendations for future work. 


\section{Chapter 7}

\section{Conclusions and Recommendations for Future Work}

\subsection{Conclusions}

An experimental and numerical study was conducted on a multi-tank thermal energy storage (TES) for solar hot water heating applications. The setup was previously built, instrumented, and commissioned at the Queen's Solar Calorimetry Lab in Kingston, Ontario, and consisted of three commercially available $270 \mathrm{~L}$ domestic hot water tanks and three side-arm, natural convection heat exchangers (NCHE). The tanks were connected in both series and parallel charging and discharging configurations, and the system configurations were evaluated under: (i) constant temperature charging and constant volume discharging, and (ii) variable input power charging and variable volume discharging.

The first study consisted of six experimental tests of 8 hours in duration, with two $3 \mathrm{~kW}$ electric heaters supplying a constant charge temperature of $55^{\circ} \mathrm{C}$ at a flow

rate of $3 \mathrm{~L} / \mathrm{min}$. Five equal volume draws of $60 \mathrm{~L}$ and $135 \mathrm{~L}$ were conducted at a flow rate of $11.4 \mathrm{~L} / \mathrm{min}$ and were initiated at the beginning of each hour after the 
fourth hour inclusive (i.e., draws occurred at the start of Hours 4, 5, 6, 7 and 8). The second study consisted of three experimental tests of 48 hours in duration, with a simulated solar input charge profile based on a sinusoidal function with a maximum output power of $6 \mathrm{~kW}$. The daily charge cycle occurred for 10 hours each day, with 14 hours between charge cycles to observe standby losses. Realistic draw profiles were used according to a modified draw schedule based on the CSA-F379.1-88 Standard for Solar Domestic Hot Water Systems.

Numerical modelling was conducted using the TRNSYS simulation environment, and the model was found to be in good agreement with the experimental results. The error in experimental and simulation results for the 9 tests varied between $\pm 4.46^{\circ} \mathrm{C}$ and $\pm 8.24^{\circ} \mathrm{C}$ assuming a $95 \%$ confidence level. Discrepancies between data were found mainly in the regions of high temperature gradients as a result of the limitations in the modelling components and assumptions.

The three test configurations which were studied include: (i) series charge and series discharge, (ii) parallel charge and parallel discharge, and (iii) series charge and parallel discharge. To quantify the performance of these configurations, delivered energy values and stored exergy values were compared, and annual simulations were conducted for Ottawa, Ontario.

The experimentally obtained delivered energy values were found to be within $9.7 \%$ and $23.1 \%$ of the simulation values for constant temperature charging and constant volume discharging, while the variable input power charge and variable volume discharge tests resulted in delivered energy values between $6.8 \%$ and $10.1 \%$ of the simulation values. For both test conditions, the parallel charge and parallel discharge configuration delivered more energy during discharge than the other two configurations. 
Comparing stored exergy levels, the parallel charge and parallel discharge configuration had a larger amount of stored exergy at the end of the test period for the constant temperature charge and constant volume discharge tests than the other configurations. Experimental and modelled exergy levels varied between $4.5 \%$ and $16.1 \%$, due to the discrepancies in modelling the tank temperature profiles. For the variable input power charge and variable volume discharge tests, the series charge and series discharge configuration had the highest experimental stored exergy level, primarily due to the high temperatures reached in the first tank.

Finally, the results of the annual performance simulation study demonstrated that the parallel charge and parallel discharge configuration behaved similarly to the single tank configuration, and achieved the highest solar fraction and system efficiency compared to the other multi-tank configurations.

In conclusion, the results indicated that both experimentally and numerically, the parallel charge and parallel discharge configuration achieved the best overall performance.

\subsection{Recommendations for Future Work}

The focus of this study was in performing charge and discharge tests under a variety of operating conditions for a multi-tank thermal energy storage system. Several parameters were kept constant throughout this study. including charge flow rate, charge profile, discharge flow rate, and draw profiles, and these areas would bencfit from further study.

In a realistic system, a flow mixer would be used to adjust the flow rate of hot water being drawn from the storage system in instances where the delivery temperature exceeded the set-point temperature. In this regard, less hot water would be drawn 
from the system. This was implemented in the annual simulation model, however, this could be incorporated into the experimental apparatus.

Another study could explore longer test times, with different draw profiles based on the reviewed literature. In addition, multiple draw profiles could be considered for weekday and weekend consumption, as well as taking into account seasonal variations to compare the system performance under winter and summer loads.

One of the challenges during experimental testing was diverting the charge flow around the heat exchangers during draws, as to avoid preheating of the inlet water flow prior to entering the bottom of the tanks. The electric heaters were also manually shut off to avoid overheating of the charge loop for the case of variable input power. For a residential installation, this wouldn't be practical, so it would be beneficial to repeat the experimental tests without diverting the charge flow and shutting off the heaters. The increase in temperature of the water entering the bottom of the tanks, coupled with the associated buoyancy forces, may induce mixing and plume entrainment at high discharge velocities.

Some of the shortfalls of the numerical model were the inability to model the charging of the inlet water flow to the tanks during draws. To account for this, the heat exchanger model would need to be modified to accept an additional flow input. In addition, the heat exchanger model was also unable to correctly model the reverse thermosyphon flow in the heat exchangers during periods of falling collector loop temperatures. Currently, the model treats the pressure drop and the heat transfer rate as being zero across the heat exchanger as the pressure drop becomes negative and the thermosyphon flow reverses in direction. This could be improved by characterizing the performance of the heat exchanger for negative pressure drops by developing new empirical correlations. 
A final improvement to the numerical model would be to explore alternate tank models, such as Type 534. The Type 60 TRNSYS component which was used to model the tanks in this study produced considerable discrepancies in regions of high temperature gradients, and the results may be improved by using a larger number of nodes. 


\section{List of References}

[1] NRCan. "Energy Use Data Handbook - 1990 to 2009." Technical report, Office of Encrgy Efficicncy, Natural Resources Canada, Ottawa, ON, Canada. [Online] http://oee.nrcan.gc.ca/Publications/statistics/handbook11/ (2012).

[2] J. A. Duffie and W. A. Beckman. Solar Engineering of Thermal Processes. ISBN-13 978-0-471-69867-8. John Wiley and Sons, Inc., Hoboken, NJ, 3rd edition (2006).

[3] C. A. Cruickshank. Evaluation of a Stratified Multi-Tank Thermal Storage for Solar Heating Applications. Ph.D. thesis, Queen's University, Kingston, ON, Canada (2009).

[4] Q. Lin, S. J. Harrison, and M. Lagerquist. "Analysis and Modelling of Compact Heat Exchangers for Natural Convection Applications." In "Proceedings of the Eurosun Conference," Copenhagen, Denmark (2000).

[5] W. Weiss and F. Mauthner. "Solar Heat Worldwide: Markets and Contribution to the Energy Supply 2010." Technical report, AEE INTEC, Gleisdorf, Austria. Report produced in the framework of the IEA SHC programme (2012).

[6] I. Dinçer and M. A. Rosen. Thermal Energy Storage - Systems and Applications. ISBN 0-471-49573-5. John Wiley and Sons, Inc., New York, NY (2002).

[7] R. M. Dickinson and C. A. Cruickshank. "Review of Combined Space and Domestic Hot Water Heating Systems for Solar Applications." In "Proceedings of ASME 2011 - 5th International Conference on Energy Sustainability," Washington. DC. DOI: 10.1115/ES2011-54543 (2011).

[8] R. M. Dickinson, C. A. Cruickshank, and S. J. Harrison. "Charge and Discharge Strategies for a Multi-Tank Thermal Energy Storage." In "Proceedings of Innostock 2012 - 12th International Conference on Energy Storage," Lleida, Spain (2012). 
[9] R. M. Dickinson, C. A. Cruickshank, and S. J. Harrison. "Charge and Discharge Strategies for a Multi-Tank Thermal Energy Storage." In Press: Applied Energy DOI: 10.1016/j.apenergy.2012.11.032 (2012).

[10] R. M. Dickinson, C. A. Cruickshank, and S. J. Harrison. "The Effect of Discharge Configurations on the Thermal Behaviour of a Multi-Tank Storage System." In "Proceedings of SHC 2012 - 1st International Conference on Solar Heating and Cooling for Buildings and Industry," San Francisco, CA. DOI: $10.1016 /$ j.egypro.2012.11.026 (2012).

[11] N. Altuntop, M. Arslan, V. Ozceyhan, and M. Kanoglu. "Effect of Obstacles on Thermal Stratification in Hot Water Storage Tanks." Applied Thermal Engineering 25(14-15), 2285-2298 (2005).

[12] K. G. T. Hollands and M. F. Lighstone. "A Review of Low-Flow, Stratified-Tank Solar Water Heating Systems." Solar Energy 43(2), 97-105 (1989).

[13] L. J. Shaw and S. Furbo. "Entrance Effects in Solar Storage Tanks." Solar Energy 75(4), 337-348 (2003).

[14] Y. M. Han, R. Z. Wang, and Y. J. Dai. "Thermal Stratification within the Water Tank." Renewable and Sustainable Energy Reviews 13, 1014-1026 (2009).

[15] M. Y. Haller, C. A. Cruickshank, W. Streicher, S. J. Harrison, E. Andersen, and S. Furbo. "Methods to Determine Stratification Efficiency of Thermal Energy Storage Processes - Review and Theoretical Comparison." Solar Energy 83(10), $1847 \cdot 1860(2009)$.

[16] D. W. Mather, K. G. T. Hollands, and J. L. Wright. "Single- and Multi-Tank Energy Storage for Solar Heating Systems: Fundamentals." Solar Energy 73(1), $3-13$ (2002).

[17] C. A. Cruickshank and S. J. Harrison. "Thermal Response of a Series- and Parallel-connected Solar Energy Storage to Multi-Day Charge Sequences." Solar Energy 85(1), 180-187. DOI: 10.1016/j.solener.2010.09.010 (2011).

[18] M. Perlman and B. E. Mills. "Development of Residential Hot Water Use Patterus." ASHRAE Transactions 91(2), 657-679 (1985).

[19] T. J. Merrigan. "Residential Hot Water Use in Florida and North Carolina." ASHRAE Transactions 94(1), 1099-1109 (1988). 
[20] M. Perlman and N. H. Milligan. "Hot Water and Energy Use in Apartment Buildings." ASHRAE Transactions 94(1), 1087-1098 (1988).

[21] B. R. Becker and K. E. Stogsdill. "Development of a Hot Water Use Data Base." ASHRAE Transactions 96(2), 422-427 (1990).

[22] Gilbert Associates Inc. "EPRI EA-4006, Research Project 1101-1." Electric Power Research Institute, Palo Alto, CA (1985).

[23] E. Hirst, R. Goeltz, and M. Hubbard. "Determinants of Electricity Use for Residential Water Heating: The Hood River Conservation Project." Energy Conversion and Management 27(2), 171-178 (1987).

[24] P. Fairey and D. Parker. "A Review of Hot Water Draw Profiles Used in Performance Analysis of Residential Domestic Hot Water Systems." Florida Solar Energy Center (2004).

[25] ANSI/ASHRAE Standard 90.2-1993. "Energy Efficient Design of Low-Risc Residential Buildings." American Society of Heating, Refrigerating and Air Conditioning Engineers pages 53-54 (1993).

[26] M. P. Bouchelle, D. S. Parker, and M. T. Anello. "Factors Influencing Water Heating Energy Use and Peak Demand in a Large Scale Residential Monitoring Study." In "Proceedings of the 12th Symposium on Improving Building Systems in Hot and Humid Climates," San Antonio, TX (2000).

[27] M. Thomas, A. C. S. Hayden, O. Ghiricociu, R. L. D. Cane, and R. Gagnon. "A New Study of Hot-Water Use in Canada." ASHRAE Transactions 117(1), $673-682(2011)$.

[28] CAN/CSA-P.3-04. "Testing Method for Measuring Energy Consumption and Detcrmining Efficiencies of Gas-Fired Storage Water Heaters." (2004).

[29] CAN/CSA-P.7-98. "Testing Method for Measuring Energy Loss of Gas-Fired Instantaneous Water Heaters." (1998).

[30] ANSI/ASHRAE Standard 118.2-2006. "Method of Testing for Rating Residential Water Heaters." American Society of Heating, Refrigerating and Air Conditioning Engineers (2006).

[31] "SRCC: OG-300 Operating Guidelines for Certifying Solar Water Heating Systemis." Solar Rating and Certification Corporation, Cocoa. FL (2012). 
[32] "CAN/CSA-F379.1-88: Solar Domestic Hot Water Systems (Liquid to Liquid Heat Transfer)." Canadian Standards Association, Mississauga, Ontario (2004).

[33] E. Andersen and S. Furbo. "Thermal De-stratification in Small Standard Solar Tanks Due to Mixing During Tapping." In "Proceedings of the ISES Solar World Congress," Jerusalem, Israel (1999).

[34] S. Furbo, E. Andersen, A. Thü̈, L. J. Shah, and K. D. Andersen. "Performance Improvement by Discharge from Different Levels in Solar Storage Tanks." Solar Energy 79, 431-439 (2005).

[35] U. Jordan and S. Furbo. "Thermal Stratification in Small Solar Domestic Storage Tanks Caused by Draw-offs." Solar Energy 78(2), 291-300 (2005).

[36] V. Ragoonanan, J. H. Davidson, K. O. Homan, and S. C. Mantell. "The Benefit of Dividing an Indirect Thermal Storage into Two Compartments: Discharge Experiments." Solar Energy 80, 18-31 (2006).

[37] U. Jordan and K. Vajen. "Influence of the DHW Load Profile on the Fractional Energy Savings: A Case Study of a Solar Combi-System with TRNSYS Simulations." Solar Energy 69(6), 197-208 (2000).

[38] A. A. Dehghan and A. Barzegar. "Thermal Performance Behavior of a Domestic Hot Water Solar Storage Tank During Consumption Operation." Energy Conversion and Management 52, 468-476 (2011).

[39] J. F. Haltiwanger and J. H. Davidson. "Discharge of a Thermal Storage Tank Using an Immersed Heat Exchanger with an Annular Baffle." Solar Energy 83, 193-201 (2009).

[10] S. A. Klein et al. "TRNSYS 17 - A TRaNsient SYstem Simulation Program - User Manual." Solar Energy Laboratory - University of Wisconsin-Madison, Madison, WI (2010).

[41] B. J. Newton. Modeling of Solar Storage Tanks. Master's thesis, Department of Mechanical Engineering, University of Wisconsin-Madison, Madison, WI (1995).

[42] Y. Allard, M. Kummert, M. Bernier, and A. Moreau. "Intermodel Comparison and Experimental Validation of Electrical Water Heater Models in TRNSYS." In "Proceedings of Building Simulation 2011 - 12th Conference of the International Building Performance Simulation Association," Sydney, Australia (2012). 
[43] K. F. Fraser, K. G. T. Hollands, and A. P. Brunger. "An Empirical Model for Natural Convection Heat Exchangers in Solar Heating Systems." Solar Energy 55(2), 75-84 (1995).

[44] J. M. Purdy, S. J. Harrison, and P. H. Oosthuizen. "Thermal Evaluation of Compact Heat Exchangers in a Natural Convection Application." In "Proceedings of the 11th IHTC - International Heat Transfer Conference," Kyongju, Korea (1998).

[45] S. J. Harrison. "Passive Heat Exchanger Anti-Fouling for Solar DHW Systems." In "Proceedings of ISEC, ISEC2005-76232," Orlando, FL (2005).

[46] "National Instruments LabVIEW Version 8.0." Austin, TX (2005).

[47] "Temperature Measurement." Supplement to American Society of Mechanical Engineers PTC 19.3 (1974).

[48] Y. H. Zurigat, P. R. Liche, and A. J. Ghajar. "Turbulent Mixing Correlations for a Thermocline Thermal Storage Tank." AIChE Symposium Series, S.B. Yilmaz, ed., AIChE 84(263), 160-168 (1988).

[49] C. A. Cruickshank and S. J. Harrison. "Simulation and Testing of Stratified Multi-tank Thermal Storages for Solar Heating Systems." In "Proceedings of the EuroSun 2006 Conference," Glasgow, Scotland (2006).

[50] "Engineering Equation Solver." University of Wisconsin Madison, Madison, WI (2012).

[51] J. Burch and C. Christensen. "Towards Development of an Algorithm for Mains Water Temperature." In "Proceedings of the Solar 2007 Conference," Cleveland, $\mathrm{OH}(2007)$.

[52] W. Weiss, editor. Solar Heating Systems for Houses - A Design Handbook for Solar Combisystems. James and James, London, UK (2003).

[53] E. Andersen and S. Furbo. "Theoretical Variations of the Thermal Performance of Different Solar Collectors and Solar Combi Systems as Function of the Varying Yearly Weather Conditions in Denmark." Solar Energy 83(4), 552-565 (2009).

[54] M. Lundh. K. Zass, C. Wilhemls, K. Vajen, and U. Jordan. "Influence of Store Dimensions and Auxiliary Volume Configuration on the Performance of MediumSized Solar Combisystems." Solar Energy 84(7), 1095-1102 (2010). 
[55] F. C. Hooper. "The Possibility of Complete Solar Heating of Canadian Buildings." In "69 th Annual General and Professional Meeting of the Engineering Institute of Canada," Toronto, ON, Canada (1955).

[56] International Energy Agency - Solar Heating and Cooling Programme. "IEASHC Task 26 - Solar Combisystems." http://www.iea-shc.org/task26. Accessed October, 2011.

[57] T. Letz, C. Bales, and B. Perers. "A New Concept for Combisystems Characterization: The FSC Method." Solar Energy 83(9), 1540-1549 (2009).

[58] T. Letz. "Validation and Background Information on the FSC Procedure." Technical report, International Energy Agency. A Report of IEA-SHC Task 26, Subtask A (2002).

[59] P. D. Lund. "Sizing and Applicability Considerations of Solar Combisystems." Solar Energy 78(1), 59-71 (2005).

[60] International Energy Agency - Solar Heating and Cooling Programme. "CombiSun." http://www.elle-kilde.dk/altener-combi/dwload.html. Accessed October, 2011.

[61] European Commission. "Altener Project - Solar Combisystems." http://www. elle-kilde.dk/altener-combi/. Accessed October, 2011.

[62] International Energy Agency - Solar Heating and Cooling Programme. "IEASHC Task 32 - Advanced Storage Concepts for Solar and Low Energy Buildings." http://www . iea-shc.org/task32. Accessed October, 2011.

[63] T. Letz. "The Extended FSC Procedure for Large Storage Capacity." Technical report, International Energy Agency. Report A1 of IEA-SHC Task 32, Subtask A (2007).

[64] R. Heimrath and M. Haller. "The Reference Heating System, the Template Solar System of Task 32." Technical report, International Energy Agency. Report A2 of IEA-SHC Task 32, Subtask A (2007).

[65] T. Letz. "Performances of Solar Combisystems with Advanced Storage Concepts." Technical report, International Energy Agency. Report A3 of IEA-SHC Task 32, Subtask A (2007). 
[66] J. C. Hadom, T. Letz, and M. Haller. "Method and Comparison of Advanced Storage Concepts." Technical report, International Energy Agency. Report A4 of IEA-SHC Task 32, Subtask A (2007).

[67] SBRN. "Solar Building Research Network - Website." http://www . solarbuildings.ca/. Accessed October, 2011.

[68] R. Charron and A. Athienitis. "Design and Optimization of Net Zero Energy Solar Homes." ASHRAE Transactions 112, 285-295 (2006).

[69] J. Gusdorf, R. Charron, and K. Winder. "Canada's EQuilibrium ${ }^{\mathrm{TM}}$ Housing Demonstration Initiative: Net-Zero Energy Houses in Cold Climates." In "ACEEE Summer Study on Energy Efficiency in Buildings," pages 88-102 (2010).

[70] Natural Resources Canada. "HOT2000." http://canmetenergycanmetenergie.nrcan-rncan.gc.ca/. Accessed October, 2011.

[71] Natural Resources Canada. "RETScreen Clean Energy." http://www. retscreen.net/. Accessed October, 2011.

[72] A. Hugo, R. Zmeureanu, and H. Rivard. "Solar Combisystem with Seasonal Thermal Storage." Journal of Building Performance Simulation 3(4), 255-268 (2010).

[73] Canadian Mortgage and Housing Corporation. "Better Buildings: Case Study Number 60: Solar Energy for Domestic Water and Space Heating." www.cmhcschl.gc.ca/en/inpr/bude/himu/bebu/upload/65276.pdf. Accessed October, 2011.

[74] R. S. Figliola and D. E. Beasley. Theory and Design for Mechanical Measurements. ISBN: 978-0-471-44593-7. Wiley, Hoboken, NJ, 4th edition (2006).

[75] S. J. Kline and F. A. McClintock. "Describing Uncertainties in Single Sample Experiments." Mechanical Engineering 75 (1953).

[76] R. J. Moffat. "Uncertainty Analysis in the Planning of an Experiment." Journal of Fluids Engineering 107, 173-181 (1985).

[77] Guildine Instruments Limited. "Certificate of Calibration. Certificate no. GCS 10525." Smith Falls, ON, Canada (2007). 


\section{Appendix A}

\section{Previous Work on Solar Combisystems}

Solar heating systems are widely used in several European countries for domestic hot water leating, and in the past decade, an increasing number of solar combined space and hot water heating systems (typically referred to as "combisystems") have begun to take precedence. In Canada, however, the majority of all residential solar thermal installations are for heating domestic hot water.

To date, various combisystem configurations have been investigated under the auspices of the International Energy Agency, Task 26 and Task 32. Within these tasks, various system configurations were modelled and test procedures developed to allow standard performance evaluations to be conducted. This work, although extensive, has limited application within the North American context. At present, little research has been conducted on the applicability of these systems for residential housing. In particular, due to Canada's more severe winters, larger solar collector arrays would be required to significantly contribute to the space heating load. This has drawbacks, as much of the solar capacity would not be utilized during the summer, leading to poor economic performance and possible overheating that could accelerate degradation or scald occupants. Therefore, there is a need to optimize the configuration of solar combisystems to avoid over-sizing while maximizing the utilization of solar energy in 
a safe and economic manner.

The focus of this study was to review the current literature on solar combined space and domestic hot water heating systems, with a particular emphasis on the work which has been conducted by the International Energy Agency. In addition, a review of combined space and domestic hot water systems currently installed in Canada are also discussed.

In contrast to a traditional SDHW system, additional solar energy is required when using a solar combisystem to meet the demand imposed by space heating loads. The space heating demand is influenced by several factors, including building size, conduction/convection losses through the building envelope, ventilation, infiltrations, internal thermal gains from occupants, equipments, and lighting, passive solar gains through windows, the presence of thermal mass, and user behavior [52].

In order to meet this increase in energy demand, the collector area is typically increased. In climates where space heating loads account for a smaller fraction of the total heating loads, i.e., where domestic hot water (DHW) production dominates space heating, the increase in collector array size has minimal drawbacks during the warmer seasons. In cold climates, however, the space heating load has a significantly large seasonal variation compared to the DHW load. The larger collector area would prove beneficial to offset these loads; however, such a design would lead to massive overheating during the summer months when space heating is not required. A significant factor that influences the performance of a solar combisystem is varying weather conditions. Andersen and Furbo [53] reported that solar combisystems with high efficiency solar collectors are more influenced by weather variations from one year to another than systems with low efficiency solar collectors. Additionally, evacuated tube solar collectors utilize large parts of diffuse radiation relatively better than flat plate collectors. 
Apart from seasonal variations, space heating demands are relatively continuous throughout the day, while DHW draw profiles can have short, unpredictable peaks of consumption, largely dependent on the user and varying between 15 and $120 \mathrm{~L}$ per day per person at a temperature of $45^{\circ} \mathrm{C}$ [52].

In order to accommodate the additional heating loads as well as minimize mixing inside the tank, an auxiliary volume is occasionally used so that each tank supplies water for a dedicated purpose. Lundh et al. [54] investigated both the geometry and dimensioning of thermal storages, as well as internal and external auxiliary volume configurations for medium-sized solar combisystems and large storage volumes. This work was conducted using the TRNSYS simulation software (a modelling tool designed to simulate the transient performance of thermal energy systems [40]). The authors concluded that an internal volume yields higher fractional energy savings (this concept is explained later) for almost any volume and geometry configuration of the internal storage tank compared to external auxiliary volumes [54].

\section{A.1 Solar Combisystems}

In Canada, little research has been conducted on the applicability of combisystems for residential housing. In particular, due to Canada's more severe winters, one of the major challenges limiting the growth of the combisystem market lies in the difficulty of optimizing the system such that space heating loads could be met during the winter months. while simultancously preventing significant overheating during the summer months. Hooper [55] investigated the feasibility of designing such a solar system for a Canadian residence, addressing the challenge of providing all necessary heating (including space heating) at all times during the year without requiring auxiliary heat sources. 
One of the primary drawbacks of using a larger collector array to meet the space heating loads is that much of the solar capacity would be wasted during the summer, leading to poor economic performance and possible overheating that could accelerate system degradation or scald occupants. As a result, there is a need to optimize the configuration of these systems (in particular, the thermal energy storage) to avoid over-sizing while maximizing the utilization of solar energy in a safe and economic manner.

The optimum design of a thermal energy storage (TES) for a combisystem depends on many factors, including the temporal distribution, magnitude and temperature of the solar energy supply and thermal loads. The variation of the load throughout the day and season, the required charge and discharge rates, and the spatial limitations related to the installation and placement of the storage, must also be considered [52]. Moreover, the sizing and orientation of the solar array and overall system controls are also important considerations.

\section{A.1.1 The International Energy Agency}

Various combisystem configurations have previously been investigated under the auspices of the International Energy Agency (IEA) Solar Heating and Cooling (SHC) programme. The IEA was established in 1974 as an autonomous agency within the framework of the Organization for Economic Co-operation and Development (OECD) to carry out a comprehensive programme of energy co-operation among its 25 member countries and the Commission of the European Communities. Subsequently, the SHC programme was established in 1977 with the purpose of advancing active solar, passive solar and photovoltaic technologies and their application in buildings. 


\section{A.1.2 IEA-SHC Task 26}

From December 1998 to December 2002, 35 experts from Europe and the USA collaborated on a project under the IEA-SHC Task 26 Solar Combisystems [56]. The focus of Task 26 was to review, analyze, test, compare, and optimize designs for combisystems which were available at the time for detached single-family and multi-family houses. Additionally, the development of a standardized test procedure for rating solar combisystems would lead to greater confidence in this technology by the end user.

Within Task 26, three subtasks were defined:

- Subtask A System Survey and Dissemination of Task Results;

- Subtask B Development of Performance Test Methods and Numerical Models for Combisystems and Their Components; and

- Subtask C Optimization of Combisystems for the Market.

The results of Task 26 are summarized in the book entitled "Solar Heating Systems for Houses - A Design Handbook for Solar Combisystems" [52]. The book covers 21 solar combisystem configurations, each classified under two categories. The first category involves the method used for storing the heat produced by the solar collectors for space heating. The design can consist of either a distributed storage system using multiple tanks and stratifiers, or a lack of controlled storage device for space heating (c.g.. a flooring system which combines the functions of heat delivery and storage). In addition, the storage tank can utilize natural convection with either built-in stratifiers or without stratifiers. The second category involves the management philosophy for heat produced by the auxiliary heater. The space heating loop can have a combined TES: charged by either the solar collectors, auxiliary heater or both (referred to as 
Mixed mode): fed alternatively by the auxiliary heater or by the solar collector(s) (Parallel mode), or fed by the auxiliary heater or both solar collector and auxiliary heater connected in series on the return line of the space heating loop (Serial mode). In addition, the combisystem may feature a drainback design (i.e., where the circulating fluid drains out of the collector when not in use). an integrated heater inside the TES, and/or an auxiliary energy source.

\section{The Fractional Solar Consumption Method}

The various combisystem designs considered in Task 26 were compared through annual system simulations performed using the simulation tool TRNSYS. A set of reference conditions, involving energy demands, energy sources, parameter settings, and standard components, were documented [52].

One of the outcomes of Task 26 is a means of characterizing the performance of solar combisystems according to the Fractional Solar Consumption (FSC) Method $[52,57]$. This performance parameter is considered as the maximum theoretical fractional energy savings that could be reached if the solar combisystem had no losses. It is a dimensionless quantity, suitable for comparing systems in terms of climate, collector size, collector orientation, tilt angles, and building space and water heating loads. The objective is to compare the actual fractional energy savings of the system with the theoretical FSC. The fractional energy savings are defined as the saved auxiliary energy consumption compared to the energy consumption of a reference system without solar. Within Task 26 , the reference systems vary depending on the combisystem considered. In general, the reference system has no solar collector, but has the same auxiliary energy source, the same heat distribution lines and heat emission devices, and a comparable DHW production unit as well as a similar controller. The fractional energy saving can include only thermal energy, or additionally, can include 
parasitic energy introduced through the use of pumps, controllers, etc., and/or can include penalties for periods when the solar combisystem does not meet the defined comfort requirements [52].

To determine the FSC, the usable solar energy is divided by the yearly reference consumption. The usable solar energy is dependent on the solar collector area, monthly solar irradiation in the collector plane, and monthly reference consumption. The yearly reference consumption is the summation of all monthly reference consumptions. Finally, the monthly reference consumption is the monthly energy consumption without a solar combisystem. defined by the sum of the space and domestic hot water heating loads plus the losses, divided by a reference boiler efficiency. Some limitations to the use of this method include orientations only up to $45^{\circ} \mathrm{C}$ from south and $\mathrm{DHW}$ loads of 150-300 L/day. A validation of this method was also conducted [58].

Using this approach, it was concluded that the best system investigated under Task 26 in terms of thermal performance was System \#15 from Germany. The simulation conditions used were for a single family house having $60 \mathrm{kWh} / \mathrm{m}^{2}$ annual space heating demand (as defined for the reference building) and a collector area near $10 \mathrm{~m}^{2}$ for the Zurich climate. This system consists of a compact unit in which all components (auxiliary condensing gas burner, DHW flat-plate heat exchanger with its primary pump, solar loop, heat exchanger and solar hydraulic unit) are integrated. The space heating storage tank has two stratifiers with an external load-side heat exchanger for domestic hot water.

\section{Dimensioning Guidelines}

When considering the optimization of each of the aforementioned combisystem designs, it is favorable to minimize costs and space requirements. This is achieved through the integration of multiple components within the system. Trends show that 
for most systems, space requirements increase as collector area increases. However, highly integrated systems (e.g.. systems using a heating floor as a heat sink, highly integrated systems with the boiler and store in a single unit) were exceptions to this trend and are very space efficient [52].

In addition to the space requirements by the system components, the collector area needed for solar combisystems is significantly larger than for SDHW systems and this factor requires consideration. The usual range of collector areas of a solar combisystem is $10-30 \mathrm{~m}^{2}$ for a single family house, but can go up to several hundred square metres for multi-family houses [52]. Such large designs pose challenges in building integration, as some systems may not be aesthetically appealing. Task 26 discusses several methods for roof integration such as on-roof assembly, collectors as roof cover modules, collector modules with framing, and collectors as factorybuilt units. In addition, faade integration leads to a more balanced collector yield throughout the year.

It is shown that the highest solar fraction (the fraction of energy provided by solar technology) for systems located in the Northern Hemisphere is achieved with southward orientation (slightly westwards), having an optimum tilt angle of about $55^{\circ}$ [52]. Nevertheless, the decrease in performance between tilt angles from $30^{\circ}$ to $75^{\circ}$ and an orientation varying within $30^{\circ}$ from south is very small (less than a $10 \%$ reduction in energy savings for a central European climate). Additionally, a solar collector mounted vertically (i.e., façade integration) on a south-facing wall has only $20 \%$ less fractional savings than an optimally mounted collector, and has much higher fractional savings than a horizontally mounted collector.

Lund [59] investigated the sizing of collector area in solar combisystems with short-term heat storage. He concluded that increasing the collector area in a solar 
combisystem to achieve higher solar fractions could be justified economically in average or older buildings in northern and central Europe, but not in low energy of very cnergy efficient buildings.

Regarding the sizing of TES, it was found from Task 26 that solar combisystems with relatively small collector areas can have a decrease in the fractional energy savings if the storage is too large, as a result of increased heat losses [52]. An accepted rulc of thumb for TES is 50-100 L of storage volume for every square metre of flat-plate collector area.

Lastly, the savings achieved by a solar combisystem due to the auxiliary heater are dependent on three parameters: the boiler efficiency, the temperature set-point for the auxiliary heated part of the TES (high set-points result in high losses to the surroundings, while low set-points may not achieve the desired thermal comfort), and the volume heated by the auxiliary heater. Design Tools for Combisystems

Within the framework of Task 26, several tools were created to aid in the design of solar combisystems. Developed in 1975, the f-chart method provides a means to estimate the fraction of the total heating load that would be supplied by solar energy for a given system [2]. This tool, while applicable to solar combisystems, does not take into account the dynamic nature of the system.

The Task 26 nomogram allows for the sizing or comparison of various system designs within the Task 26 framework. The nomogram is used by first selecting a system (as described in Task 26), a climate, collector area, and reference consumption for consideration. While this method provides a quick estimate of the fractional energy savings, it is limited to the systems and climates considered within the Task.

In addition to the nomogram tool, the program "CombiSun" [60] was developed based on the FSC method. The program is applicable for various climates, and can accommodate new system designs which differ from those evaluated with Task 26. 
As well. CombiSun can use results from TRNSYS to calculate the FSC values for a range of collector areas [52]. Unfortunately, the limitations of CombiSun are the same as those of the FSC method.

\section{A.1.3 Altener Project}

From April 2001 to March 2003, as a follow-up to Task 26, the ALTENER Project "Solar Combisystems", documented and theoretically evaluated more than 200 solar combisystem designs installed in 7 European countries. In addition, 39 combisystems were also monitored in detail. The objective of the project was to demonstrate efficient combisystem designs. One of the outcomes of the project is a report entitled "Conditions and Problems to be Aware of When Integrating Solar Combisystems" [61]. This particular report summarizes the various challenges encountered in selecting and installing these systems. Some of the challenges relate to system components and designs (such as collector placement and overheating in the collector loop), while other aspects include the interaction of the solar heating system with the building and existing space heating system, and erroneous and/or insufficient installation or maintenance.

\section{A.1.4 IEA-SHC Task 32}

From July 2003 to December 2007, IEA-SHC Task 32 (Advanced Storage Concepts for Solar Thermal Systems in Low-Energy Buildings) addressed the integration of solar combisystems into high solar fraction, low-energy houses [62].

As a result of Task 32, several reports pertaining to solar combisystems were produced within Subtask A. Report A1 entitled "The Extended FSC (FSC) Procedure for Large Storage Capacity", improved the original FSC method developed during 
Task 26. so that it is now applicable to larger storage capacities [63]. The changes now consider a heat storage capacity term which is dependent on the storage material used as well as a storage size correction factor. Report A1 shows that the new correction factors more accurately predict the behavior of the fractional energy savings for solar combisystems compared to the original method.

Report A2 entitled "The Reference Heating System, the Template Solar System of Task 32" [64] defines reference conditions for the simulation of solar combisystems for various European climates and building loads. The reference conditions are based on a further development of those used in Task 26, and are intended to establish a basis for comparing new system designs using TRNSYS simulation within the framework of Task 32 .

Report A3 entitled "Performances of Solar Combisystems with Advanced Storage Concepts" [65] presents the system designs and results using the Extended FSC method for storage solutions based on water storage, phase change material storage, and sorption storage. Only water storage will be discussed here.

Four different solar combisystem configurations were investigated using water as the storage medium. The first system, The Template Solar System, is the reference system described in Report A2 of Task 32; it provides a basis for comparing the other system designs. Regarding the reference system, energy from the collector loop is transferred to the storage tank via a counter-flow heat exchanger and a stratification inlet pipe. A second external exchanger is used to transfer heat from the storage tank to the DHW, and the storage tank has a direct flow outlet to and return inlet from the space heating loop. An auxiliary gas boiler is also available in a separate loop with the storage tank.

The second system consists of two configurations which were investigated at the Technical University of Denmark. Both systems use an external heat exchanger for 
the DHWV as in the Template system. The first configuration consists of an immersed heat exchanger for the collector loop, and treats space heating in the same way as the Template system. The second configuration consists of an external heat exchanger and a stratification inlet pipe for the collector loop, and a return inlet stratifier for the space heating loop.

The third solar combisystem, the HEIG-VD system, utilizes a drainback design in the collector loop and connects directly to the central storage tank with no statificrs. Domestic hot water is heated using an external flat-plate heat exchanger similar to the Template system, but can be heated as well by an auxiliary gas burner which can alternate between heating the DHW loop and space heating loop.

Lastly, the SPF system represents a hypothetical system. It also features a drainback design, stratifiers, and includes an auxiliary heating loop connected directly to the tank. The operation of the auxiliary heating loop is controlled independently by two temperature sensors. The space heating loop employs a Direct Feed Flow Controlled strategy, which regulates the flow rate delivered to the space heating system as opposed to varying the supply temperature. This approach has been found to significantly enhance system performance. Domestic hot water is heated using an external heat exchanger as well.

Report A4 entitled "Method and Comparison of Advanced Storage Concepts" [66] compares the performance of the previously listed Combisystems. The results suggest that drainback systems outperform the other systems. Additionally, stratifiers in the TES typically improve the thermal performance, with the exception that only limited improvement in thermal performance is achieved if the return temperature of the space heating loop is at a low level. Lastly, the results indicate that a high ratio of storage size to collector area improves thermal performance, particularly if the collector area is large compared to the heating load - a larger TES could store more energy for use 
during periods when solar energy is unavailable.

Through comparison of the Extended FSC and fractional energy saving curves, it was shown that the SPF and HEIG-VD systems perform much better due to the drainback design. Comparing these two designs, the HEIG-VD system uses less parasitic electricity for operating pumps and valves and thus has the best performance.

\section{A.1.5 Canadian Combisystems}

Although the number of combisystems currently installed in Canada are limited, they have gained much interest in the last few years. This is due in part to the Canada Mortgage and Housing Corporations (CMHC) EQuilibrium Housing Demonstration Initiative launched in 2006, as well as the contributions from the Solar Buildings Research Network (SBRN). The EQuilibrium initiative is intended to promote the development of Net-Zero Energy houses for the Canadian market by both public and private sectors. A Net-Zero Energy house is defined as a house that produces as much energy as it consumes on an annual basis. Furthermore, the SBRN, funded under the Natural Sciences and Engineering Research Council of Canadas (NSERC) Strategic Network Grants program, has performed research and demonstration projects on technologically advanced optimized solar buildings and their energy systems [67]. This included the experimental and numerical evaluation of novel thermal storage concepts and the analysis of solar storage systems.

In a recent paper by Charron and Athienitis [68], strategies are discussed for designing a passive net-zero house for the Canadian climate. The authors suggest that solar combisystems be used in conjunction with auxiliary heating to meet the heating needs during the winter months. Additionally, to avoid overheating during summer months. they suggest using a façade integration approach for the collectors. This solution is more beneficial compared to roof systems as summer peak generation 
is reduced and overall winter heat losses from walls covered with collectors are lower. This result has been confirmed both by simulations and by the monitoring of test façades [52].

Furthermore, Gusdorf et al. [69] evaluated the design and performance of three projects that were part of the EQuilibrium initiative - two of which have solar combisystems discussed in the next paragraphs. Energy use was modelled using the building energy simulation program HOT2000 [70], and renewable energy production from photovoltaic (PV) and SDHW systems were modelled using RETScreen [71]. Of the 15 houses involved in the EQuilibrium program, 10 had installed solar combisystems.

The first house equipped with a combisystem discussed by Gusdorf et al. was named the Avalon Discovery III, located in Red Deer, Alberta, Canada. The combisystem included $15.3 \mathrm{~m}^{2}$ of flat-plate panels mounted vertically on south-facing walls, and $908 \mathrm{~L}$ of water storage in two insulated tanks. The system was predicted to produce $3420 \mathrm{kWh} / \mathrm{yr}$, or $29 \%$ of the combined space heat and DHW energy consumption [69]. From July 2009 to April 2010, the measured energy production from the solar combisystem accounted for $24 \%$ of the total space heat and DHW consumption.

The second house was named the Riverdale NetZero Project, a semi-detached duplex, located in Edmonton, Alberta, Canada. The house featured a combisystem for each unit, having a collector area of $22 \mathrm{~m}^{2}$ and water storage tanks of $300 \mathrm{~L}$ for DHW and 17,000 L for space heating. The predicted annual energy production accounted for $59 \%$ of the combined space heat and DHW energy consumption. Due to the complexity of the system, data was only available beginning January 2010. From March to April 2010, the monitored data showed that $70 \%$ of the total space heat and DHW load was provided by the combisystem, while the remaining $30 \%$ was supplied by an electric heater. 
In re-evaluating the designs of both houses, the Avalon Design Team concluded that a smaller solar thermal collection and storage system is preferred to their oversized system due to the additional expenses incurred by equipment costs, labor, system complexity and space requirements. The Riverdale Team concluded that large, complex combisystems are not practical. Builders have since eliminated these systems in favor of large PV systems in subsequent Net-Zero projects.

While these combisystem designs may not meet all of the heating loads for the Canadian climate, the possibility of long-term storage presents a feasible option in achieving high solar fractions. In a paper by Hugo et al. [72], the authors demonstrated using the TRNSYS simulation software that solar energy alone could cover the entire heating and domestic hot water loads of a one-storey detached house in Montreal, Canada.

\section{Combisystem in Ottawa, Canada}

Located close to Carleton University, a multi-family housing project with seven units and a common area underwent a retrofit in January 2005 [73]. A total of 160 evacuated tube collectors (having a total absorptive surface area of $16 \mathrm{~m}^{2}$ ) were mounted to the roof at a tilt angle of $60^{\circ}$. The combisystem includes a collector loop which circulates a glycol solution to a heat exchanger located inside a $450 \mathrm{~L}$ storage tank. As this tank is heated, a pump circulates the hot water to a second tank, which in turn feeds a central gas boiler. The boiler has internal concentric tanks for DHW and space heating. This provides DHW to four of the seven units and the common area, and space heating to three units and the common area. Furthermore, the second tank is equipped with an internal heat exchanger such that when the temperature of the tank reaches the boiler set-point $\left(70-80^{\circ} \mathrm{C}\right)$, hot water from the second tank disperses into the space-heating loop. It is estimated that the solar combisystem produces $39.5 \mathrm{GJ}$ 
per year. and displaces approximately $30 \%$ of anmual gas consumption.

The collector array was sized to meet the heating requirements necessary throughout the winter months. Although an estimated collector area of $12 \mathrm{~m}^{2}$ would meet the DHW consumption over the year, the system was found to overheat in the summer months as a result of the surplus collector material. To prevent overheating towards the end of April and throughout the summer each year, 30 to $40 \%$ of the tubes are manually turned so that the collectors are parallel to the sun's rays at noon, thus reducing solar gains. 


\section{Appendix B}

\section{Empirical Correlation of Natural \\ Convection Heat Exchanger Performance}

\section{Characteristics}

The method used in determining the performance characteristics of the natural convection heat exchangers follows the procedure outlined by Cruickshank [3] and Lin et al. [4], and was described in Chapter 3.

To fit the experimental data to an empirical correlation, the natural convection flow rate $\dot{m}_{\mathrm{s}}$, pressure drop $\Delta P$. modified effectiveness $\epsilon^{\prime}$, and modified capacitance ratio $C_{r}^{\prime}$. were calculated based on the tank temperatures, heat exchanger inlet and outlet temperatures, and the collector loop flow rate. The heat transfer across the heat exchanger was given in Eq. (3.5), and from this, the natural convection flow rate can be expressed as:

$$
\dot{m}_{s}=\frac{\dot{m}_{\mathrm{c}} c_{p_{\mathrm{c}}}\left(T_{1}-T_{4}\right)}{c_{p_{s}}\left(T_{2}-T_{3}\right)}
$$


The modified effectiveness, pressure drop, and modified capacitance ratio were calculated using Eqs. (3.8),(3.9), and (3.11), respectively, for constant temperature charge tests. The results of these calculations were plotted in Fig. B.1, and curve fits were applied which matched the form of the empirical correlations presented in Eqs. (3.10) and (3.12). Figures B.1(a) and B.1(b) correspond to the series charge test presented in Section 5.2.

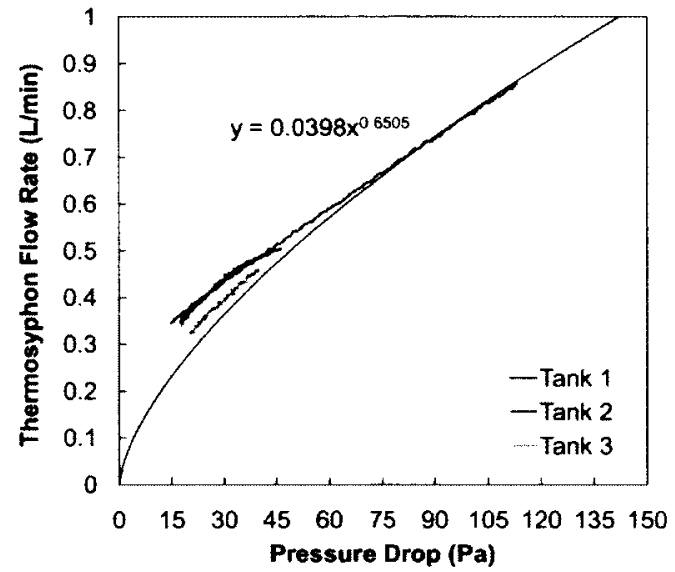

(a) Flow rate correlation with series charge data.

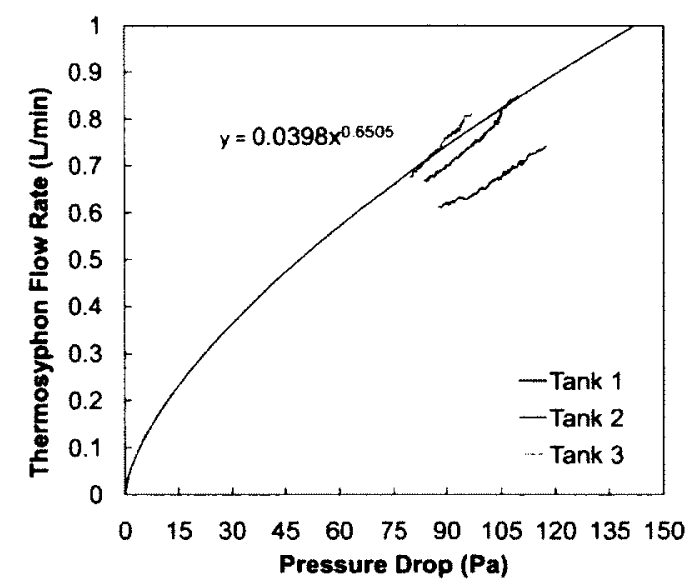

(c) Flow rate correlation with parallel charge data.

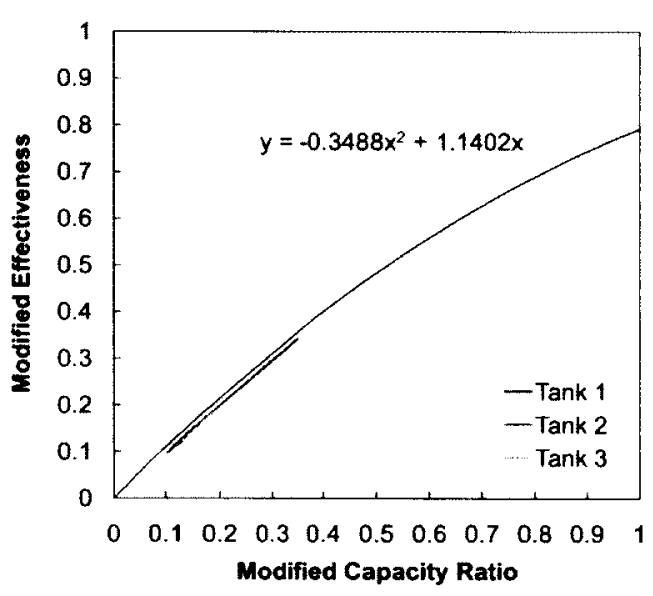

(b) Modified effectiveness correlation with series charge data.

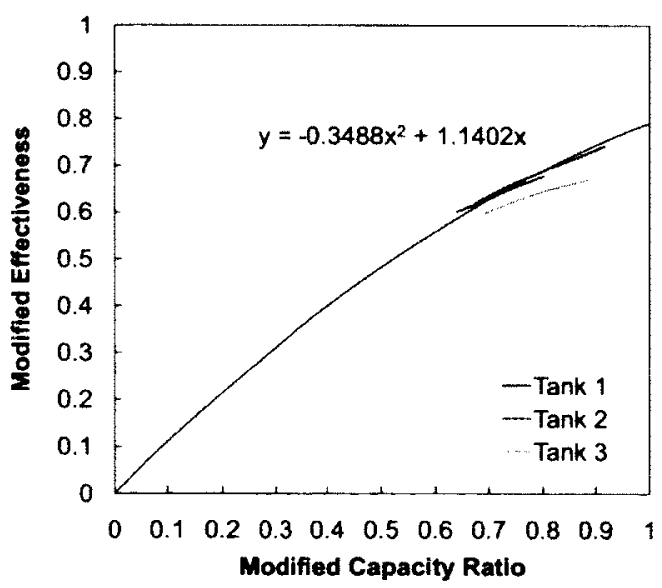

(d) Modified effectiveness correlation with parallel charge data.

Figure B.1: Plot of empirical correlations for charging in either series or parallel. 
Based on the results of this analysis and the agreement between the experimental data and the empirical correlations, the coefficients used in the previous study by Cruickshank [3] were considered applicable to the present study, where $a$ and $b$ were determined to be $2.388 \mathrm{~kg} / \mathrm{h}(0.0398 \mathrm{~L} / \mathrm{min})$ and 0.6505 , respectively, and $c, d$ and $e$ were verified to be $-0.3488,1.1402$, and 0 , respectively. 


\section{Appendix C}

\section{Instrumentation Calibration and Uncertainty Analysis}

Uncertainty in any experimental analysis is a significant factor in determining the accuracy of the measured data. As an example, small errors in measurements, such as temperatures or flow rates, can translate into large errors in calculated values. Without a proper analysis of these errors and how they propagate through calculations, it is difficult to assess whether the calculated values are representative of the true values. and how much they may differ. Errors can be classified into two general categories: systematic (or bias) errors, and random (or precision) errors [74]. Systematic errors remain constant in repeated measurements, and represent the offset between the true value and the sample mean. In contrast, random errors represent the distribution of the measured values about the sample mean. Calibration techniques can help reduce the systematic error of the measured data, while random errors can be estimated through statistical analyses. For all measurements, a confidence level of $95 \%$ was assumed for the random errors. The uncertainty analysis was conducted based on the methods developed by Kline and McClintock [75] and Moffat [76]. For

a given result, $R$, which consists of $L$ independent variables, a relationship can be 
expressed as:

$$
R=f_{1}\left\{x_{1}, x_{2}, \ldots, x_{L}\right\}
$$

where $x_{1}, x_{2}, \ldots, x_{L}$ represent different variables. each with some measure of uncertainty that affects the result. The true mean value, $R^{\prime}$, is therefore given as the mean value of the result, $\bar{R}$ plus an uncertainty, $u_{R}$, which is based on the individual uncertainties of $x$ propagated through to the result.

$$
R^{\prime}=\bar{R} \pm u_{R}
$$

The best estimate for $u_{R}$ is given by the root-sum-square method (RSS), where the RSS form can be derived from the linearized approximation of the Taylor series expansion, given by:

$$
\theta_{i}=\frac{\partial R}{\partial x_{i_{x=\bar{x}}}} \quad i=1,2, \ldots, L
$$

Finally, the uncertainty can be approximated as:

$$
u_{R}= \pm\left[\sum_{i=1}^{L}\left(\theta_{i} u_{\bar{x}_{i}}\right)^{2}\right]^{1 / 2}
$$

\section{C.1 Discharge Flow Rate and Draw Volume Uncertainty}

The experimental analysis consisted of draws at a constant flow rate of $11.4 \mathrm{~L} / \mathrm{min}$. In order to maintain a constant flow rate, an Armstrong balancing valve was installed at the discharge end of the system upstream from the solenoid valve. The balancing valve was calibrated by diverting the discharge flow into a graduated cylinder, thereby allowing the flow rate to be determined by measuring the time required to fill the cylinder with $2 \mathrm{~L}$ of water. Tests were repeated several times for both the series and 
parallel discharge configurations to ensure that the discharge configuration did not affect the resulting flow rate. The flow rate was calculated according to Eq. (C.5):

$$
\dot{\forall}=\frac{\forall}{t}
$$

where $\dot{\forall}$ is the volume flow rate of water in $\mathrm{L} / \mathrm{min}, \forall$ is the measured volume of water in $\mathrm{L}$, and $t$ is the recorded time in minutes. The uncertainty values in the measurements of volume $\left(u_{\forall}\right)$ and time $\left(u_{t}\right)$ were estimated to be $\pm 40 \mathrm{~mL}$ and $\pm 0.15 \mathrm{~s}$, and the error in the volume flow rate was calculated using the root-sum-square method as previously discussed. The resulting uncertainty calculation for the volume flow rate is given by Eq. (C.6).

$$
u_{\dot{\forall}}= \pm\left[\left(\frac{\partial \dot{\forall}}{\partial \forall} u_{\forall}\right)^{2}+\left(\frac{\partial \dot{\forall}}{\partial t} u_{t}\right)^{2}\right]^{1 / 2}
$$

The partial derivatives in Eq. (C.6) can be obtained from Eq. (C.5), resulting in the following expression:

$$
\begin{gathered}
u_{\dot{\forall}}= \pm\left[\left(\frac{1}{t} u_{\forall}\right)^{2}+\left(\frac{-\forall}{t^{2}} u_{t}\right)^{2}\right]^{1 / 2} \\
u_{\dot{\forall}}= \pm\left[\left(\frac{1}{0.1754 \mathrm{~min}} \cdot 0.04 \mathrm{~L}\right)^{2}+\left(\frac{-2 \mathrm{~L}}{0.03077 \min ^{2}} \cdot 0.0025 \mathrm{~min}\right)^{2}\right]^{1 / 2}
\end{gathered}
$$

Therefore, the error for the flow rate measurement was $\pm 0.28 \mathrm{~L} / \mathrm{min}$, or $2.5 \%$ of the measured flow rate of $11.4 \mathrm{~L} / \mathrm{min}$ (i.e., $\dot{\forall}=11.4 \pm 0.28 \mathrm{~L} / \mathrm{min}$ ). 
With the balancing valve calibrated to maintain a constant discharge flow rate, the volume of delivery water was calibrated to ensure that the draw profiles programmed into LabVIEW were delivering comparable volumes of water. Moreover, the delivered energy values calculated in Chapter 6 made use of the volumes measured by LabVIEW at each time interval. In order to measure the draw volume during discharging periods, a positive displacement flow meter was installed along the mains line, where a voltage pulse was produced and transmitted to the DA system for each $0.0381644 \mathrm{~L}$ of fluid volume flow passing through the flow meter. LabVIEW subsequently calculated the draw volume based on the voltage pulse count, and closed the solenoid valve once the calculated volume reached the target volume specified by the draw schedule. Calibration of the positive displacement flow meter was conducted by diverting the discharge flow into pails and recording the mass of water after each test. Between each test, the tare weight of the containers was also recorded.

Calibration tests were performed at draw volumes between $10 \mathrm{~L}$ and $50 \mathrm{~L}$, with 20 data points being obtained at the lowest volume $(10 \mathrm{~L})$, and 5 data points for each subsequent volume (Fig. C.1). Gravimetric volumes were plotted against the calculated LabVIEW volumes, and the residuals were plotted with respect to the LabVIEW readings to show the spread of data. To reduce the systematic error in the draw volumes, a linear regression was applied to the data in Fig. C.1(a), and the draw volumes were adjusted by a factor of 0.9879 with an offset of $2.2 \mathrm{~L}$ (i.e., the LabVIEW calculated flow rates were multiplied by 0.9879 , and then $2.2 \mathrm{~L}$ was added to the calculated volume in order to obtain closer values to the gravimetric data).

A precision interval with a probability of $95 \%$ has been included to illustrate the random errors associated with the discharge volume, where subsequent draws will produce errors in volumes within this interval with 20 to 1 odds. To determine the precision interval, the sample standard deviation was determined using the calibrated 


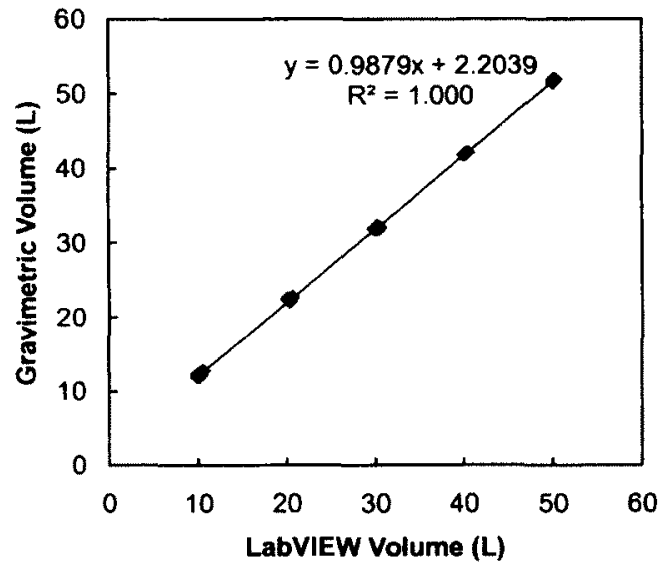

(a) Comparison of uncalibrated draw volumes.

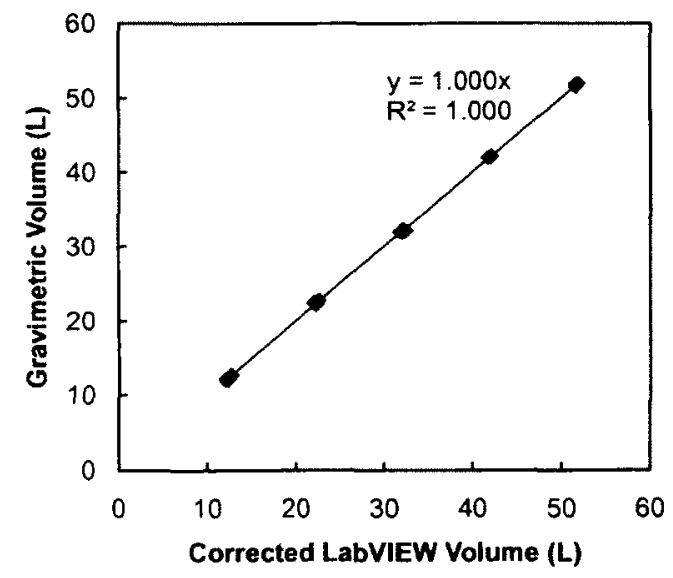

(c) Comparison of calibrated draw volumes.

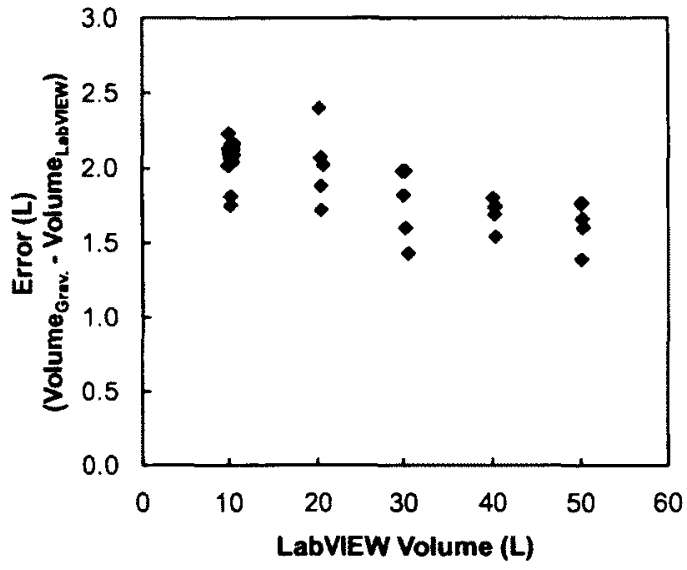

(b) Residual plot of uncalibrated errors.

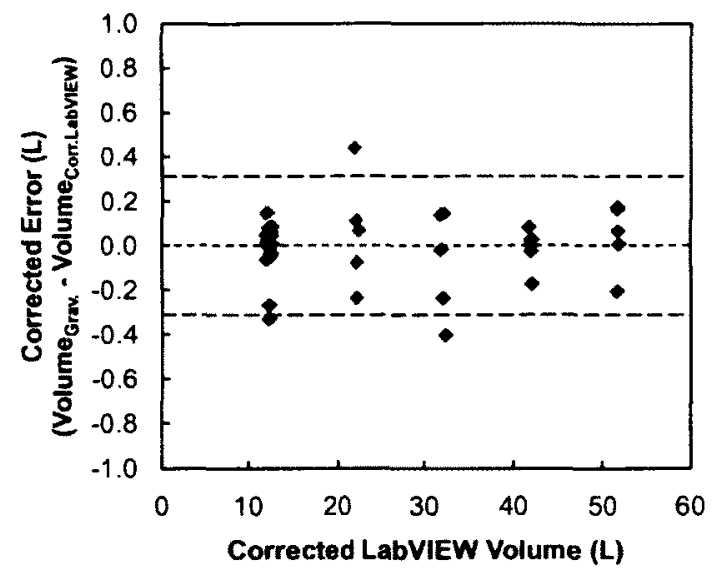

(d) Residual plot of calibrated errors.

Figure C.1: LabVIEW draw volumes and gravimetric volumes before and after calibration. 
errors in Fig. C.1(d) and Eq. (C.9), where $x_{i}$ represents the error value at each data point and $\bar{x}$ represents the sample mean. The precision interval was calculated according to Eq. (C.10) using a Student's t-distribution.

$$
\begin{aligned}
S_{x} & =\left[\frac{1}{L-1} \sum_{i=1}^{L}\left(x_{i}-\bar{x}\right)^{2}\right]^{1 / 2} \\
x_{i} & =\bar{x} \pm t_{L-1,95} S_{x} \quad(95 \%)
\end{aligned}
$$

Based on this analysis, the uncertainty associated with the draw volumes was found to be $\pm 0.31 \mathrm{~L}$.

\section{C.2 Collector Loop Flow Rate Uncertainty}

The collector loop flow meter had undergone a similar calibration to the one presented for draw volumes as part of the previous study [3], where the collector loop flow was diverted into a reservoir. The collector loop flow rate measured by the flow meter (i.e.. LabVIEW) was compared with the gravimetric flow rate, and a linear regression analysis was performed to obtain a calibration factor for the flow meter. Based on a $95 \%$ confidence level. the uncertainty corresponding to the collector loop flow rate measurements from LabVIEW was determined to be $\pm 0.06 \mathrm{~L} / \mathrm{min}$ (i.e., the charge flow rate was $3.00 \pm 0.06 \mathrm{~L} / \mathrm{min})$.

\section{C.3 Thermocouple Uncertainty}

The experimental apparatus consisted of forty-four Type $\mathrm{T}$ thermocouples which recorded the temperature profiles within the tanks, the inlet and outlet heat exchanger temperatures, as well as the mains and delivery water temperatures. The majority 
of the temperature sensors were fully calibrated within recent years as part of the previous study [3], and as such, some of the previous calibration data was used.

Calibration of the twelve heat exchanger thermocouples was originally conducted using an EXTECH temperature bath and a Guildline platinum resistance thermometer. The thermometer was independently calibrated to an accuracy of $\pm 0.012^{\circ} \mathrm{C}$ by the manufacturer [77], and was placed inside the temperature bath with the thermocouple leads for comparison. The temperature sensors were calibrated for a range of 0 to $60^{\circ} \mathrm{C}$, and the resulting uncertainty associated with the temperature measurements was calculated as $\pm 0.16^{\circ} \mathrm{C}$ based on a $95 \%$ precision interval (i.e., 20 to 1 odds). The procedure for determining the uncertainty value was similar to that shown for the draw volume calibration.

Additional thermocouples were added to the experimental apparatus to measure the mains and delivery temperatures in order to calculate the delivered energy during draws. Calibration of the two thermocouples was carried out following the same procedure as the heat exchanger thermocouples for a temperature range of 10 to $60{ }^{\circ} \mathrm{C}$ (Fig. C.2). A linear regression was applied to the data in Fig. C.2(a), and the measured LabVIEW temperatures were then adjusted by a factor of 0.9575 with an offset of $1.61{ }^{\circ} \mathrm{C}$ (i.e., the delivery and mains temperatures were multiplied by 0.9575 , and then $1.61^{\circ} \mathrm{C}$ was added to the calculated temperatures). A precision interval has been included in Fig. C.2(d) to illustrate the random errors associated with the thermocouple measurements, where subsequent temperature measurements may contain errors within this interval with 20 to 1 odds (i.e., a probability of $95 \%$ ). The resulting uncertainty associated with the delivery and mains temperatures was calculated as $\pm 0.07^{\circ} \mathrm{C}$.

Finally, the remaining thirty thermocouples inside the storage tanks were tested for their repeatability by first discharging the tanks so that the stored water was 


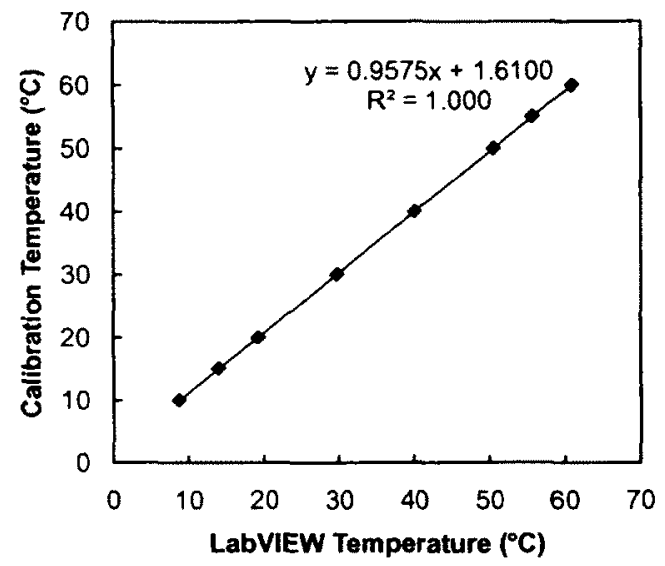

(a) Conparison of uncalibrated temperatures.

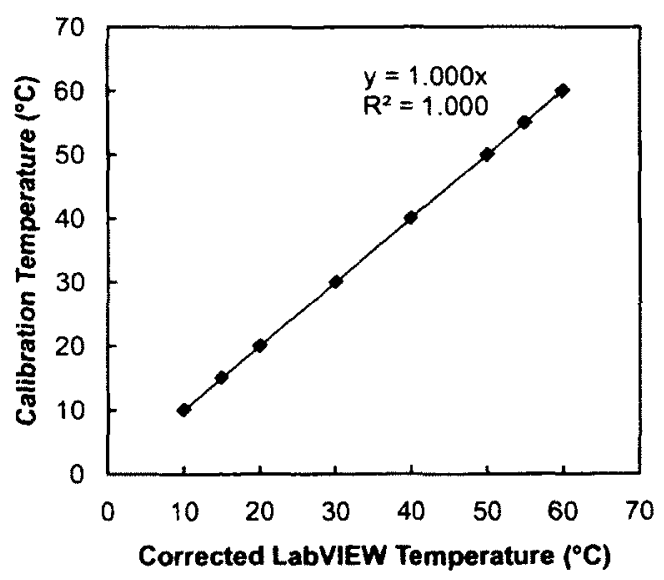

(c) Comparison of calibrated temperatures.

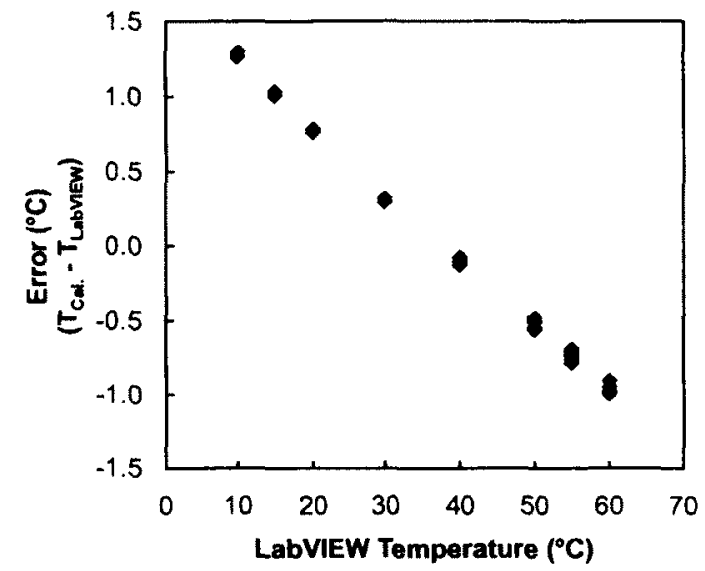

(b) Residual plot of uncalibrated errors.

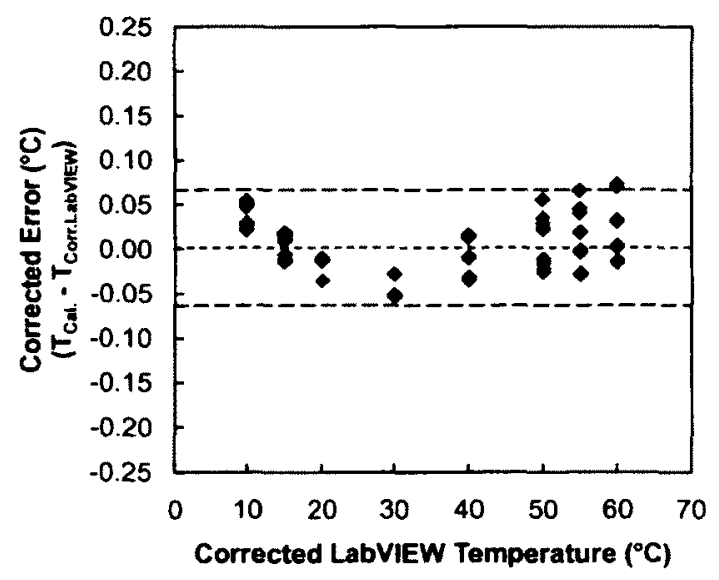

(d) Residual plot of calibrated errors.

Figure C.2: Delivery and mains thermocouple measurements before and after calibration. 
uniform at mains temperature. followed by mixing the fluid across all three tanks with a circulating pump. Data was recorded over one hour, resulting in 510 data points with a standard deviation of $\pm 0.13^{\circ} \mathrm{C}$. As the thermocouples were fixed to the temperature probe, the systematic error was not obtained through calibration with a temperature bath, but was estimated as $\pm 1.0^{\circ} \mathrm{C}$ based on the ASME PTC 19.3-1974 Standard for Type T thermocouples [47].

\section{C.4 Error Propagation in Delivered Energy Calculations}

Based on the uncertainty values obtained previously for the delivery and mains temperatures and the draw volume measurements, an analysis was conducted to determine the impact of these measurement errors on the calculated energy values, Eq. (6.1), presented in Chapter 6. The relative uncertainty associated with the delivered energy, $u_{Q}$, is therefore given by:

$$
\begin{aligned}
& u_{Q}= \pm\left[\left(\frac{\partial Q}{\partial \forall} u_{\forall}\right)^{2}+\left(\frac{\partial Q}{\partial \rho_{\mathrm{w}}} u_{\rho_{\mathrm{w}}}\right)^{2}\right.+\left(\frac{\partial Q}{\partial c_{p_{\mathrm{w}}}} u_{c_{p_{\mathrm{w}}}}\right)^{2} \\
&\left.+\left(\frac{\partial Q}{\partial T_{\text {del }}} u_{T_{\mathrm{drl}}}\right)^{2}+\left(\frac{\partial Q}{\partial T_{\text {mains }}} u_{T_{\text {mains }}}\right)^{2}\right]^{1 / 2} \\
& u_{Q}= \pm\left[\left(\rho_{\mathrm{w}} c_{p_{\mathrm{w}}}\left(T_{\text {del }}-T_{\text {mains }}\right) u_{\forall}\right)^{2}+\left(\forall c_{p_{\mathrm{w}}}\left(T_{\text {del }}-T_{\text {mains }}\right) u_{\rho_{\mathrm{w}}}\right)^{2}\right. \\
&\left.+\left(\forall \rho_{\mathrm{w}}\left(T_{\text {del }}-T_{\text {mains }}\right) u_{c_{p_{\mathrm{w}}}}\right)^{2}+\left(\forall \rho_{\mathrm{w}} c_{p_{\mathrm{w}}} u_{T_{\mathrm{del}}}\right)^{2}+\left(\forall \rho_{\mathrm{w}} c_{p_{\mathrm{w}}} u_{T_{\text {mains }}}\right)^{2}\right]^{1 / 2}
\end{aligned}
$$




$$
\begin{aligned}
\frac{u_{Q}}{Q}= \pm\left[\left(\frac{1}{\forall} u_{\forall}\right)^{2}+\right. & \left(\frac{1}{\rho_{\mathrm{w}}} u_{\rho_{\mathrm{w}}}\right)^{2}+\left(\frac{1}{c_{p_{\mathrm{w}}}} u_{c_{p_{\mathrm{w}}}}\right)^{2} \\
& \left.+\left(\frac{1}{T_{\text {del }}-T_{\text {mains }}} u_{T_{\mathrm{dcl}}}\right)^{2}+\left(\frac{1}{T_{\text {del }}-T_{\text {mains }}} u_{T_{\text {mains }}}\right)^{2}\right]^{1 / 2}
\end{aligned}
$$

The density and specific heat capacity values of water were calculated at the average of the delivery and mains temperatures. To approximate the uncertainty associated with these values, the density and specific heat capacity of water was calculated for $30^{\circ} \mathrm{C}$ (which was observed to be the average of the delivery and mains temperatures during the majority of draws), and a range of $\pm 10^{\circ} \mathrm{C}$ was used to determine the corresponding uncertainty values. The resulting uncertainty was found to be $\pm 0.32 \%$ and $\pm 0.15 \%$ to account for any deviations due to temperature variation.

Based on these uncertainties values, the error associated with the delivered energy was calculated at the end of each draw. Table C.1 summarizes the uncertainty values used in the analysis for some sample values, and Table C.2 lists the corresponding calculated energy and uncertainty in terms of $\mathrm{MJ}$.

\begin{tabular}{|c|c|c|c|c|c|c|c|c|}
\hline Test & $\begin{array}{c}\forall \\
(\mathrm{L})\end{array}$ & $\begin{array}{l}u_{\forall} \\
(\mathrm{L})\end{array}$ & $\frac{u_{\rho_{\mathrm{w}}}}{\rho_{\mathrm{w}}}$ & $\frac{u_{c_{p_{\mathrm{w}}}}}{c_{p_{\mathrm{w}}}}$ & $\begin{array}{c}T_{\text {del }} \\
\left({ }^{\circ} \mathrm{C}\right)\end{array}$ & $\begin{array}{c}T_{\text {mains }} \\
\left({ }^{\circ} \mathrm{C}\right)\end{array}$ & $\begin{array}{c}u_{T} \\
\left({ }^{\circ} \mathrm{C}\right)\end{array}$ & $\frac{u_{Q}}{Q}$ \\
\hline 1 & 61.77 & \pm 0.31 & \pm 0.0015 & \pm 0.0032 & 52.65 & 12.49 & \pm 0.07 & \pm 0.0067 \\
\hline 4 & 135.67 & \pm 0.31 & \pm 0.0015 & \pm 0.0032 & 50.60 & 11.54 & \pm 0.07 & \pm 0.0049 \\
\hline 7 & 15.57 & \pm 0.31 & \pm 0.0015 & \pm 0.0032 & 59.13 & 15.89 & \pm 0.07 & \pm 0.021 \\
\hline 7 & 30.28 & \pm 0.31 & \pm 0.0015 & \pm 0.0032 & 52.67 & 12.52 & \pm 0.07 & \pm 0.011 \\
\hline 8 & 45.32 & \pm 0.31 & \pm 0.0015 & \pm 0.0032 & 47.16 & 14.29 & \pm 0.07 & \pm 0.0084 \\
\hline 8 & 75.50 & \pm 0.31 & \pm 0.0015 & \pm 0.0032 & 40.59 & 13.85 & \pm 0.07 & \pm 0.0065 \\
\hline 9 & 90.32 & \pm 0.31 & \pm 0.0015 & \pm 0.0032 & 39.63 & 15.59 & \pm 0.07 & \pm 0.0064 \\
\hline 9 & 135.33 & \pm 0.31 & \pm 0.0015 & \pm 0.0032 & 45.34 & 15.25 & \pm 0.07 & \pm 0.0054 \\
\hline
\end{tabular}

Table C.1: Uncertainty values used in the error propagation for delivered energy. 
Table C.2: Delivered energy uncertainty for a range of tested draw volumes.

\begin{tabular}{ccc}
\hline Test & $\begin{array}{c}\forall \\
(\mathrm{L})\end{array}$ & $\begin{array}{c}Q \\
(\mathrm{MJ})\end{array}$ \\
\hline 1 & 61.77 & $10.31 \pm 0.07$ \\
4 & 135.67 & $22.04 \pm 0.11$ \\
7 & 15.57 & $2.79 \pm 0.06$ \\
7 & 30.28 & $5.50 \pm 0.06$ \\
8 & 45.32 & $6.20 \pm 0.05$ \\
8 & 75.50 & $8.41 \pm 0.05$ \\
9 & 90.32 & $9.04 \pm 0.06$ \\
9 & 135.33 & $16.94 \pm 0.09$ \\
\hline
\end{tabular}

The relative uncertainty, $u_{Q} / Q$, was found to be in the range of $0.49 \%$ to $2.1 \%$. Higher errors were observed at low draw volumes as a result of the high uncertainty value associated with the draw volumes, while temperature variation had a more notable impact at high draw volumes (e.g., comparing the $135 \mathrm{~L}$ draw from Test 4 and Test 9 , the calculated error was $0.49 \%$ and $0.54 \%$, respectively). The estimated uncertainty values for the specific heat capacity and density had a minor impact on the relative uncertainty of the energy delivered. 


\section{Appendix D}

\section{Inter-Tank Fluid Circulation in the Series Charge and Parallel Discharge Configuration}

Tests were conducted between two tanks, where Tank 1 was initially charged to $50^{\circ} \mathrm{C}$ and the second tank was initially at mains temperature $\left(16^{\circ} \mathrm{C}\right)$. The tests were intended to study the extreme situation of the series charge and parallel discharge configuration, where one tank was fully charged and the second tank was fully discharged. No further charging or discharging of the tanks occurred, and the temperature profiles (Fig. D.1) were recorded over a 24-hour period.

It was observed that over the first 12 hours of circulation, hot water from Tank 1 began flowing into the top of the second tank along the top header, while the cool water from the bottom of Tank 2 flowed into the bottom of the first tank along the bottom header (where the mains water enters the heat exchangers). The circulation between the tanks was driven by the pressure difference (shown in Fig. D.2), which resulted in near equal tank pressures and temperatures at the end of the testing period.

In an effort to determine whether the circulation of fluid had a detrimental impact 

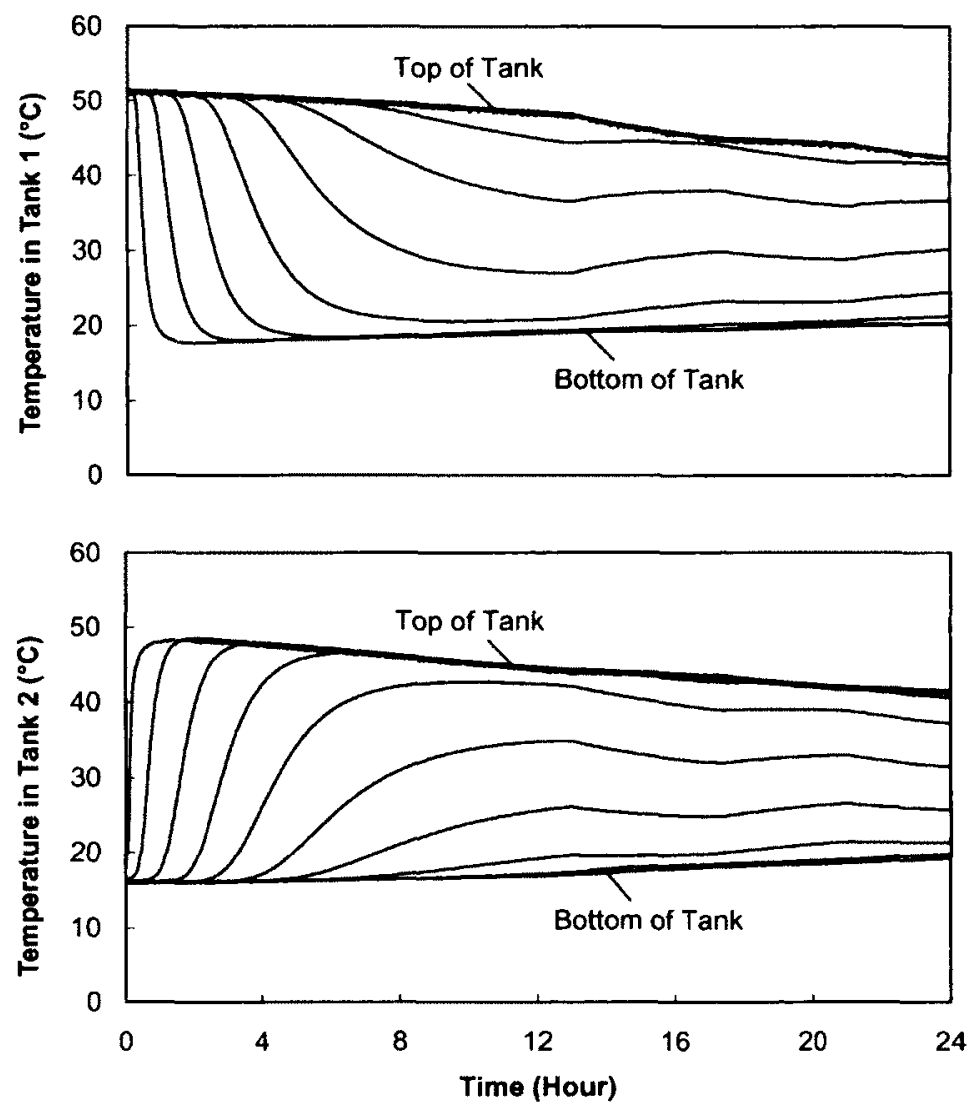

Figure D.1: Temperature profiles for Tank 1 (initially at $50^{\circ} \mathrm{C}$ ) and Tank 2 (initially at $16^{\circ} \mathrm{C}$ ) as they equalize in temperature and pressure. 


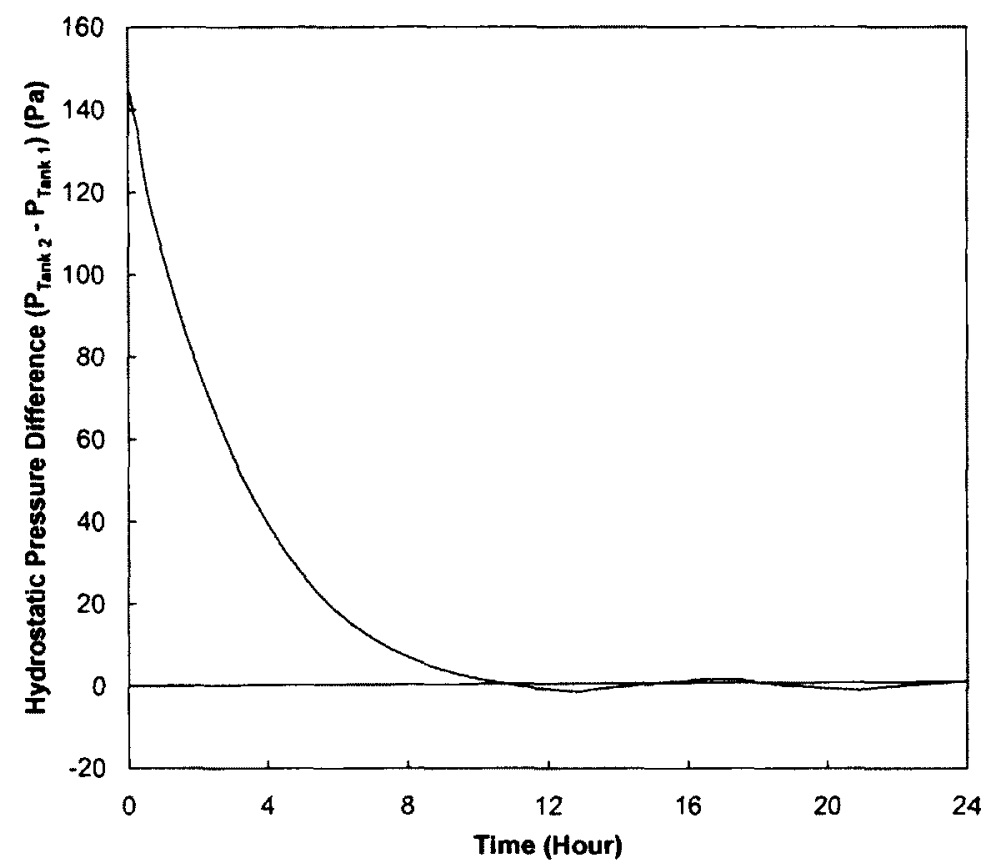

Figure D.2: Hydrostatic pressure difference between Tank 1 (initially at $50^{\circ} \mathrm{C}$ ) and Tank 2 (initially at $16^{\circ} \mathrm{C}$ ).

on the performance of the system, an exergy analysis was conducted to quantify the stratification of the two tanks following the procedure outlined in Section 6.3. Specific exergy values were calculated for each thermocouple and were summed to represent the exergy stored in the system. Comparing the exergy values between the start and end of the 24-hour test period, the stored exergy was found to decrease by $34.4 \%$ (from $111.9 \mathrm{~kJ} / \mathrm{kg}$ to $73.4 \mathrm{~kJ} / \mathrm{kg}$ ).

To prevent water from circulating between tanks, check valves were installed at the top of each tank. The second motivation behind adding check valves was due to the limitations in the TRNSYS model which did not account for the flow between tanks. To incorporate this flow circulation into the model. a new component based on experimental data would need to be included, similar to how the natural convection heat exchanger flow rate was correlated to the net hydrostatic pressure difference between the tank and the heat exchanger. 


\section{Appendix E}

\section{Supplemental Figures and Results}

The following figures were produced as part of the experimental and numerical studies presented in Chapters 5 and 6.

Fig. E.1 Experimental and simulation results for Test 1, series charge and series discharge, $60 \mathrm{~L}$ draws.

Fig. E.2 Experimental and simulation results for Test 2, parallel charge and parallel discharge, $60 \mathrm{~L}$ draws.

Fig. E.3 Experimental and simulation results for Test 3, series charge and parallel discharge, $60 \mathrm{~L}$ draws.

Fig. E.4 Specific exergy values for the three system configurations with constant temperature charging and $60 \mathrm{~L}$ draws.

Fig. E.5 Specific exergy comparison of experimental and simulation results for Test 7 , series charge and scries discharge configuration with variable input power charge profile and variable volume draws.

Fig. E.6 Specific exergy comparison of experimental and simulation results for Test 9. series charge and parallel discharge configuration with variable input power charge profile and variable volume draws. 

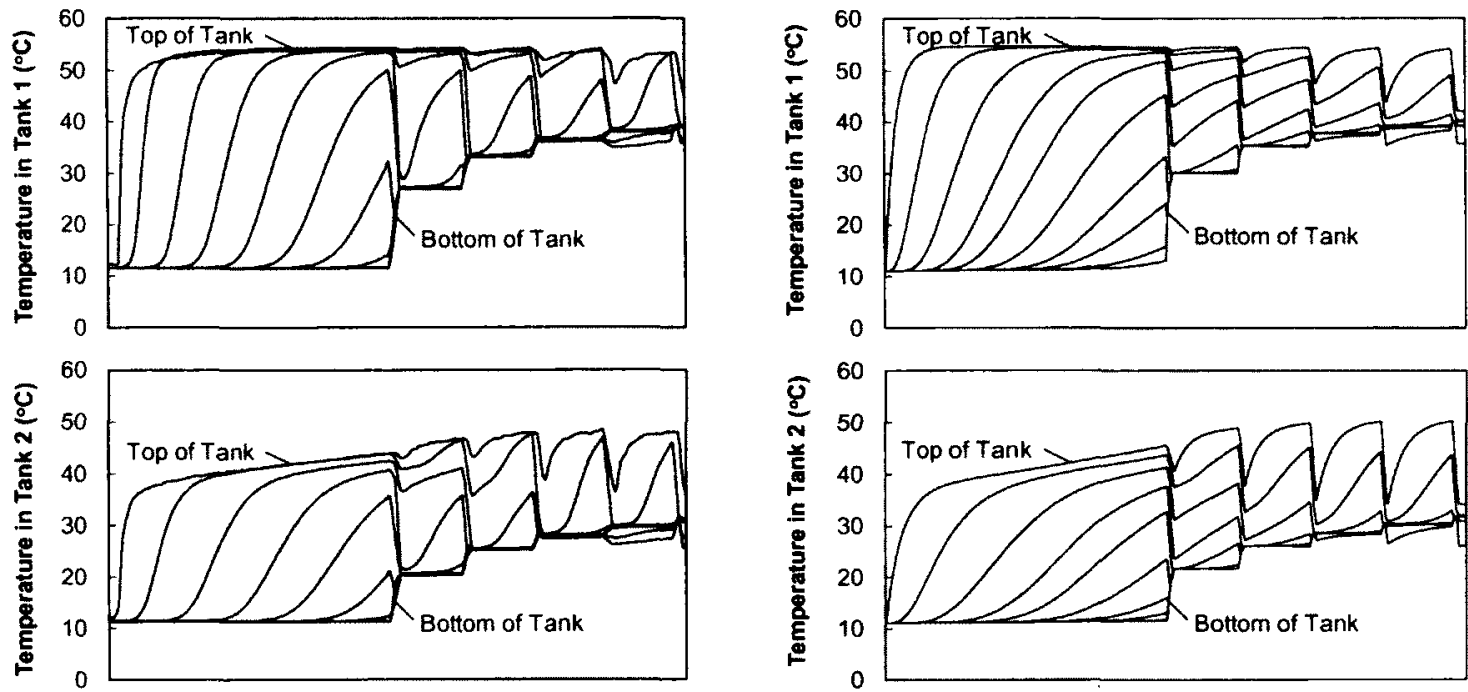

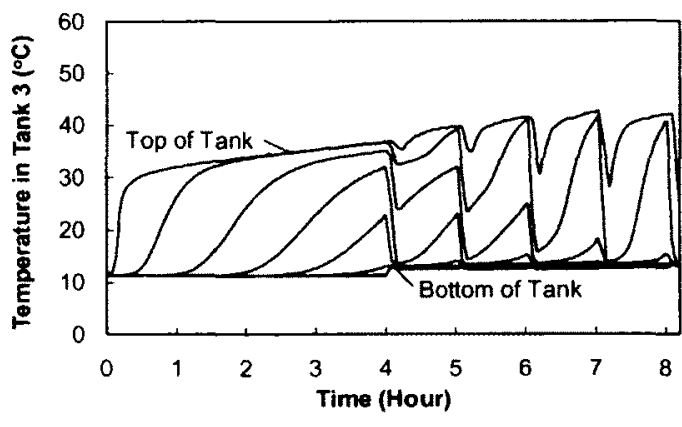

(a) Experimental Results.

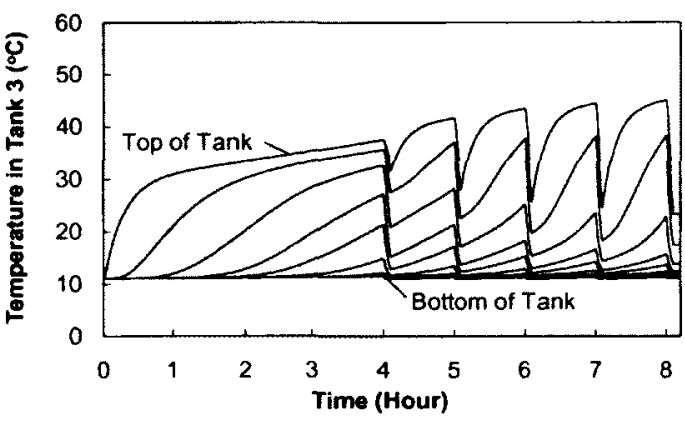

(b) Simulation Results.

Figure E.1: Experimental and simulation results for Test 1, series charge and series discharge, $60 \mathrm{~L}$ draws. 

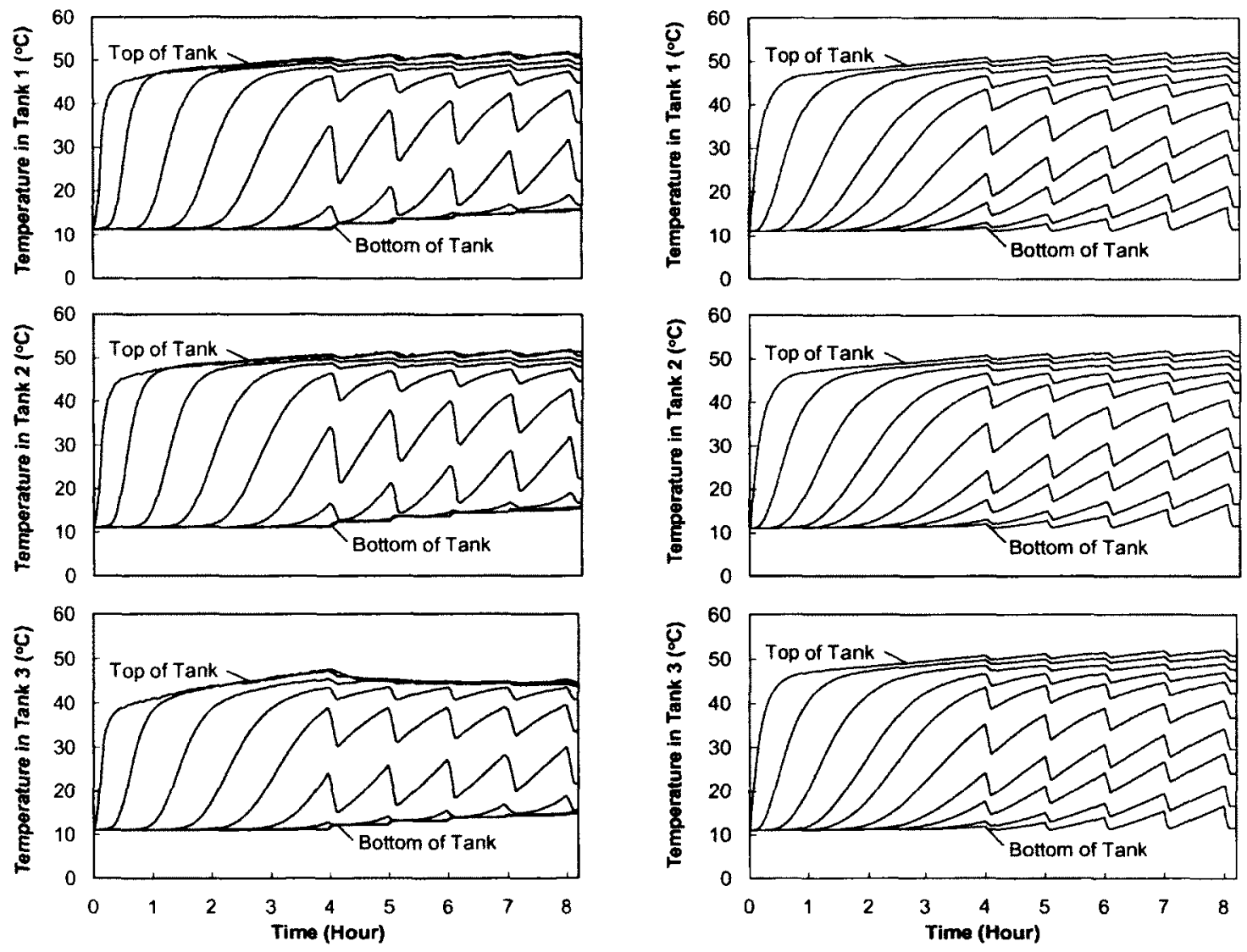

(a) Experimental Results.

(b) Simulation Results.

Figure E.2: Experimental and simulation results for Test 2, parallel charge and parallel discharge, $60 \mathrm{~L}$ draws. 

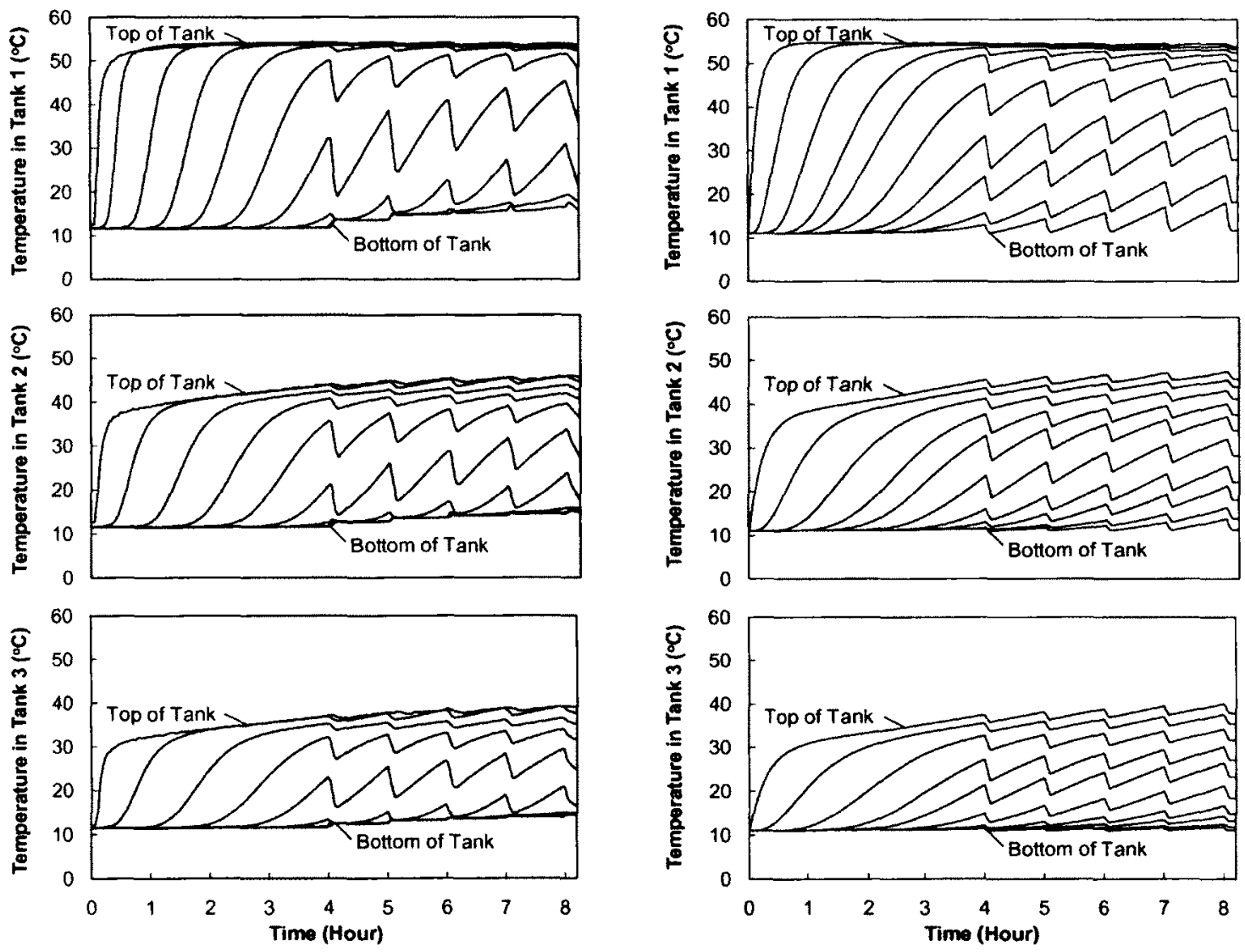

(a) Experimental Results.

(b) Simulation Results.

Figure E.3: Experimental and simulation results for Test 3, series charge and parallel discharge, $60 \mathrm{~L}$ draws. 


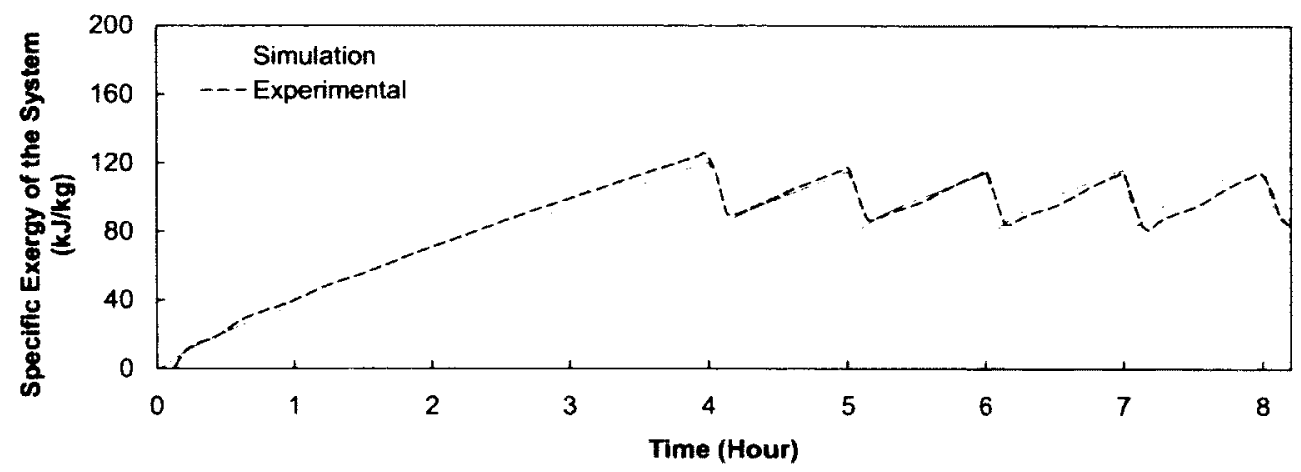

(a) Test 1 exergy values for the series charge and series discharge configuration.

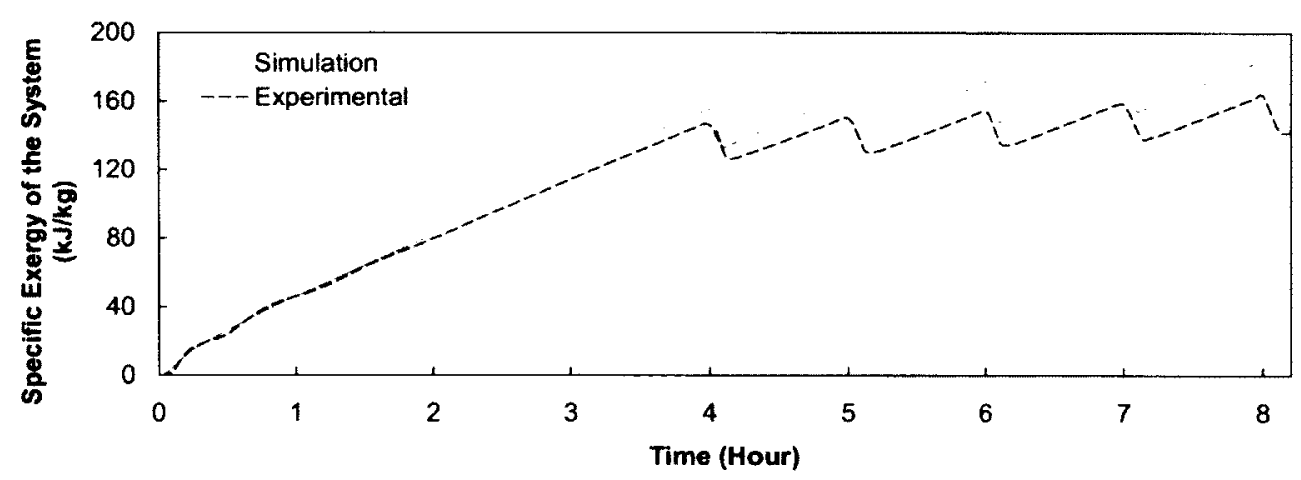

(b) Test 2 exergy values for the parallel charge and parallel discharge configuration.

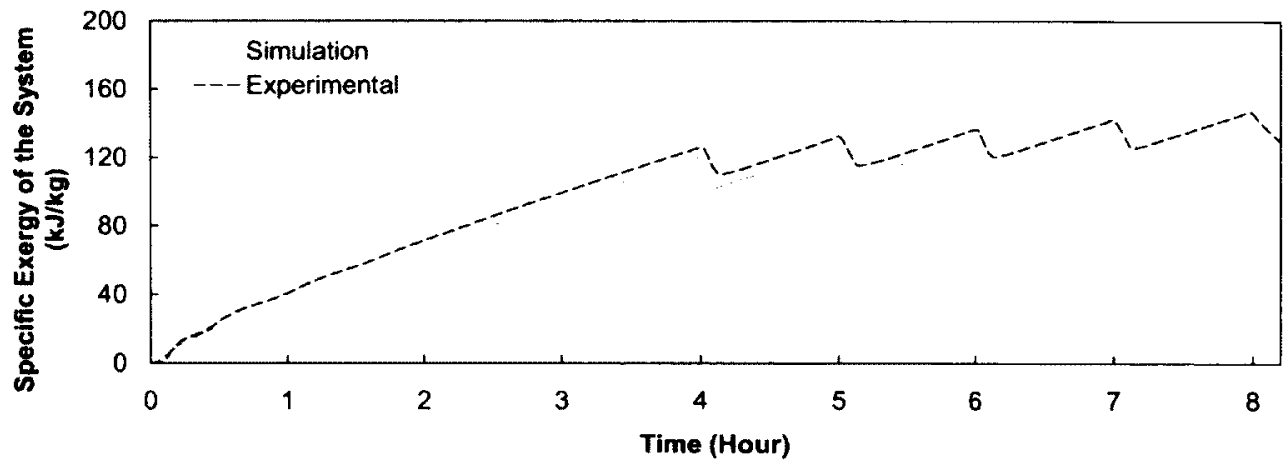

(c) Test 3 exergy values for the series charge and parallel discharge configuration.

Figure E.4: Specific exergy values for the three system configurations with constant temperature charging and $60 \mathrm{~L}$ draws. 

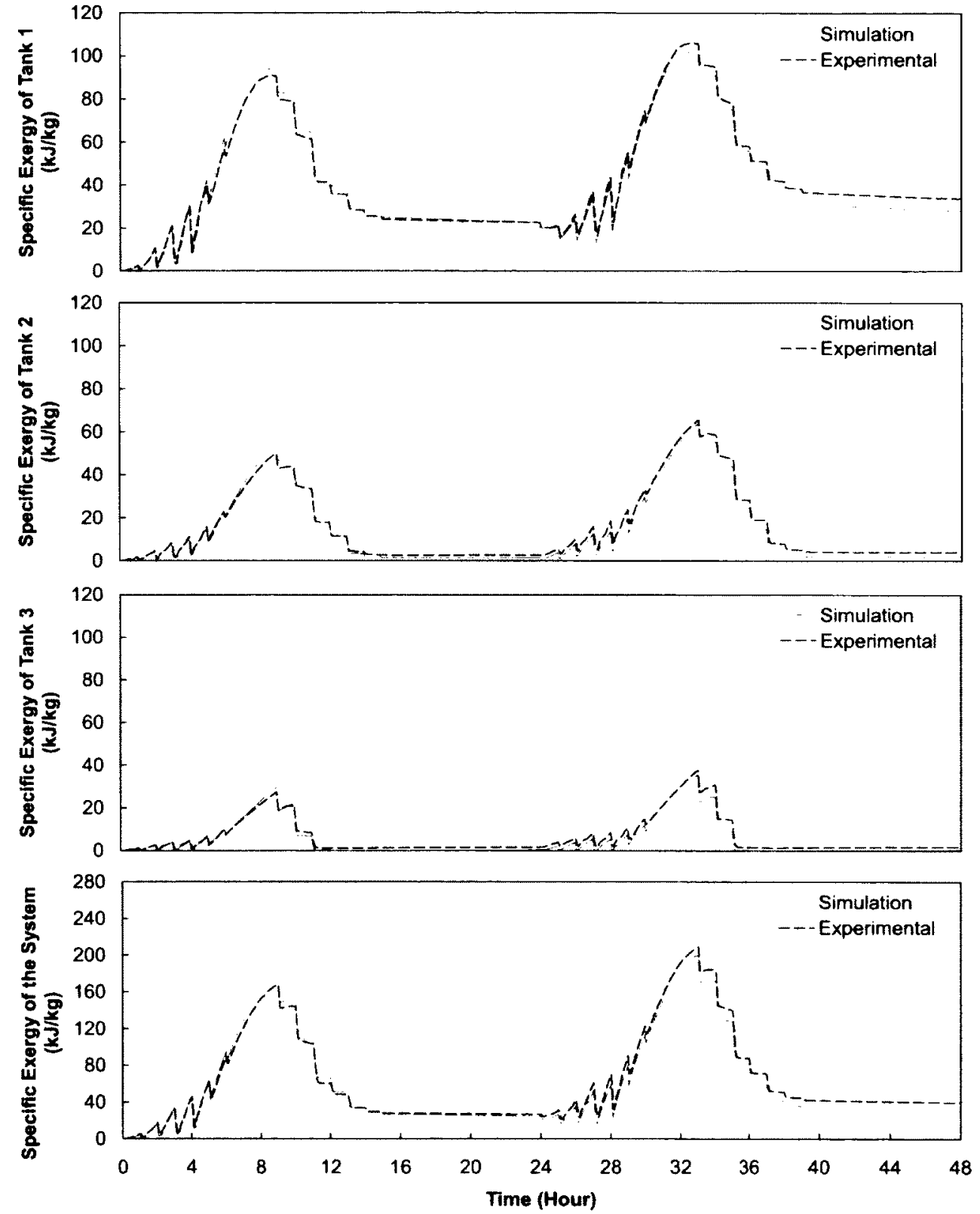

Figure E.5: Specific exergy comparison of experimental and simulation results for Test 7 , series charge and series discharge configuration with variable input power charge profile and variable volume draws. 

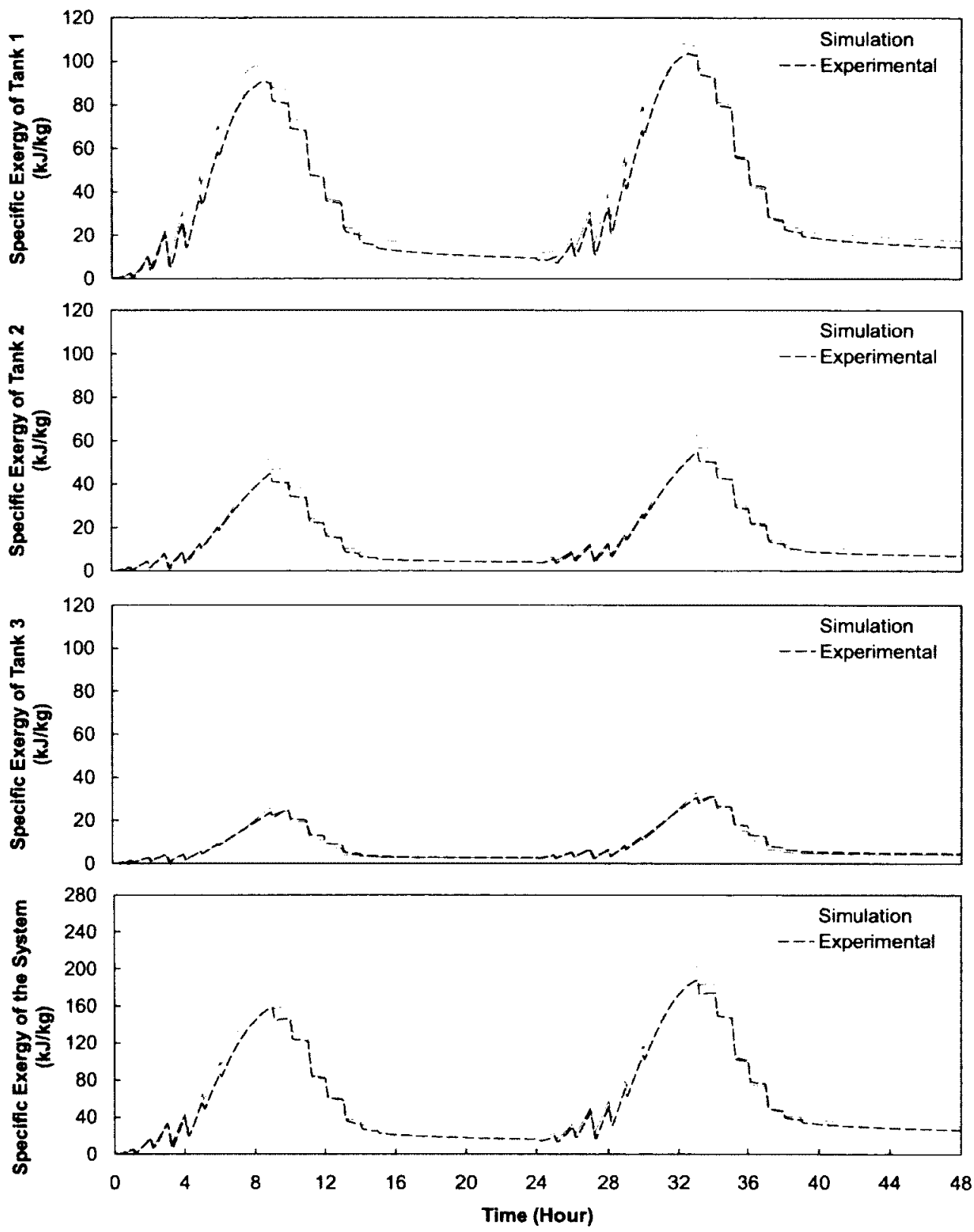

Figure E.6: Specific exergy comparison of experimental and simulation results for Test 9, series charge and parallel discharge configuration with variable input power charge profile and variable volume draws. 


\section{Appendix F}

\section{Error Analysis of Experimental and Simulation Results}

In order to quantify the error between the experimental and simulation results, the experimental thermocouple data was compared with the corresponding TRNSYS node temperatures at an interval of 0.04 hours (2.4 minutes). Interpolation of the thermocouple data was conducted using the EES software. Based on the temperature difference between the thermocouple measurements and the corresponding TRNSYS nodes. the sample standard deviation and $95 \%$ confidence intervals were calculated and are summarized in Tables F.1 and F.2. The values presented in Table F.1 were calculated based on 6,180 data points for each of the six constant temperature charge and constant volume discharge tests, while Table F.2 consisted of 36,030 data points for each of the three variable input power charge and variable volume discharge tests.

The results of this analysis demonstrated that the numerical model varied between $\pm 3.40^{\circ} \mathrm{C}$ and $\pm 8.81^{\circ} \mathrm{C}$ for the constant temperature charge and constant volume discharge tests, while the range in error was between $\pm 3.10^{\circ} \mathrm{C}$ and $\pm 7.49^{\circ} \mathrm{C}$ for the variable input power charge and variable volume discharge tests. While these values were considerably higher than the uncertainty associated with the experimental 
measurements $\left( \pm 1.0^{\circ} \mathrm{C}\right)$, it was expected that some deviation would occur due to the limitations of the Type 60 TRNSYS component, and the complexity of hourly draws which were introduced into the model for this study. The accuracy of the numerical model may be improved by considering alternate tank models which are capable of using a higher number of nodes, such as Type 534, which allows up to 500 nodes per simulation $[42]$.

Table F.1: Temperature error between experimental and simulation results for constant temperature charge and constant volume discharge tests.

\begin{tabular}{clccccc}
\hline Test & Configuration & $\begin{array}{c}\text { Draw Volume } \\
(\mathrm{L})\end{array}$ & $\begin{array}{c}\text { Tank 1 } \\
\left({ }^{\circ} \mathrm{C}\right)\end{array}$ & $\begin{array}{c}\text { Tank 2 } \\
\left({ }^{\circ} \mathrm{C}\right)\end{array}$ & $\begin{array}{c}\text { Tank 3 } \\
\left({ }^{\circ} \mathrm{C}\right)\end{array}$ & $\begin{array}{c}\text { System } \\
\left({ }^{\circ} \mathrm{C}\right)\end{array}$ \\
\hline 1 & Series Series & 60 & \pm 6.28 & \pm 4.02 & \pm 4.19 & \pm 5.04 \\
2 & Parallel Parallel & 60 & \pm 6.37 & \pm 6.43 & \pm 8.81 & \pm 8.24 \\
3 & Series Parallel & 60 & \pm 6.47 & \pm 4.15 & \pm 3.40 & \pm 4.97 \\
\hline 4 & Series Series & 135 & \pm 5.45 & \pm 3.90 & \pm 3.65 & \pm 4.47 \\
5 & Parallel Parallel & 135 & \pm 6.52 & \pm 6.89 & \pm 7.11 & \pm 7.14 \\
6 & Series Parallel & 135 & \pm 7.30 & \pm 4.66 & \pm 3.48 & \pm 5.47 \\
\hline
\end{tabular}

Table F.2: Temperature error between experimental and simulation results for variable input power charge and variable volume discharge tests.

\begin{tabular}{clcccc}
\hline Test & Configuration & $\begin{array}{c}\text { Tank 1 } \\
\left({ }^{\circ} \mathrm{C}\right)\end{array}$ & $\begin{array}{c}\text { Tank 2 } \\
\left({ }^{\circ} \mathrm{C}\right)\end{array}$ & $\begin{array}{c}\text { Tank 3 } \\
\left({ }^{\circ} \mathrm{C}\right)\end{array}$ & $\begin{array}{c}\text { System } \\
\left({ }^{\circ} \mathrm{C}\right)\end{array}$ \\
\hline 7 & Series Series & \pm 4.61 & \pm 4.38 & \pm 3.45 & \pm 4.46 \\
8 & Parallel Parallel & \pm 6.12 & \pm 6.56 & \pm 5.63 & \pm 6.12 \\
9 & Series Parallel & \pm 7.49 & \pm 5.47 & \pm 3.10 & \pm 5.84 \\
\hline
\end{tabular}




\section{Appendix G}

\section{Annual Simulation Model}

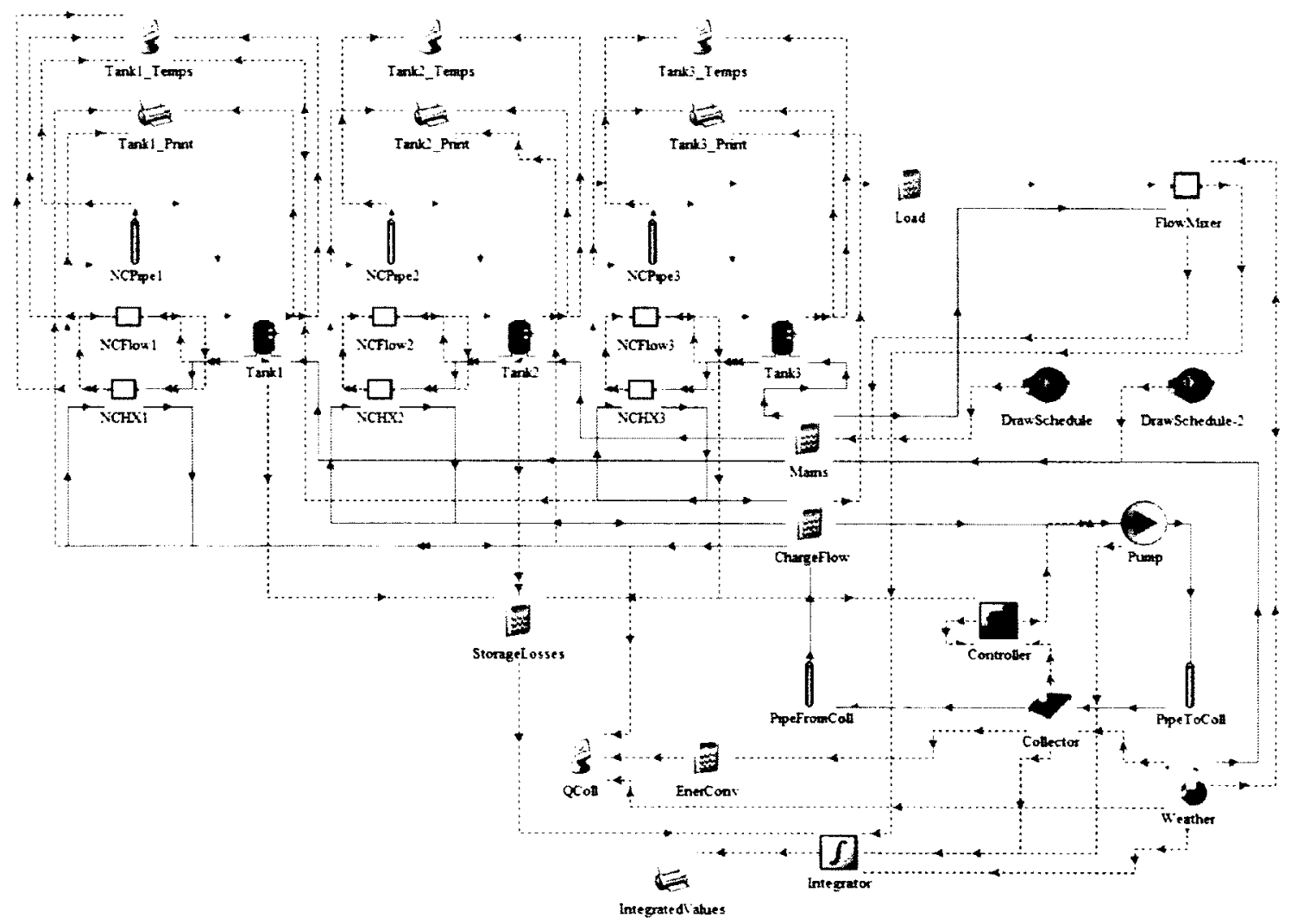

Figure G.1: Annual simulation model of the parallel charge and parallel discharge configuration in TRNSYS. 


\section{Appendix $\mathbf{H}$}

\section{Sample TRNSYS Deck File}

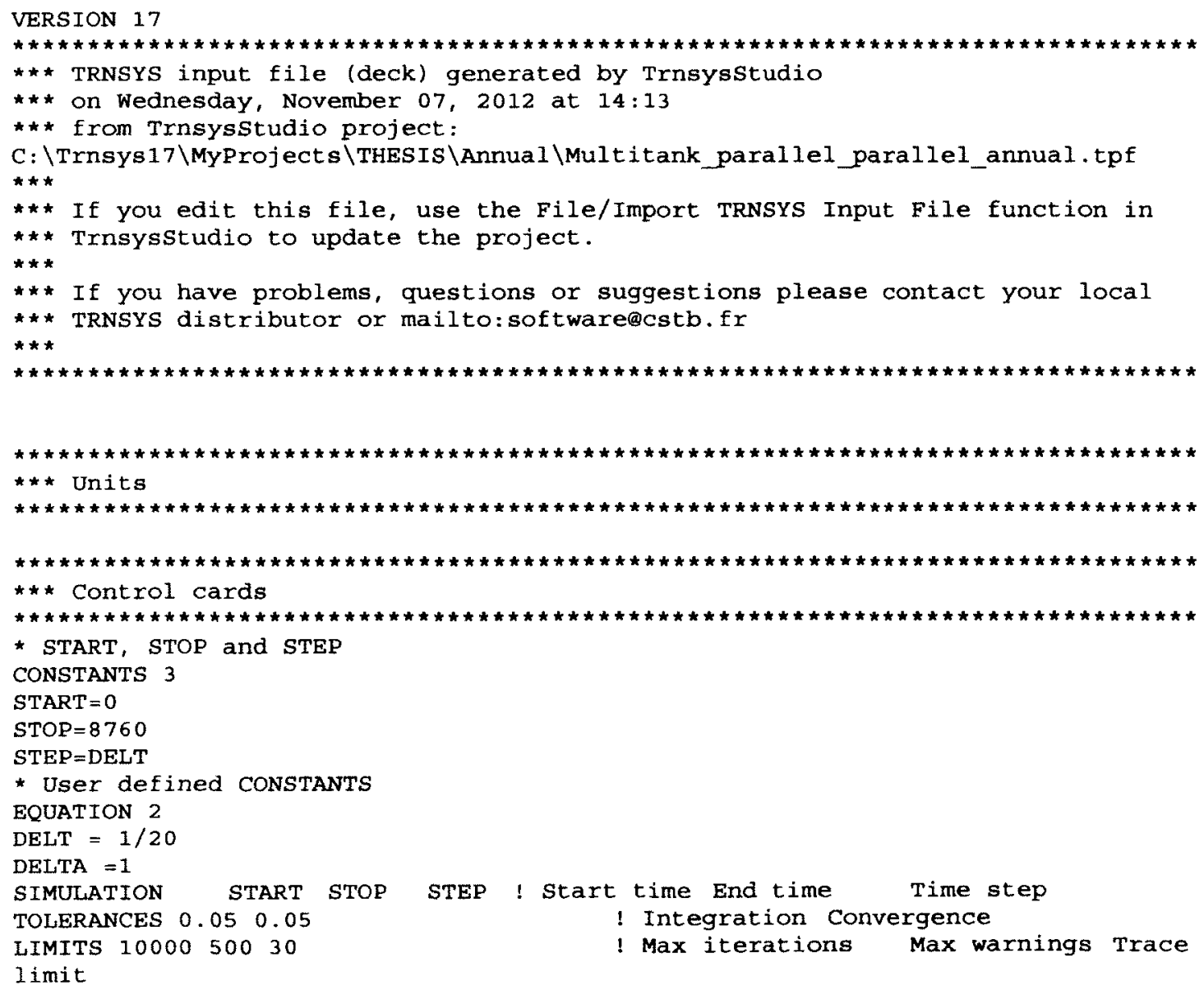




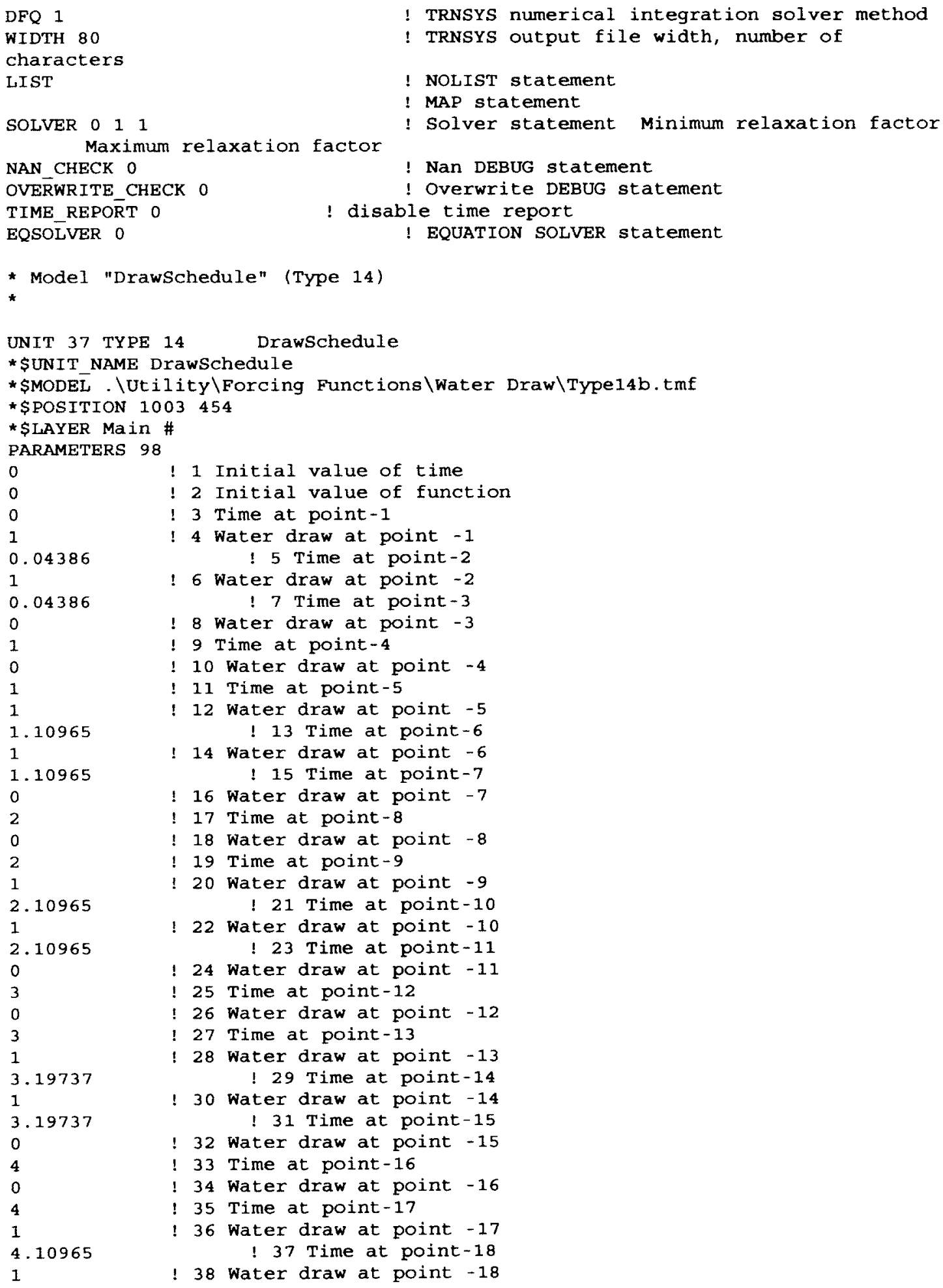




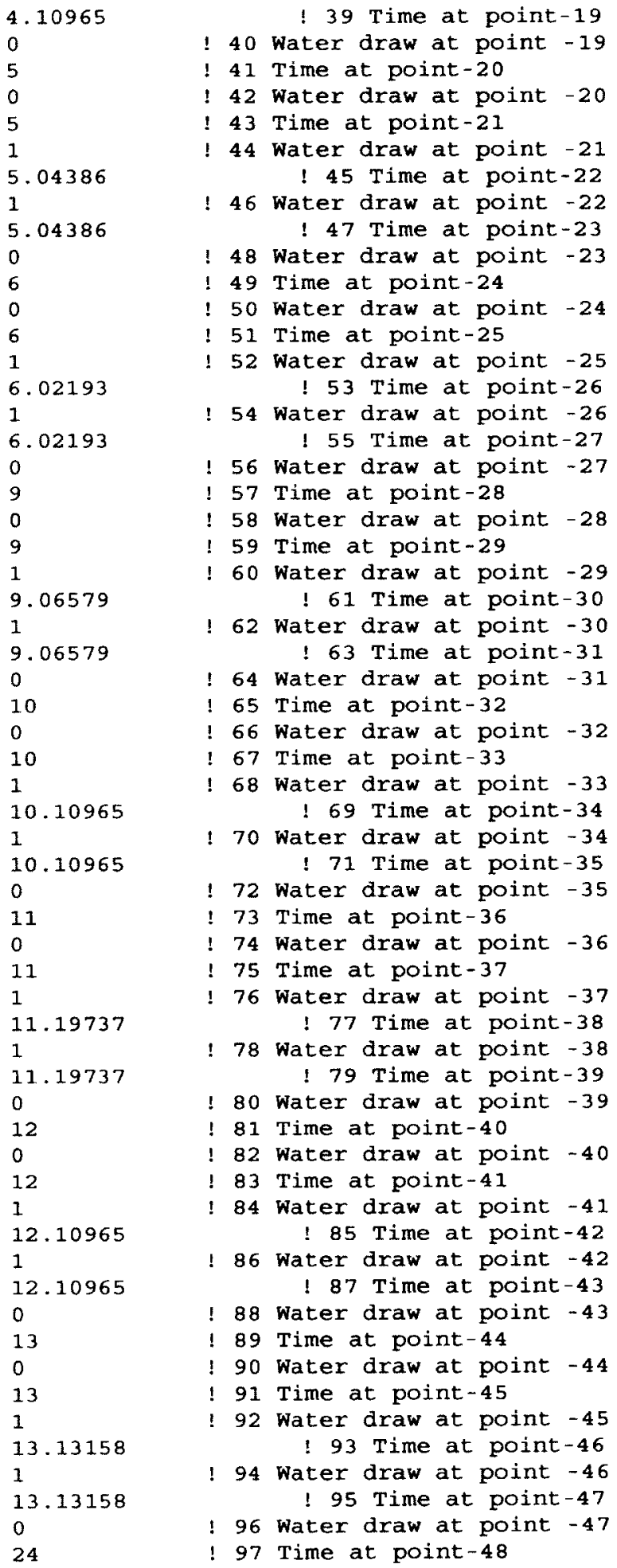




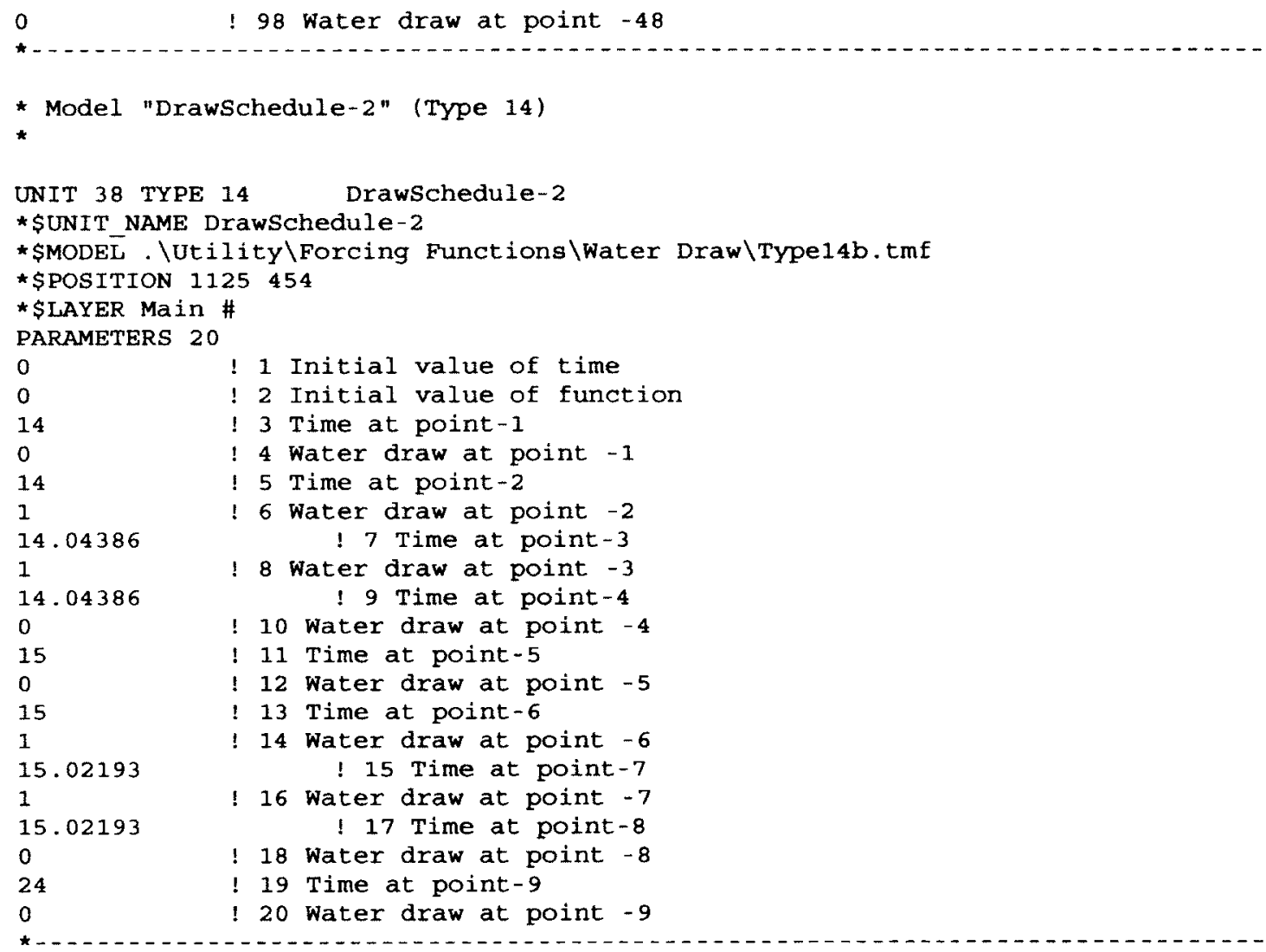

\section{* EQUATIONS "Mains"}

EQUATIONS 5

$T s i=[42,5]$

mso Tank $1=[43,2] / 3$ !equivalent to $11.4 \mathrm{~L} / \mathrm{min}$ for water divided by 3 for each $\tan \bar{k}$

mso Tank2 $=[43,2] / 3$ !equivalent to $11.4 \mathrm{~L} / \mathrm{min}$ for water divided by 3 for each tank

mso Tank $3=[43,2] / 3$ !equivalent to $11,4 \mathrm{~L} / \mathrm{min}$ for water divided by 3 for each tank

mso $=684 *([37,1]+[38,1])$

*\$UNIT_NAME Mains

*\$LAYER Main

*\$POSTTION 799500

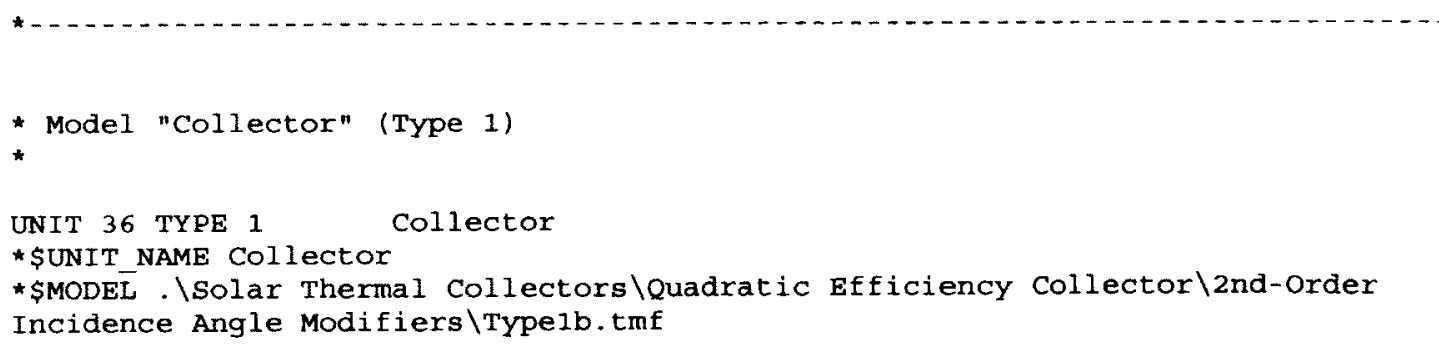




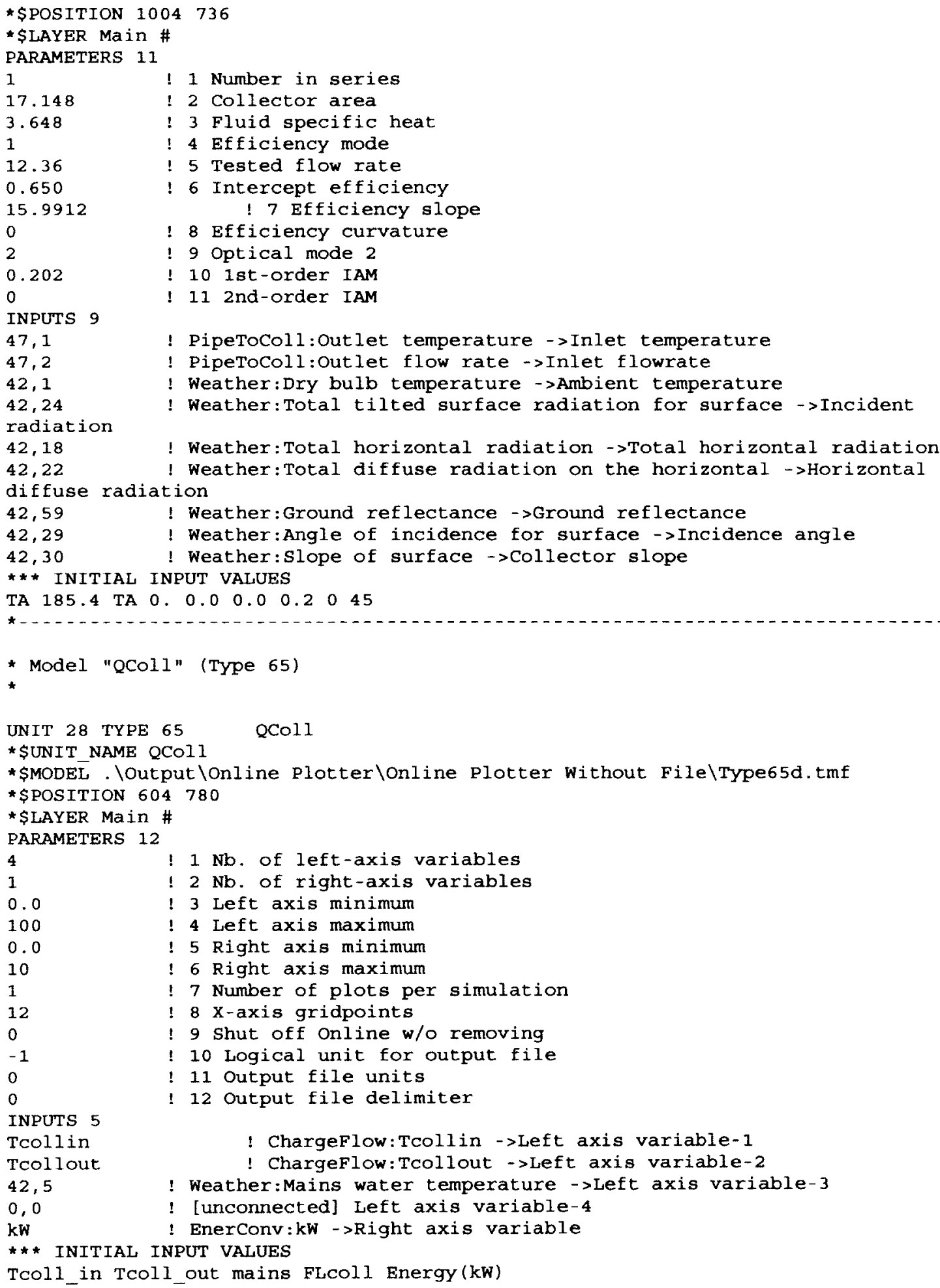




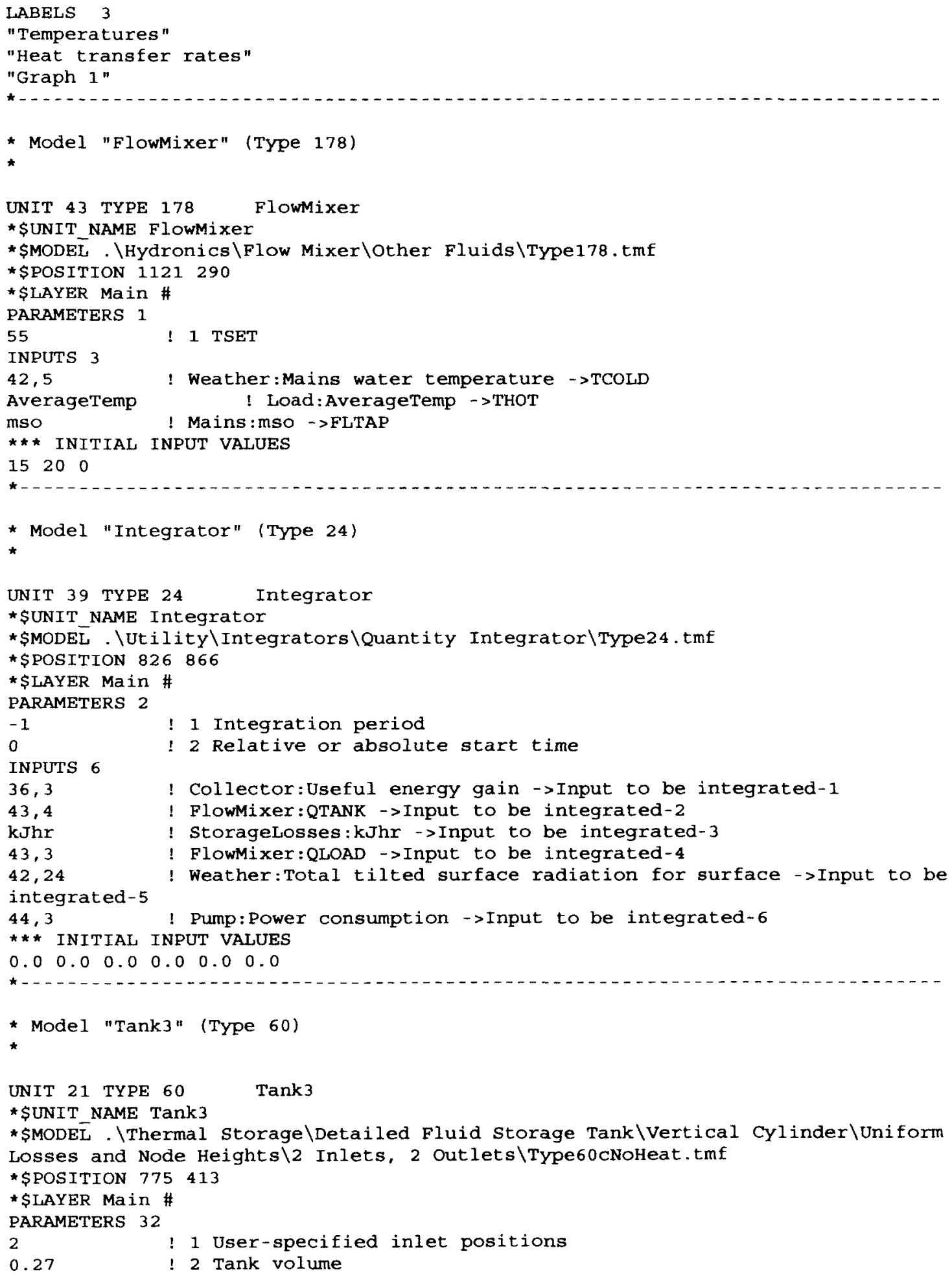




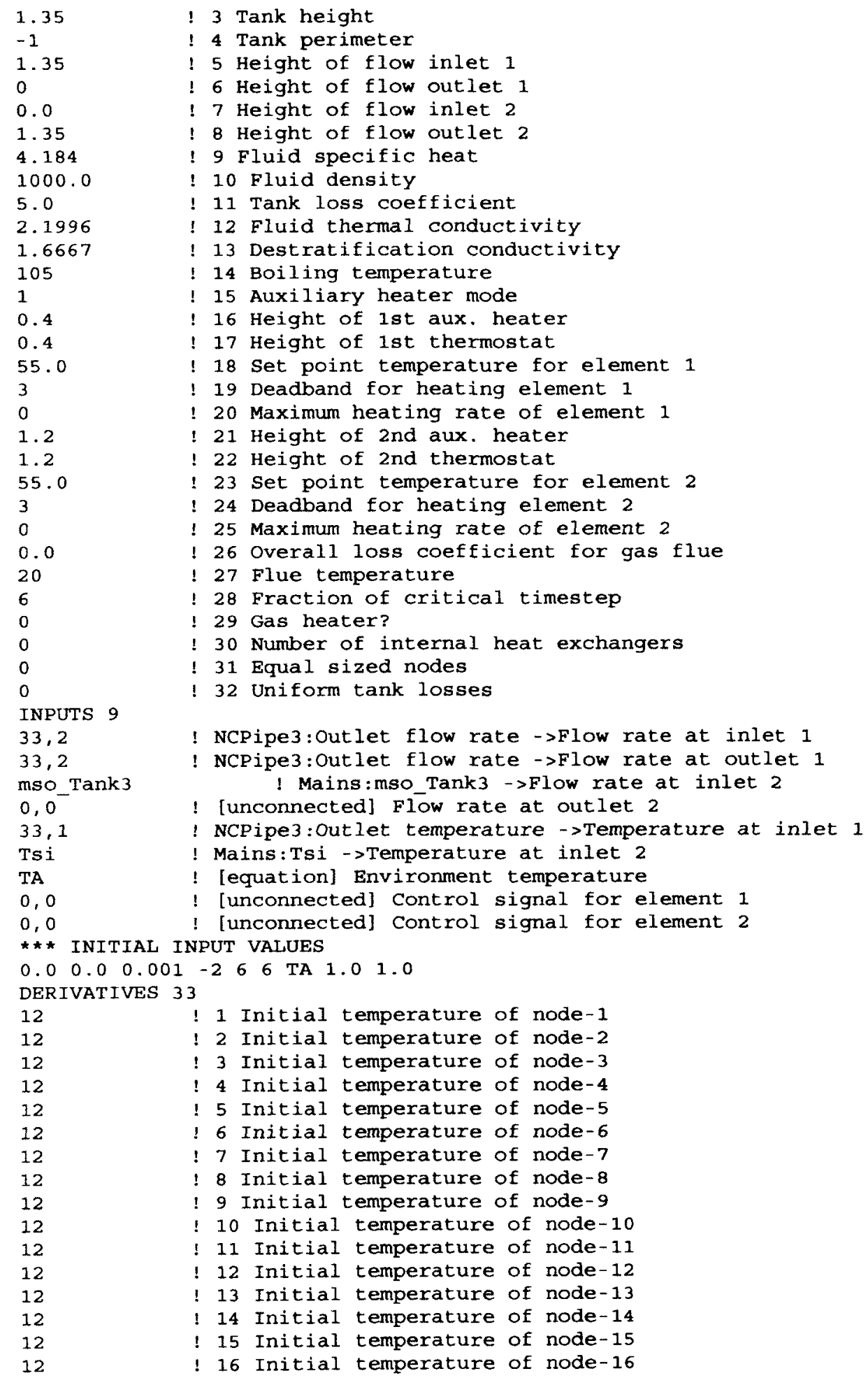




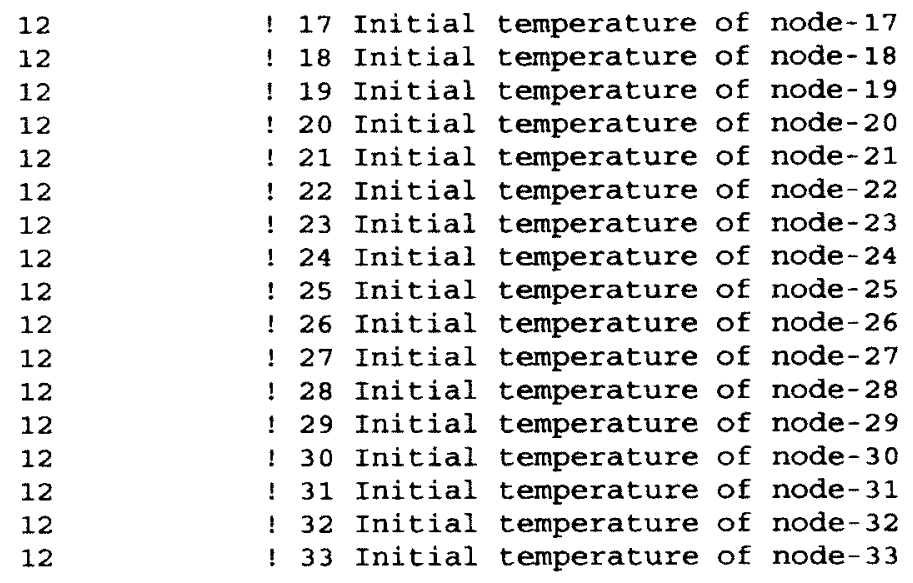

* Model "Tank2" (Type 60)

UNIT 17 TYPE $60 \quad$ Tank2

* \$UNIT NAME Tank2

*\$MODEL . TThermal storage\Detailed Fluid Storage Tank\Vertical Cylinder\Uniform

Losses and Node Heights $\backslash 2$ Inlets, 2 out lets $\backslash$ Type 60 cNoHeat.tmf

*\$POSITION $553 \quad 413$

* \$LAYER Main \#

PARAMETERS 32

0.27

1.35

! 1 User-specified inlet positions

$-1$

1.35

0

0.0

1.35

4.184

1000.0

5.0

2. 1996

1.6667

105

1

0.4

0.4

55.0

3

1.2

1.2

55.0

3

0

0.0

20

6

0

! 2 Tank volume

! 3 Tank height

! 4 Tank perimeter

! 5 Height of flow inlet 1

! 6 Height of flow outlet 1

! 7 Height of flow inlet 2

18 Height of flow outlet 2

! 9 Fluid specific heat

! 10 Fluid density

! 11 Tank loss coefficient

! 12 Fluid thermal conductivity

! 13 Destratification conductivity

! 14 Boiling temperature

! 15 Auxiliary heater mode

! 16 Height of 1st aux. heater

! 17 Height of 1st thermostat

! 18 set point temperature for element 1

! 19 Deadband for heating element 1

! 20 Maximum heating rate of element 1

! 21 Height of 2nd aux. heater

! 22 Height of 2nd thermostat

! 23 set point temperature for element 2

! 24 Deadband for heating element 2

! 25 Maximum heating rate of element 2

! 26 Overall loss coefficient for gas flue

! 27 Flue temperature

! 28 Fraction of critical timestep

! 29 Gas heater?

! 30 Number of internal heat exchangers 


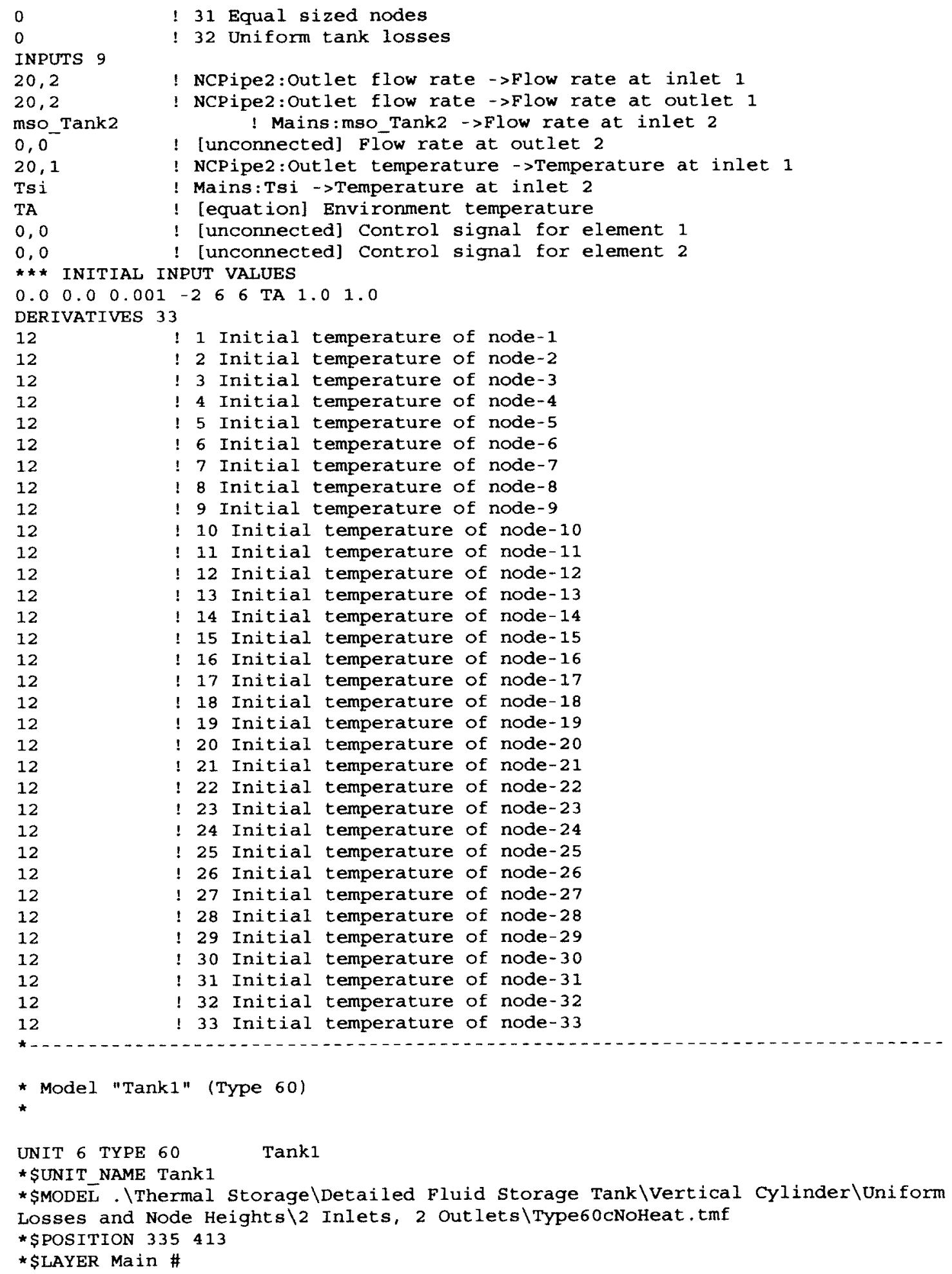




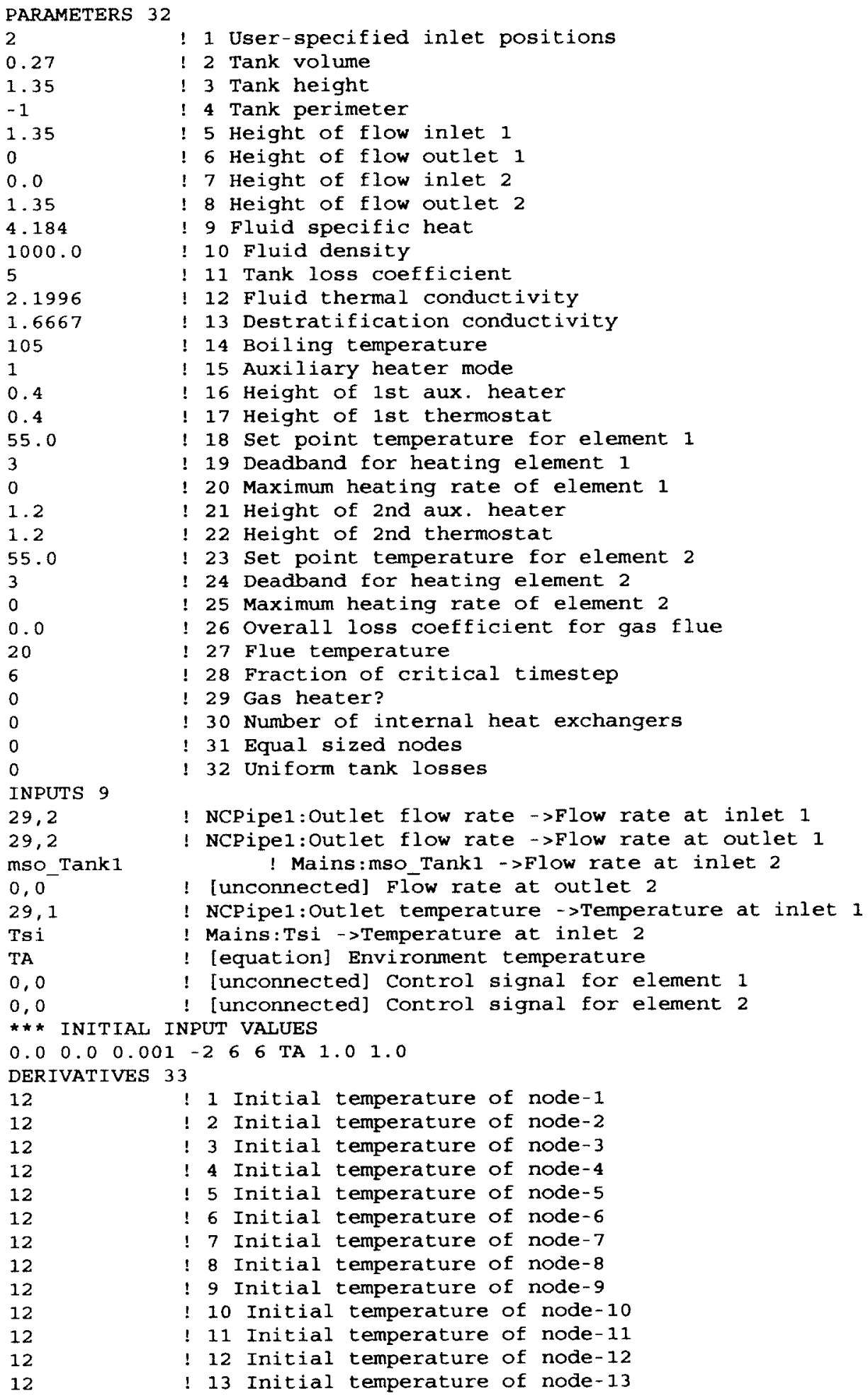




\begin{tabular}{|c|c|c|c|c|c|c|}
\hline 12 & $!$ & 14 & Initial & temperature & of & node- 14 \\
\hline 12 & $!$ & 15 & Initial & temperature & of & node- 15 \\
\hline 12 & $!$ & 16 & Initial & temperature & of & node- 16 \\
\hline 12 & $!$ & 17 & Initial & temperature & of & node -17 \\
\hline 12 & $!$ & 18 & Initial & temperature & of & node- 18 \\
\hline 12 & $!$ & 19 & Initial & temperature & of & node- 19 \\
\hline 12 & $!$ & 20 & Initial & temperature & of & node- 20 \\
\hline 12 & $!$ & 21 & Initial & temperature & of & node- 21 \\
\hline 12 & $!$ & 22 & Initial & temperature & of & node- 22 \\
\hline 12 & $!$ & 23 & Initial & temperature & of & node -23 \\
\hline 12 & $!$ & 24 & Initial & temperature & of & node- 24 \\
\hline 12 & $!$ & 25 & Initial & temperature & of & node- 25 \\
\hline 12 & $!$ & 26 & Initial & temperature & of & node- 26 \\
\hline 12 & $!$ & 27 & Initial & temperature & of & node -27 \\
\hline 12 & $!$ & 28 & Initial & temperature & of & node -28 \\
\hline 12 & $!$ & 29 & Initial & temperature & of & node- 29 \\
\hline 12 & $!$ & 30 & Initial & temperature & of & node -30 \\
\hline 12 & $!$ & 31 & Initial & temperature & of & node -31 \\
\hline 12 & $!$ & 32 & Initial & temperature & of & node -32 \\
\hline 12 & $!$ & 33 & Initial & temperature & of & node- 33 \\
\hline
\end{tabular}

* Model "PipeFromColl" (Type 31)

UNIT 46 TYPE 31 PipeFromcoll

* \$UNIT NAME PipeFromColl

* \$MODET . \HYaronics $\backslash$ Pipe_Duct $\backslash$ Type $31 . t m f$

*\$POSITION 802716

* \$LAYER Water Loop \#

PARAMETERS 6

0.01 ! 1 Inside diameter

$10 \quad ! 2$ Pipe length

8 ! 3 Loss coefficient

$1030 \quad 4$ Fluid density

3.648 ! 5 Fluid specific heat

TA ! 6 Initial fluid temperature

INPUTS 3

36,1 ! Collector:Outlet temperature $\rightarrow$ Inlet temperature

36,2 ! Collector:Outlet flowrate - Inlet flow rate

TA ! [equation] Environment temperature

** INITIAL INPUT VALUES

TA 185.4 TA

* Equations "EnerConv"

EQUATIONS 1

$\mathrm{kW}=[36,3] / 3600$

* \$UNIT_NAME EnerConv

*\$LAYER Main

*\$POSITION 715780

4-

* Model "Controller" (Type 2)

* 


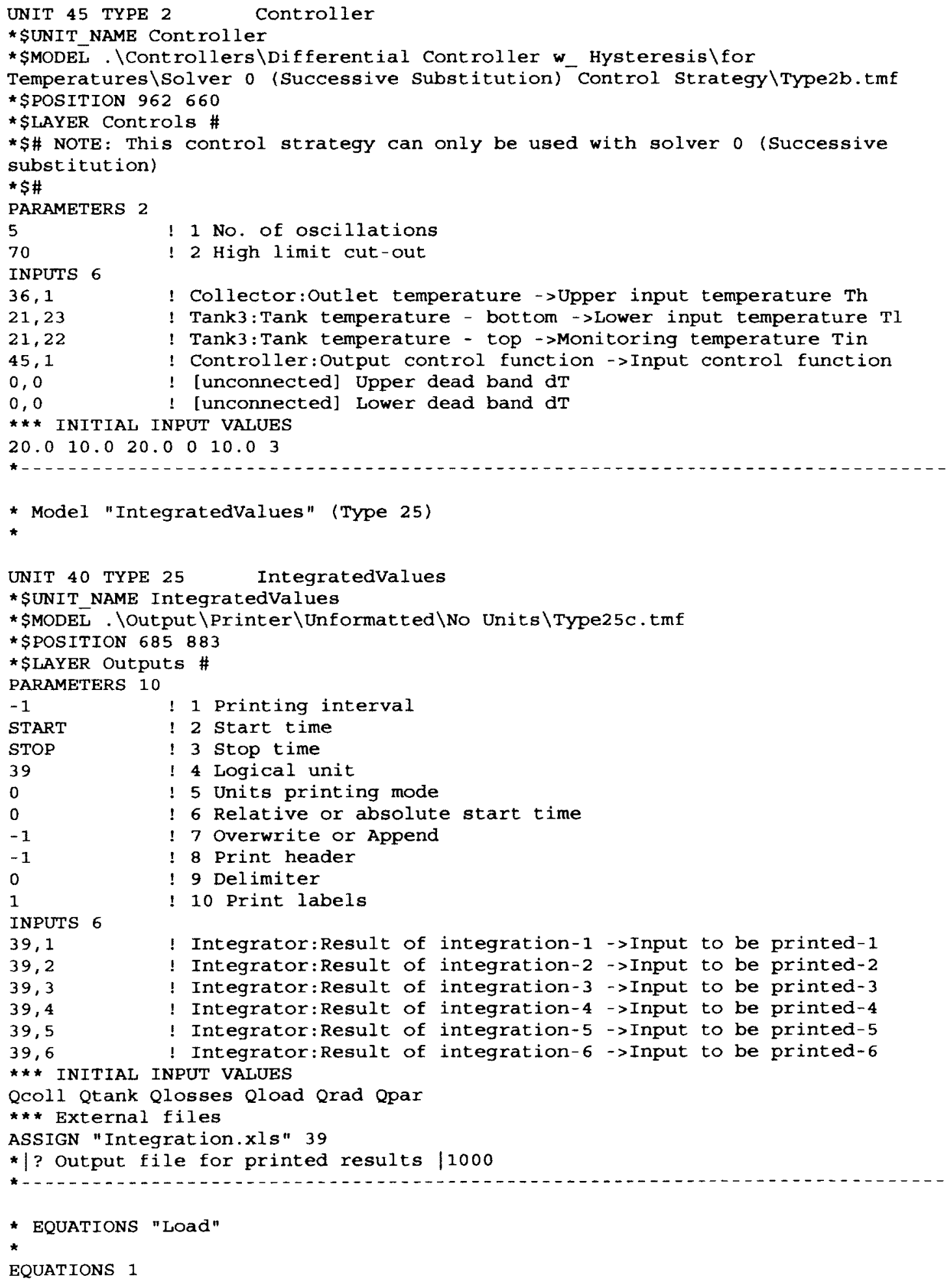




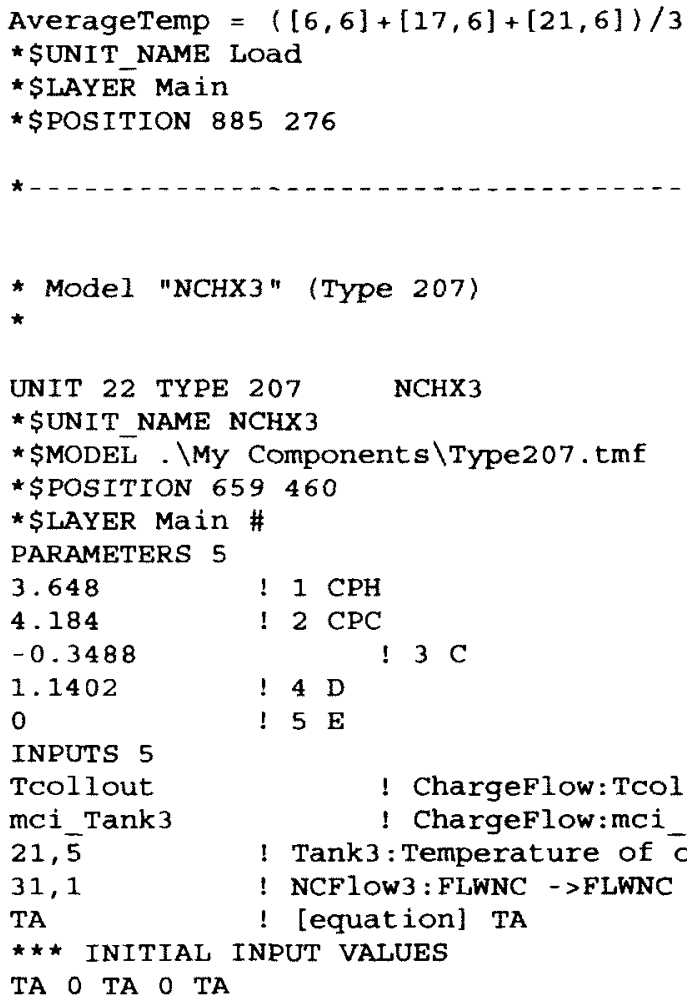




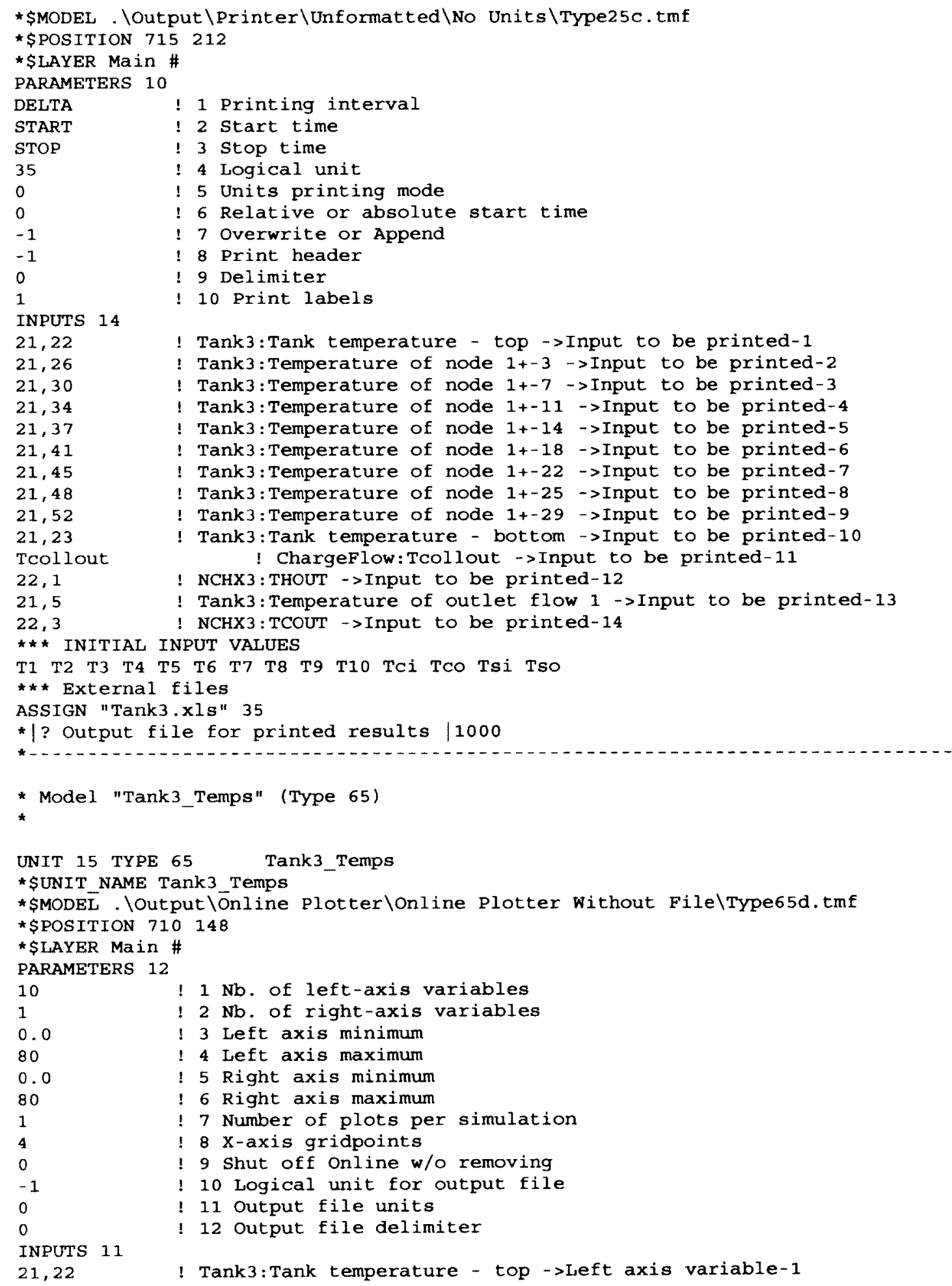




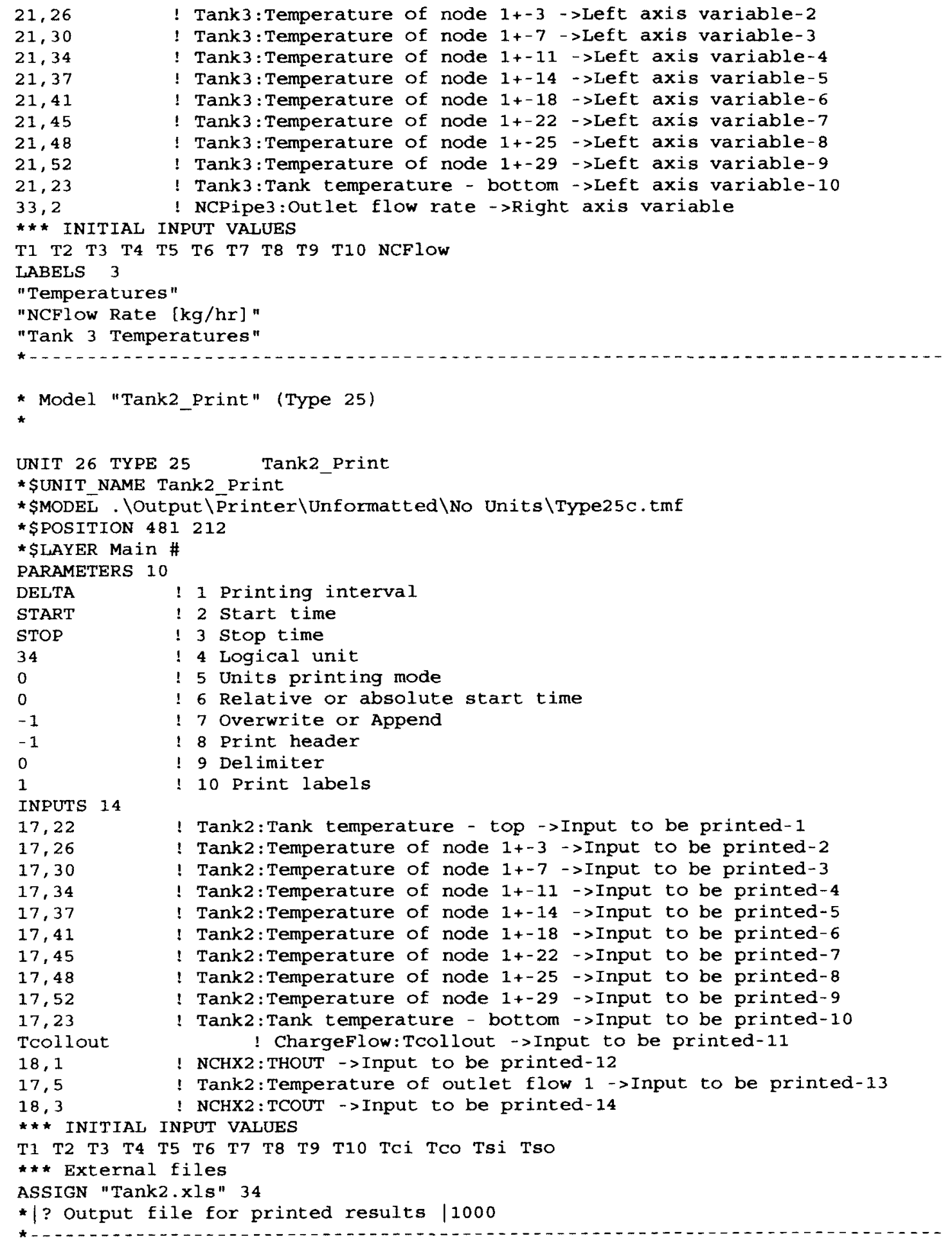




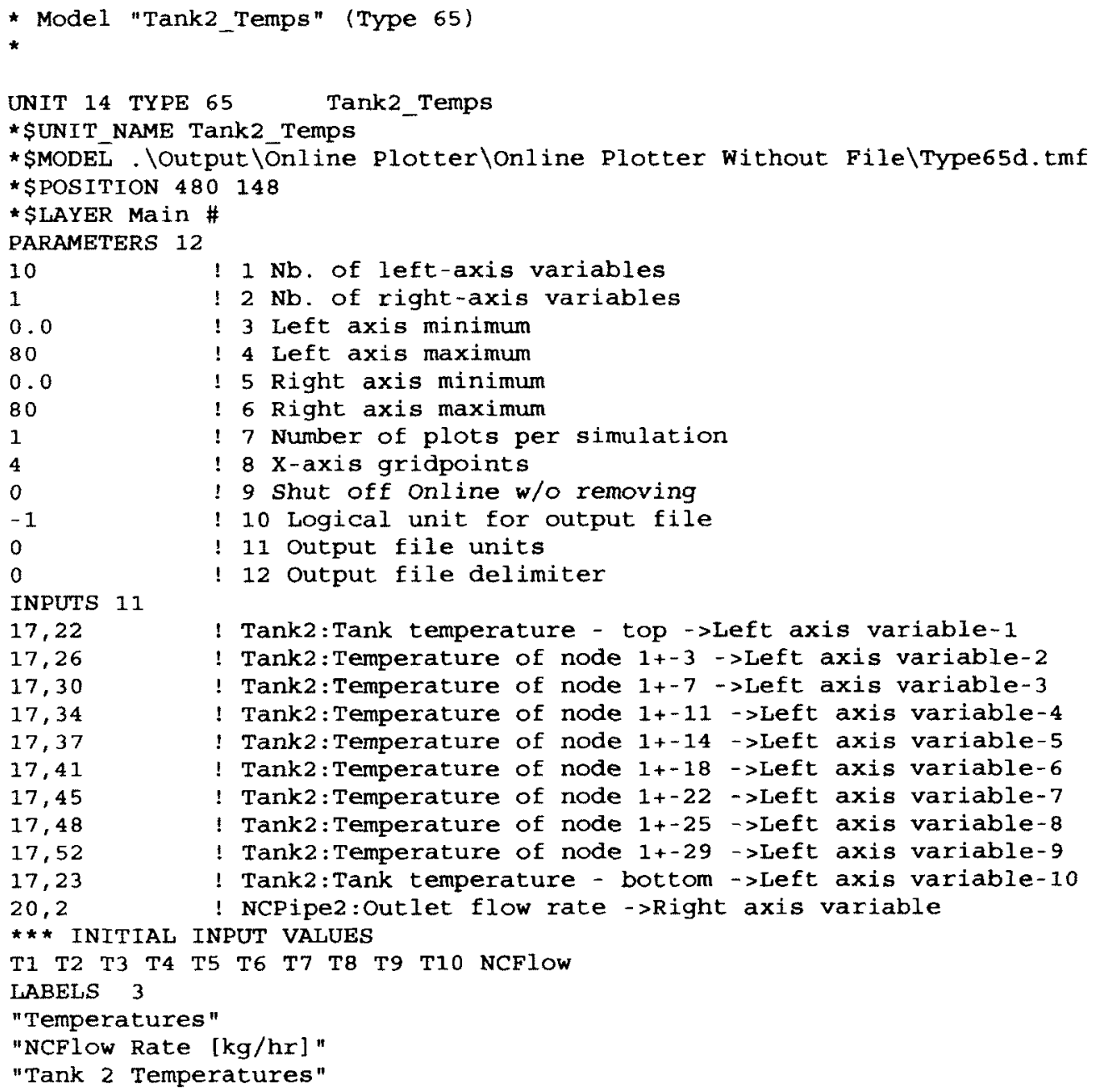




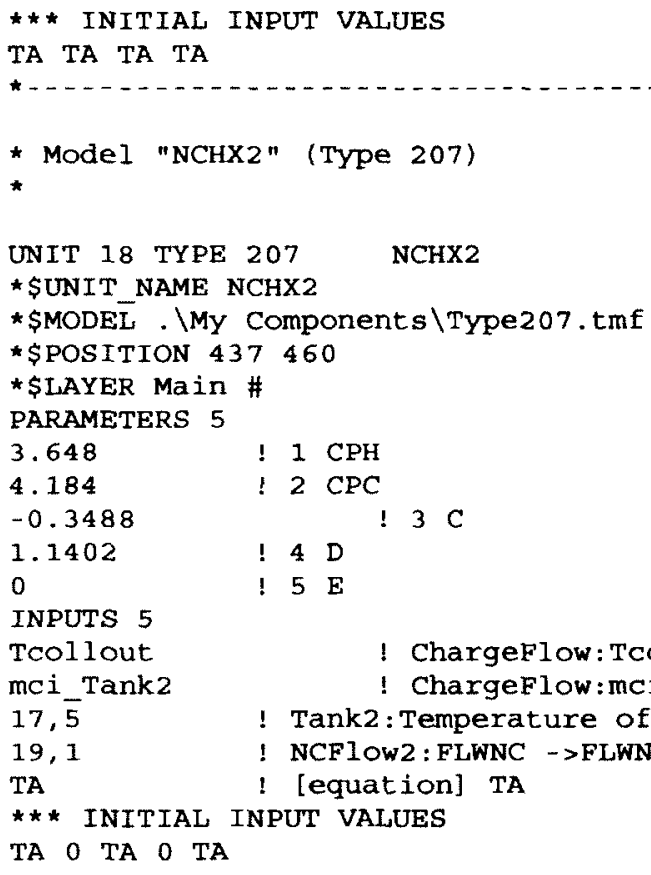




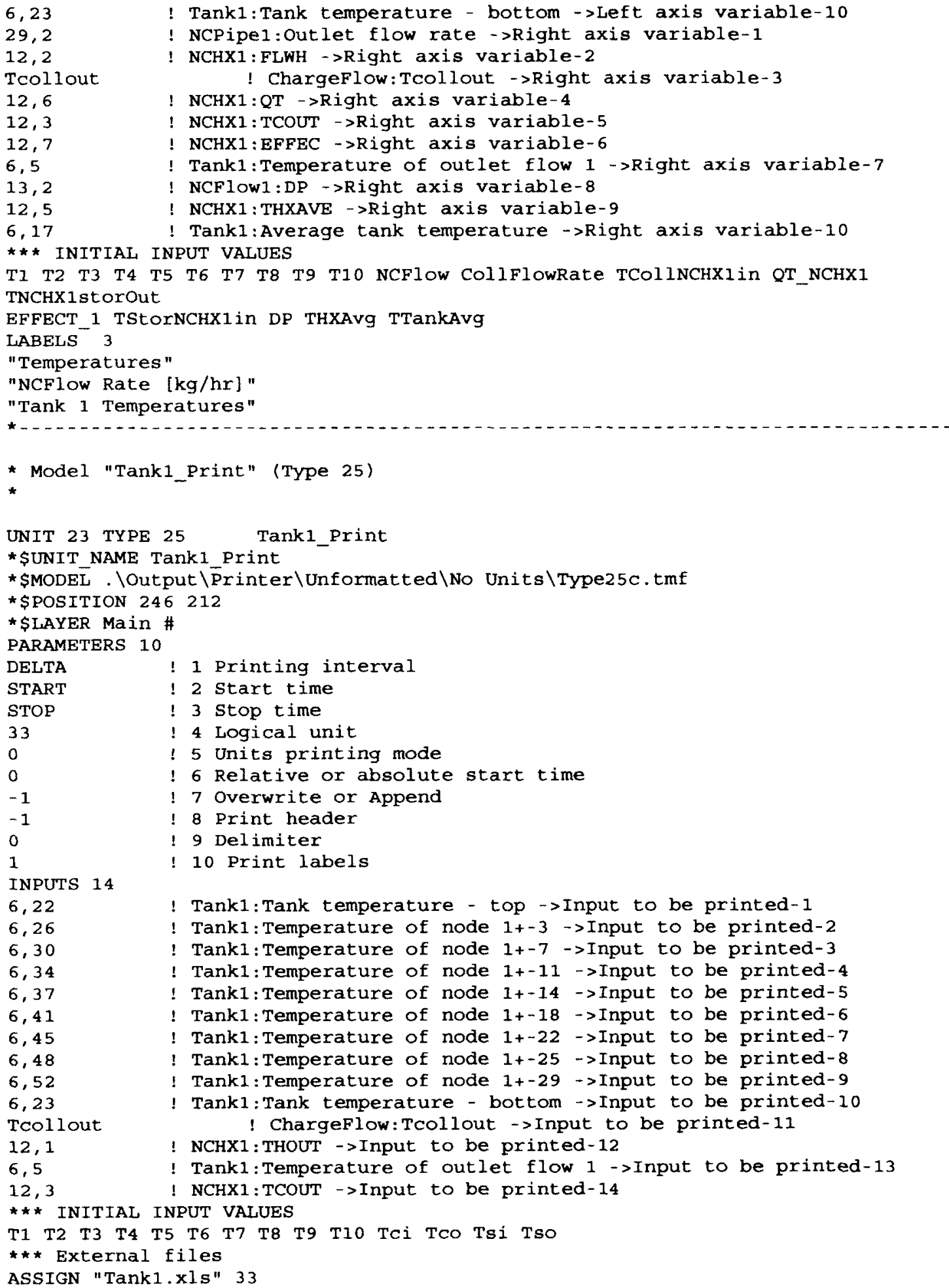


*|? Output file for printed results |1000

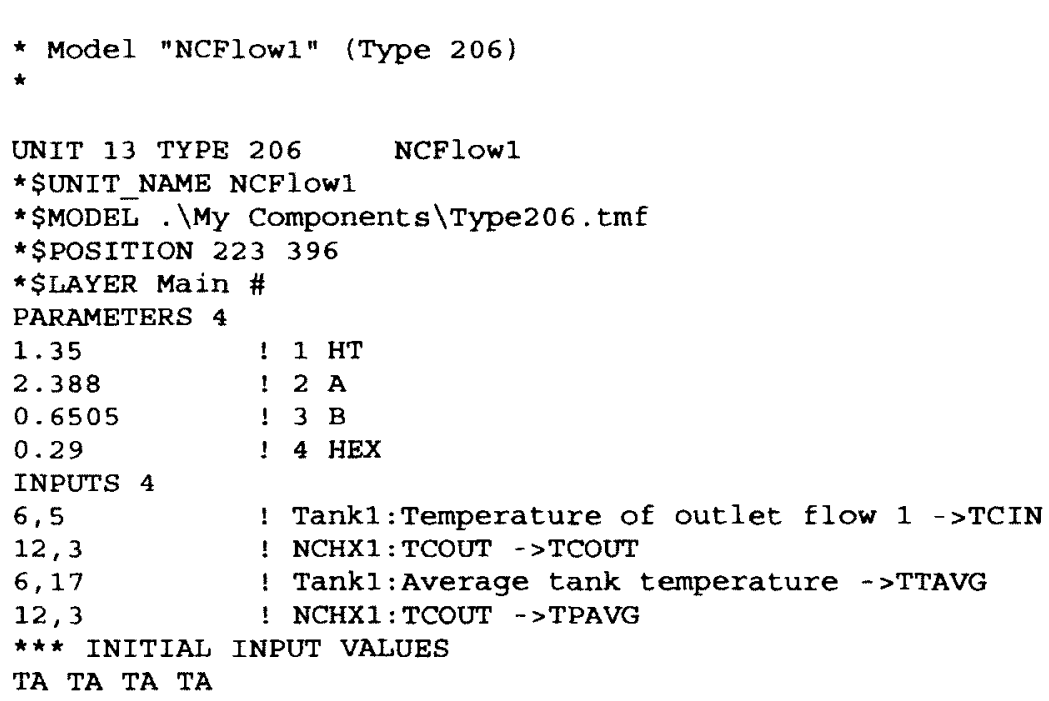




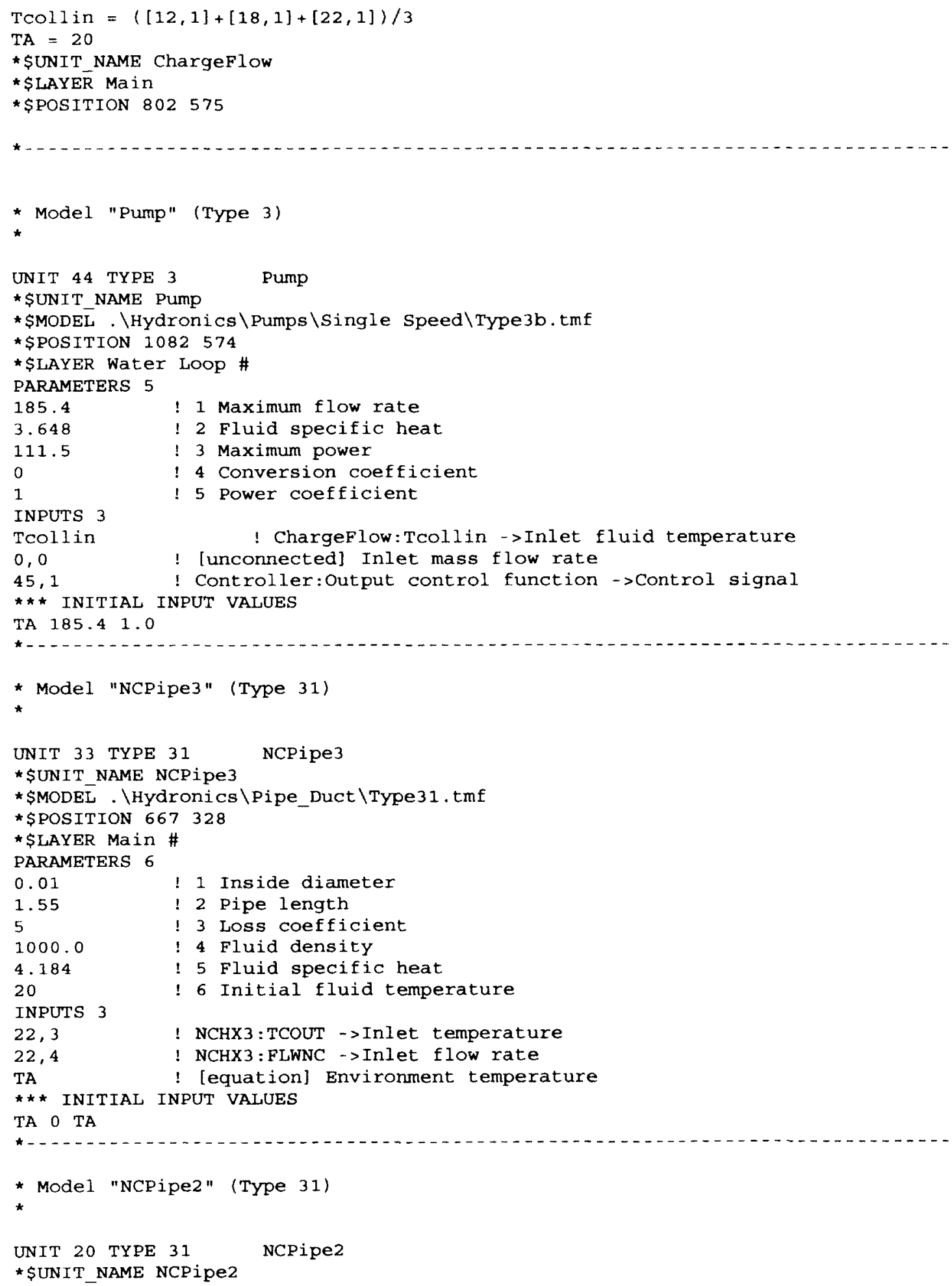




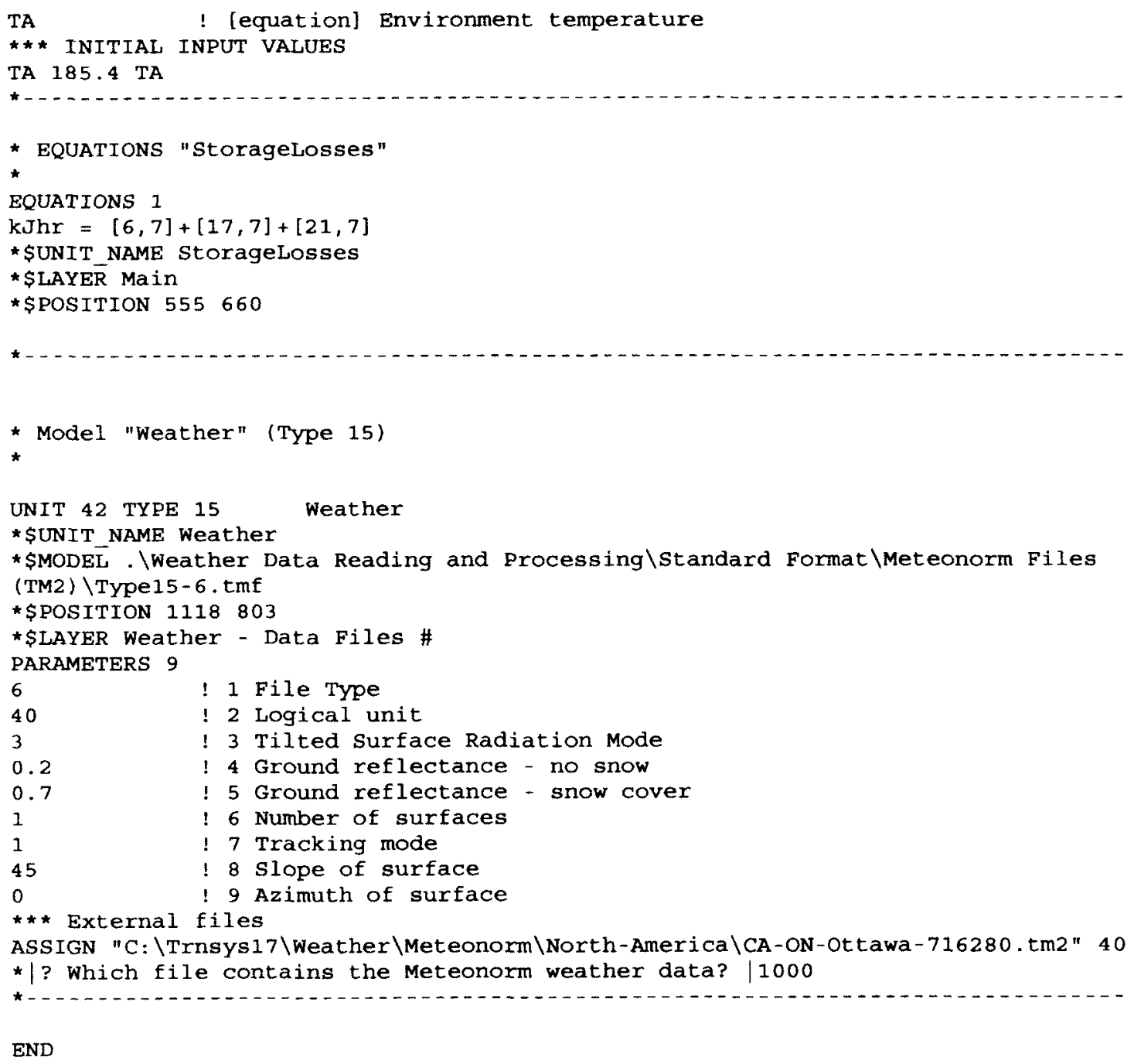

END 